\title{
A MICROSIMULATION OF TRAFFIC, PARKING, AND EMISSIONS AT CALIFORNIA POLYTECHNIC STATE UNIVERSITY- SAN LUIS OBISPO
}

\author{
A Thesis \\ presented to \\ the Faculty of California Polytechnic State University, \\ San Luis Obispo
}

\author{
In Partial Fulfillment \\ of the Requirements for the Degree \\ Master of Science in Industrial Engineering
}

by

Steven Michael Kilbert

February 2011 


\section{(C) 2011 \\ Steven Michael Kilbert \\ ALL RIGHTS RESERVED}




\section{COMMITTEE MEMBERSHIP}

TITLE:

AUTHOR:

DATE SUBMITTED:

COMMITTEE CHAIR:

Dr. Tali Freed, Ph.D., P.E. Associate Professor,

Department of Industrial and Manufacturing Engineering

COMMITTEE MEMBER: Dr. Anurag Pande, Ph.D. Assistant Professor, Department of Civil and Environmental Engineering

COMMITTEE MEMBER: Dr. Tao Yang, Ph.D., Professor, Department of Industrial and Manufacturing Engineering 


\section{ABSTRACT \\ A MICROSIMULATION OF TRAFFIC, PARKING, AND EMISSIONS AT CALIFORNIA POLYTECHNIC STATE UNIVERSITY- SAN LUIS OBISPO}

\section{Steven Michael Kilbert}

Traffic and parking congestion are significant issues at many universities nationwide. The delays experienced result in wasted time, money, and fuel for students, faculty and staff, not to mention the negative contributions to the environment. This paper quantifies the amount of vehicle emissions generated during an average morning peak hour in the university environment. Using VISSIM and CMEM microsimulation packages, a model is created for California Polytechnic State University- San Luis Obispo to aggregate the collective transportation behaviors and practices of the campus and recognize the implications these behaviors pose on the transportation network as a whole. Reasonable estimates are generated for overall $\mathrm{HC}, \mathrm{CO}$, and $\mathrm{NO}_{\mathrm{x}}$ type emissions as well as fuel consumption. Scenarios are proposed which reflect the sensitivity of outputs to key input parameters. The findings of this research can be useful for future campus planning and the ideas can be extended to similar environments with traffic and parking problems such as business parks, corporate campuses, downtown districts, and special event venues.

Keywords: Microsimulation, Emissions, VISSIM, CMEM, University Traffic and Parking 


\section{Acknowledgements}

I'd like to dedicate this thesis in loving memory of my grandmother, Marjorie Mohr Kilbert (1926-2011). Mrs. Kilbert was a devout teacher and educator of mathematics and computers in Mercer County, Pennsylvania.

If it weren't for the guidance and support I received from several individuals, this thesis would not have been possible:

I'd like to first thank my committee members: Thanks to Dr. Tali Freed for her assistance and direction in the advisory role; Thanks to Dr. Anurag Pande for sharing his extensive knowledge and expertise in the area of transportation simulation; Thanks to Dr. Tao Yang for his support references and guidance with use of software and programming.

Secondly, I'd like to thank other faculty and students who have helped along the way: Thanks to Dr. Sema Alptekin for encouraging me to read about and explore new types of simulation; Thanks to Dr. Jianbiao Pan for his assistance with statistics; Thanks to Nezamuddin Nezamuddin (University of Texas at Austin) for sharing his extensive knowledge and expertise in the area of transportation simulation, Thanks to Dr. Avinash Unnikrishnan (University of West Virginia) for his recommendation of the CMEM simulation package; Thanks to Joseph Yu (Cal Poly student) for his technical assistance with the VISSIM software; Thanks to George Scora (University of California at Riverside) for his technical assistance with CMEM software package

I'd also like to thank other university personnel at Cal Poly; Thanks to Dean Susan Opava of Graduate \& Research Programs at Cal Poly for providing the financial support necessary to acquire a VISSIM license; Thanks to Debbie Hart, Assistant to the Dean, for her efforts in acquiring the VISSIM license; Thanks to Susan Rains and Max Schadd at the University Police Department for providing data and communicating current campus traffic and parking policies; Thanks to Pamela Timm at Cal Poly Facilities \& Planning for providing historical data and pointing to university planning references

Finally, I'd like to thank to thank my family and friends for their support and encouragement. 


\section{Table of Contents}

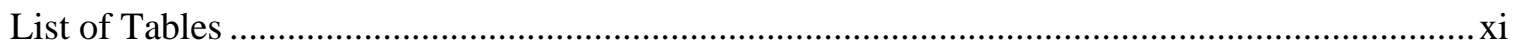

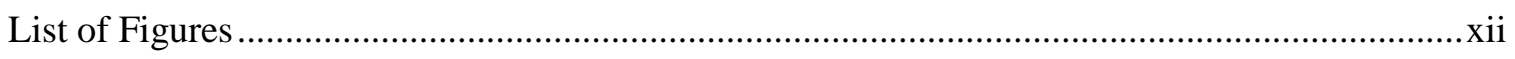

\section{CHAPTERS}

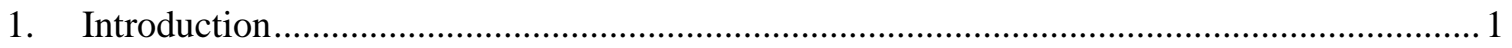

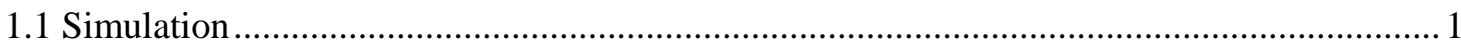

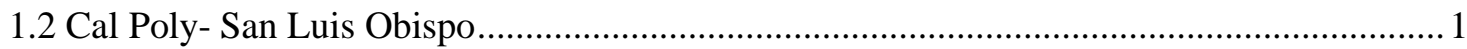

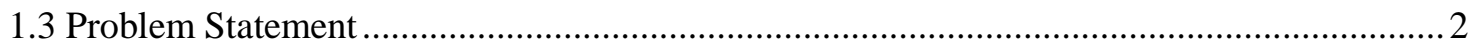

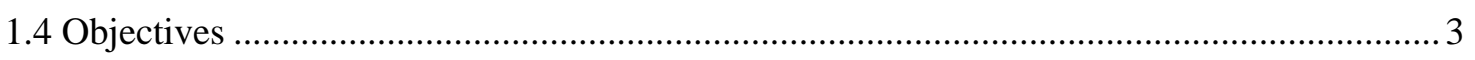

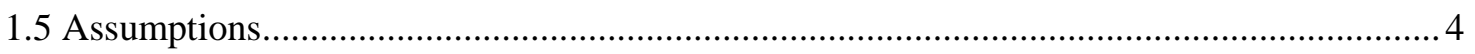

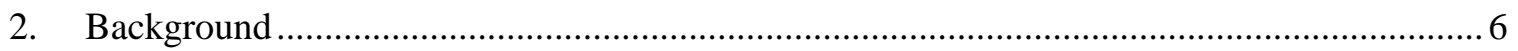

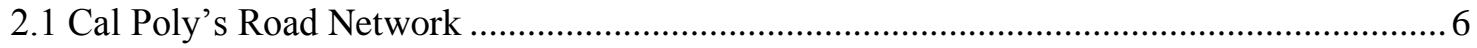

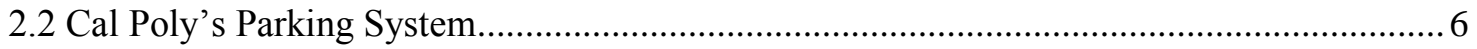

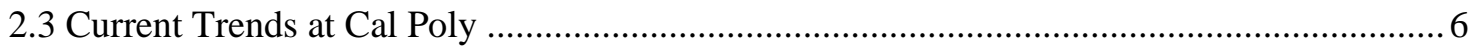

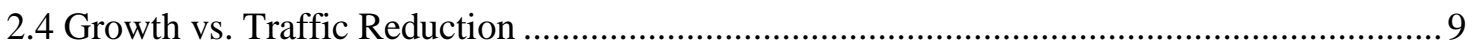

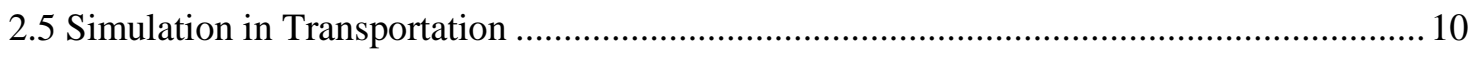

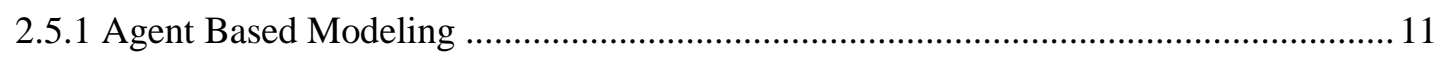

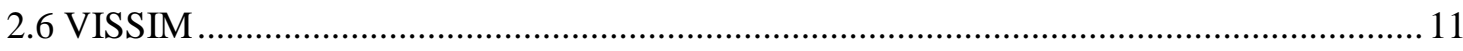

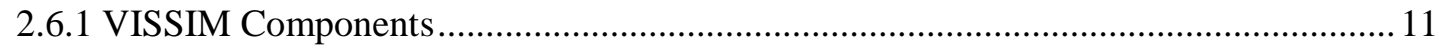

2.6.2 Car Following/Lane-Changing Methodology ............................................................. 12

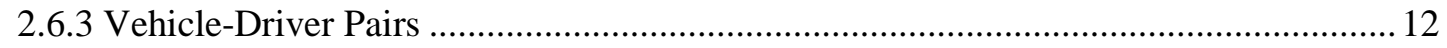

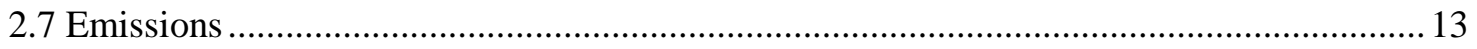

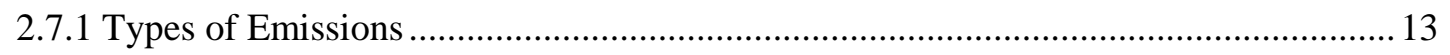

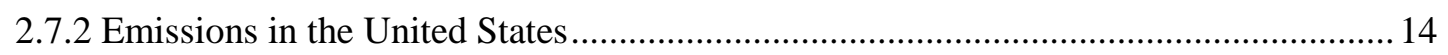

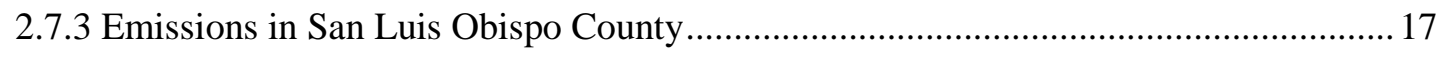

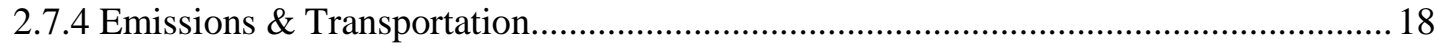

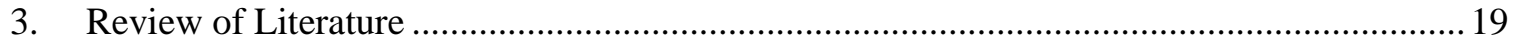

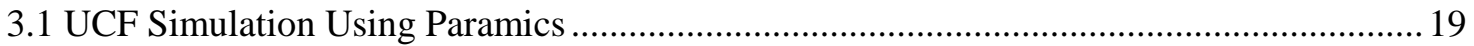

3.2 Environmental Impacts of Traffic Management \& Control ................................................. 19

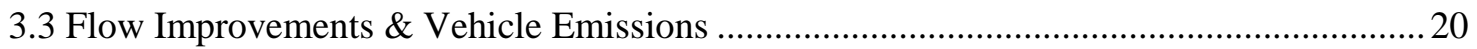

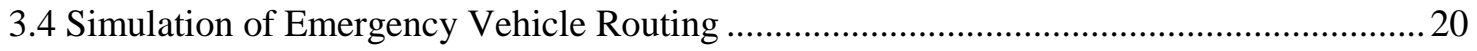

3.5 Development of a Microscopic Modal Emissions Model ...................................................21 


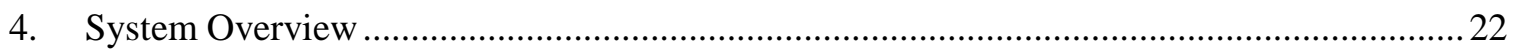

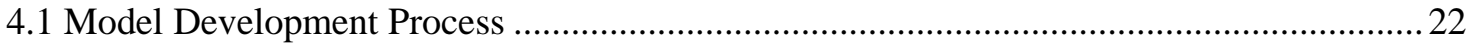

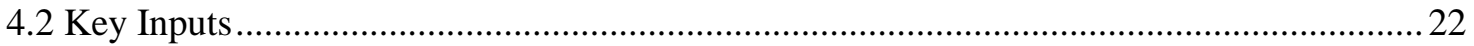

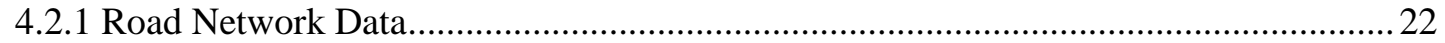

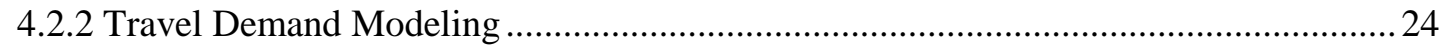

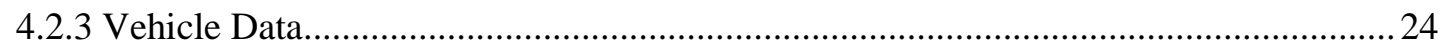

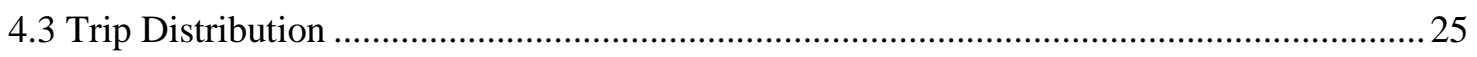

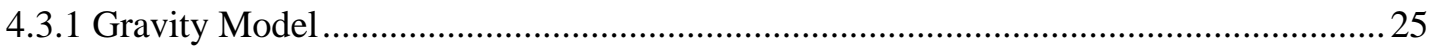

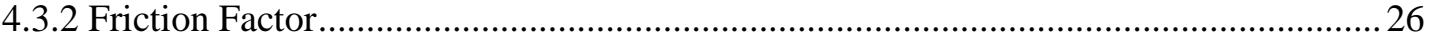

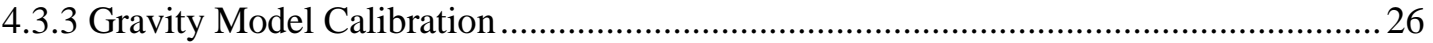

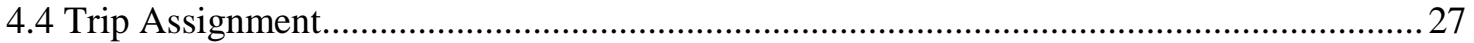

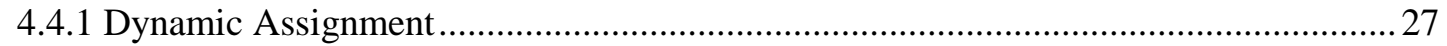

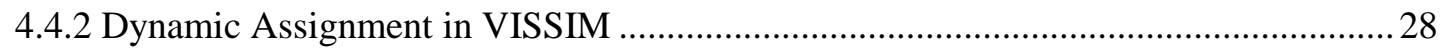

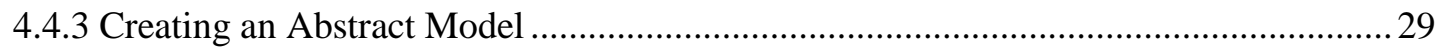

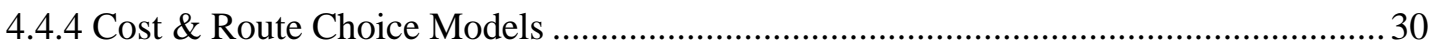

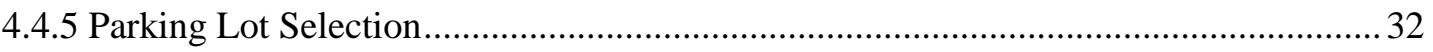

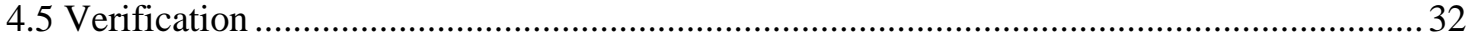

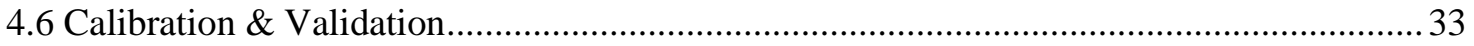

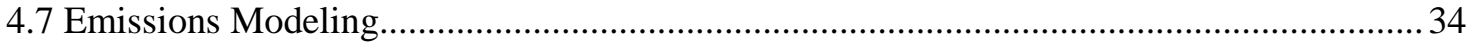

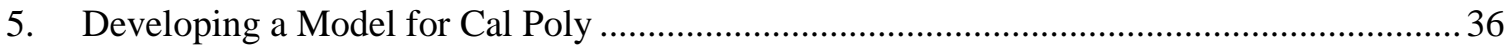

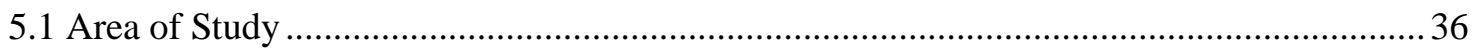

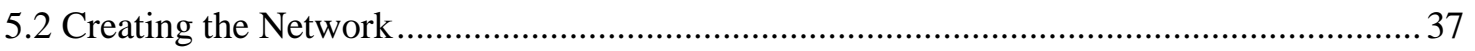

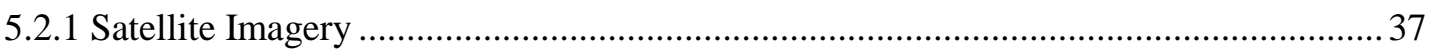

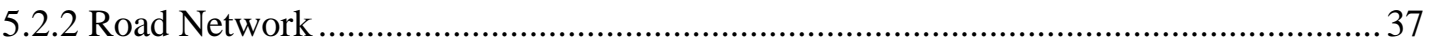

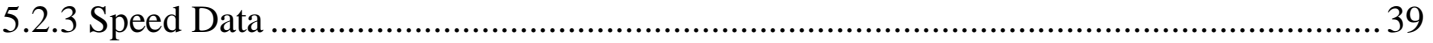

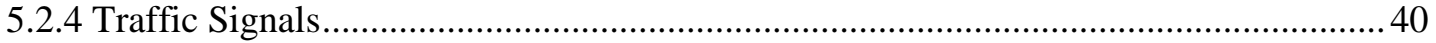

5.2.5 Intersections, Conflict Areas, and Priority Rules........................................................ 41

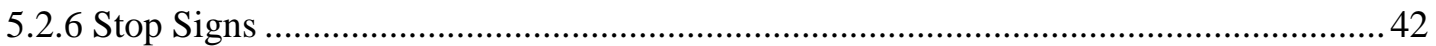

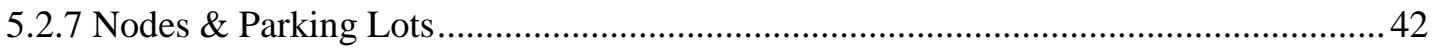

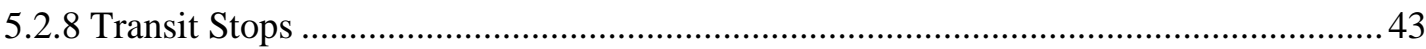

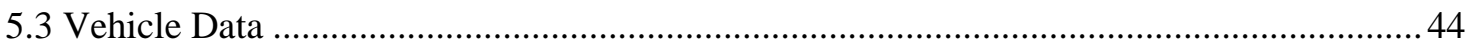

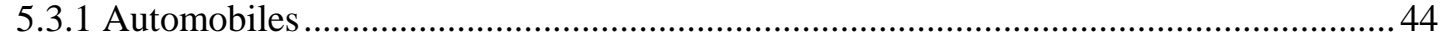

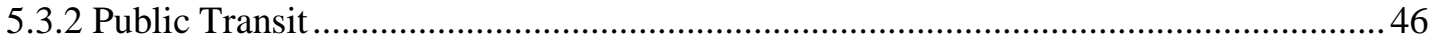


5.4 Application of Gravity Model: Trip Distribution .......................................................... 47

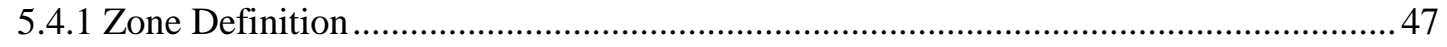

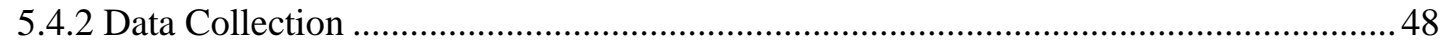

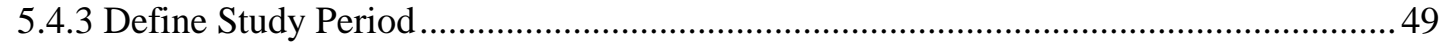

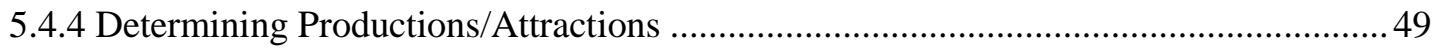

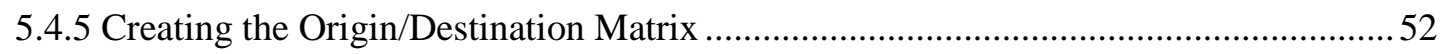

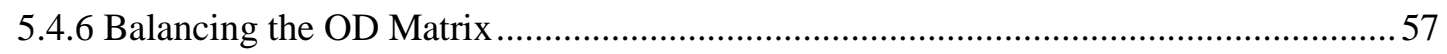

5.5 Application of Dynamic Assignment: Trip Assignment ................................................... 64

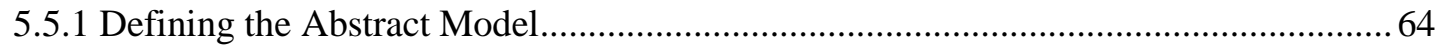

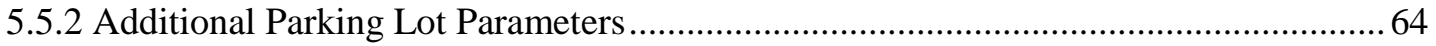

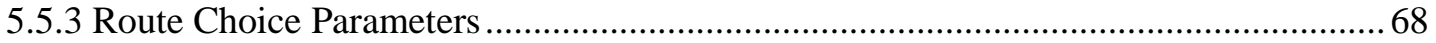

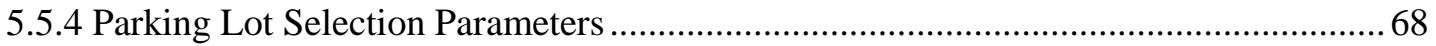

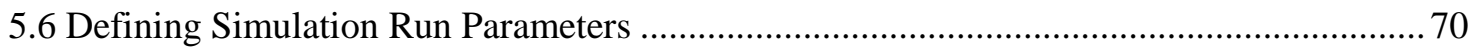

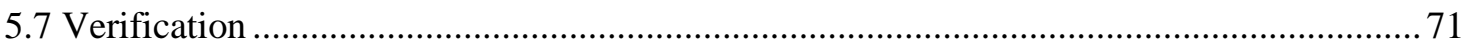

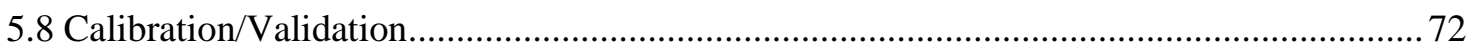

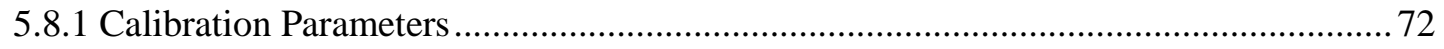

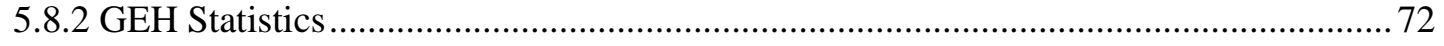

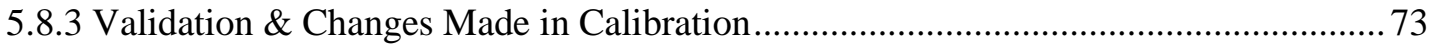

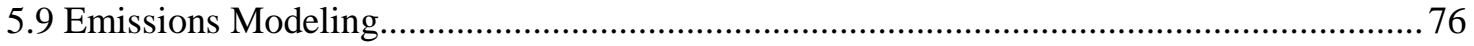

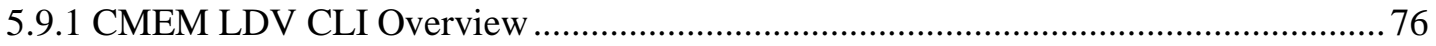

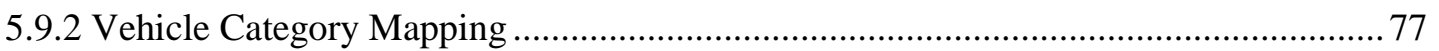

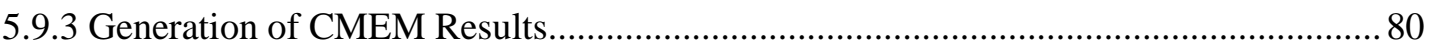

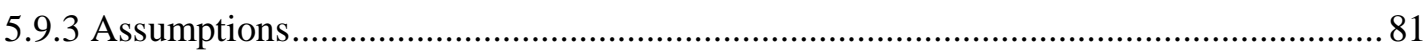

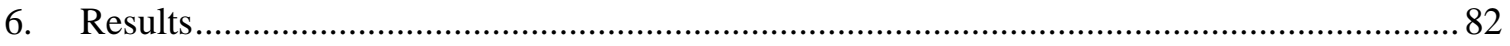

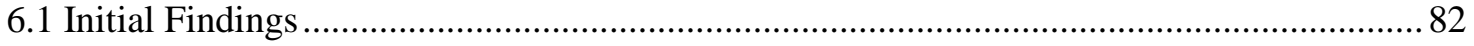

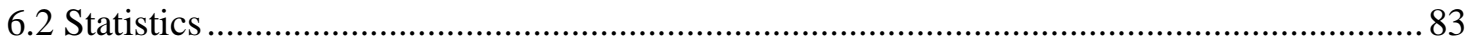

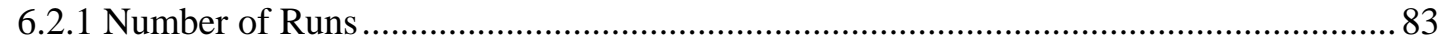

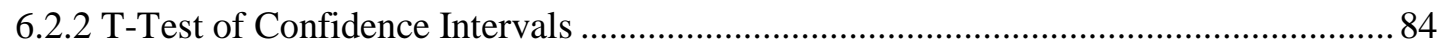

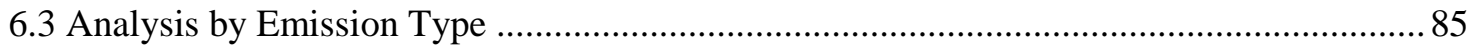

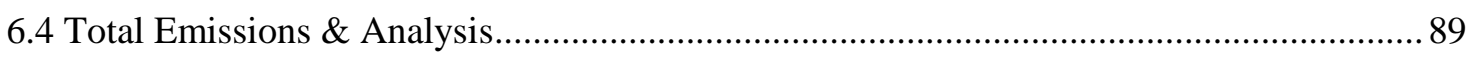

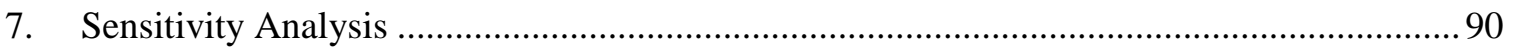

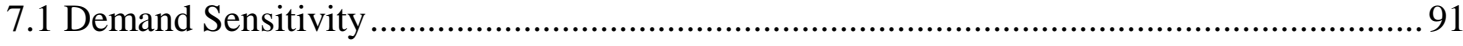

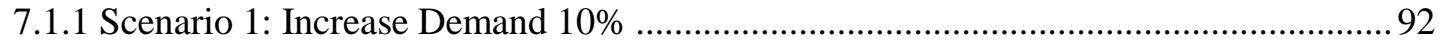




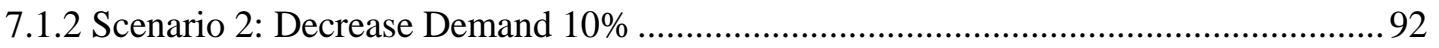

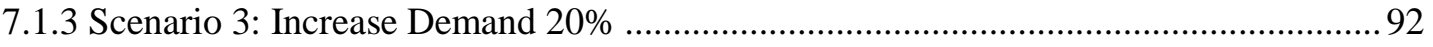

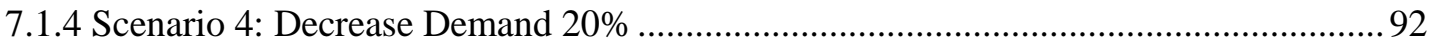

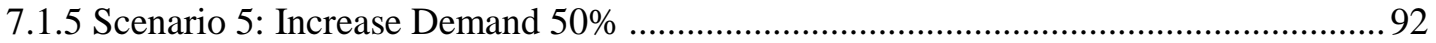

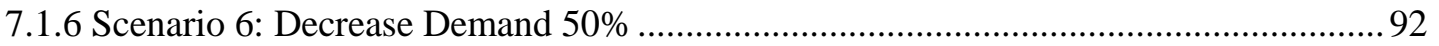

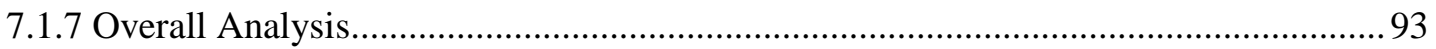

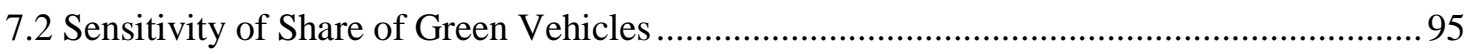

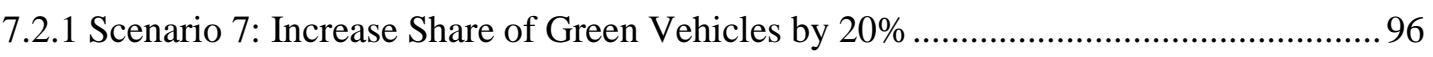

7.2.2 Scenario 8: Increase Share of Green Vehicles by 50\% .............................................. 96

7.2.3 Scenario 9: Increase Share of Green Vehicles by 100\% …......................................... 96

7.2.4 Scenario 10: Increase Share of Green Vehicles by $200 \%$.............................................96

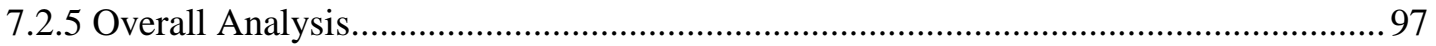

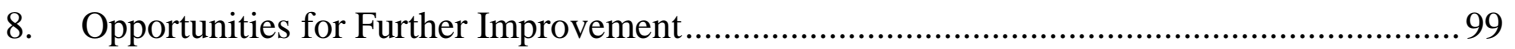

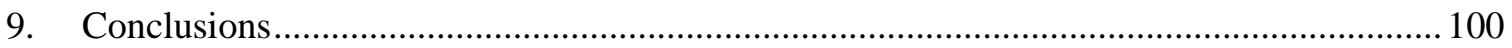

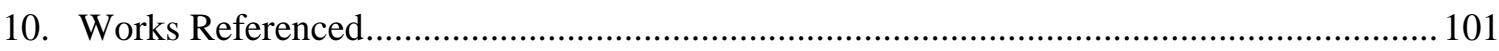

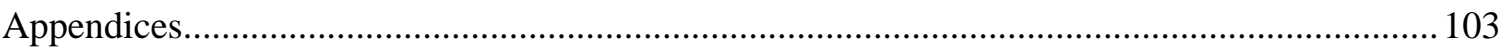

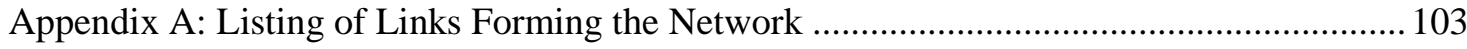

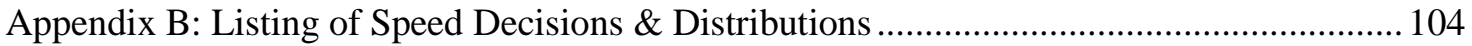

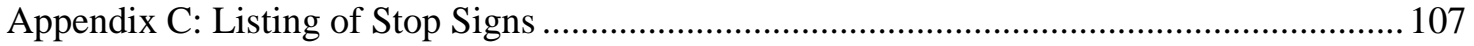

Appendix D: Maps of Transit Routes in the Cal Poly Network ............................................. 108

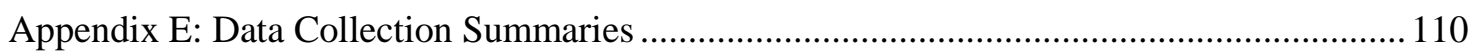

Appendix F: OD Matrix Setup Calculations (Partial Sample).............................................. 113

Appendix G: Calculation of Parking Lot Utilities \& Probabilities ........................................ 116

Appendix H: Intersection Configuration for Model Verification ......................................... 119

Appendix I: Data Collection Summaries for Key Interior Intersections................................ 125

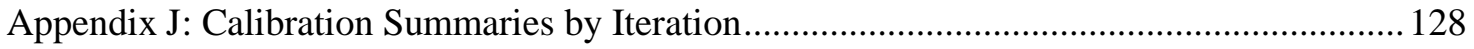

Appendix K: Sample Vehicle Mapping Calculations for Emissions Modeling ...................... 131

Appendix L: Sample CMEM Model Control File .................................................................. 134

Appendix M: Partial Sample CMEM Vehicle Definition File................................................... 134

Appendix N: Partial Sample CMEM Vehicle Activity File ................................................ 135

Appendix O: Partial Sample CMEM Vehicle Model Run File.............................................. 143

Appendix P: Partial Sample CMEM Vehicle Summary File ................................................ 148

Appendix Q: Partial Sample Emissions Summary Output ................................................... 149 
Appendix R: Additional Background Information

Emissions Modeling.

150

Parking Decisions

151 


\section{List of Tables}

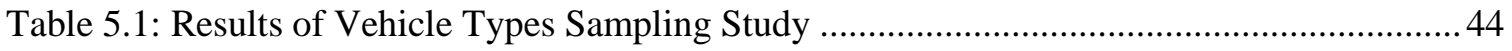

Table 5.2: Sample Vehicles for Each Vehicle Type Category ...................................................... 45

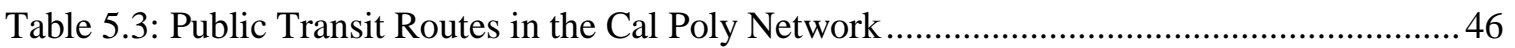

Table 5.4: Names \& Descriptions of Traffic Analysis Zones for Cal Poly .................................. 48

Table 5.5: Volumes of Inbound/Outbound Traffic for each Entrance/Exit to Cal Poly ................50

Table 5.6: Split of Inbound Trips to Cal Poly to Potential Interior Zones .....................................51

Table 5.7: Split of Outbound Trips from Cal Poly from Potential Interior Zones .......................... 51

Table 5.8: Production and Attraction Matrix for the Cal Poly Network .......................................52

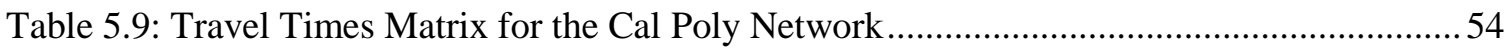

Table 5.10: Friction Factors Matrix for the Cal Poly Network ....................................................55

Table 5.11: Origin/Destination Matrix for the Cal Poly Network's AM Peak Hour......................56

Table 5.12: Iteration \#2 of the Origin/Destination Matrix for the Cal Poly Network.....................58

Table 5.13: Iteration \#3 of the Origin/Destination Matrix for the Cal Poly Network.....................59

Table 5.14: Iteration \#4 of the Origin/Destination Matrix for the Cal Poly Network.....................60

Table 5.15: Iteration \#5 of the Origin/Destination Matrix for the Cal Poly Network....................61

Table 5.16: Iteration \#6 of the Origin/Destination Matrix for the Cal Poly Network.....................62

Table 5.17: Iteration \#7 of the Origin/Destination Matrix for the Cal Poly Network....................63

Table 5.18: Listing of Parking Lots \& Capacities for the Cal Poly Network ................................ 66

Table 5.19: Attraction Factors for Parking Lots in the Cal Poly Network ...................................67

Table 5.20: Summary of GEH Statistics for Calibration of the Cal Poly Model........................... 73

Table 5.21: Summary of Changes Made During Calibration of the Cal Poly Model .................... 75

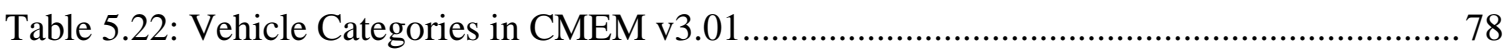

Table 5.23: Vehicle Mapping Splits for Cal Poly's AM Peak Hour ............................................ 79

Table 5.24: Balance of Vehicle Type Categories in VISSIM and CMEM ...................................79

Table 6.1: Summary of Total Emissions for Cal Poly's AM Peak Hour........................................ 82

Table 6.2: Calculation of the Sufficient Number of Runs for Simulation by Performance Metric 84

Table 7.1: Summary of Demand Sensitivity for Cal Poly's AM Peak Hour .................................91

Table 7.2: Summary of Share of "Green" Vehicles Sensitivity for Cal Poly's AM Peak Hour ....95 


\section{List of Figures}

Figure 2.1: Commuter Parking Permits per Student at Cal Poly ................................................. 7

Figure 2.2: Percentage of Cal Poly Student Population living On-Campus ................................... 8

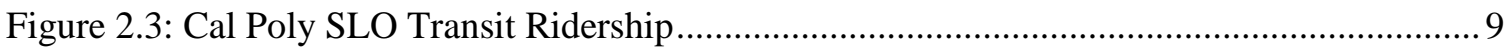

Figure 2.4: Visual Comparison of Types of Transportation Simulation ...................................... 10

Figure 2.5: Rates of Change for Pollutant Types by Source Category in the United States from 1990-2008

Figure 2.6: Rate of Change for Carbon Dioxide Emissions in the United States in Relation to

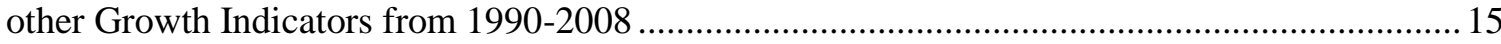

Figure 2.7: Breakdown of Pollutant Emissions by Source Category …....................................... 15

Figure 2.8: Air Pollution Sources in San Luis Obispo County ..................................................... 17

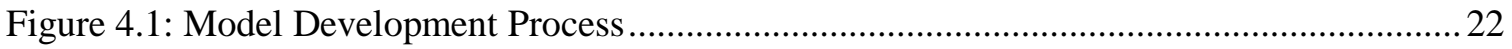

Figure 4.2: Outline for Determining Vehicle Classifications in VISSIM ...................................25

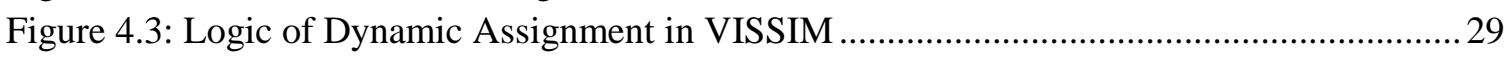

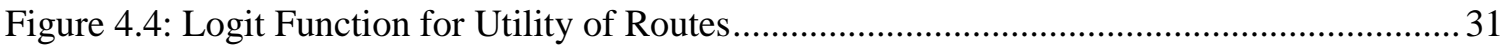

Figure 4.5: Kirchoff Distribution Formula for Utility of Routes ................................................. 31

Figure 4.6: Kirchoff Distribution Formula Expressed as a Logit Function .................................. 32

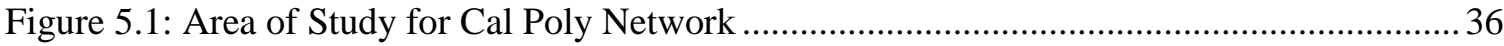

Figure 5.2: Assemblage of Satellite Imagery for the Cal Poly Network .......................................37

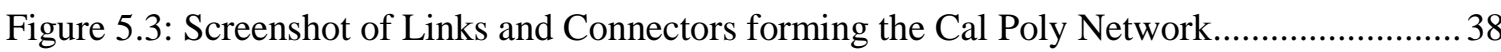

Figure 5.4: Sample Speed Distribution for Areas of Cal Poly's Core ............................................ 39

Figure 5.5: Signal Timing Parameters for California Blvd Pedestrian Crosswalk ....................... 40

Figure 5.6: Signal Timing Parameters for Grand Ave Pedestrian Crosswalk................................. 41

Figure 5.7: Sample Dwell Time Distribution for Grand Ave Parking Kiosk .............................. 42

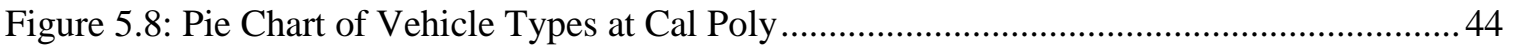

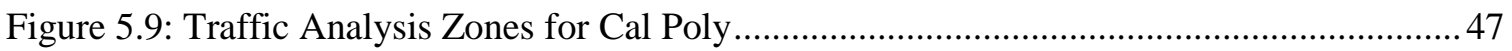

Figure 5.10: Summary of Potential Peak Hours from Grand Ave Field Study .............................. 49

Figure 5.11: Cost Coefficents for Route Choice Model for All Vehicle Types............................. 68

Figure 5.12: Coefficients for Parking Lot Selection for All Vehicle Types ..................................69

Figure 5.13: Simulation Run Parameters for the Cal Poly Network ............................................. 70

Figure 5.14: Formula for Calculation of GEH Statistics to Compare Average Volumes ...............72

Figure 5.15: Outline of the Selected Version of the Comprehensive Modal Emissions Model

Used for Modeling Emissions During Cal Poly's AM Peak Hour ............................................... 76

Figure 6.1: Formula for Calculating the Sufficient Number of Runs for Simulation ....................83

Figure 6.2: T-Test Confidence Intervals of Means for Performance Metrics ................................ 84

Figure 6.3: Bar Graph of HC Emissions by Random Seed...................................................... 85

Figure 6.4: Bar Graph of CO Emissions by Random Seed....................................................... 86

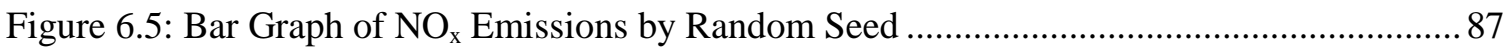

Figure 6.6: Bar Graph of Fuel Consumption by Random Seed ................................................. 88

Figure 7.1: Sensitivity Plot showing how Demand Impacts Emissions and Consumption for Cal

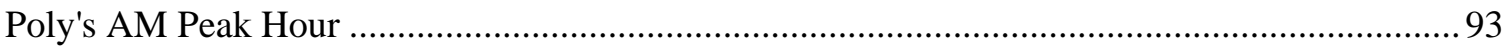

Figure 7.2: Sensitivity Plot showing how Share of "Green" Vehicles Impacts Emissions and

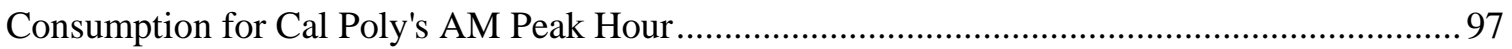




\section{Introduction}

\subsection{Simulation}

Simulation is a tool for analyzing the design and operation of a system. Whether the system is an assembly line, a machine shop, a service counter, or a road network, the use of simulation allows for a deeper level of thought that investigates the logic of how and why operations occur the way they do, which may normally be taken for granted. Simulation involves creating a replicate model of a system by taking into account its inputs, outputs, and any potential variability. Once a valid model is constructed, the simulation can then be used to analyze the system and its problems and generate statistics on key performance measures.

Furthermore, the simulation can also be used to test changes or modifications to a system in an "off-line" mode, where the actual system is unaffected. In recent years, simulation has been applied to investigate and alleviate many transportation problems.

\subsection{Cal Poly- San Luis Obispo}

California Polytechnic State University (Cal Poly) is a high-ranking polytechnic university for both undergraduate and graduate students and is part of the 23 campus California State University system. Located in San Luis Obispo (population 44,000) along the central coast of California, Cal Poly boasts an enrollment of just over 18,000 undergraduates and 1000 graduates. Additionally, Cal Poly employs over 2900 faculty members and staff. Cal Poly houses approximately 6000 undergraduates each year and attracts many visitors as a key venue for many sporting events and the performing arts. 


\subsection{Problem Statement}

With a high demand for excellent education and entertainment, traffic and parking congestion on campus have long been issues and will continue to be with future growth. Not only do delays affect students, faculty, staff, and visitors, but they also generate emissions harmful to the environment. As a leading institution in many disciplines including engineering, there is a strong push to make the Cal Poly campus a leader is terms of being "green". This philosophy was emphasized in 2010 in the words of former Cal Poly President Warren J. Baker: "As a polytechnic university, it is at the core of our mission to examine the ways in which knowledge may be applied to improve society, manage scarce resources, and protect and preserve our environment. Sustainability is a high priority for the university and a key issue that should cut across all we do, including teaching, research, and the practices we engage in on the campus" (Multari 2010).

With regards to transportation, Cal Poly, as well as the California State University system, lacks a model sufficient enough to aggregate the current behaviors of its motorists and recognize the implications posed by the interactions of these behaviors. Transportation is an integral component to Cal Poly's impact on the environment and its sustainability efforts, as it contributes to approximately $40 \%$ of campus greenhouse gas emissions. Yet, transportation remains less quantified and less visited in comparison to the campus's efforts in other areas of sustainability such as water quality, energy consumption, and land development (Multari 2010). Without a model of the current transportation environment, Cal Poly also doesn't have adequate means to forecast the effects of future growth and policy and may see increased difficulty in adhering to new environmental legislation. 


\subsection{Objectives}

The use of simulation can help the campus recognize the collective behaviors and patterns of transportation present on campus and the implications these behaviors pose to the transportation network as a whole. With analysis of a valid simulation model, it is possible to determine which components of a network generate the most "waste" and hypothetically test solutions to eliminate this "waste". "Waste" can have many different meanings in a transportation network whether it is excessive vehicle emissions, inappropriate traffic control devices, poor road geometry, or the generation of conflicting movements. The objectives of this study are:

- To create a simulation model that mimics the real life traffic situation seen on Cal Poly's campus during one of its heaviest peak periods

- To quantify the physical emissions generated by vehicles during this particular time period

- To determine the sensitivity of results based on fluctuation of several key input parameters

- To determine the potential effect of some select campus transportation policies anticipated in Cal Poly's near-future 


\subsection{Assumptions}

Due to the complexity of simulation modeling and microscopic traffic simulation in particular, a "perfect" model in nearly impossible to achieve. It is important to note than no models are correct, but some are useful (Colvin 2009). Models may be deemed useful if they adhere to stated objectives and are capable of generating the key performance metrics required at a reasonable level of accuracy. The VISSIM model described in this study relies on the following assumptions:

- Area of Study is limited to the Cal Poly campus and several nearby streets and intersections (See Area of Study for more information including closures, areas of construction, and streets limited to certain traffic only)

- Time of Study is limited to the AM Peak Hour (7:30AM-8:30AM) on an average weekday (Tuesday, Wednesday, or Thursday)

- Time of Simulation is limited to the AM Peak Hour plus 15 minutes prior. The 15 -minute time period between 7:15AM and 7:30AM is primarily used for ease of integrating public transit schedules that are observed within the area of study

- Warm-up time is assumed to be negligible: The traffic flows before 7:30AM are not significant to influence traffic soon thereafter. Flows begin almost exclusively at 7:30AM

- Peak hour vehicle inputs are generated on a random basis which generates a somewhat uniform flow among smaller time intervals forming the peak hour. In reality, the flow during these smaller time intervals may not be so uniform.

- Pedestrian traffic is not accounted for due to modeling complexity and limitations with the current version of software; the exception to this is the pedestrian vehicle class which is modeled at two signalized crosswalks

- The iterative matrix balancing process which is part of the gravity model is based off the distribution of attractions. The common state of the practice used in transportation planning is based off the distribution of productions. Both methods generate close to the same results, however.

- Dynamic Routing is not included in the model. Dynamic routing is used in conjunction with the dynamic assignment module to re-route vehicles to different parking lots when lots reach become 
full or reach a certain occupancy level. During the time period of study, the need for dynamic routing rarely exists. The only exception occurs when a couple lots are filled within 5-10 minutes of the simulation end, where small queues of vehicles begin to build. The impact of these queues is essentially negligible given that the flow of most traffic is not impacted.

- Off-campus signalized intersections of Foothill \& California, Foothill \& Santa Rosa, and Highway $1 \&$ Highland are modeled as 4-way stops for transit vehicles only. Vehicle ingress/egress points reside inside these intersections, so most vehicles do not encounter them (See Traffic Signals for more information).

- Railroads and the crossing at Foothill Blvd and California Blvd is not included in the model

- Specific assumptions concerning vehicle types modeled as well as traffic compositions, vehicle classes, and vehicle color distributions are discussed further in $\underline{5.3 \text { Vehicle Data }}$

- The California Blvd entrance to Cal Poly does not accommodate $100 \%$ of the demand it generates for all random seeds and under different scenarios. This is somewhat realistic in that traffic is often backed-up along California Blvd to the intersections of Foothill Blvd or Hathway Ave

- Specific assumptions associated with the emissions model (CMEM) are specified in 5.9 Emissions Modeling)

- Unless otherwise specified in 5. Developing a Model for Cal Poly, VISSIM's default parameters are assumed 


\section{Background}

\subsection{Cal Poly's Road Network}

Cal Poly's road network is essentially horseshoe-shaped, where N Perimeter Road spans the northern part of the horseshoe and S Perimeter Rd spans the southern part of the horseshoe, with the horseshoe opening facing west. There are six entrances to Cal Poly (Grand Ave, Foothill Blvd, Cuesta Ave, California Blvd, Highland Dr, and Stenner Creek Rd) which are serviced largely from two nearby highways (CA-1 and Highway 101). The campus has two sets of traffic signals used for pedestrian crossings, while most other intersections are controlled by stop-signs or the right-of-way. The campus experiences congestion near the tops of the hours each weekday due to large volumes of pedestrians crossing streets to get to class.

Additionally, the campus tends to have several peak hours between the morning, midday, and evening.

\subsection{Cal Poly's Parking System}

Cal Poly's parking system is somewhat impacted. The campus contains 8792 parking spaces (Cal Poly

UPD, March 2010). Approximately 3492 spaces are available for campus residents, along with 2992

spaces for general parking, 1410 spaces for staff parking, and 183 for disabled drivers. There are approximately 62 spots with short-term time limits along with 342 parking meters which run at a rate of $\$ 1.50$ USD per hour. Forty-eight spots are available for loading, 8 for commuter programs, and 200 for equipment loading and state vehicles. There are approximately 7500 parking permits in use each quarter.

\subsection{Current Trends at Cal Poly}

With its continued growth, Cal Poly has several construction projects underway and has witnessed the completion of several others in recent years. Currently under construction are a new Center for Science, a new Meat Processing Center, the Simpson Strong-Tie, redevelopment of a central chiller plant, and expansion of the Recreation Center.

The campus has witnessed the completion of the following in recent years:

- June 2010-Completed construction of the new Technology Park

- June 2010- Completed renovation of the University Union Plaza 
- $\quad$ September 2009- S. Perimeter drive was closed to thru traffic between Grand Avenue and Cuesta Ave in accordance with a campus master plan as an effort to make the core of campus more pedestrian-friendly

- October 2008- Completion of Construction Innovations Center

- Fall 2008-Completed construction of the Poly Canyon Village Apartments development

- $\quad$ Fall 2007- Completed construction of Engineering IV and nearby parking area

- Fall 2006- California Boulevard was re-opened as a thru street between North Perimeter and Campus Way after completion of the new Alex G. Spanos stadium which extends over California Boulevard

- $\quad$ September 2004- Completed construction of the Cerro Vista Apartment Complex

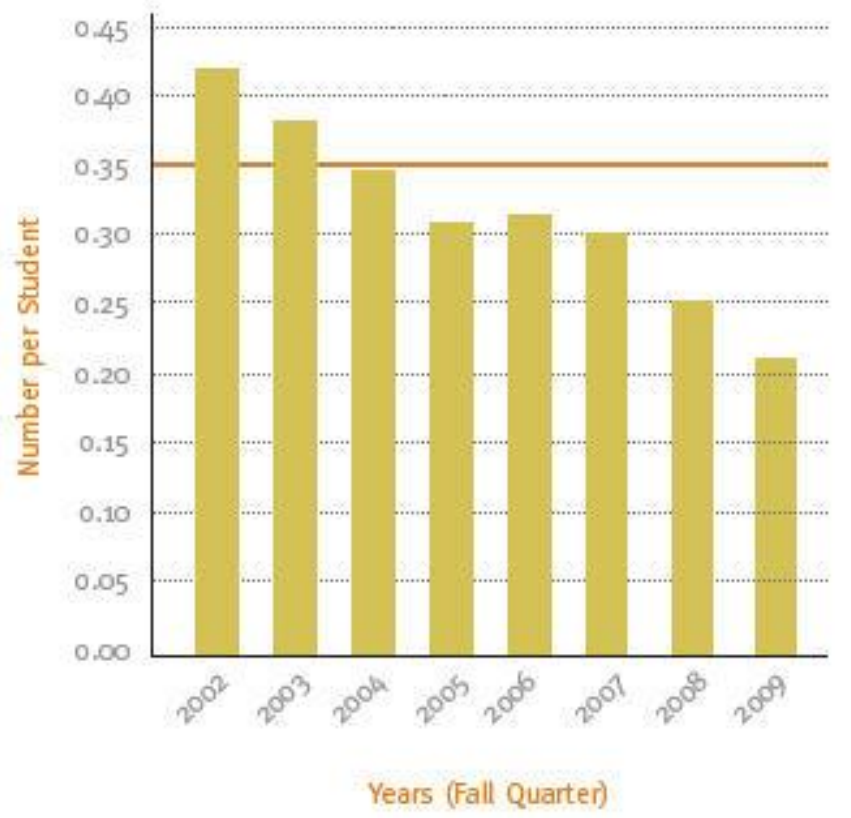

Figure 2.1: Commuter Parking Permits per Student at Cal Poly (Multari 2010)

Several years ago, Cal Poly was recognized among the best workplaces for commuters according to an annual study conducted by the National Center for Transit Research at the University of South Florida. Since then Cal Poly has taken several more steps to improve its transportation system, despite the lack of a sufficient model or evaluation tool. Based on 2009 data in Cal Poly’s third biennial report on sustainability, Cal Poly has witnessed a significant decrease in the number of parking permits sold (Figure 2.1) and a significant increase in transit ridership. The decline in parking permit sales is attributed to an 
increase in on-campus housing (Figure 2.2), increased parking costs, the relocation of parking lots further from the campus core, increased fuel costs, a recessionary economy, and continued promotion of alternative forms of transportation. Increased transit ridership (Figure 2.3) is attributed to the increase in on-campus housing, the decrease in attractiveness of parking on campus, increased transit capacity and hours of operation, and the continued ability for current members of the Cal Poly community to ride city transit for free. Cal Poly also has increased the size of its vanpool program and experimented with the introduction of several ZipCars which allow subscribed members to rent a car on an hourly basis directly from campus for a flat rate which includes insurance and fuel. These improvements are significant, but a simulation model can help us further recognize opportunities and determine to what extent it is worth continuing practices similar to these. This could further help the campus with the future attainment of proper awards or recognition.

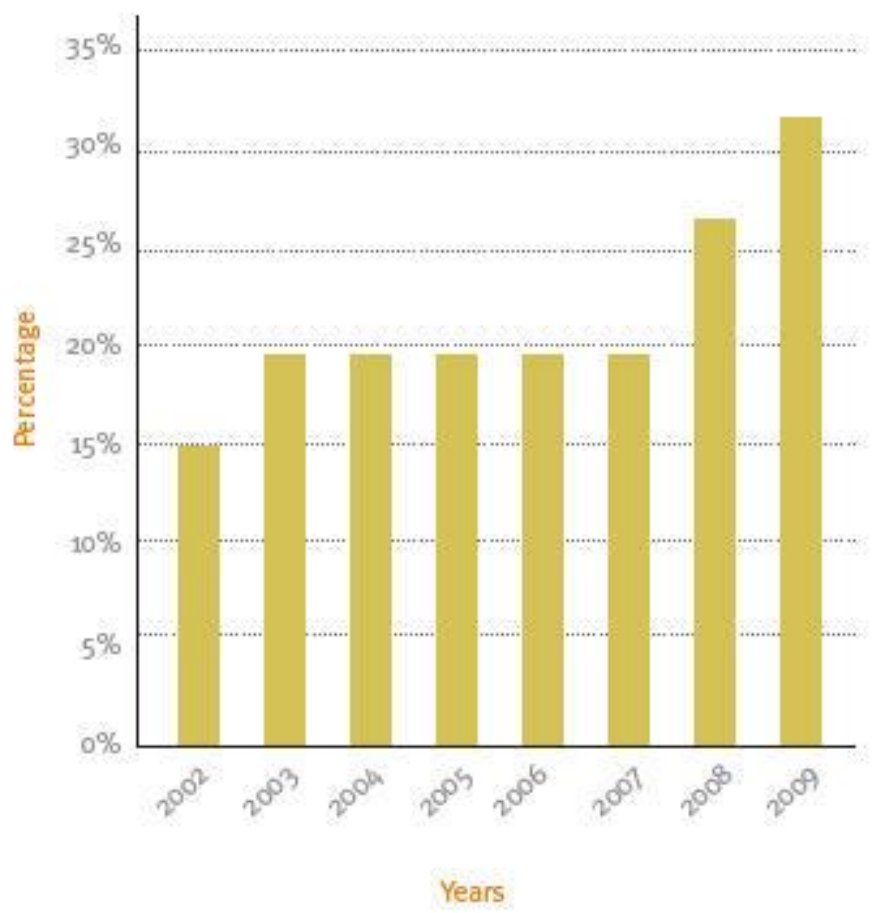

Figure 2.2: Percentage of Cal Poly Student Population living On-Campus (Multari 2010) 


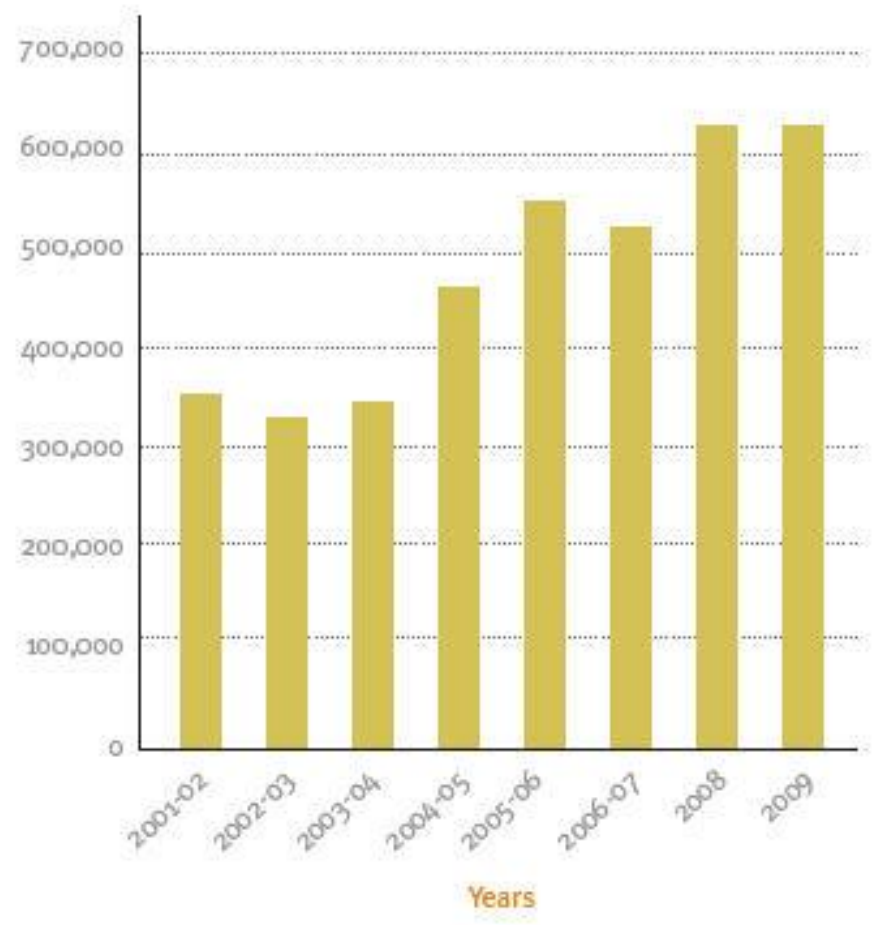

Figure 2.3: Cal Poly SLO Transit Ridership (Multari 2010)

\subsection{Growth vs. Traffic Reduction}

A common argument in transportation is whether a transportation system is improved despite the continued growth of an area. Quite often the additional demand generated from growth can harm and possibly even offset the efforts taken to improve traffic congestion or reduce vehicle emissions. This makes improvements to transportation that much more difficult. Regardless of efforts made, it is important to consider the impact of a "do nothing" alternative which is still subject to growth and additional congestion that can often lead to an even worse transportation state. Any improvements that can be made are important, but improvements that can hold despite increased growth, can really have a significant impact. 


\subsection{Simulation in Transportation}

In recent years, simulation has been applied to transportation to solve many problems such as traffic congestion, traffic growth, signal control optimization, public transit priorities, and predicting driver reactions to certain stimuli. There are two approaches used in transportation simulations: macrosimulation and microsimulation. In macrosimulation, the flow of vehicles on a road is treated as a homogenous entity like fluid flowing through a pipe. In microsimulation, the movements of individual vehicles are captured and system analysis is achieved by aggregating the collective behaviors of all vehicles (Ramasamy 2002). Screenshots of animation (Figure 2.4) show the visual differences between both of these types.

Microsimulation takes into account the interactions and interdependencies of motorists and is preferred over macrosimulation because it can capture a breakdown of flow that macrosimulation would be unable to cope with. Macrosimulation can be preferred over microsimulation however, because it is cheaper, computes faster, and vehicle-specific information may not be important to the problem at-hand. In this study, we use microsimulation because it is available at the university and because the high-level of detail is desired to mimic traffic issues at Cal Poly, especially with regard to vehicle emissions.

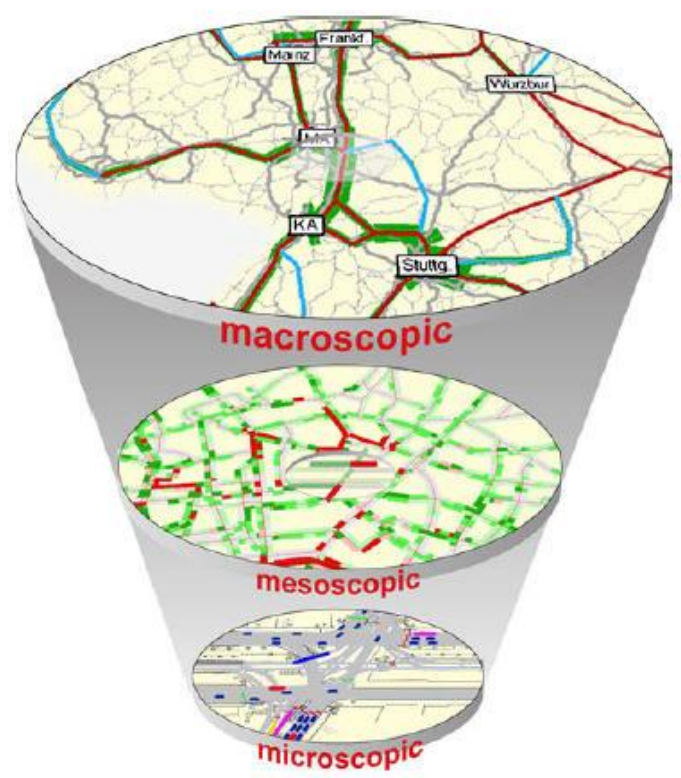

Figure 2.4: Visual Comparison of Types of Transportation Simulation (PTV Vision 2007) 


\subsubsection{Agent Based Modeling}

Within microsimulation, the concept of agent-based modeling can also be applied. In an agent-based model, entities act as autonomous agents that have their own rules for behavior and are affected by interaction with other agents. Some agents are smart in that they can learn from their experiences and environments. In transportation microsimulation, agents are often driver-vehicle pairs, whose behaviors are influenced by interactions with other driver-vehicle pairs.

\subsection{VISSIM}

VISSIM is an agent-based microsimulation software first pioneered in 1992 by PTV-AG in Karlsruhe, Germany. It is now produced in the U.S. by PTV America in Portland, Oregon and is a leading program for multi-modal traffic flow modeling. VISSIM features state-of-the-art animation, emissions analysis and playback controls, as well as inputs and outputs to many other programs. In the past, VISSIM has been used for many applications such as:

- Development, evaluation, and fine-tuning of signal priority logic

- Evaluation and optimization of traffic operations in a combined network of coordinated and actuated traffic signals

- Analysis of slow speed weaving and merging areas

- Route choice dependent questions such as the impact of a variable message sign or the potential of traffic diversion into neighborhoods

- Modeling and simulating flows of pedestrians along streets and inside buildings (VISSIM v5.20 User Manual 2009)

One of the latest editions of the software, version 5.20 is used in our study at Cal Poly.

\subsubsection{VISSIM Components}

VISSIM is made up of two main components - a traffic simulator and a signal state generator. The traffic simulator is a microscopic traffic flow simulation model including car following and lane changing logic. The signal state generator is a signal control software polling detector information from the traffic simulator on a discrete time basis (down to $1 / 10$ of a second) to determine the signal status for the following time step and return this data to the traffic simulator (VISSIM User Manual 2009). 


\subsubsection{Car Following/Lane-Changing Methodology}

VISSIM is one of the most accurate tools for traffic simulation modeling because of the methodology of how vehicles move through a road network. VISSIM uses the psycho-physical driver behavior model pioneered by Rainer Wiedemann in 1974. As opposed to simple models which use constant speeds or deterministic car following logic, Wiedemann's model views the interaction of vehicles as an iterative process of acceleration and deceleration. This is built off the basic idea that a driver of a faster vehicle starts to decelerate as he/she reaches their individual perception threshold of a slower moving vehicle. When the driver slows down, he/she does not know the speed of the neighboring vehicle, so he/she drops to a speed just below that of the neighboring vehicle until another threshold is reached where he/she begins accelerating again. This iterative process is repeated until speed is matched or conditions change. The variation in driver thresholds is accounted for in stochastic distributions of speed and spacing which are updated periodically based on changes in aggregate driver behavior and improvements in vehicle technology and capabilities.

\subsubsection{Vehicle-Driver Pairs}

VISSIM is agent-based in that drivers are paired with vehicles to travel through a network. Each driver has their own behavior characteristics which are controlled by their current state in the simulation and the capabilities of the vehicles they are paired with. The behavior of a driver-vehicle pair can change quite often during simulation based on the current situation and behaviors of nearby motorists. 


\subsection{Emissions}

Given the increases of global climate change and the continued acquisition of health problems due to environmental stimuli, emissions generated by the human race and its behaviors continue to be a growing concern for the future of mankind.

\subsubsection{Types of Emissions}

Air pollutants are emitted from a variety of sources including stationary fuel combustion, industrial processes, highway vehicles, and non-road sources. Pollutants from these sources enter the atmosphere in the forms of solids, liquids and gases and either stay in those states or react with other matter. Pollution has become a major concern when the concentration of these constituents in a portion of the atmosphere reaches a level of imbalance at which some biological processes are disturbed and cannot be carried out as they normally would. Although pollution mostly impacts the environment on a local level, some global effects are beginning to be noticed. Perhaps the best known example of this is global climate change which is a result of greenhouse gas emissions. Greenhouse gas emissions are generated by the combustion of fossil fuels combined with deforestation which leads to an over-concentration of carbon dioxide, a gas that often traps heat in the atmosphere.

According to National Ambient Air Quality Standards (NAAQSs), there are six main types of pollutants, known as criteria pollutants. Five of these pollutants (particulate matter, sulfur dioxide, nitrogen dioxide, carbon monoxide, and particulate lead) are considered primary pollutants, in that their generation can directly affect the atmosphere. Ozone, on the other hand, is classified as a secondary pollutant in that it is not directly emitted, but is formed by chemical reactions in the atmosphere between sunlight, volatile organic compounds (VOCs) and nitrous oxides. VOCs such as hydrocarbons as well as nitrous oxides are emitted directly from the same variety of sources but only pose a risk if they react in the atmosphere to form ozone compounds. It is important to know that the ozone compound $(\mathrm{O} 3)$ of concern exists in the lower atmosphere (troposphere) in the form of smog and is different from the ozone in the upper atmosphere that protects us from the sun. Pollutants are often classified into categories that account for primary pollutants and pollutants that trigger the creation of ozone. These categories include particulate matter, sulfur oxides, nitrogen oxides, and volatile organic compounds (VOCs). Particulate matter generally takes the form of fine dusts, noncombustible ash, and incompletely burned soot. Sulfur and 
nitrogen oxides describe several compounds that combine either sulfur or nitrogen with different quantities of oxygen. Common compounds in these classes are nitrogen monoxide, nitrogen dioxide, and sulfur dioxide. VOCs can take the form of hydrocarbons, which are compounds that contain only hydrogen and/or carbon atoms, as well as aldehydes, ketones, and chlorinated solvents (Cooper 2002).

\subsubsection{Emissions in the United States}

In the United States, the Environmental Protection Agency (EPA) is tasked with the duties of monitoring pollution and improving the quality of the environment and has been historically successful in making the United States a world leader in pollution control. According to the EPA in 2000, the United States generates somewhere between $10-33 \%$ of the world's emissions, depending on the type of pollutant. Emissions and their impact in the United States began to be recognized sometime after the Great Depression when their existence increased rapidly. It wasn't until legislation was passed in 1970 that emissions began to decline. According to EPA estimates in 2000, this decreasing trend has slowed and could perhaps be reversing itself in the near future (Cooper 2002). A more recent report on air quality from the EPA in 2010 based off of data from 2008 (Figure 2.5) still shows reduction for most types of emissions, with the exception of carbon dioxide which has increased approximately 20\% from 1990 to 2008 (Figure 2.6). The nationwide spike in fuel prices and the economic recession of 2008 is a significant factor in these trends and future trends.

\begin{tabular}{|c|c|c|c|c|c|c|c|c|}
\hline Source Category & $\mathrm{PM}_{25}$ & $\mathrm{PM}_{10}$ & $\mathrm{NH}_{3}$ & $\mathrm{SO}_{2}$ & No. & VOC & $\mathrm{CO}$ & Lead \\
\hline $\begin{array}{l}\text { Stationary Fuel } \\
\text { Combustion }\end{array}$ & -773 & -813 & +43 & $-10,490$ & $-5,323$ & +445 & -228 & -0.42 \\
\hline $\begin{array}{l}\text { Industrial and } \\
\text { Other Processes }\end{array}$ & -343 & -217 & -446 & -731 & -144 & $-3,150$ & -442 & -2.80 \\
\hline Highway Vehicles & -213 & -216 & +153 & -439 & $-4,386$ & $-5,970$ & $-71,389$ & -0.42 \\
\hline Non-Road Mobile & -17 & -24 & -28 & +85 & +474 & -76 & $-3,411$ & -0.27 \\
\hline Totol Change & $-1,346$ & $-1,270$ & -278 & $-11,575$ & $-9,379$ & $-8,751$ & $-75,470$ & -3.91 \\
\hline $\begin{array}{l}\text { Percent Change } \\
\text { (1990 vs. 2008) }\end{array}$ & $-58 \%$ & $-39 \%$ & $-6 \%$ & $-50 \%$ & $-36 \%$ & $-35 \%$ & $-53 \%$ & $-79 \%$ \\
\hline
\end{tabular}

Figure 2.5: Rates of Change for Pollutant Types by Source Category in the United States from 1990-2008 (U.S. EPA 2010) 


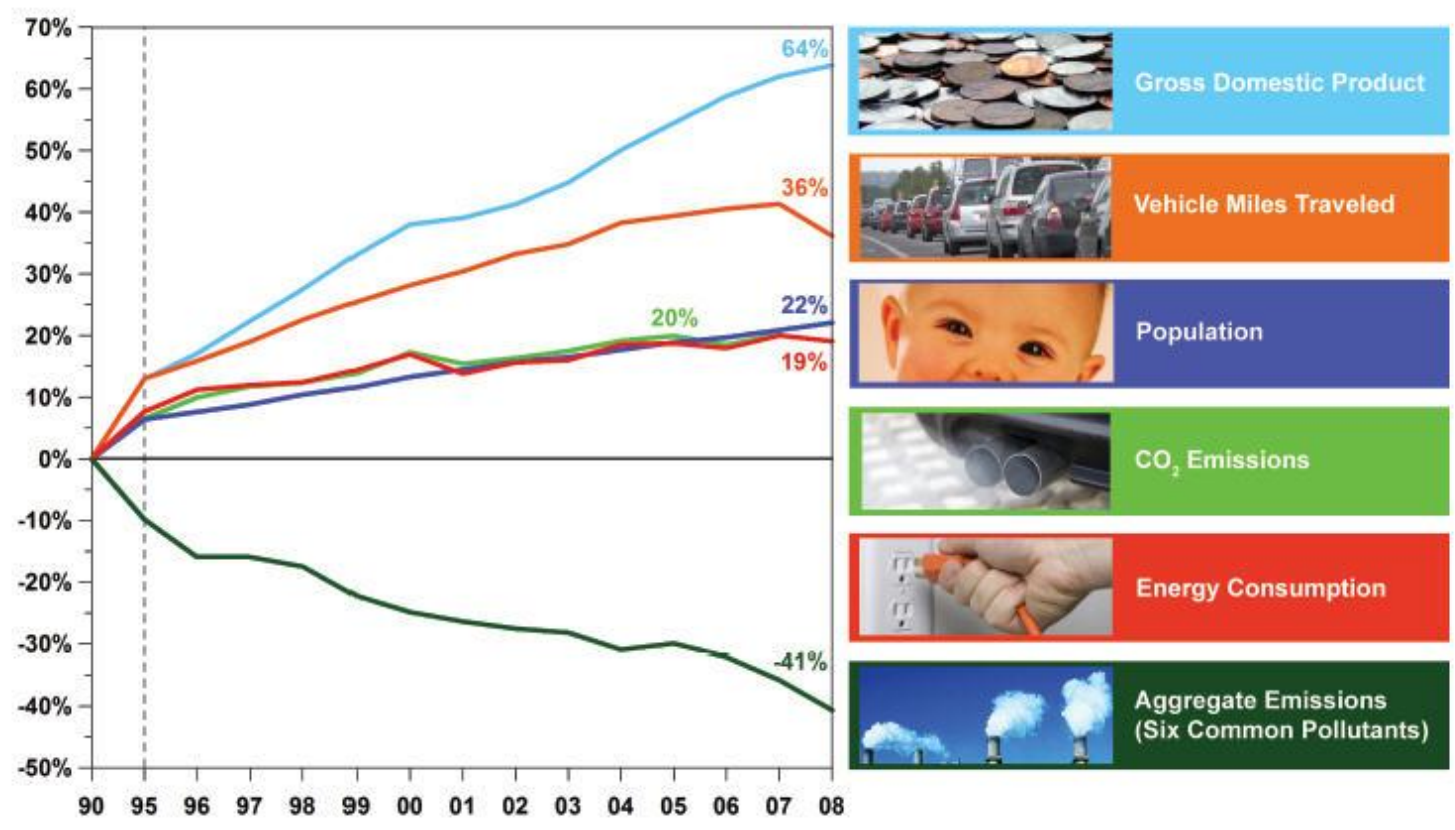

Figure 2.6: Rate of Change for Carbon Dioxide Emissions in the United States in Relation to other Growth Indicators from 1990-2008 (U.S. EPA 2010)

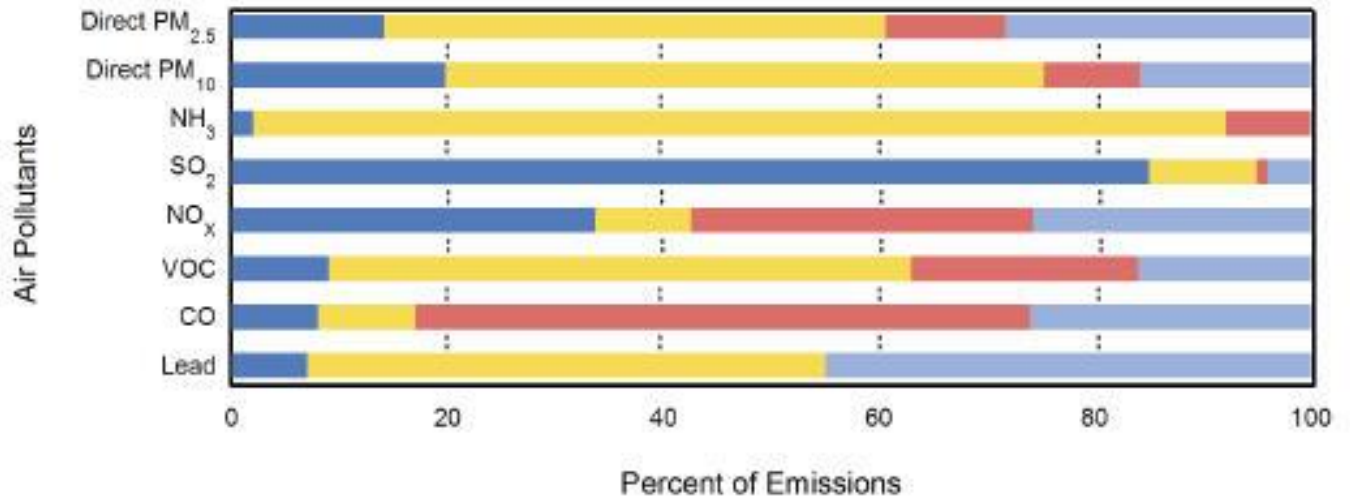

Source Category

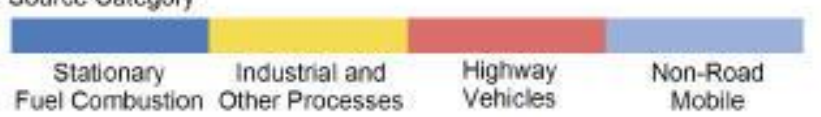

Figure 2.7: Breakdown of Pollutant Emissions by Source Category (U.S. EPA 2010) 
The above chart (Figure 2.7) from 2008 shows the percent of emissions of each pollutant type attributed to one of four source categories. Based on this data, the EPA has made several estimates regarding current emissions:

- Approximately $70 \%$ of $\mathrm{SO}_{2}$ emissions are sourced from electric utilities

- Approximately over $80 \%$ of ammonia emissions $\left(\mathrm{NH}_{3}\right)$ are the result of agricultural processes or operations

- Approximately 50\% of VOC emissions are generated from either solvents or highway vehicles The EPA has also made several estimates for emissions not specified in the above chart:

- Approximately $94 \%$ of $\mathrm{CO}_{2}$ emissions are the result of the combustion of fossil fuels which include electricity generation, transportation, industrial processes, and residential or commercial processes. Electricity generation accounts for about $42 \%$ share of $\mathrm{CO}_{2}$ emissions while transportation accounts for nearly one-third (33\%) of $\mathrm{CO}_{2}$ emissions.

- Approximately $64 \%$ of $\mathrm{CH}_{4}$ (methane) emissions result from livestock, landfills and natural gas systems while coal mining and manure management comprise approximately $10 \%$ and $8 \%$, respectively. 


\subsubsection{Emissions in San Luis Obispo County}

The San Luis Obispo County Air Pollution Control District is the local agency charged with working to protect the health of over 265,000 county residents by preserving good air quality. It is responsible for ensuring the county's air meets standards established by the California Air Resources Board and the US EPA (San Luis Obispo Air Pollution Control District 2008). The monitoring and control of pollution on a local basis is important, especially since most pollutants affect the environment and people on a local level. The county has historically maintained a "good" air quality rating and adheres to most state or federal standards. Sources of pollution in the county (see Figure 2.8 below) are largely attributed to transportation due to its size and relative lack of industry compared to more urban areas. This graph focuses on sources specific to generation of reactive organic gases and nitrogen oxides.

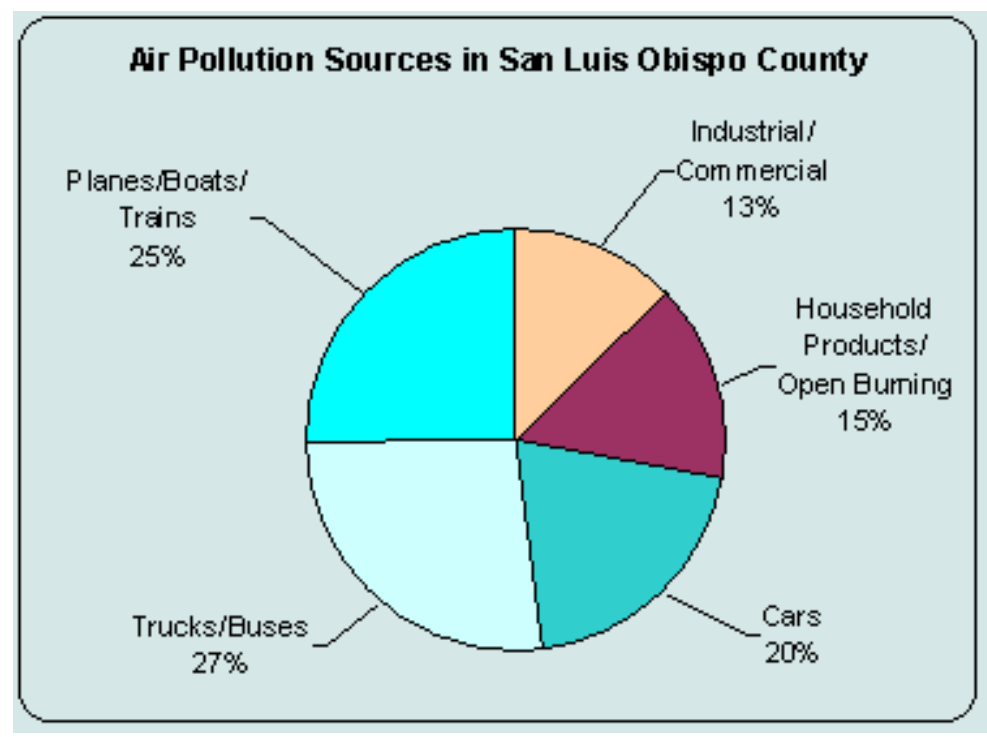

\section{Figure 2.8: Air Pollution Sources in San Luis Obispo County (San Luis Obispo County Air Pollution Control District 2008)}

The county currently has the most difficulty meeting federal and state standards for PM-10 emissions, which refers to particulate matter on the order of ten micrometers in size, a type of emission which is largely influenced by transportation. 


\subsubsection{Emissions \& Transportation}

As seen from both US and San Luis Obispo County statistics, transportation is a large contributor to emissions. In fact, the United States has more cars per capita than any other nation. According to EPA statistics from 2008 , highway and non-road mobile sources constitute about $80 \%$ of national carbon monoxide emissions and $33 \%$ of carbon dioxide emissions (US EPA 2010). In addition to these emissions, nitrous oxides $\left(\mathrm{NO}_{\mathrm{x}}\right)$, volatile organic compounds $(\mathrm{VOCs})$, sulfur dioxide and particulate matter are also pollutants of concern sourced from transportation. Particulate matter results because even the best internal combustion engine does not fully burn $100 \%$ of its fuel.

There are many factors that influence the amount of vehicle emissions generated. These factors can be divided into vehicle factors and environmental conditions. In terms of vehicle factors, the amount of emissions generated is influenced by the design and operating features of the engine, the operational and maintenance practices of the driver, fuel consumption, and add-on pollution control technology. Vehicles have been continually improved over the years with technology that controlled the flow rate of fuel to the engine as well as catalytic converters which treat exhaust emissions so they are less harmful. Catalytic converters help control exhaust emissions particularly by oxidizing $\mathrm{CO}$ and $\mathrm{VOCs}$ to form $\mathrm{CO}_{2}$ and water and reducing nitrous oxides to nitrogen and oxygen gas. In terms of environmental factors, the amount of emissions generated is influenced by the density of the ambient air, temperature, soak time (time since last engine start), and the secondary load placed on the engine by factors such as air conditioning. Transportation air pollution is difficult to control in that arises from a large number of small, diverse, decentralized sources which are highly mobile and close to receptors (people living and working in areas near vehicles). Furthermore, the automobile has long been an economic status symbol and driving one is integral to many lifestyles. The growth of transportation is also very large, which often offsets any attempts to reduce emissions. On an international level, the significance of mobile source pollution is growing at an even faster rate than industrial pollution (Cooper 2002). Achieving success in controlling emissions can is best reached through continual advances in vehicle technology, stricter legislation, and transportation control measures. Simulation is an excellent tool for analyzing the impacts of all three of these methods. 


\section{Review of Literature}

The following section is a literature review of related studies in traffic simulation and emissions modeling. Additional literature is reviewed in Appendix R: Additional Background Information.

\subsection{UCF Simulation Using Paramics}

Shankar Ramasamy, a graduate student at the University of Central Florida, used PARAMICS software and its dynamic assignment module to model the congested UCF road network in 2002 during the AM and PM Peak hours. PARAMICS is another leading simulation software for modeling traffic and transportation made by Quadstone Limited of Edinburgh, United Kingdom. Ramasamy's model was used to assess what geometric and operational improvements could improve safety and efficiency on UCF's campus. He found that congestion could improve by widening a main thoroughfare to four lanes and adding a traffic signal. This plan, however, may generate additional commuter traffic not intended for the campus, which provided light to the idea of an off-campus satellite parking area with shuttle service. Additionally, Ramasamy found that the campus could significantly improve in terms of bicycling and carpooling.

\subsection{Environmental Impacts of Traffic Management \& Control}

As part of IEEE's 2009 International Conference on Energy and Environment Technology, researchers from the School of Transportation at Nanjing, China's Southeast University presented a study which evaluated traffic management and control as a transportation planning strategy with consideration of the environment. Specifically, they compared policies with emphasis on mitigating traffic congestion and emphasis on mitigating traffic emissions - policies which are usually different and often conflict. They used VISSIM microscopic simulation software to simulate the use of a central or side bus lane along North Taiping Road as a traffic mitigation measure. The Comprehensive Modal Emissions Model (CMEM) was used to capture the behavior of vehicles from the simulation to generate key emissions statistics. Using gray system theory and analytic hierarchy process (AHP) analysis, the researchers analyzed several indices corresponding to policies mitigating traffic congestion and traffic emissions. In the case of a central bus lane, traffic congestion indices were significantly improved while the use of a side bus lane tended to improve vehicle emission statistics instead. They concluded an ideal model should try to optimize both policies of traffic mitigation and traffic emissions and the most ideal solution should be sought by using an 
analysis such as AHP, where weights are assigned to different evaluation parameters which convey performance.

\subsection{Flow Improvements \& Vehicle Emissions}

In 2005, Robert Noland and Mohammed Quddus, researchers at the Center for Transport Studies at London's Imperial College used VISSIM microsimulation and the comprehensive modal emissions model (CMEM) to study flow improvements and vehicle emissions. Their objective was to determine the affect in terms of vehicle emissions of increasing the availability of road space as a measure to smooth traffic flow. Based on economic theory, many previous studies suggested that adding lanes to a major roadway as a traffic mitigation measure reduced travel times which generated additional "induced" demand. With this additional induced demand, some argue that emissions are increased while others argue that the reduction of stop-and-go traffic and the improved smoothening of traffic flow do, in fact, reduce emissions despite the additional induced demand. The researchers chose CMEM for emissions modeling because of its ability to account for second-by-second accelerations and calculated the break-even points for emissions of carbon monoxide (CO), carbon dioxide (CO2), nitrous oxides (NOx) and hydrocarbons (HCs) generated along a hypothetical roadway representative of a typical thoroughfare in the United Kingdom. They found in most cases that a mitigating measure of widening a two lane segment to three lanes increased traffic to a point where any emission reduction benefits were offset. They found this result to be even more significant with traffic compositions consisting of greater mixes of newer and cleaner vehicle models since the low emissions generated by those models has more difficulty offsetting the impact of its demand increases.

\subsection{Simulation of Emergency Vehicle Routing}

Mansooreh Mollaghasemi and Mohamed Abdel-Aty, both faculty members at the University of Central Florida, developed an emergency response model in 2003 for use at Orlando International Airport. They used PARAMICS and its dynamic assignment module to evaluate emergency vehicle routing strategies from several nearby fire stations during the PM Peak Hour, should an incident occur at Orlando International. The use of a microscopic simulation tool was important in their study because of the inability to test emergency situations in the field. They were able to determine which fire stations were capable of the shortest response times given a variety of traffic conditions. In applying scenarios, they also were able to determine different priorities for response based on variable incident locations at the airport. 


\subsection{Development of a Microscopic Modal Emissions Model}

Under sponsorship of the National Cooperative Highway Research Program, researchers from the University of California at Riverside, the University of Michigan and the Lawrence Berkeley National Laboratory, developed a comprehensive model for modal emissions (CMEM) in 1998. The resulting model was developed to evaluate operational improvements that are more 'microscopic' in nature, as opposed to the standard models of the time such as EMFAC and MOBILE which evaluate emissions and operations at a more regional level (Scora 2006). In order to create CMEM at a microscopic level, researchers decided to create a model based on various states of vehicles such as properly functioning, deteriorating, malfunctioning. Furthermore, they chose to study different operating modes for vehicles such as acceleration, deceleration, and steady-state cruising on a second-by-second basis. Using a physicalload based approach, researchers collected data from approximately 340 vehicles of a variety of types. Three test cycles were completed for each vehicle: 1) a 3-bag FTP test, a high speed cycle (US06), and a modal emission cycle (MEC01). Based on the results of these tests and all assumptions made, a model was developed to quantify vehicle tailpipe emissions as a function fuel rate, engine-out emissions indices, and time-dependent catalyst fractions (CPFs). This model is presently the most accurate of any microscopic software for estimating vehicle emissions. 


\section{System Overview}

\subsection{Model Development Process}

The following figure describes the model development process that is selected for carrying out the transportation simulation. Feedback loops can exist between any two steps in the process, regardless of sequence.

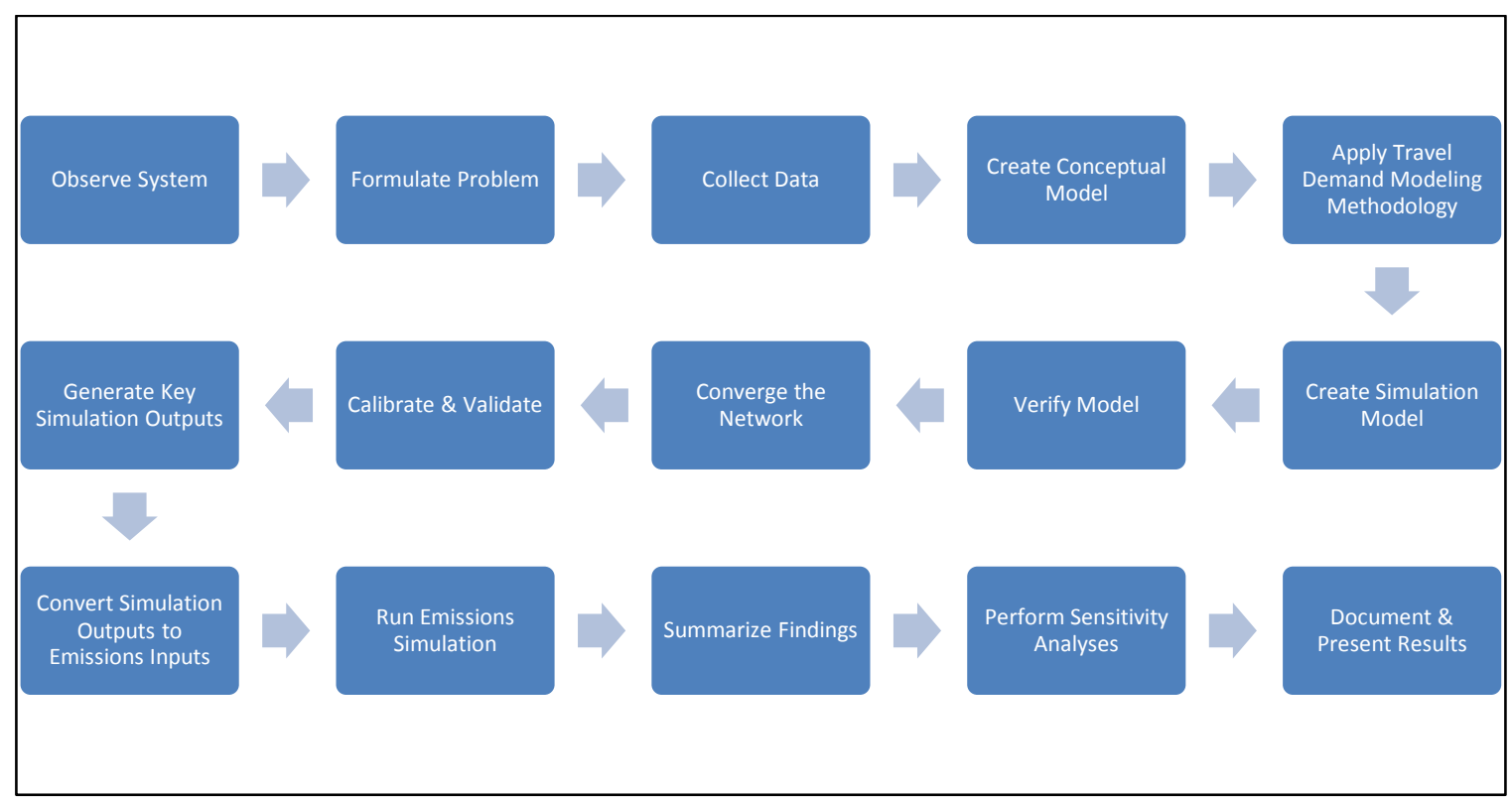

Figure 4.1: Model Development Process

\subsection{Key Inputs}

There are three main types of inputs to the simulation model—road network data, vehicle data, and travel demand data. From an economics perspective, the road network constitutes supply (the spaces available to be occupied by vehicles) while the trip-making habits of motorists constitute demand.

\subsubsection{Road Network Data}

Constructing the road network involves replicating the current layout of streets, intersections, parking lots and other roadway features located in the area of study within the VISSIM modeling environment. An accurate model of the current road network is necessary for predicting traffic behavior and for testing potential changes to the transportation system.

The first step is in creating a road network in VISSIM is creating the links (streets) and connectors (intersection movements). VISSIM features the ability to load and scale satellite photos as background images so links and connectors can easily be overlaid on top. This eliminates the need to collect mass 
amounts of geometric data and provides a realistic aerial visualization of the area of study. Spline points enable the ability to trace actual curvatures in links and connectors. In creating the connectors at intersections, it is important to know the lane configurations at each approach and departure and which approaches map to which departures. Equally important is the width of lanes and lengths (capacities) of dedicated turn lanes or turn pockets. This data can be obtained through observations in the field.

Once a road network is created, it is necessary to create speed distributions that the vehicles will follow. Speed distributions are used in the model in the form of desired speed decisions and reduced speed decisions. Desired speed decisions describe the ranges of speeds vehicles travel on a particular stretch of roadway or when entering a new segment of roadway. Desired speed decisions typically oscillate around the speed limit during free-flow conditions. Reduced speed decisions are used for sharp curves, or entering congested areas such as schools where speed is temporarily reduced. Speed distributions in VISSIM can be normal or empirical in nature and can be obtained from field studies or law enforcement statistics. They can also be estimated using rules-of-thumb based on professional expertise.

Besides speed distributions, traffic control devices and their operating rules also need to be input to the model. Signalized intersections require signal heads and the input of signal timing plans. With placement of loop detectors in the pavement, actuated signals can also be modeled. At any intersection, it is good practice to specify operating rules for areas where collisions may occur. Conflict Areas in VISSIM can be created when paths branch, cross or merge to determine which paths have priority and which paths must yield. At a 4-way stop intersection, VISSIM's Priority Rules are used to determine the order in which stopped vehicles proceed.

When a dynamic assignment module is used (see Creating an Abstract Model), the placement of parking lots and nodes are also important. Parking lots and nodes are used to define the zones in dynamic assignment where trips are either produced or attracted. Parking lots describe ingress/egress points within these zones while nodes are used to identify intersections or areas of the network where paths can diverge. 


\subsubsection{Travel Demand Modeling}

Travel Demand Modeling is a process used to forecast the volume of traffic that will use a given transportation element in the future. Traditionally, the process of travel demand modeling involves four key phases- trip generation, trip distribution, mode choice, and trip assignment. Trip Generation quantifies the number of people making trips and for what purposes they make trips. Trip Distribution then determines where these trips begin and end, depending on which locations attract and produce trips. Mode choice determines which modes of transportation are used to make these trips and can often be rooted in utility theories. Finally, trip assignment determines which routes will be taken by which persons to get from each possible origin to each possible destination. Travel demand is determined by aggregating the trips of all people in an area. For the purposes of this simulation, the phase of Trip Generation is covered by the existing habits of motorists. This could change, however, with the introductions of new developments on or around the Cal Poly campus. Trip Distribution serves as a key input to the simulation model for traffic volumes and also affects Trip Assignment in the model. Mode Choice is not a large factor because each mode is analyzed separately.

\subsubsection{Vehicle Data}

Vehicle inputs in VISSIM are drawn from traffic compositions. Traffic compositions are usually derived from field studies that quantify how many vehicles of different types travel in the area of study. Traffic compositions can be composed of one or more vehicle classes or types. Vehicle Types can be composed of multiple vehicle makes, models and colors, while vehicle classes can encompass one or more vehicle types. Vehicle Model distributions are defined as groups of vehicles which share the same color distribution, acceleration/deceleration profiles, occupancies, and widths. Figure 4.2 below shows breakdown for determining proper vehicle inputs. 


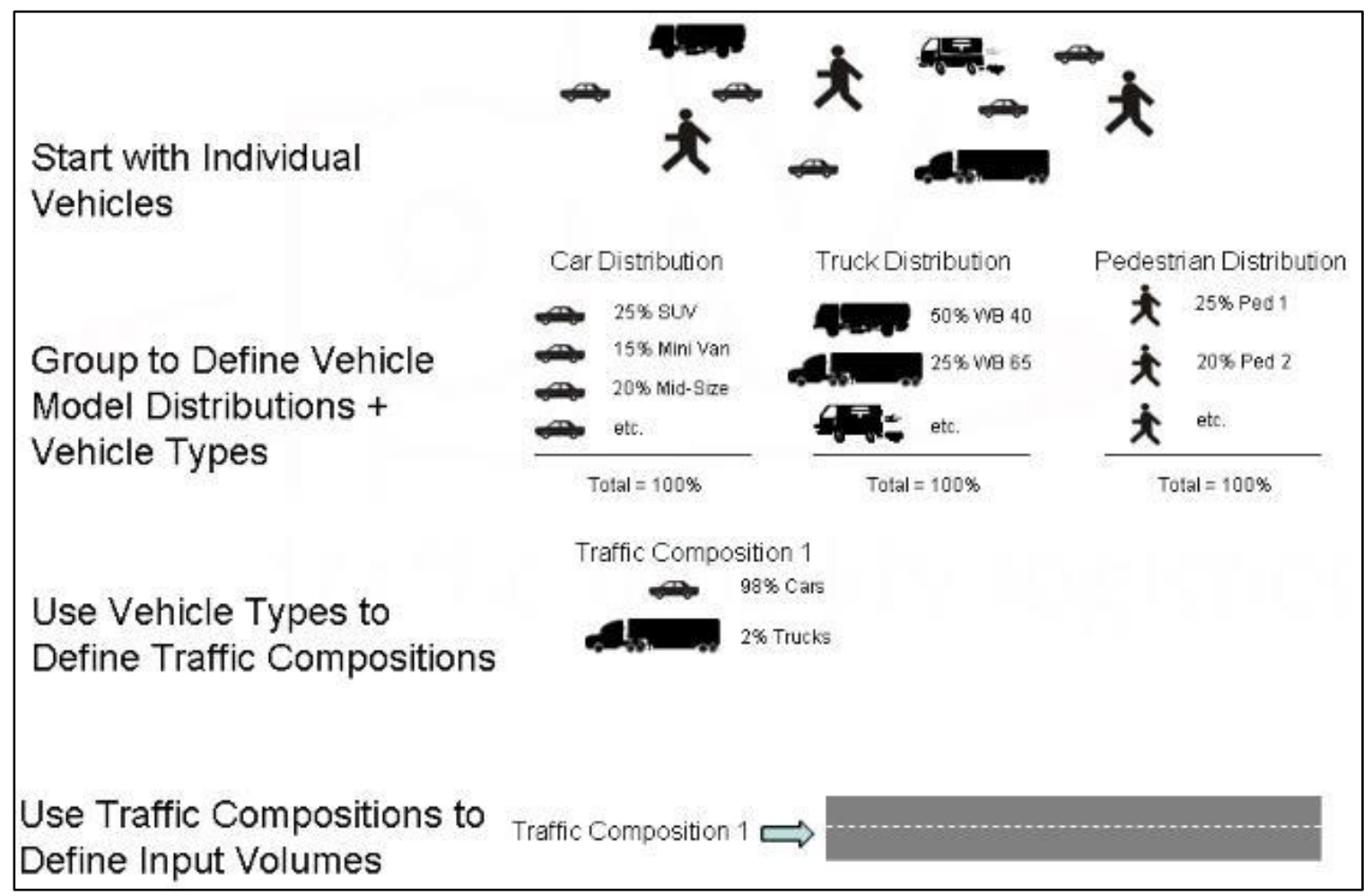

Figure 4.2: Outline for Determining Vehicle Classifications in VISSIM (PTV Vision 2010)

A final input to the model is routing information which describes the paths vehicles take from one point to

another. Specific routing information can be applied to certain vehicle types or vehicle classes (heavy vehicles, tall vehicles, carpools, etc.) within VISSIM. The routing information is considered in traffic assignment stage of travel demand modeling.

\subsection{Trip Distribution}

Trip Distribution is a key process for input to the simulation model because it estimates the number of trips going from place to place in the road network and serves as a basis for Trip Assignment. The most commonly used method for Trip Distribution is the Gravity Model.

\subsubsection{Gravity Model}

The gravity model applies the gravitational concepts of Isaac Newton to the problem of distributing traffic throughout an urban area. In order to apply the Gravity Model, the area of study must be divided into Traffic Analysis Zones (TAZs). Each zone represents an area with similar characteristics or purposes. Zones are often divided by physical barriers such as highways, arterials, railroads, fences, or other geographical features. The gravity model converts totals of trip productions and trip attractions from each 
of these zones into trip interchanges. Similar to the Newtonian gravitational concept, the Gravity Model is based off two principal assumptions:

- A trip produced in a zone is more likely to be attracted to an attraction zone with a higher number of attractions (stronger pull)

- A trip produced in a zone is more likely to be attracted to an attraction zone that is physically closer to it (minimum distance)

The standard form of the gravity model is as follows:

$\mathrm{T}_{\mathrm{ij}}=\mathrm{P}_{\mathrm{i}} *\left(\mathrm{~A}_{\mathrm{j}} \mathrm{F}_{\mathrm{ij}} \mathrm{K}_{\mathrm{ij}} / \Sigma \mathrm{A}_{\mathrm{j}} \mathrm{F}_{\mathrm{ij}} \mathrm{K}_{\mathrm{ij}}\right)$

Where;

$\mathrm{T}_{\mathrm{ij}}=$ trips produced in zone $\mathrm{I}$ and attracted to zone $\mathrm{j}$

$\mathrm{P}_{\mathrm{i}}=$ total trip production at $\mathrm{i}$

$A_{j}=$ total trip production at $j$

$F_{i j}=$ friction or travel time factor (calibration term) for interchange $\mathrm{ij}$

$\mathrm{K}_{\mathrm{ij}}=$ socioeconomic adjustment factor for interchange $\mathrm{ij}$

\subsubsection{Friction Factor}

The friction factor is typically an inverse function of impedance describing the spatial separation between zones. It is most often measured by travel time. The total travel time between zones can be calculated by dividing the minimum path distance by the posted speed limits along the route. The equation for the friction factor is as follows:

$\mathrm{F}_{\mathrm{ij}}=1 / \mathrm{t}_{\mathrm{ij}}{ }^{\mathrm{c}}$

Where;

$\mathrm{C}=$ calibration factor

$\mathrm{T}_{\mathrm{ij}}=$ travel time between $\mathrm{I}$ and $\mathrm{j}$

In order to achieve a proper value for the friction factor, the gravity model is calibrated and adjustments to the friction factor, if needed, can be made to the calibration coefficient, $c$.

\subsubsection{Gravity Model Calibration}

The following steps are necessary to calibrate the gravity model:

1. Determine the number of trips generated from the origins 
2. Determine the number of trips ending at the destinations

3. Create table of productions \& attractions

4. Create table of travel time between zones

5. Create table of friction factors

6. Create table of $\mathrm{A} * \mathrm{~F} * \mathrm{~K}$ terms

7. Insert terms into Gravity Model equation to determine trip counts

8. Assemble these trip counts in an OD (Origin/Destination) matrix

9. Adjust the attraction/production factors and revise the table. Repeat until all calculated attractions and productions are within 5\% of each of the anticipated attractions and productions.

\subsection{Trip Assignment}

The process of trip assignment uses travel demand data generated in the OD matrix to determine which routes will be taken by which vehicles to get from each possible origin to each possible destination. Traffic assignment usually is applied with some type of route choice model, which is a specific case of discrete choice modeling or theory. In route choice modeling, a set of potential routes is generated and alternative routes are selected by drivers using certain evaluation criteria such as travel time, travel distance, and cost.

\subsubsection{Dynamic Assignment}

The standard procedure for traffic assignment is static assignment. In static assignment, a route choice model is applied where drivers are placed on routes within their network. The shortcoming of static assignment is that it fails to account for fluctuations in demand throughout the study period and changes in the road network. In VISSIM, an alternative exists in dynamic assignment which can account for these changes. Dynamic assignment makes routing in large networks easier than static assignment because there is no need to manually code each possible route and route split. Dynamic assignment is able to generate routes on its own and evaluate routes according to criteria which can be modified globally or locally. Dynamic assignment can also be more accurate than static routing in a large network because of the error involved in modeling multiple routes and multiple decision points. 


\subsubsection{Dynamic Assignment in VISSIM}

In VISSIM, dynamic assignment is based off an iterated simulation of microscopic traffic flow. This means that drivers chose their routes through the network almost continuously based on the experiences they have experienced or are experiencing along the route, as opposed to making only one decision at the start or a few decisions at a few key points. In this learning process there are several assumptions:

- Not every driver-vehicle pair uses the best route to get from their origin to their destination so it is important to consider all routes. However, these less attractive routes are typically used by a minor percentage of vehicle-driver pairs. Some of these routes may become negligible depending on travel demand and the existence of free-flow conditions.

- Different sub-route alternatives may become attractive along a route based on current traffic conditions even if they barely affect the motorist's overall travel time or distance. These decisions are captured in the iterative microscopic simulation.

- Based on past routing decisions, VISSIM builds an archive of past routing decisions. In the case that traffic situations are replicated, these routing decisions may be applied. This parallels the assumption that drivers will behave according to habits from past experiences and not always make simultaneous routing decisions.

- Based on past travel times, VISSIM creates a better model of anticipated general costs to the driver which improves cost modeling and helps determine when drivers behave according to habit versus when they are evoked to change their routing decision (if a driver's cost threshold for a route is exceeded, they will chose an alternative route).

- The route choice portion of dynamic assignment is captured using a variation of the Logit model based on the concept of general cost (VISSIM User Manual v5.20 2009).

The following diagram describes how the Dynamic Assignment process works in VISSIM: 


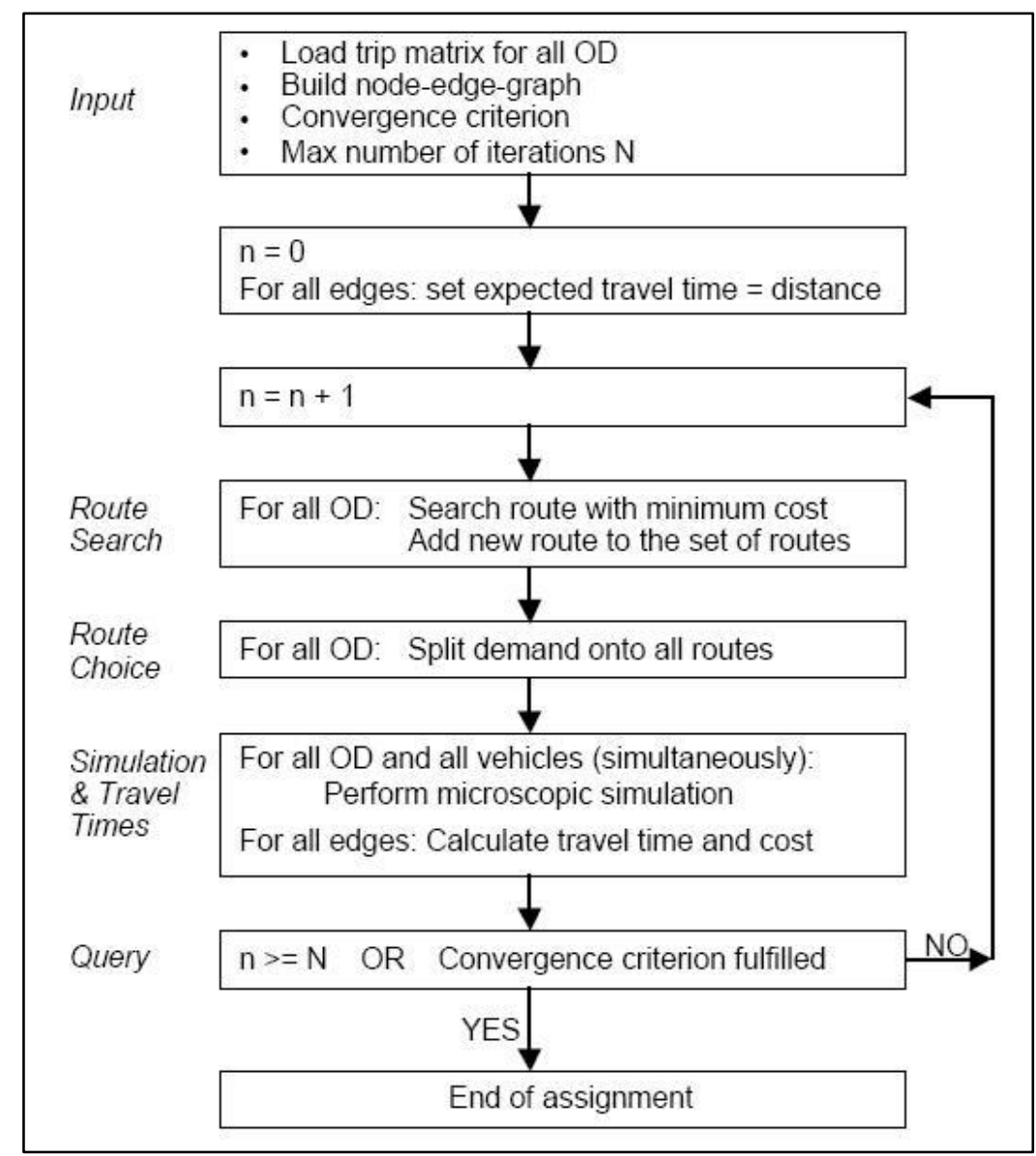

Figure 4.3: Logic of Dynamic Assignment in VISSIM (PTV Vision 2010)

\subsubsection{Creating an Abstract Model}

Based on the layout of the model, VISSIM constructs an abstract idea of the road network where intersections are nodes and the roads between intersections are edges of an abstract graph. This level of abstraction is more suitable for modeling human understanding of route choice and makes for more efficient modeling. To picture this in an everyday use, if someone were to tell their friend how to get to their house, they would describe a series of intersections and turning movements (abstracted view) but not necessarily get into detail about the length to travel along a certain link or which lanes to choose (detailed view).

In order for VISSIM to construct an abstract idea of the road network, it is necessary to create zones that correspond to those referenced in the OD matrix. Zones are modeled as parking lots in VISSIM and can be one of two types: zone connectors or abstract parking lots. Zone connectors are used to model origin and 
destination points where traffic enters/exits the network without using real parking while abstract parking lots are used to model origin and destination points where traffic enters/exits an actual parking lot. Abstract parking lots contain additional parameters for capacity and initial occupancy. Parking lots can only be placed on links and it is not uncommon to have multiple parking lots per zone. Nodes are used to model any areas of the road network where paths could diverge, including the entrances/exits to parking lots and the network (nodes are placed beyond the parking lots). Edges are formed either within a node or between two nodes and serve as building blocks forming routes (sequences of routing decisions).

\subsubsection{Cost \& Route Choice Models}

Travel time may be a key factor for influencing route choice, but travel distance and financial cost should not be discounted, even if they do not change with the simulation. Because of this, VISSIM models general cost as a combination of these factors according to the equation

General Cost $=\alpha *$ travel time $+\beta *$ travel distance $+\gamma^{*}$ financial cost $+\sum$ supplement 2

where $\alpha, \beta$, and $\gamma$ are coefficients that can be weighted for different vehicle types by the user. Supplement 2 can be used to add any additional cost without a weighted coefficient. General costs are calculated for each edge in the network. General costs for routes are determined by summing the general costs of all edges forming those routes. The general costs of routes are used in the simulation to determine the most attractive routes for vehicles to travel on.

To access how attractive a route is for a driver-vehicle pair, we can invert the general cost function into a utility function. That is, if $\mathrm{C}_{\mathrm{j}}$ represents the general cost of route $j$, then the utility of route $j$ can be described by the function $U_{j}=1 / C_{j}$. As mentioned above, the general cost for route $j$ is a summation of the general costs of all edges forming route $j$.

In discrete choice modeling, the most theoretically correct and widely used function for utility is the Logit function. Figure 4.4 shows the utility function used in VISSIM to determine the utility of a route. 


$$
\begin{aligned}
& p\left(R_{j}\right)=\frac{e^{\mu U_{j}}}{\sum_{i} e^{\mu U_{i}}} \\
& \text { where } \\
& \begin{array}{l}
U j=\text { utility of route } j \\
p(R j)=\text { probability of route } j \text { to be chosen } \\
\mu=\text { sensitivity factor of the model }(>0)
\end{array}
\end{aligned}
$$

\section{Figure 4.4: Logit Function for Utility of Routes (PTV Vision 2010)}

In this function, $\mu$ is a sensitivity factor that determines how much influence is generated by differences in utilities (i.e. a large $\mu$ indicates a high account for different utilities while a low $\mu$ indicates a low account for different utilities to the point that differences in utility seem negligible). If this Logit function is combined with the previous utility function, we end up with a situation where the model considers the difference between 5 and 10 minutes of travel time to be the same as the difference between 105 and 110 minutes. This is because the Logit function is invariant against translation and considers only the absolute difference of the utilities (VISSIM v5.20 User Manual 2009). To accommodate for this shortcoming, VISSIM uses the more-appropriate Kirchoff Distribution Formula:

$$
\begin{aligned}
& p\left(R_{j}\right)=\frac{U_{j}^{k}}{\sum_{i} U_{i}^{k}} \\
& \text { where } \\
& U j=\text { utility of route } j \\
& p(R j)=\text { probability of route } j \text { to be chosen } \\
& k=\text { sensitivity of the model }
\end{aligned}
$$

\section{Figure 4.5: Kirchoff Distribution Formula for Utility of Routes (PTV Vision 2010)}

In this function, $k$ is a sensitivity factor that determines the same influence of the differences in utilities except the relative difference in utility is determined by the distribution. The Kirchoff Formula can be expressed as a Logit function if the utility function is transformed to logarithmic form: 


$$
p\left(R_{j}\right)=\frac{U_{j}^{k}}{\sum_{i} U_{i}^{k}}=\frac{e^{k \cdot \log U_{j}}}{\sum_{i} e^{k \cdot \log U_{i}}}=\frac{e^{-k \cdot \log C_{j}}}{\sum_{i} e^{-k \log C_{i}}}
$$

where $C j$ is the general cost of route $j$.

Figure 4.6: Kirchoff Distribution Formula Expressed as a Logit Function (PTV Vision 2010)

This function is used in VISSIM for route choice.

\subsubsection{Parking Lot Selection}

When a zone used in dynamic assignment is comprised of multiple parking lots, it becomes necessary for a driver-vehicle pair bound to that zone to select a specific parking lot. Like route choice modeling, parking lot selection is also a special case of discrete choice modeling. Parking lot selection can be influenced by many factors such as out-of-pocket cost, past and current availability of parking spaces, closeness to final destination, distance from current position, geometry of spaces, and shade availability. VISSIM has a utility function based off of cost, attraction, distance to center of zone, distance from current vehicle position, and availability of free spaces. Users can weight these different factors with coefficients of their choosing and determine utility functions for specific vehicle types and decision situations in their models.

The cost component draws from the general cost function while the attraction component draws from the attraction parameter specified for each parking lot. A Logit function is used for parking lot selection to determine choice probabilities for each parking lot. The sensitivity of this function can be set based on altering a Logit scaling factor.

\subsection{Verification}

Verification is the process of determining whether the simulation model correctly represents the conceptual idea of the actual system. It asks the question, is the model built right for its intended purpose? In the case of a transportation simulation, the conceptual idea of the actual system refers to the defined road network and its layout on which traffic will operate. The conceptual idea of the actual system is determined by what is needed to accomplish the objectives of simulation. The process of matching demand components associated with a transportation system is referred to as calibration, which is discussed later.

There are several techniques which can be used for model verification. These include: 
- Inspecting output for reasonable results

- Watching animation for correct behavior

- Use software functionality to trace and debug incorrect behavior

\subsection{Calibration \& Validation}

Calibration is the process by which the demand components of a microscopic simulation model are refined and adjusted to match conditions observed in the field. Components often include release counts, turning movement volumes, queue lengths, travel times, delays, traffic speed, and traffic density. Calibration of these components improves a model's accuracy and its ability to replicate the system being studied. Without a well-calibrated model, the validity of processes such as predicting future behavior or modeling alternate scenarios is compromised.

Due to the stochastic nature of simulation models, a large number of simulation runs are to be conducted for calibration of the model and estimation of the measures of effectiveness with reasonable accuracy (Mollaghasemi 2003). Each simulation runs with a different "random seed" which utilizes the same operational conditions but generates slightly different results.

A seed value is essentially a starting value for a random number generator. When a random seed is chosen to run a simulation, a random number generator assigns values for certain parameters based off stochastic (probabilistic) distributions either built in to the software or provided by the user. In a microscopic traffic simulation, the random number generator generates values for parameters such as car following, lane changing, driver behavior, route choice, and release of demand which can occur as often as every time-step. When the same random seed is used repeatedly, the simulation returns the same exact results, provided the network has not been modified. When different random seeds are used from run to run, the simulation returns different results based on a differing values assigned to parameters.

A reasonable amount of accuracy is defined by the modeler according to their objectives and the performance metrics they wish to obtain. Most modelers conduct multiple simulation runs, each with different random seeds and draw upon statistical tests to determine appropriate levels of confidence or criteria for acceptance in comparing their simulation data to field-obtained data. It is important to note that perfect calibration is impossible to achieve and the extent of the calibration effort should be limited to only what is required in order for the modeler to create a "good enough" representation of a system and the 
performance metrics of interest. When this "good enough" representation of a system is achieved, the model's validity for its intended purpose can be assumed.

\subsection{Emissions Modeling}

Microscopic traffic simulation can be used as a tool to quantify many measures of performance for a road network, including vehicle emissions. A valid microscopic simulation model captures some of the key parameters and behaviors which generate vehicle emissions on a relatively small time scale, which cannot be achieved by higher-level macroscopic models. Some of these parameters include current speed, acceleration, trajectory, and power.

Emissions data can be generated either by the microsimulation program itself or through an outside program that uses the data from simulation. The current version of VISSIM (v5.30) in the United States provides an emissions output module which provides emissions statistics associated with several types of evaluation files. The emissions statistics associated with a majority of the types of these evaluation files are contingent on certain parameters and filters specified via the Emissions API, or application programming interface. The Emissions API requires programming knowledge in C++. The emissions statistics generated in the node-type evaluation file are an exception to using the API, in that those emissions statistics are generated based off of delay, similar to the processes used in Transyt 7, a simulation program designed for signal timing and optimization.

There are several outside programs which also can estimate emissions based on data generated from another source, such as simulations, field studies, or surveys. Many of these packages are developed to quantify the emissions generated under certain governmental jurisdictions and determine compliance (or lack thereof) with current articles of legislation. Many of these packages are also based off data from extensive emission test results. The U.S. Environmental Protection Agency's (EPA) Office of Transportation and Air Quality (OTAQ) currently provides a software called MOVES (Motor Vehicle Emissions Simulator), which is a recent replacement for their past software held names such as MOBILE5, MOBILE6, and MOBILE6a. The most current version of MOVES software is MOVES2010a and is available online (http://www.epa.gov/otaq/models/moves/index.htm).

A software called EMFAC (EMission FACtors) is currently available in the state of California. Developed by the California Air Resources Board, EMFAC is used to quantify emissions from all types of motor 
vehicles operating on all types of roads (freeways, highways, local roads) within the state of California. This model is more specific for the current conditions and legislation present in California that MOVES cannot account for accurately enough. The most current version is EMFAC2007 and is available online (http://www.arb.ca.gov/msei/onroad/latest_version.htm). Both EMFAC and MOVES are based off of standardized driving cycles and changes in average speeds.

Another software is called the Comprehensive Modal Emissions Model (CMEM). CMEM was first developed in 1999 as the result of a four-year research project (see Development of a Microscopic Modal Emissions Model in Review of Literature) by the National Cooperative Highway Research Program (NCHRP). CMEM is better suited for modeling emissions for smaller regions, and is also very effective in capturing the activities of different vehicle operating modes (e.g. idling, accelerating, decelerating, steadystate cruising, operation of $\mathrm{A} / \mathrm{C}$, etc.), which is a shortcoming of models like MOBILE or EMFAC which are based only on standardized driving cycles and average speeds. Information on CMEM software is available online (http://www.cert.ucr.edu/cmem/) and can be ordered from the University of CaliforniaRiverside for a nominal fee. CMEM is continually improved and has been funded by the US EPA since 1999. 


\section{Developing a Model for Cal Poly}

\subsection{Area of Study}

The first step to creating a VISSIM model for Cal Poly consists of defining the area of study as indicated by the black boundaries in Figure 5.1 below.

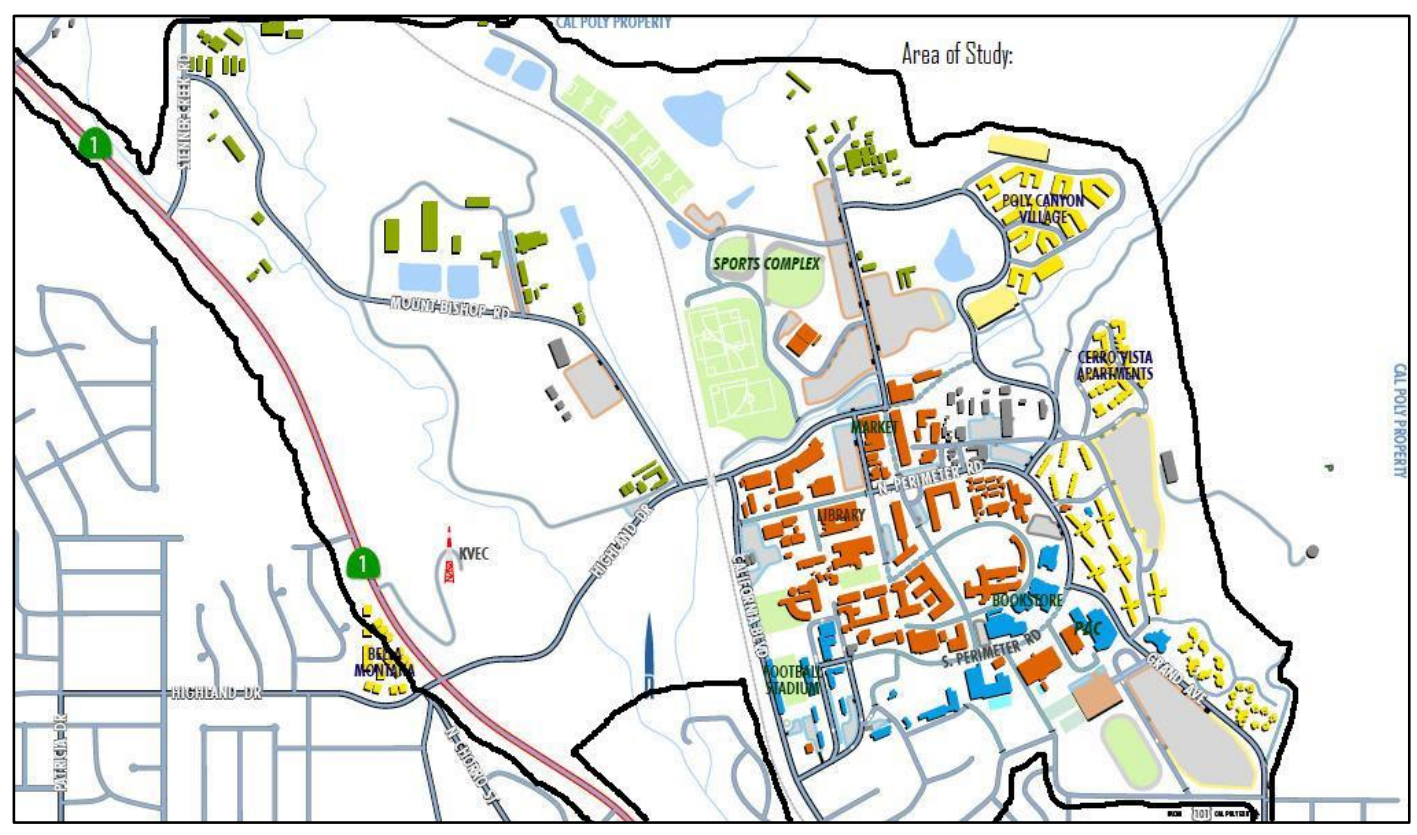

Figure 5.1: Area of Study for Cal Poly Network

The area of study includes all areas of the campus core and agricultural units south of the poultry unit. It also includes some off-campus length along the Grand Avenue and California Boulevard entrances to campus and also includes Foothill Boulevard east of Santa Rosa Street and Santa Rosa Street between Foothill Boulevard to the south and Stenner Creek Road to the north. The area of study also includes the Slack Street corridor which contains residential streets connecting Foothill Boulevard to Grand Avenue (Carpenter Street, Hathway Avenue, Longview Lane, Slack Street).

As of Fall 2010, there are several areas of the campus currently undergoing construction closed to vehicle and pedestrian traffic. These areas include the G2 Parking Lot off of Slack Street, Longview Ln and Via Carta adjacent to the Cal Poly Recreation Center, the upper portion of N Polyview Drive, and the central pedestrian walkway along Via Carta bordered by Polyview Drive on both the north and south. These areas are included in the area of study for visual and geometric purposes but are not accounted for in the model since they currently do not experience vehicle traffic. 


\subsection{Creating the Network}

\subsubsection{Satellite Imagery}

To create the Cal Poly environment, numerous screenshots of satellite imagery are taken from Google

Earth of both the campus and its surrounding areas. Each screenshot has to be scaled in VISSIM based on an existing distance and then placed so its position corresponds with adjacent images (see Figure 5.2). Due to the impracticality of measuring existing distances, the ruler tool in Google Earth is used to measure approximate distances between key landmarks. If the scaled distances do not coordinate well with other images, they are rescaled in order to minimize the level of distortion. The main purpose of the imagery is to show the road network and accurately scale the areas where links will be placed.

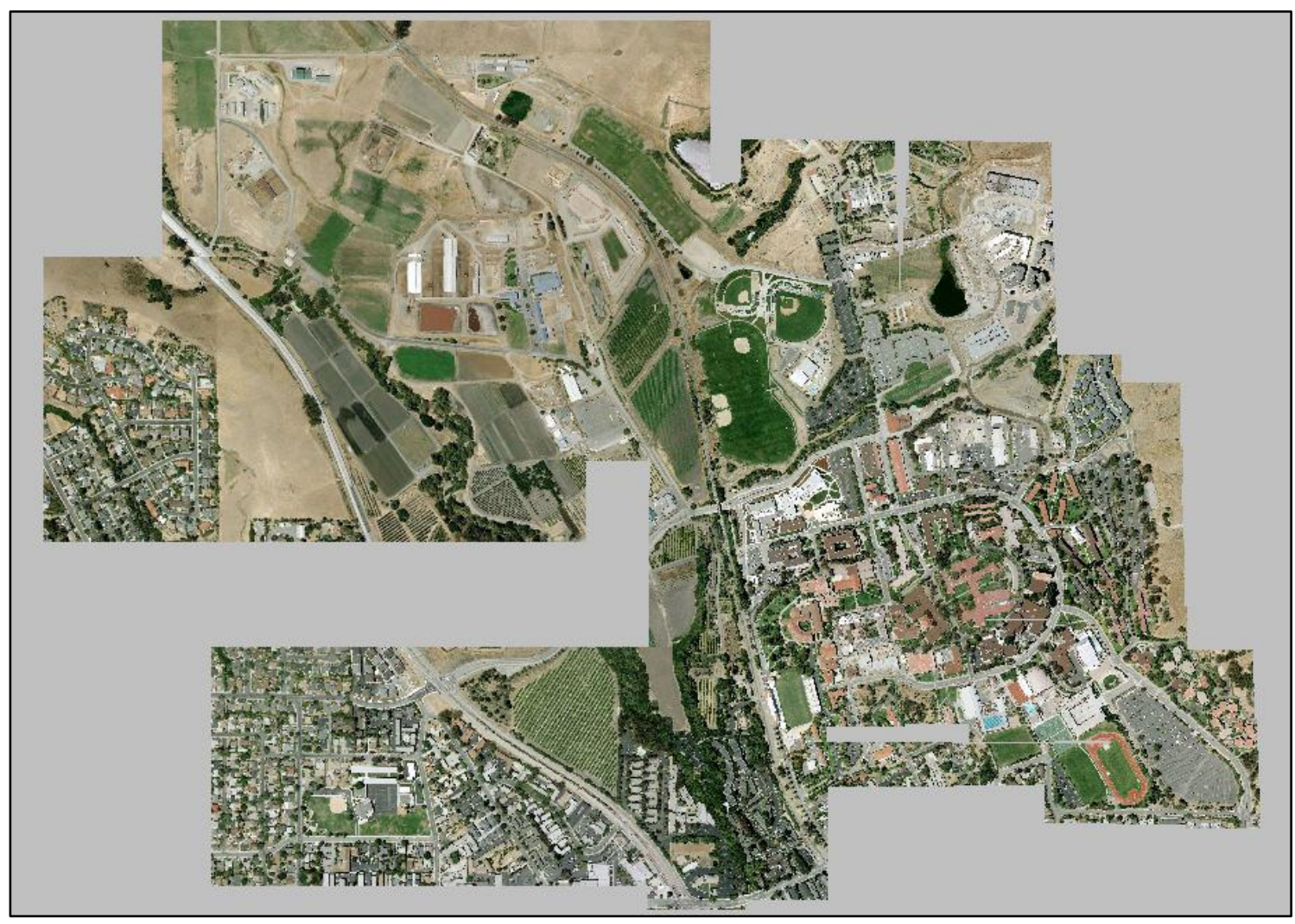

Figure 5.2: Assemblage of Satellite Imagery for the Cal Poly Network

\subsubsection{Road Network}

After the background imagery is assembled, the road network is constructed by tracing road links along the imagery. Connectors are created for each intersection based on the lane configurations from the satellite imagery which are verified for accuracy by diagrams collected from field study. In some cases, the satellite 
imagery is outdated and new configurations are created based off diagrams from the field study. These cases are mostly limited to the residential areas of Poly Canyon Village. The entrances and exits to major parking lots are also added to the model for later use. The complete network (Figure 5.3) includes 505 links, 789 connectors, and 5 lay-by transit stops for a total of 1299 links/connectors. A complete listing of the links can be found in Appendix A. Most links are given standard lane widths of $12 \mathrm{ft}$. Based on prior experiences driving on the campus, there are a few instances (mainly near the residential areas) where lane widths are modified to shorter widths.

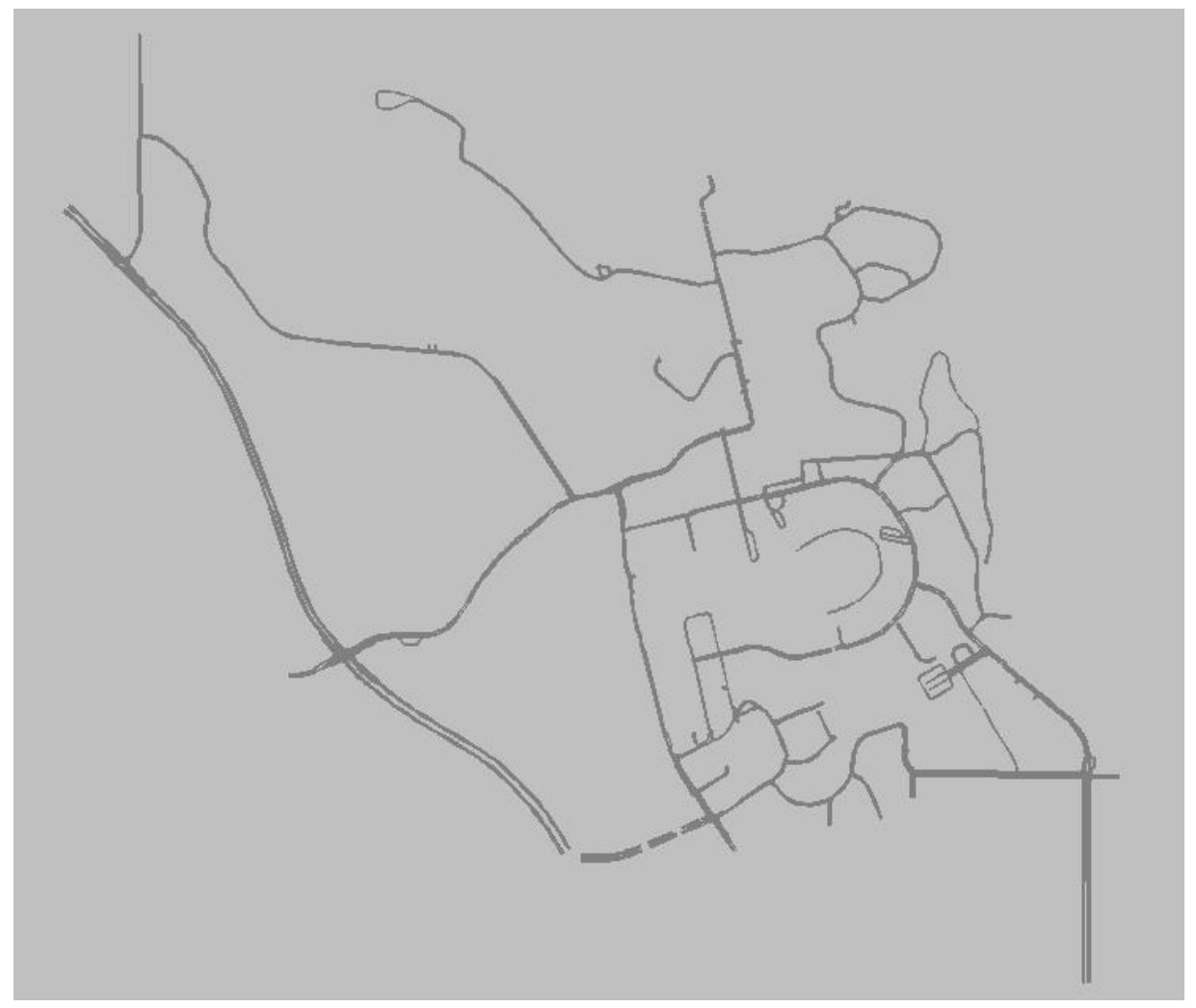

Figure 5.3: Screenshot of Links and Connectors forming the Cal Poly Network 


\subsubsection{Speed Data}

To add speed data to the model, interviews are conducted with personnel from Cal Poly's University Police Department. Officers supplied data on the $85^{\text {th }}$ percentile speeds along key roads and gave estimated ranges for speeds based on their first-hand experiences in the field. For off-campus links, speed data is obtained from the City of San Luis Obispo. Using these data sources in combination with firsthand knowledge from driving in the network, several empirical speed distributions are constructed.

These distributions capture the actual ranges of speeds and proportions of vehicles running at those speeds. In the simulation environment, speed distributions are more valued for input than speed limits as they capture what typically happens in the network, instead what should happen in the network.

Below (Figure 5.4) is a sample of an empirical distribution used for several links in the campus core. This distribution has a minimum speed of $15 \mathrm{mph}$, a maximum speed of $30 \mathrm{mph}$, a $20^{\text {th }}$ percentile speed of 20 $\mathrm{mph}$, and an $85^{\text {th }}$ percentile speed of $25 \mathrm{mph}$ which corresponds to the posted speed limit. Vehicles crossing a speed decision in the road network that corresponds with this distribution are assigned a desired speed based on their driving behavior parameters and upon crossing a decision line, will seek to reach this desired speed. Vehicles will not always reach their desired speeds in simulation due to current conditions, lengths of speed decisions, and response to traffic control devices.

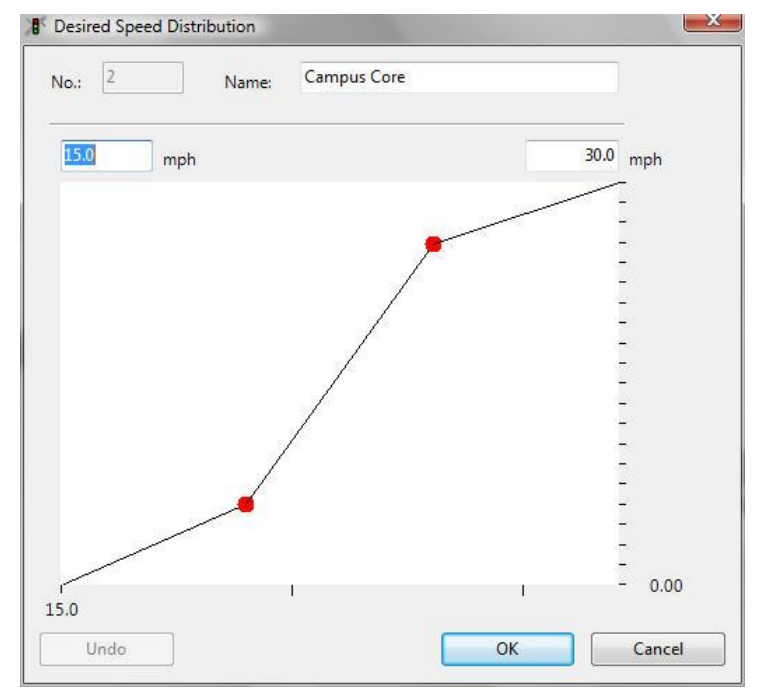

Figure 5.4: Sample Speed Distribution for Areas of Cal Poly's Core 
In total, 80 speed decisions are created for the network based on 21 empirical speed distributions. A complete listing of the speed decisions and speed distributions used in the model can be found in Appendix B.

\subsubsection{Traffic Signals}

The Cal Poly campus has two traffic signals in operation which are used for pedestrian crossings. These signals are located by the Yosemite Residences on Grand Ave and by Mustang Stadium on California Boulevard. Each signal operates two phases - a primary phase for vehicle traffic and a secondary phase for pedestrian crossing. In VISSIM, each is modeled as a Ring-Barrier Signal Controller where barriers are used to separate each phase and rings are used to describe signal groups. Each signal group corresponds to a movement or set of movements that is permitted at the same time. The signal timing plans below (Figures 5.5 and 5.6) indicate the timing parameters and signal groups. Being actuated, these signals change based on traffic being detected upstream, just as loop detectors function for real actuated signal controllers. The timing parameters are estimated from field observations and are verified for sufficient accuracy by watching animations with traffic where simulation speed equal to real time speed.

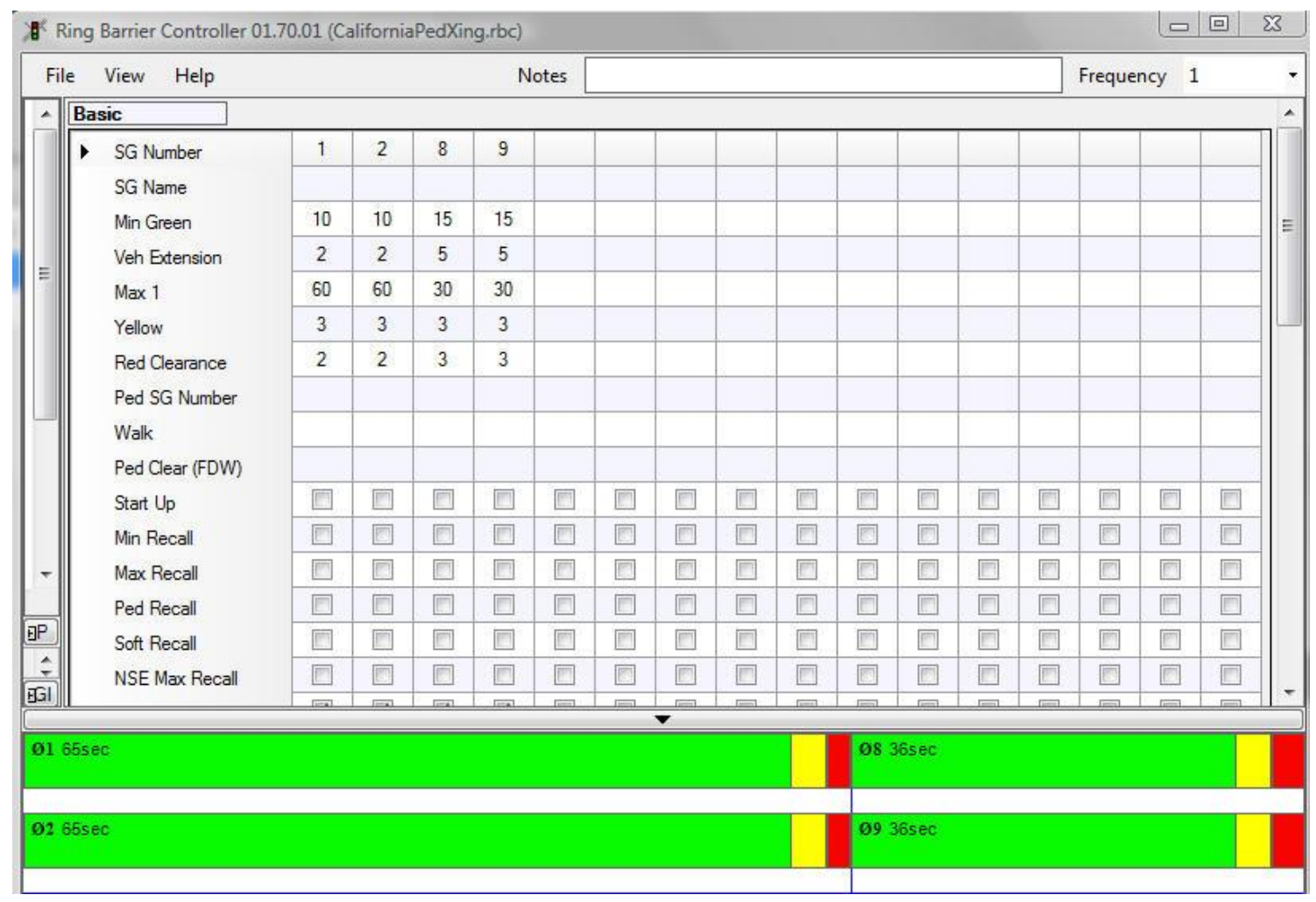

Figure 5.5: Signal Timing Parameters for California Blvd Pedestrian Crosswalk 


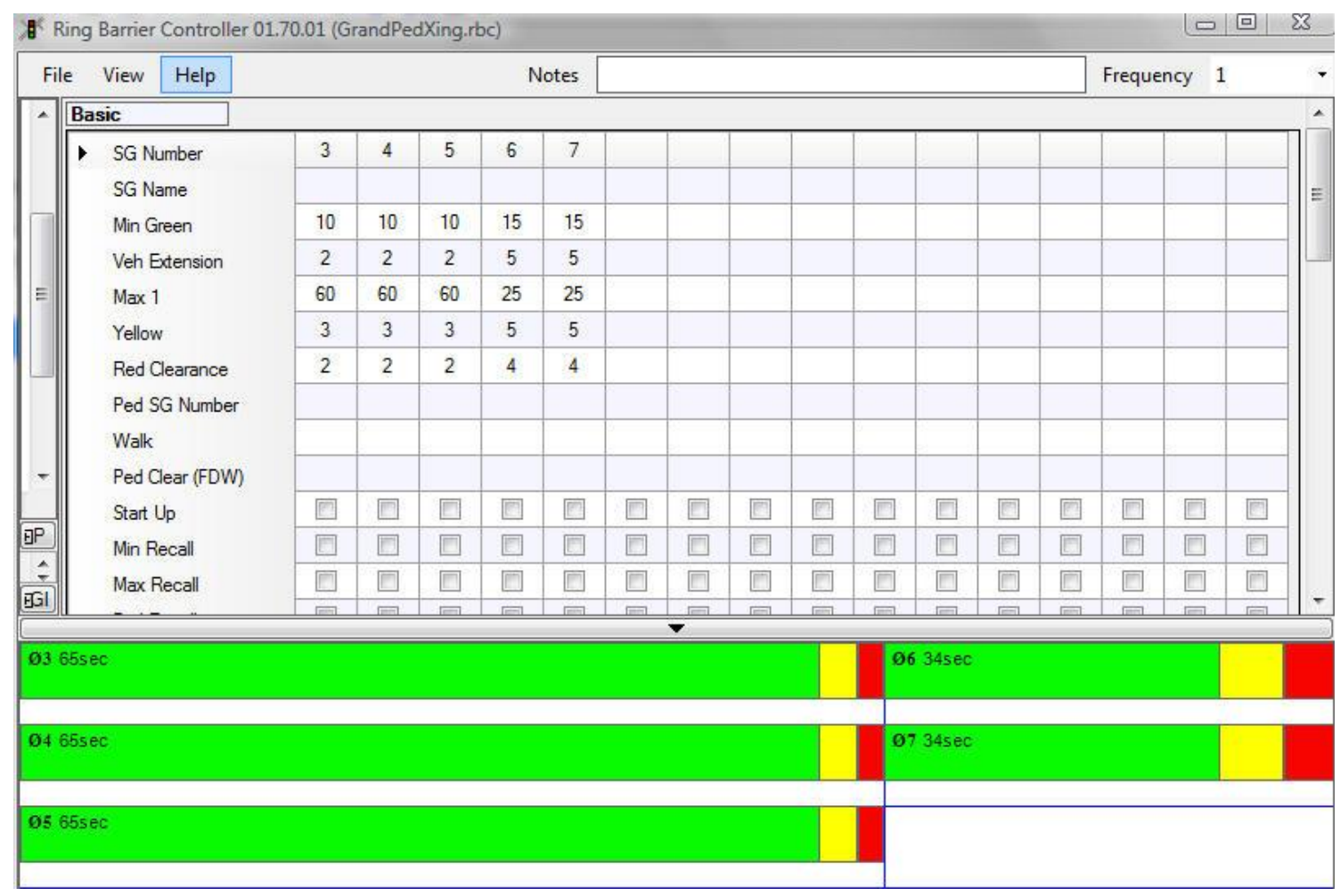

\section{Figure 5.6: Signal Timing Parameters for Grand Ave Pedestrian Crosswalk}

The area of study also includes several signals that are present at intersections outside campus boundaries.

These signals include Foothill \& California, Foothill \& Santa Rosa, and Hwy 1 \& Highland. However, since the ingress and egress points for vehicles in the network are placed inside these intersections, the functioning and timing of these signal controllers is not critical to the network performance metrics of interest. The only traffic that passes these intersections comes in the form of transit vehicles. A four-way stop is modeled at these intersections, solely for the purpose of better animation.

\subsubsection{Intersections, Conflict Areas, and Priority Rules}

The Cal Poly network modeled contains approximately 100 intersections and about 25 merge/branch areas. The right-of-way rules for these areas are specified through Conflict Areas and Priority Rules. In total, there are 1217 right-of-way rules used in the Cal Poly network; 917 of these rules exist as conflict areas while the remaining 246 exist as Priority Rules. The conflict areas are used at intersections with 2 and 3way stop controls as well as the 25 merge/branch areas. The priority rules are used at 4 -way stop intersections and lay-by transit stops. The campus contains four intersections with four-way stop control: Highland \& University, N Perimeter \& Via Carta, N Perimeter \& University, and Grand \& Slack. As mentioned previously, there are several normally signalized intersections outside the campus that are 
modeled as 4-way stops for purposes of transit use only. These intersections, therefore, do not contain right-of-way priority rules.

\subsubsection{Stop Signs}

Stop Signs are an integral part of campus traffic. In VISSIM, stop signs are placed on a per-lane basis.

When vehicles reach a stop sign, they stop for one time step and then proceed with their trip, unless a dwell time distribution is specified. The Cal Poly network contains approximately 184 stop signs. Three of these stop signs are used to model parking kiosks located at the Grand, Highland, and California entrances to campus. For these, the empirical dwell time distribution seen in Figure 5.7 is assumed, which is based off field observations observed during a traffic study at the Grand Avenue entrance.

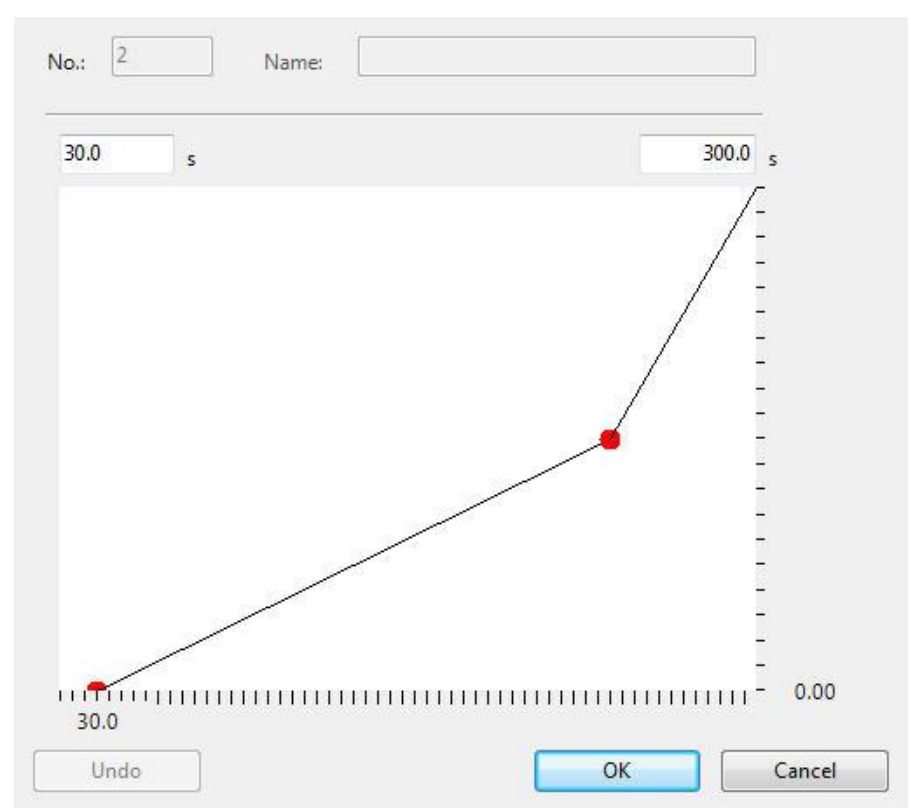

Figure 5.7: Sample Dwell Time Distribution for Grand Ave Parking Kiosk

This distribution assumes a minimum service time of 30 seconds, a maximum service time of 300 seconds ( 5 minutes), and a $50 \%$ percentile of 240 seconds ( 4 minutes). A complete listing of the stop signs in the Cal Poly model can be found in Appendix C.

\subsubsection{Nodes \& Parking Lots}

In order for the Dynamic Assignment module to function correctly, nodes and parking lots are also defined for the road network. In the Cal Poly network, a total of 117 nodes and 178 parking lots are specified. Of these nodes, approximately 128 are used for intersections and 43 are used to define parking areas. Of the 178 parking lots, 12 of are used for the each of the six entrances and exits to the network. The remaining 
166 are used for the entrances and exits of parking areas on campus. The specific placement and position of all parking lots and nodes in the simulation helps to define traffic analysis zones which are used for Dynamic Assignment.

\subsubsection{Transit Stops}

In order to create transit routes and schedules, transit stops are also defined for the network. Transit stops can either be on-street stops or lay-by stops. Lay-by stops are created by making a specific pocket lane adjacent to the slowest lane of traffic. The Cal Poly network contains 11 transit stops at the following locations:

- Northbound Grand Avenue @ Performing Arts Center (lay-by)

- Southbound Grand Avenue @ Performing Arts Center (lay-by)

- Northbound Grand Avenue @ McCollum St

- Southbound Grand Avenue @ McCollum St

- Eastbound Entrance Way @ Robert Kennedy Library (lay-by)

- Westbound Entrance Way @ Robert Kennedy Library

- Westbound Highland Dr @ Mt. Bishop Rd

- Southbound Santa Rosa St. @ Foothill Blvd

- Eastbound Foothill Blvd @ Casa St (lay-by)

- Westbound Foothill Blvd @ Casa St

- Northbound California Blvd @ Taft St 


\subsection{Vehicle Data}

\subsubsection{Automobiles}

In order to create appropriate animations and generate accurate emissions estimates for the model, it is necessary to understand the distribution of vehicle types on campus. A survey study of 4954 vehicles was conducted at campus parking lots over the course of several weekdays to determine the appropriate proportions of different vehicle types driven on campus. Compared to the estimated population of vehicles on campus (7331 parking permits sold), our sample is a significant estimator of the true proportions of vehicle types present in the Cal Poly population. The survey involved over 1000 vehicles from each use permit use type. For ease of modeling, these vehicle distributions are combined into one overall traffic composition. Table 5.1 summarizes the findings of the sampling study. The pie chart in Figure 5.8 shows the distribution of vehicles belonging to each of nine vehicle types associated with this traffic composition.

Table 5.1: Results of Vehicle Types Sampling Study

\begin{tabular}{|l|r|r|r|r|r|r|r|r|r|}
\hline & \multicolumn{3}{|c|}{ Use Type } & \multicolumn{4}{c|}{ Use Type } \\
\hline Vehicle Type & Staff & \multicolumn{1}{|c|}{ Residents } & General & Total & & Staff & Residents & General & Overall \\
\hline Economy/Hybrid & 78 & $\mathbf{7 5}$ & $\mathbf{7 5}$ & $\mathbf{2 2 8}$ & & $6.66 \%$ & $3.780 \%$ & $4.17 \%$ & $4.60 \%$ \\
\hline Compact & 249 & 611 & 472 & $\mathbf{1 3 3 2}$ & & $21.26 \%$ & $30.796 \%$ & $26.24 \%$ & $26.89 \%$ \\
\hline Mid-Size & 265 & 427 & 371 & $\mathbf{1 0 6 3}$ & & $22.63 \%$ & $21.522 \%$ & $20.62 \%$ & $21.46 \%$ \\
\hline Full-Size & 28 & 51 & 59 & $\mathbf{1 3 8}$ & & $2.39 \%$ & $2.571 \%$ & $3.28 \%$ & $2.79 \%$ \\
\hline Small SUV & 166 & 311 & 268 & $\mathbf{7 4 5}$ & & $14.18 \%$ & $15.675 \%$ & $14.90 \%$ & $15.04 \%$ \\
\hline Large SUV & 68 & 57 & 37 & $\mathbf{1 6 2}$ & & $5.81 \%$ & $2.873 \%$ & $2.06 \%$ & $3.27 \%$ \\
\hline Truck & 128 & 270 & 331 & $\mathbf{7 2 9}$ & & $10.93 \%$ & $13.609 \%$ & $18.40 \%$ & $14.72 \%$ \\
\hline Sport & 48 & 73 & 88 & $\mathbf{2 0 9}$ & & $4.10 \%$ & $3.679 \%$ & $4.89 \%$ & $4.22 \%$ \\
\hline Wagon/Crossover/Van & 141 & 109 & 98 & $\mathbf{3 4 8}$ & & $12.04 \%$ & $5.494 \%$ & $5.45 \%$ & $7.02 \%$ \\
\hline Sample Size & $\mathbf{1 1 7 1}$ & $\mathbf{1 9 8 4}$ & $\mathbf{1 7 9 9}$ & $\mathbf{4 9 5 4}$ & & $\mathbf{1 1 7 1}$ & $\mathbf{1 9 8 4}$ & $\mathbf{1 7 9 9}$ & $\mathbf{4 9 5 4}$ \\
\hline
\end{tabular}

\section{Vehicles by Type (Cal Poly )}

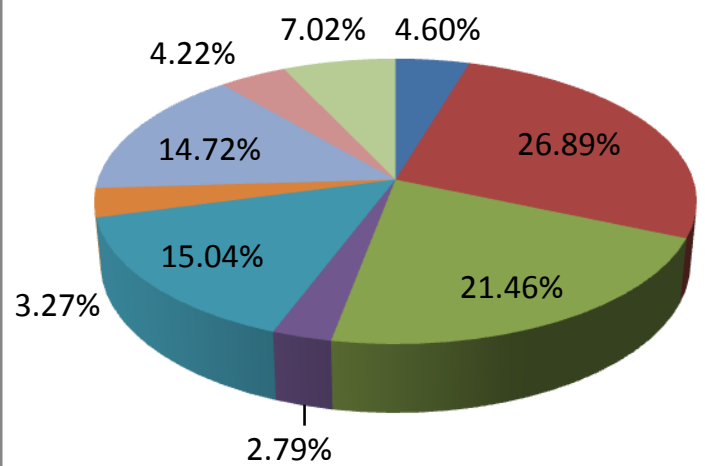

Economy/Hybrid
Compact
Mid-Size
Full-Size
Small SUV
Large SUV
Truck
Sport

Figure 5.8: Pie Chart of Vehicle Types at Cal Poly 
In VISSIM, each defined vehicle type shares common acceleration and deceleration profiles, power specification, and weight distributions. Grouping vehicles by vehicle type is convenient for emissions analysis since it is highly infeasible to model the large number of vehicle makes and models currently in operation. Generally, the performance and emissions of most vehicles of a certain type do not vary drastically (e.g. A Toyota Camry will have very similar performance and emissions to a Honda Accord.

Likewise, a Nissan Sentra will have very similar performance and emissions to a Ford Focus.) Within each vehicle type category, graphics of several representative vehicles and body colors are selected for representation in animation.

For the Cal Poly network, the nine vehicle types shown in the above pie chart are defined. The chart below shows sample vehicles for each vehicle type.

Table 5.2: Sample Vehicles for Each Vehicle Type Category

\begin{tabular}{|l|l|}
\hline Vehicle Type & Sample Vehicle Models \\
\hline Economy/Hybrid & Geo Metro, Honda Civic Hybrid, Mini Cooper, Toyota Prius \\
\hline Compact & Ford Focus, Honda Civic, Mazda 3, Nissan Sentra, Toyota Corolla \\
\hline Mid-Size & Ford Fusion, Honda Accord, Nissan Altima, Mazda 6, Toyota Camry \\
\hline Full-Size & Ford Taurus, Infiniti M, Toyota Avalon, Volkswagen Passat \\
\hline Small SUV & Ford Escape, Ford Explorer, Honda CR-V, Hyundai Santa Fe, Nissan Xterra \\
\hline Large SUV & Chevrolet Tahoe, GMC Suburban, Ford Expedition, Honda Pilot \\
\hline Truck & Ford Ranger, Ford F150, Nissan Titan, Toyota Tacoma, Toyota Tundra \\
\hline Sport & Chevrolet Camaro, Chevrolet Corvette, Ford Mustang, Nissan Z \\
\hline Wagon/Crossover/Van & $\begin{array}{l}\text { Chevrolet Express, Ford Windstar, Ford Edge, Honda Element, Nissan } \\
\text { Murano, Plymouth Voyager, Subaru Forester, Toyota Venza }\end{array}$ \\
\hline
\end{tabular}

Several assumptions are made in terms of vehicles in the network:

- Only motorized vehicles are modeled. Non-motorized vehicles such as bicycles, scooters, and skateboards are not included

- State, Delivery \& Emergency Vehicles are not accounted for in the simulation model. This includes all Cal Poly service vehicles, campus deliveries (mail, parcels, freight, food service), law enforcement, ambulances, fire engines, paramedics

- Contractor Vehicles are included in the simulation model. It is assumed they will use available parking lots

- Modeling of transit lines is limited to standard SLO Transit and RTA routes traveling within the network 


\subsubsection{Public Transit}

The area of study includes many public transit lines, which are incorporated into the simulation model. The

City of San Luis Obispo's bus system, SLO Transit, operates Routes 4, 5, 6a, and 6b within the area of study, while the County of San Luis Obispo's bus system, Regional Transit Authority (RTA), operates

Routes 9, 10, and 12a. Table 5.3 describes these routes, their stops, and operating schedules.

\section{Table 5.3: Public Transit Routes in the Cal Poly Network}

\begin{tabular}{|c|c|c|c|c|}
\hline Transit \& Route \# & Enters Network & Leaves Network & Interval & Stops \\
\hline \multirow[b]{4}{*}{ SLO Transit- Route 4} & \multirow{4}{*}{$\begin{array}{c}\text { 7:20AM @ } \\
\text { Foothill Blvd EB }\end{array}$} & \multirow{4}{*}{$\begin{array}{c}\text { 7:32AM @ } \\
\text { Grand Ave SB }\end{array}$} & \multirow[b]{4}{*}{ Every $30 \mathrm{~min}$} & Foothill@ Casa \\
\hline & & & & Entrance @ Kennedy Library* \\
\hline & & & & Grand Ave @ PAC \\
\hline & & & & GrandAve@ McCollum \\
\hline \multirow[b]{4}{*}{ SLO Transit- Route 5} & \multirow{4}{*}{$\begin{array}{c}\text { 7:26AM @ } \\
\text { Grand Ave NB }\end{array}$} & \multirow{4}{*}{$\begin{array}{c}\text { 7:39AM @ } \\
\text { Foothill Blvd WB }\end{array}$} & \multirow[b]{4}{*}{ Every $30 \mathrm{~min}$} & GrandAve@ McCollum \\
\hline & & & & Grand Ave @ PAC* \\
\hline & & & & Entrance @ Kennedy Library \\
\hline & & & & Foothill @ Casa \\
\hline \multirow[b]{3}{*}{ SLO Transit-Route $6 \mathrm{~b} / 6 \mathrm{a} * *$} & \multirow{3}{*}{$\begin{array}{c}\text { 7:20 AM @ } \\
\text { California Blvd NB }\end{array}$} & \multirow{3}{*}{$\begin{array}{c}\text { 7:42AM @ } \\
\text { Highland Dr WB }\end{array}$} & \multirow[b]{3}{*}{ Every $30 \mathrm{~min}$} & California@ @ Taft \\
\hline & & & & Entrance @ Kennedy Library* \\
\hline & & & & Highland @ Mt. Bishop Rd \\
\hline \multirow[b]{3}{*}{ SLO Transit-Route $6 a / 6 b^{* *}$} & \multirow{3}{*}{$\begin{array}{l}\text { 7:25AM @ } \\
\text { Casa St NB }\end{array}$} & \multirow{3}{*}{$\begin{array}{c}\text { 7:36AM @ } \\
\text { Grand Ave SB }\end{array}$} & \multirow[b]{3}{*}{ Every $30 \mathrm{~min}$} & Entrance @ Kennedy Library* \\
\hline & & & & Grand Ave @ PAC \\
\hline & & & & GranAve @ McCollum \\
\hline RTA-Route 9 SB & $\begin{array}{c}\text { 7:15AM @ } \\
\text { Grand Ave NB }\end{array}$ & $\begin{array}{c}\text { 7:23AM @ } \\
\text { Foothil Blvd WB }\end{array}$ & $\begin{array}{l}\text { Commuter } \\
\text { Schedule }\end{array}$ & Entrance @ Kennedy Library \\
\hline RTA-Route 10 NB & $\begin{array}{c}\text { 7:20AM @ } \\
\text { Foothill Blvd EB }\end{array}$ & $\begin{array}{c}\text { 7:32AM @ } \\
\text { Grand Ave SB }\end{array}$ & $\begin{array}{l}\text { Commuter } \\
\text { Schedule }\end{array}$ & Entrance @ Kennedy Library \\
\hline \multirow[b]{2}{*}{ RTA- Route $12 \mathrm{NB}$} & \multirow{2}{*}{$\begin{array}{c}\text { 7:36AM @ } \\
\text { Foothill Blvd EB }\end{array}$} & \multirow{2}{*}{$\begin{array}{c}\text { 7:45AM @ } \\
\text { Grand Ave SB }\end{array}$} & \multirow[b]{2}{*}{ Every $60 \mathrm{~min}$} & Foothill@ Casa \\
\hline & & & & Entrance @ Kennedy Library \\
\hline \multirow[b]{2}{*}{ RTA- Route $12 \mathrm{SB}$} & 7:25AM @ & 7:35AM@ & \multirow[b]{2}{*}{ Every $60 \mathrm{~min}$} & Entrance @ Kennedy Library \\
\hline & Hwy 1 SB & Hwy 1 SB & & Foothill@ Santa Rosa \\
\hline \multicolumn{5}{|l|}{ * Denotes time stop } \\
\hline \multicolumn{3}{|c|}{ **Route $6 \mathrm{~A}$ becomes Route $6 \mathrm{~B}$ at Kennedy Library } & & \\
\hline \multicolumn{3}{|c|}{ **Route $6 \mathrm{~B}$ becomes Route $6 \mathrm{~A}$ at Kennedy Library } & & \\
\hline
\end{tabular}




\subsection{Application of Gravity Model: Trip Distribution}

\subsubsection{Zone Definition}

Based on main thoroughfares, physical barriers, and land uses at and around Cal Poly, the area of study is divided into 33 zones for analysis. Six of the zones are classified as zones external to Cal Poly in that they connect Cal Poly to the City of San Luis Obispo. These external zones most often produce trips to the campus in the AM hours and attract trips from the campus In the PM hours. The remaining 27 zones are classified as zones internal to Cal Poly in that they are regions of the campus which students, faculty, or staff visit each day. These internal zones are each composed of one or more campus parking lots. They most often produce trips leaving the campus in the PM hours and attract trips entering the campus in the PM hours. Figure 5.9 below is a map of the zones and Table 5.4 contains names and brief descriptions of each.

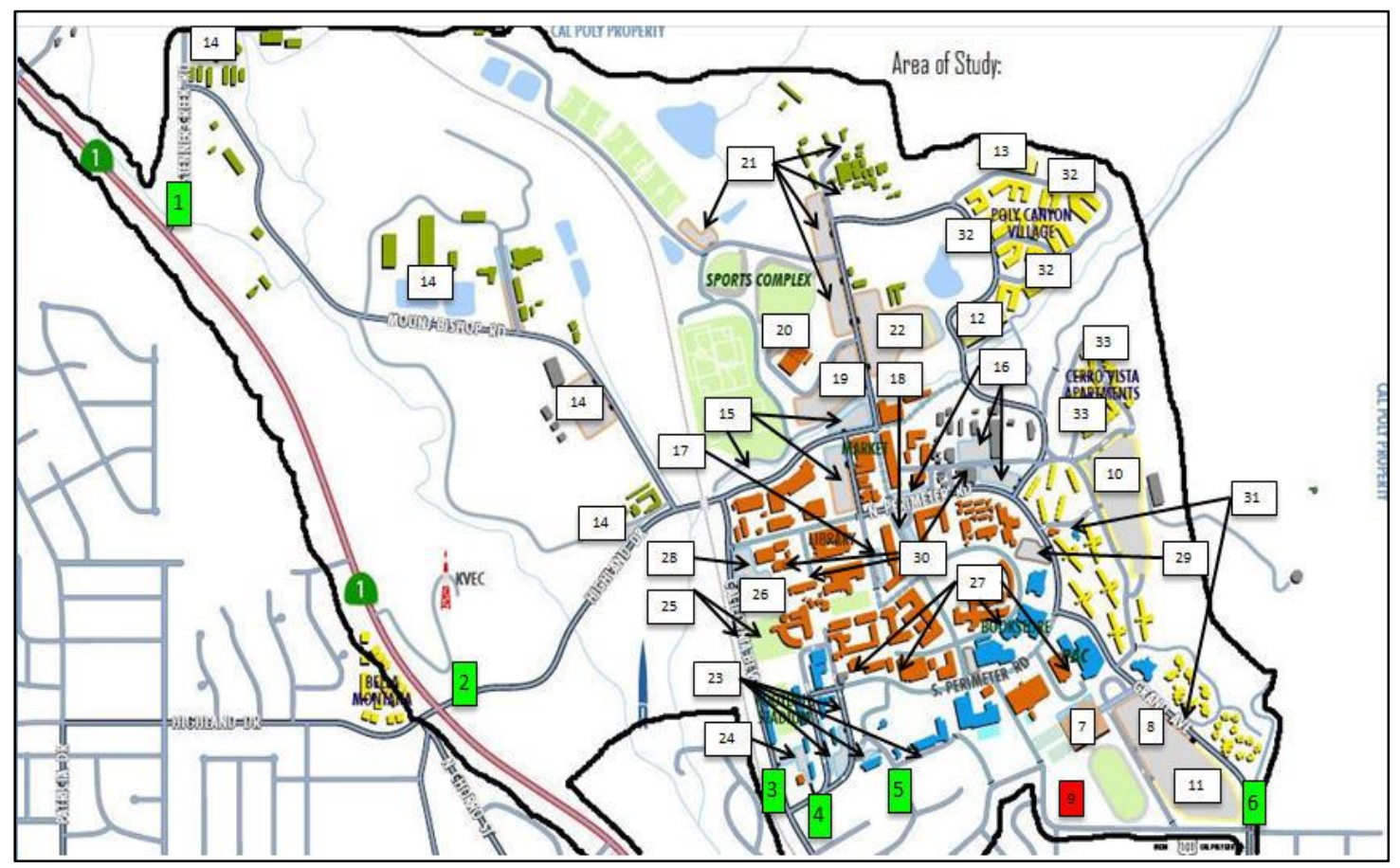

Figure 5.9: Traffic Analysis Zones for Cal Poly 
Table 5.4: Names \& Descriptions of Traffic Analysis Zones for Cal Poly

\begin{tabular}{|c|c|c|c|}
\hline Zone \# & Type & Zone Name & Capacity (spaces) \\
\hline 1 & Entrance/Exit & Stenner Creek Rd & 1 lane \\
\hline 2 & Entrance/Exit & Highland Dr & 2 lanes \\
\hline 3 & Entrance/Exit & California Blvd & 1 lane \\
\hline 4 & Entrance/Exit & California/Campus & 1 lane \\
\hline 5 & Entrance/Exit & Foothill/Crandall & 1 lane \\
\hline 6 & Entrance/Exit & Grand Ave & 2 lanes \\
\hline 7 & Structure & G-5 (Grand Ave Structure) & 911 \\
\hline 8 & Lot(s) & G1 & 504 \\
\hline 9 & Lot(s) & G2 & 109 \\
\hline 10 & Lot(s) & R1 & 838 \\
\hline 11 & Lot(s) & $\mathrm{R} 2$ & 837 \\
\hline 12 & Structure & R3 & 932 \\
\hline 13 & Structure & R4 & 962 \\
\hline 14 & Lot(s) & H1/Crops/Dairy/Poultry & 518 \\
\hline 15 & Lot(s) & $\mathrm{H} 2$ & 340 \\
\hline 16 & Lot(s) & $\mathrm{H} 4$ & 405 \\
\hline 17 & Street & $\mathrm{H} 10$ & 58 \\
\hline 18 & Lot(s) & $\mathrm{H} 11$ & 28 \\
\hline 19 & Lot(s) & $\mathrm{H} 12$ & 436 \\
\hline 20 & Lot(s) & $\mathrm{H} 13$ & 43 \\
\hline 21 & Lot(s) & H14/H15 Sports Complex/Ornamental Horticulture & 440 \\
\hline 22 & Lot(s) & $\mathrm{H} 16$ & 565 \\
\hline 23 & Lot(s) & C2 \& College Ave & 271 \\
\hline 24 & Lot(s) & C3 & 50 \\
\hline 25 & Street & $\mathrm{C} 4$ & 87 \\
\hline 26 & Lot(s) & C5 & 15 \\
\hline 27 & Lot(s) & C6/Graphics \& Power/Cohan Center/Polyview Dr & 70 \\
\hline 28 & Lot(s) & C7 & 150 \\
\hline 29 & Lot(s) & A1 & 66 \\
\hline 30 & Street & Dexter Rd/Engineering 13/Foundation & 21 \\
\hline 31 & Street & Mountain Lane/Grand Ave & 19 \\
\hline 32 & Street & Poly Canyon Village- Canyon Circle, Vista Caballo, Village Dr & 62 \\
\hline \multirow[t]{2}{*}{33} & Street & Cerro Vista Loop & 55 \\
\hline & & Sum & 8792 \\
\hline
\end{tabular}

\subsubsection{Data Collection}

Since most traffic tends to enter campus from zones external to Cal Poly, a good estimate of vehicle counts entering/leaving campus is required. Field data is collected for an average Tuesday during the Fall 2010 quarter at the Grand Avenue entrance to Cal Poly (Zone 6). Grand Avenue is specifically chosen because its volume is the largest historically. Due to lack of available resources and the infeasibility of collecting data for all zones, however, the data collection is limited to just this entrance. Data is collected in 15minute increments from 7:30AM until 9:00PM and assembled in terms of possible peak hours. The graph in Figure 5.10 shows the volume for each possible peak hour beginning with 7:30AM-8:30AM until 8:00PM-9:00PM. 


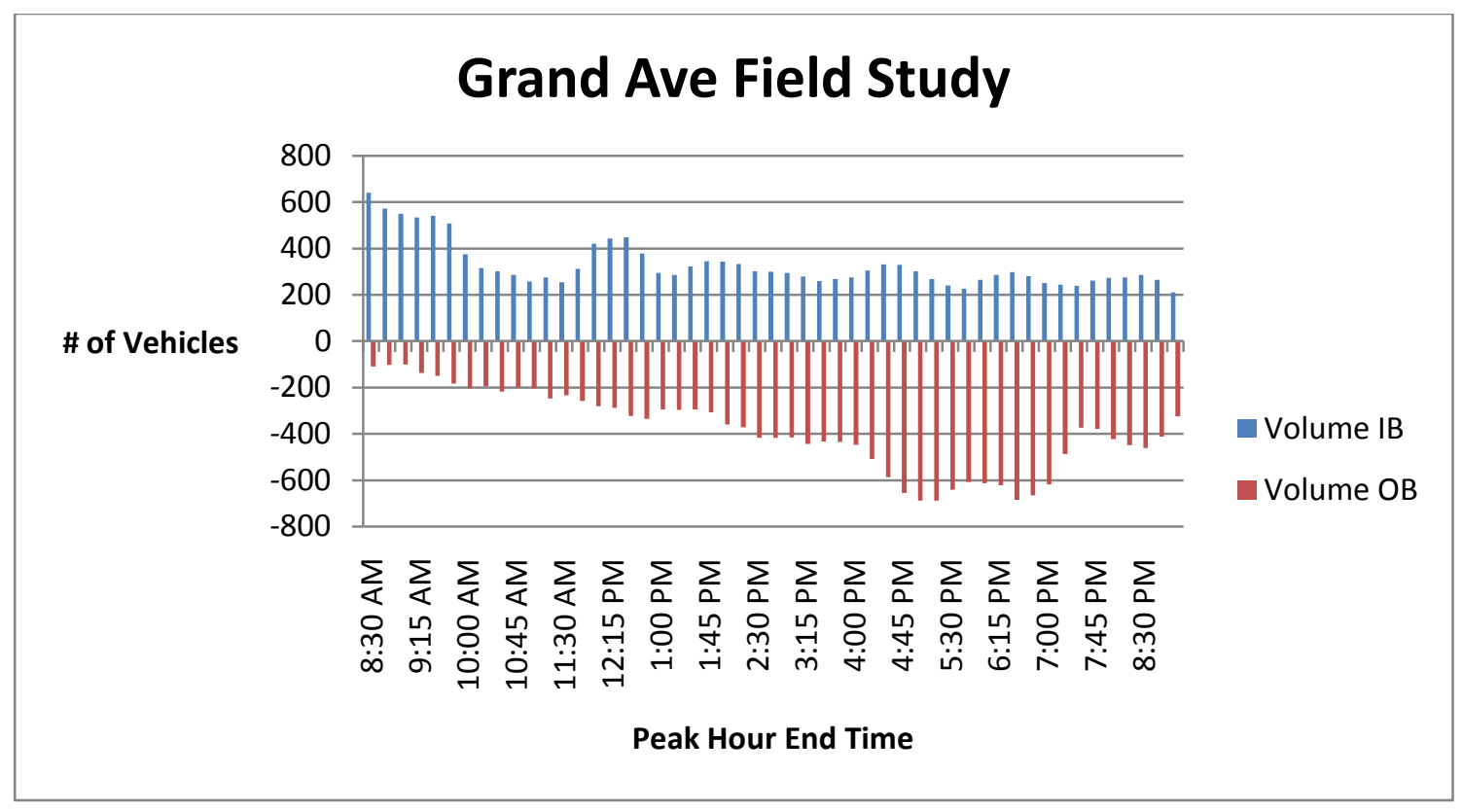

\section{Figure 5.10: Summary of Potential Peak Hours from Grand Ave Field Study}

Based on this field study, there are several peak hours determined for the campus. During the AM hours, peak volumes are observed from 7:30AM-8:30AM, 8:30AM-9:30AM, and 10:15-11:15AM. During the midday hours, peak volumes are observed from 11:30AM-12:30PM and 12:45PM-1:45PM. During the PM hours, peak volumes are observed from 4:00PM-5:00PM, 5:30PM-6:00PM, and 7:30PM-8:30PM. The AM peak hours tended to have a large amount of inbound traffic while the PM peak hours tended to have a large amount of outbound traffic. The midday peak hours tended to have a large amount of traffic in both directions, but not as large in magnitude as the inbound or outbound volumes witnessed in the AM or PM. A detailed summary of the field study is available in Appendix E.

\subsubsection{Define Study Period}

Based on the field data and for purposes of simplifying modeling efforts, the AM peak hour from 7:30AM8:30AM was chosen for the simulation model. This peak hour has the highest overall volume of any peak hour and best captures the transportation for multiple types of Cal Poly personnel (e.g. students going to school, faculty \& staff going to work, visitors arriving for the day).

\subsubsection{Determining Productions/Attractions}

A good estimate for AM Peak volumes for the external zones is attained by pooling field study data with historical data from Cal Poly and the City of San Luis Obispo and applying heuristic methods. The history of campus projects and road closures is accounted for to properly consider historical data. 
The heuristic approach used involves the following steps:

1. Estimate overall split of campus traffic among the entrance/exits to campus based on available data

2. Based on the volume from the Grand Ave field study, calculate the volumes associated with each entrance/exit

3. Based on the inbound/outbound splits from the Grand Ave field study, calculate the volumes of inbound/outbound traffic for each entrance/exit

4. Based on firsthand knowledge of campus, capacities and attractiveness of zones, determine split of inbound traffic for each entrance/exit to interior zones

5. Based on firsthand knowledge of campus, capacities and attractiveness of zones, determine split of outbound traffic for each entrance/exit from interior zones

6. Apply the splits from Steps $4 \& 5$ and calculate volumes for all cases. Sum the attractions and productions of internal zones

7. Use the data from Steps $3 \& 6$ to assemble a matrix of Productions and Attractions

Table 5.5 below summarizes the results of Steps 1-3.

\section{Table 5.5: Volumes of Inbound/Outbound Traffic for each Entrance/Exit to Cal Poly}

\begin{tabular}{|c|c|c|c|c|c|c|c|c|c|c|c|c|c|c|}
\hline \multicolumn{2}{|c|}{ External Zone } & \multicolumn{2}{|c|}{ Grand Avenue (6) } & \multicolumn{2}{|c|}{ Highland Blvd (2) } & \multicolumn{2}{|c|}{ California Blvd (3) } & \multicolumn{2}{|c|}{ Campus Way (4) } & \multicolumn{2}{|c|}{ Foothill/Crandall (5) } & \multicolumn{2}{|c|}{ Stenner Creek (1) } & Totals \\
\hline Split of Ca & mpus Traffic & \multicolumn{2}{|c|}{$34 \%$} & \multicolumn{2}{|c|}{$23 \%$} & \multicolumn{2}{|c|}{$28 \%$} & \multicolumn{2}{|c|}{$10 \%$} & \multicolumn{2}{|c|}{$3 \%$} & \multicolumn{2}{|c|}{$2 \%$} & $100 \%$ \\
\hline \multicolumn{2}{|c|}{ Total Volume } & \multicolumn{2}{|c|}{750} & \multicolumn{2}{|c|}{507} & \multicolumn{2}{|c|}{618} & \multicolumn{2}{|c|}{221} & \multicolumn{2}{|c|}{66} & \multicolumn{2}{|c|}{44} & 2206 \\
\hline Inbound Split & Outbound Split & $85.47 \%$ & $14.53 \%$ & $85.47 \%$ & $14.53 \%$ & $85.47 \%$ & $14.53 \%$ & $85.47 \%$ & $14.53 \%$ & $85.47 \%$ & $14.53 \%$ & $85.47 \%$ & $14.53 \%$ & \\
\hline Inbound Vol & Outbound Vol & 641 & 109 & 434 & 74 & 528 & 90 & 189 & 32 & 57 & 10 & 38 & 6 & 2206 \\
\hline
\end{tabular}

In applying Steps 4-5, it is assumed there are no trips between zones internal to the campus. That is, all trips made occur between one zone external to campus and one zone internal to campus. Table 5.6 shows the split of trips of inbound traffic to potential interior zones. The volume of traffic assigned to each zone is based on several factors including quantity and availability of parking, use types (general, residential, staff, temporary), proximity to campus buildings, and any out-of-pocket costs (parking fees). Table 5.7 shows the split of trips of outbound traffic from interior zones by applying the same methodology. 
Table 5.6: Split of Inbound Trips to Cal Poly to Potential Interior Zones

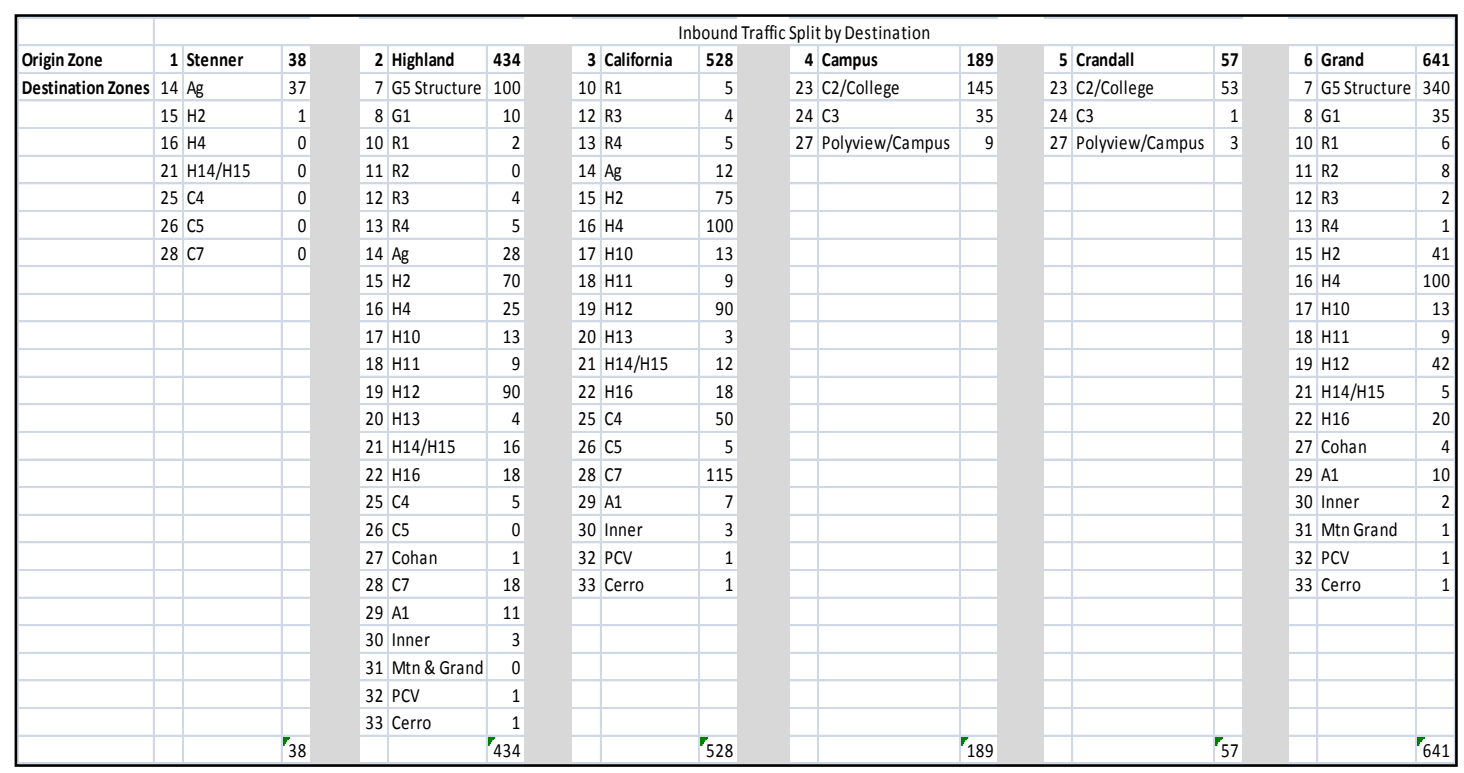

Table 5.7: Split of Outbound Trips from Cal Poly from Potential Interior Zones

\begin{tabular}{|c|c|c|c|c|c|c|c|c|c|c|c|c|c|c|c|c|c|}
\hline \multirow[b]{2}{*}{ Origin Zone } & \multicolumn{17}{|c|}{ Outbound Traffic Split by Origin } \\
\hline & & 1 Stenner & 6 & 2 Highland & 74 & & California & 90 & & 4 Campus & 32 & & Crandall & 10 & & Grand & 109 \\
\hline \multirow[t]{25}{*}{ Destination Zones } & 14 & $4 \mathrm{Ag}$ & 6 & 7 G5 Structure & 8 & 10 & R1 & 6 & 23 & $3 \mathrm{C} 2 /$ College & 31 & 23 & C2/College & 9 & & G5 Structure & 58 \\
\hline & 15 & $5 \mathrm{H} 2$ & 0 & $8 \mathrm{G} 1$ & 0 & 12 & R3 & 6 & 24 & $4 \mathrm{C} 3$ & 1 & 24 & C3 & 1 & & G1 & 4 \\
\hline & 16 & $6 \mathrm{H} 4$ & 0 & 10 R1 & 5 & 13 & R4 & 6 & 27 & 7 Polyview/Campus & 0 & 27 & Polyview/Campus & 0 & 10 & R1 & 6 \\
\hline & & $1 \mathrm{H} 14 / \mathrm{H} 15$ & 0 & 11 R2 & 3 & 14 & $\mathrm{Ag}$ & 4 & & & & & & & & R2 & 6 \\
\hline & 25 & 5 C4 & 0 & 12 R3 & 4 & 15 & $\mathrm{H} 2$ & 16 & & & & & & & 12 & R3 & 4 \\
\hline & 26 & $6 \mathrm{C5}$ & 0 & $13 \mathrm{R} 4$ & 4 & 16 & H4 & 1 & & & & & & & 13 & R4 & 4 \\
\hline & & $8 \mathrm{C} 7$ & 0 & $14 \mathrm{Ag}$ & 5 & 17 & $\mathrm{H} 10$ & 5 & & & & & & & 15 & $\mathrm{H} 2$ & 4 \\
\hline & & & & $15 \mathrm{H} 2$ & 9 & 18 & H11 & 2 & & & & & & & & $\mathrm{H} 4$ & 0 \\
\hline & & & & $16 \mathrm{H} 4$ & 1 & 19 & H12 & 30 & & & & & & & 17 & $\mathrm{H} 1 \mathrm{O}$ & 2 \\
\hline & & & & $17 \mathrm{H} 10$ & 4 & 20 & H13 & 0 & & & & & & & 18 & H11 & 0 \\
\hline & & & & $18 \mathrm{H} 11$ & 0 & 21 & $\mathrm{H} 14 / \mathrm{H} 15$ & 1 & & & & & & & 19 & $\mathrm{H} 12$ & 5 \\
\hline & & & & $19 \mathrm{H} 12$ & 17 & 22 & H16 & 6 & & & & & & & 21 & $\mathrm{H} 14 / \mathrm{H} 15$ & 0 \\
\hline & & & & $20 \mathrm{H} 13$ & 0 & 25 & C4 & 4 & & & & & & & 22 & H16 & 1 \\
\hline & & & & $21 \mathrm{H} 14 / \mathrm{H} 15$ & 1 & 26 & C5 & 0 & & & & & & & 27 & Cohan & 2 \\
\hline & & & & $22 \mathrm{H} 16$ & 4 & 28 & $\mathrm{C7}$ & 1 & & & & & & & 29 & A1 & 8 \\
\hline & & & & $25 \mathrm{C} 4$ & 4 & 29 & A1 & 0 & & & & & & & 30 & Inner & 0 \\
\hline & & & & $26 C 5$ & 0 & 30 & Inner & 0 & & & & & & & 31 & Mtn Grand & 1 \\
\hline & & & & 27 Cohan & 0 & 32 & PCV & 1 & & & & & & & 32 & PCV & 2 \\
\hline & & & & $28 \mathrm{C} 7$ & 0 & 33 & Cerro & 1 & & & & & & & 33 & Cerro & 2 \\
\hline & & & & 29 A1 & 4 & 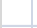 & & 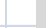 & & & & & & & . & & \\
\hline & & & & 30 Inner & 0 & & & & & & . & & & & 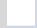 & & \\
\hline & & & & $31 \mathrm{Mtn} \&$ Grand & 0 & & & & & & 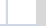 & & & & & & \\
\hline & & & & $32 \mathrm{PCV}$ & 1 & & & & & & 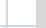 & & & & 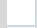 & & \\
\hline & & & & 33 Cerro & 0 & & & & & & & & & & & & \\
\hline & & & 6 & & 74 & & & 90 & & & 32 & & & 10 & & & 109 \\
\hline
\end{tabular}

In a special case, it is assumed there are approximately 8 trips per hour between the Highland Dr external zone (Zone 2) and California Blvd external zone (Zone 3) which is attributed to traffic needing to enter the campus at either Campus Way (Zone 4) or Crandall Way (Zone 5).

By assembling and aggregating the data from the above steps, a matrix of productions and attractions is created as seen in Table 5.8. 
Table 5.8: Production and Attraction Matrix for the Cal Poly Network

\begin{tabular}{|c|c|c|}
\hline \multicolumn{3}{|c|}{ Production/Attractions Matrix } \\
\hline AM Peak Hr & 7:30 AM & 8:30 AM \\
\hline Zone & Productions & Attractions \\
\hline 1 (Stenner) & 38 & 6 \\
\hline 2 (Highland) & 434 & 74 \\
\hline 3 (California) & 528 & 90 \\
\hline 4 (Campus) & 189 & 32 \\
\hline 5 (Crandall) & 57 & 10 \\
\hline 6 (Grand) & 641 & 109 \\
\hline Sum & 1887 & 321 \\
\hline 7 (GStruct) & 66 & 440 \\
\hline $8(G 1)$ & 4 & 45 \\
\hline $9(\mathrm{G} 2)^{*}$ & 0 & 0 \\
\hline $10(\mathrm{R} 1)$ & 17 & 13 \\
\hline $11(\mathrm{R} 2)$ & 9 & 8 \\
\hline $12(\mathrm{R} 3)$ & 14 & 10 \\
\hline $13(\mathrm{R} 4)$ & 14 & 11 \\
\hline $14(\mathrm{Ag})$ & 15 & 77 \\
\hline $15(\mathrm{H} 2)$ & 29 & 187 \\
\hline $16(\mathrm{H} 4)$ & 2 & 225 \\
\hline $17(\mathrm{H} 10)$ & 11 & 39 \\
\hline $18(\mathrm{H} 11)$ & 2 & 27 \\
\hline $19(\mathrm{H} 12)$ & 52 & 222 \\
\hline $20(\mathrm{H} 13)$ & 0.4 & 7 \\
\hline 21 (Mixed) & 2 & 33 \\
\hline $22(\mathrm{H} 16)$ & 11 & 56 \\
\hline 23 (Mixed) & 40 & 198 \\
\hline $24(C 3)$ & 2 & 36 \\
\hline $25(C 4)$ & 8 & 55 \\
\hline $26(C 5)$ & 0.3 & 5 \\
\hline 27 (Mixed) & 2 & 17 \\
\hline $28(C 7)$ & 1 & 133 \\
\hline $29(\mathrm{~A} 1)$ & 12 & 28 \\
\hline 30 (Mixed) & 0.3 & 8 \\
\hline 31 (Mixed) & 1 & 1 \\
\hline 32 (PCV) & 4 & 3 \\
\hline 33 (Cerro) & 3 & 3 \\
\hline Sum & 321 & 1887 \\
\hline
\end{tabular}

\subsubsection{Creating the Origin/Destination Matrix}

After the creation of the Production/Attraction matrix, the rest of the gravity model is applied to create an

Origin/Destination matrix. This includes the creation of a travel time matrix, an impedance matrix, and an adjustment factor matrix.

Travel time (minutes) is computed by dividing a zone-to-zone driving distance (miles) by the speed limit(s) posted along the shortest path (miles per hour) and multiplying by 60 minutes per hour. A travel time 
matrix is created by carrying these calculations out for each zone pair. Distances are measured with precision down to hundredths of a mile. In the case that the path between a pair of zones contains multiple links or multiple speed limits, travel time is computed as the sum of travel times for all links or changes in speed limit. As an example, the travel time between Highland Drive (Zone 2) and H12 Parking (Zone 22) is calculated with the formula Travel Time $=((0.45 / 25)+(0.4 / 30)) * 60$, where the path between Zones 2 and 22 is composed of 2 segments: one segment for 0.45 miles with a speed limit of $25 \mathrm{mph}$ and the other segment for 0.40 miles with a speed of $30 \mathrm{mph}$. For the Cal Poly network, several pairs of zones do not physically have paths between them or have paths that are very impractical and are likely to never be used. In these cases, an infinite travel time is assumed for the zone pair which suggests the demand between these zones is essentially negligible. The travel time matrix is shown in Table 5.9.

Based on the travel times matrix, an impedance matrix is constructed. Impedance is a measure of resistance to vehicle travel which is derived from the inverse of travel time, according to the formula mentioned previously (see Friction Factor). The constant in the formula, $c$ is assumed to be 2 for this case. For the several pairs of zones where infinite travel times are assumed, friction factors for these pairs are equal to zero. When factored in to the gravity model equation used to create the Origin-Destination matrix, these pairs will generate zero demand because of multiplication of this zero friction factor. The impedance matrix is shown in Table 5.10.

For purposes of simplicity, an adjustment factor matrix for capturing the influence socioeconomic factors is not used in the Cal Poly model. This equates to using a matrix where the socioeconomic adjustment factors for all zone pairs are equal to one.

Finally, the Origin/Destination matrix is assembled by applying the gravity model formula as mentioned previously in Gravity Model. This matrix describes the volumes of vehicles (demand) traveling between each origin-destination pair. The calculations for each zone pair are done by distributing attractions and can be found in Appendix F. The Origin/Destination matrix created is shown in Table 5.11. 
Table 5.9: Travel Times Matrix for the Cal Poly Network

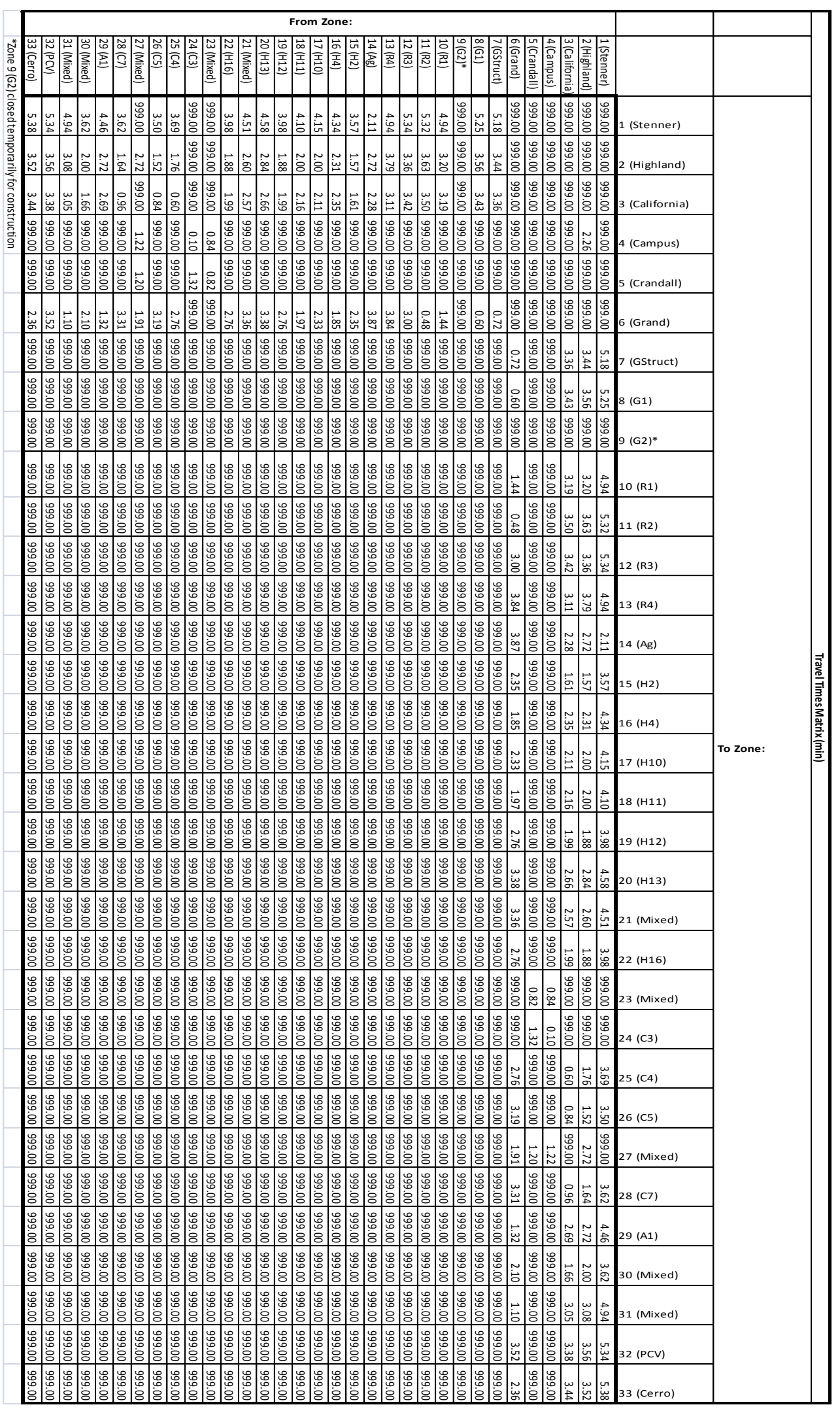


Table 5.10: Friction Factors Matrix for the Cal Poly Network

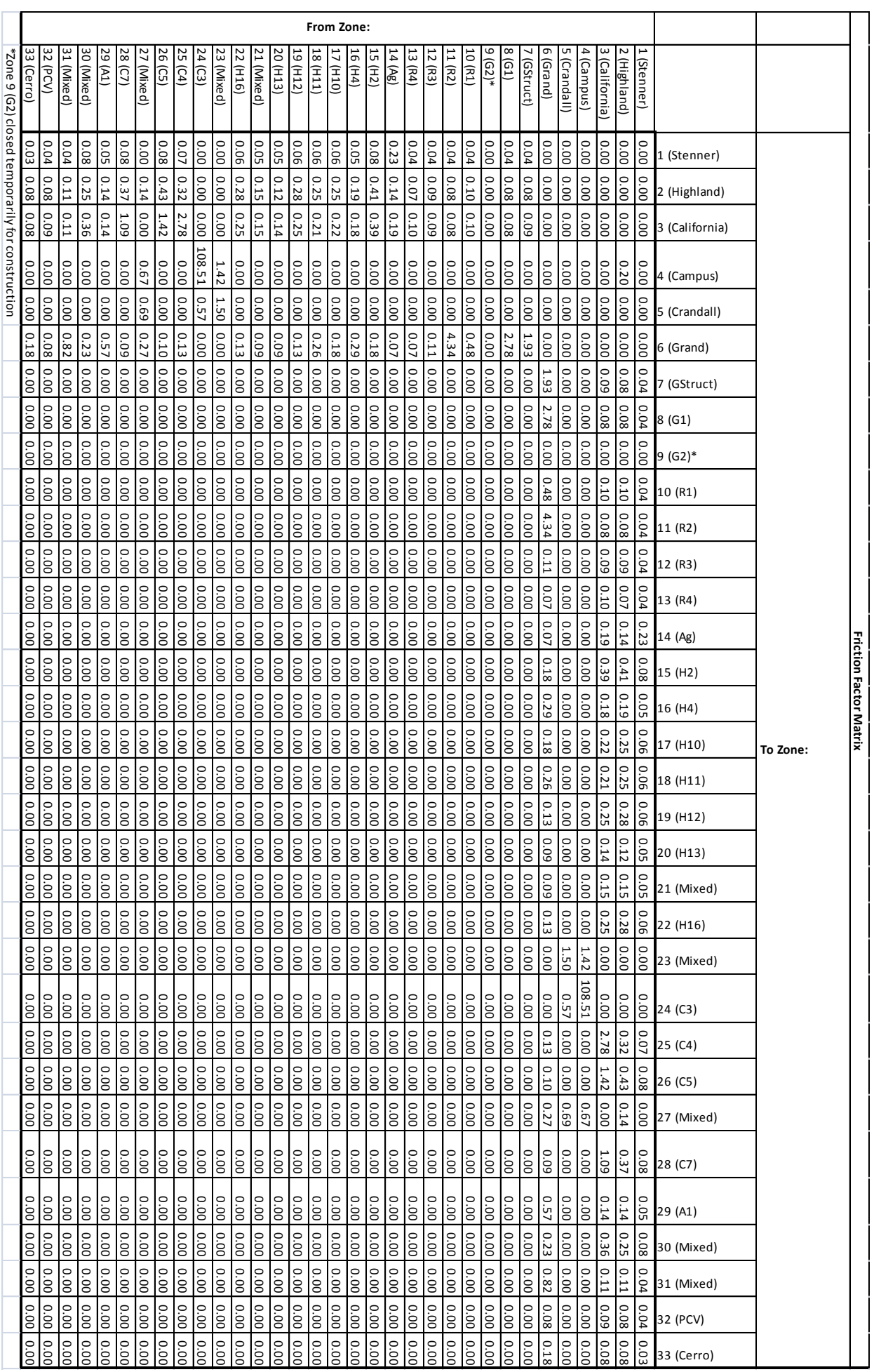


Table 5.11: Origin/Destination Matrix for the Cal Poly Network's AM Peak Hour

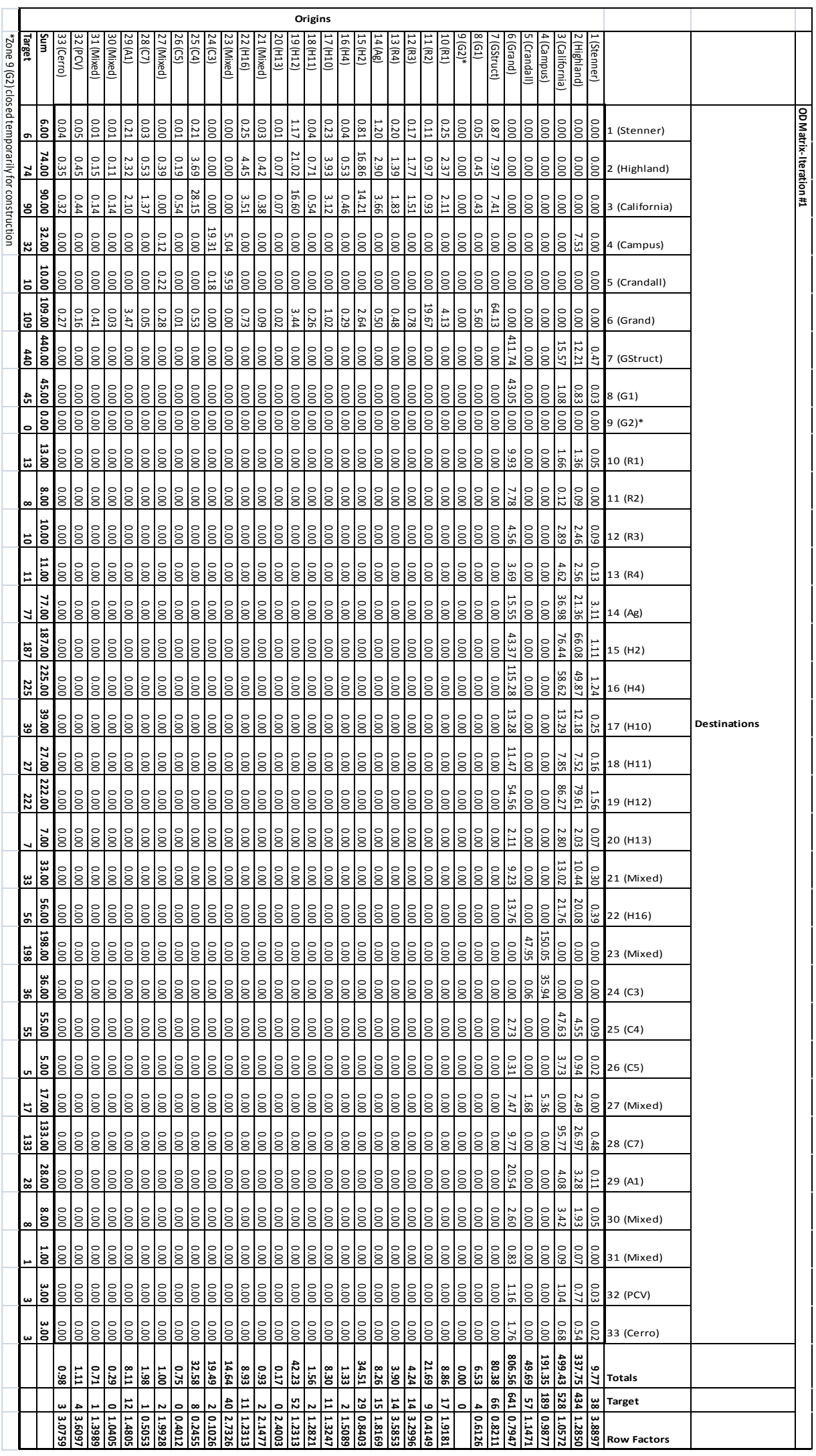




\subsubsection{Balancing the OD Matrix}

After the Origin/Destination matrix is created it needs to be balanced. Balancing is an iterative process where the matrix values are multiplied by factors to more closely match column or row totals. This process repeats until a stopping rule is satisfied. These factors are determined by comparing column or row totals to current values. Every time a column factor is used, the rows will become imbalanced while every time a row factor is used, the columns will become unbalanced. Thus, each iteration involves alternating between column and row factors to multiply the matrix by.

For the purposes of the Cal Poly model, a stopping rule is set when all productions and attractions are within $25 \%$ of their target values (sum/target ratios greater than 0.75 and less than 1.25 ). It took 7 iterations to reach conditions that met this rule. Since the first matrix is created by distributing attractions (which were therefore balanced), getting to the second matrix is achieved by computing row factors and multiplying the matrix by them to balance productions. The following iteration is achieved by computing column factors and multiplying the matrix by them to re-balance attractions. This alternation continues until the stopping rule is satisfied in Iteration \#7. The different iterations of the balancing process can be seen in Tables 5.12-5.17. 
Table 5.12: Iteration \#2 of the Origin/Destination Matrix for the Cal Poly Network

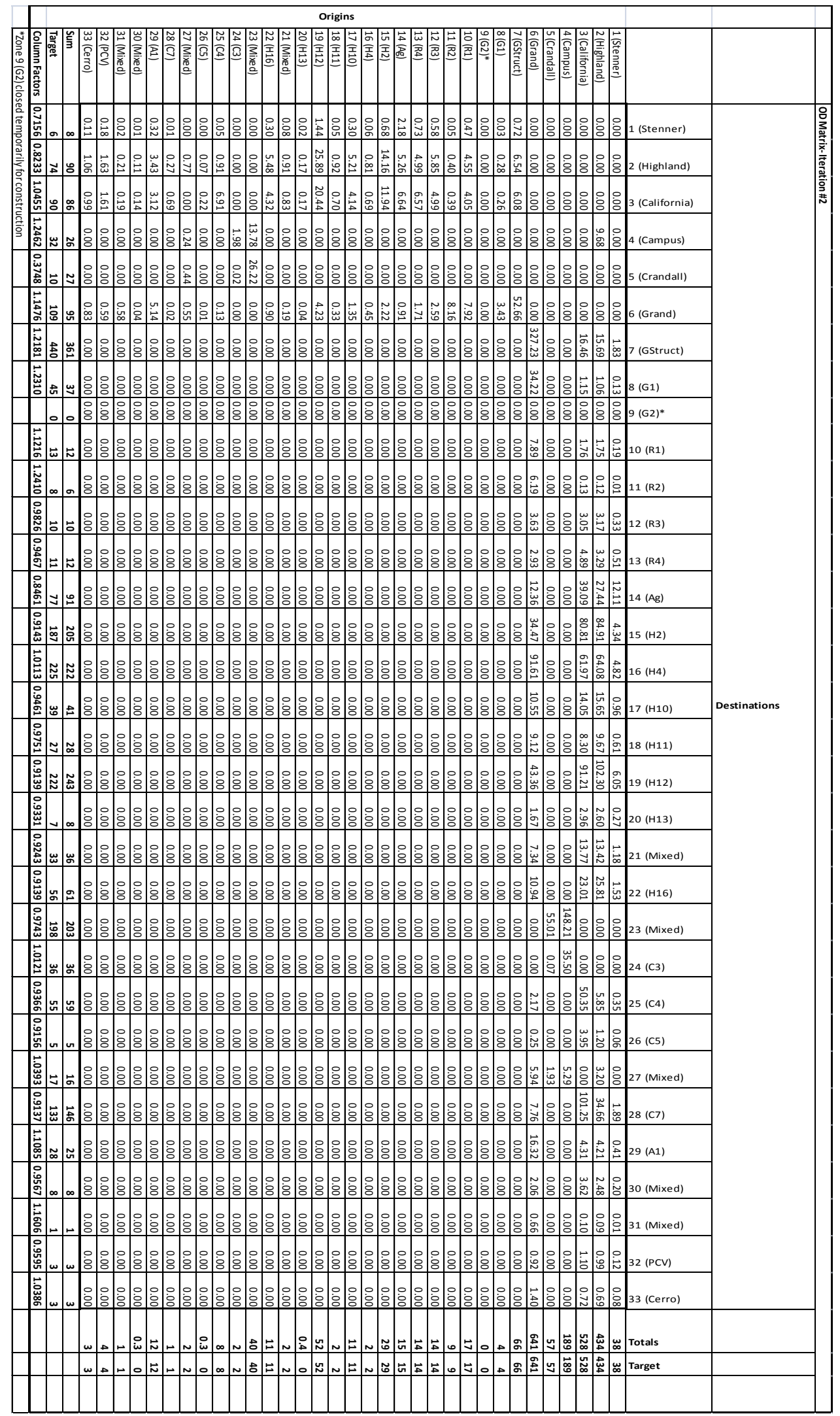


Table 5.13: Iteration \#3 of the Origin/Destination Matrix for the Cal Poly Network

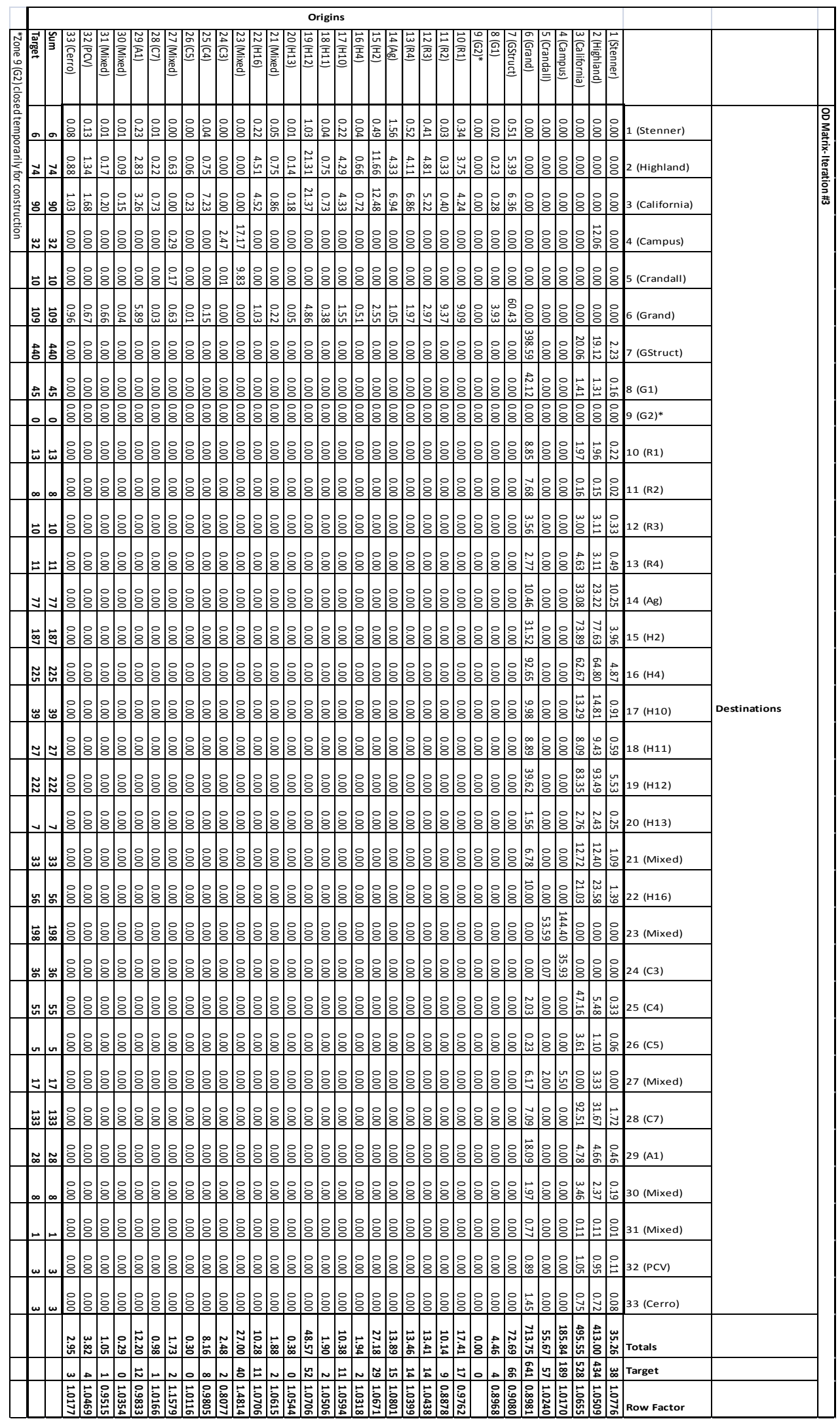


Table 5.14: Iteration \#4 of the Origin/Destination Matrix for the Cal Poly Network

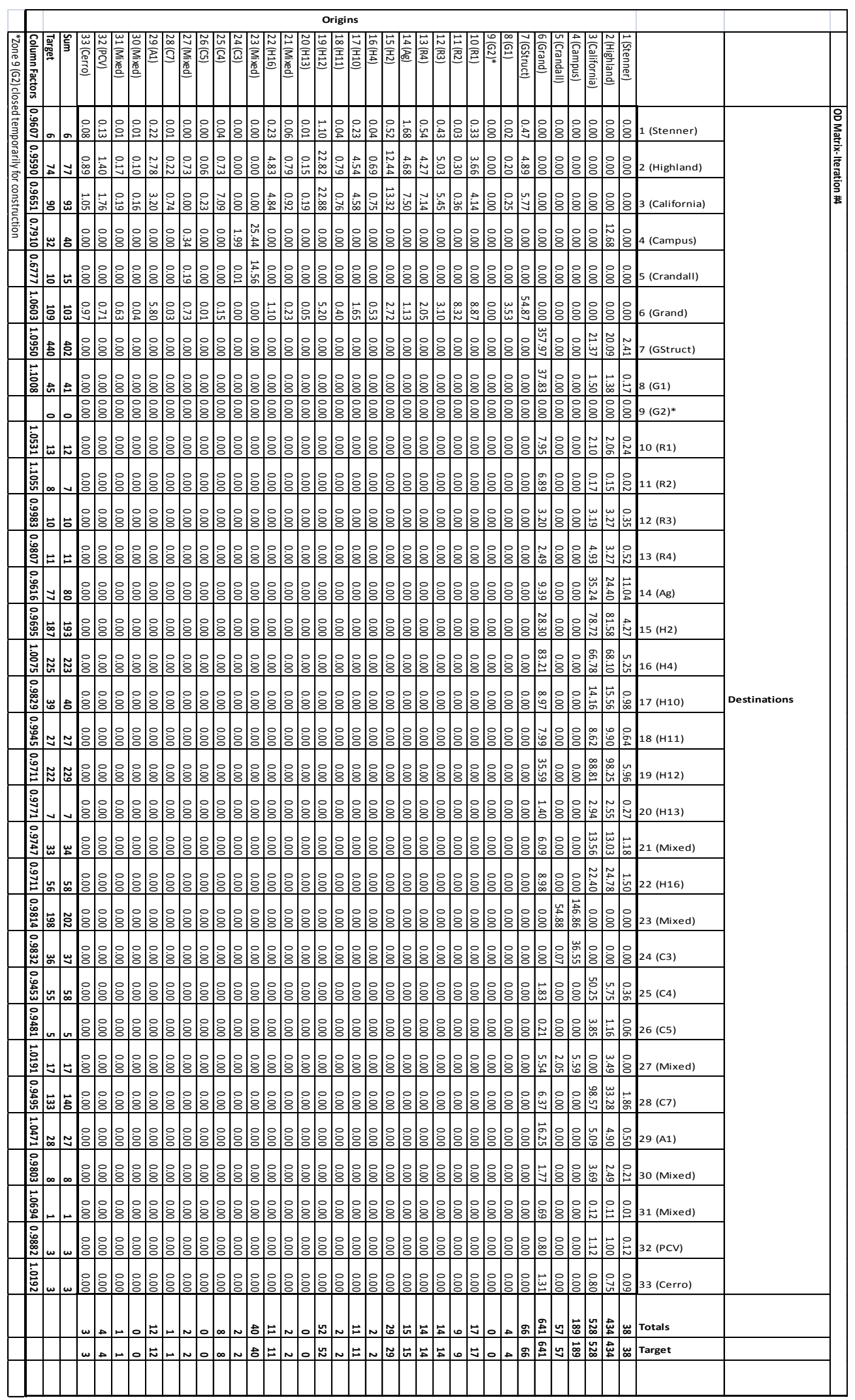


Table 5.15: Iteration \#5 of the Origin/Destination Matrix for the Cal Poly Network

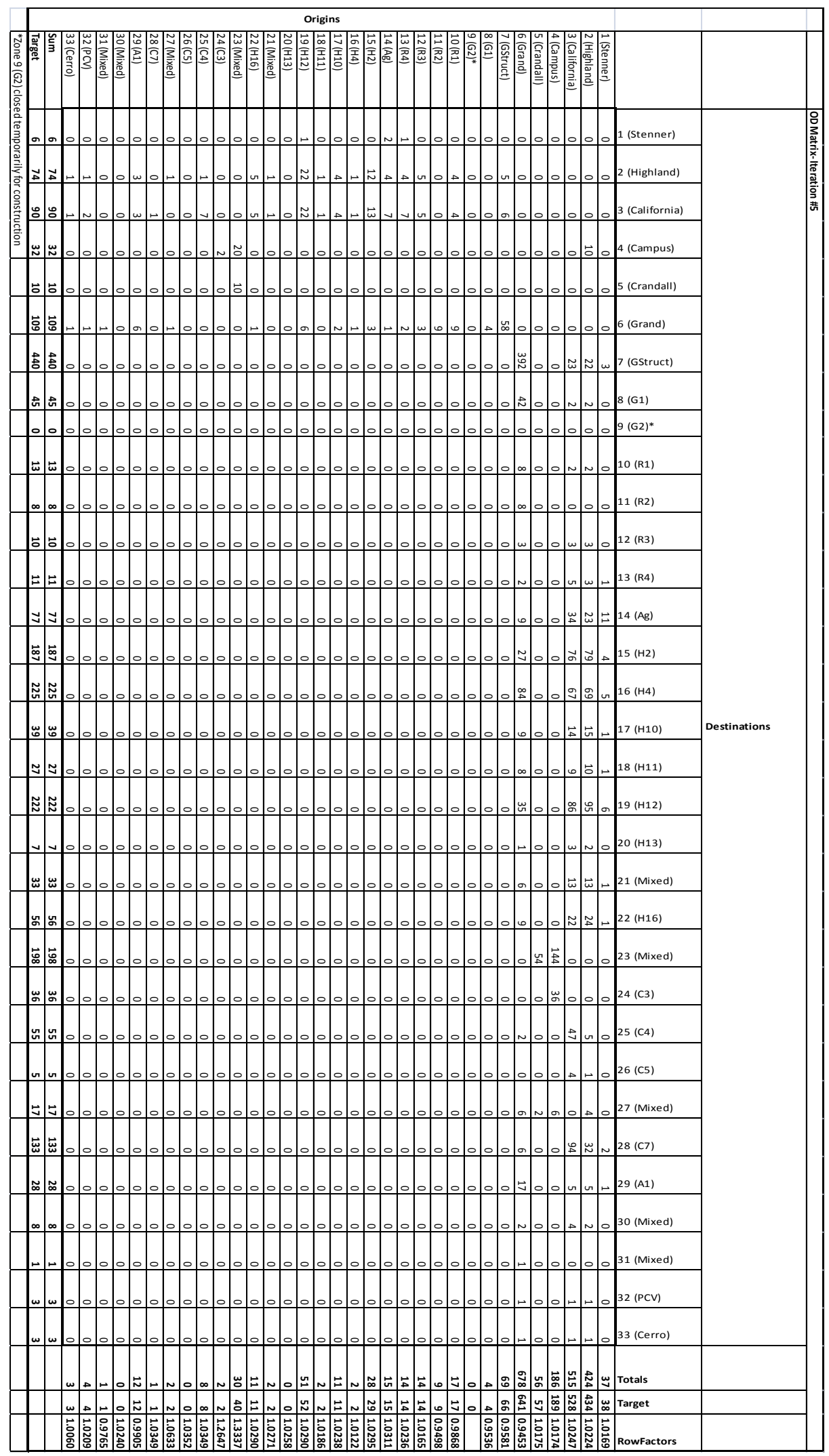


Table 5.16: Iteration \#6 of the Origin/Destination Matrix for the Cal Poly Network

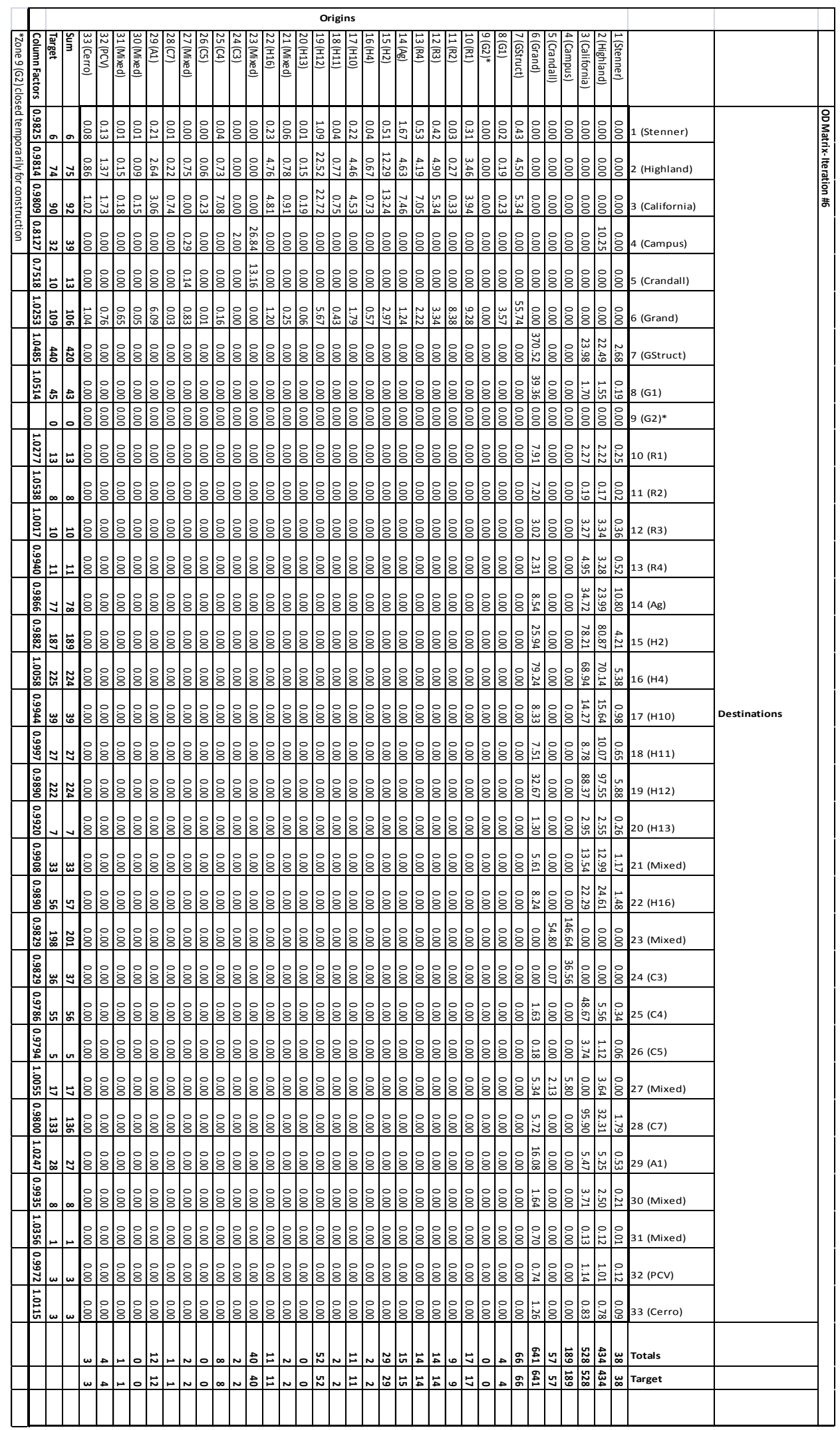


Table 5.17: Iteration \#7 of the Origin/Destination Matrix for the Cal Poly Network

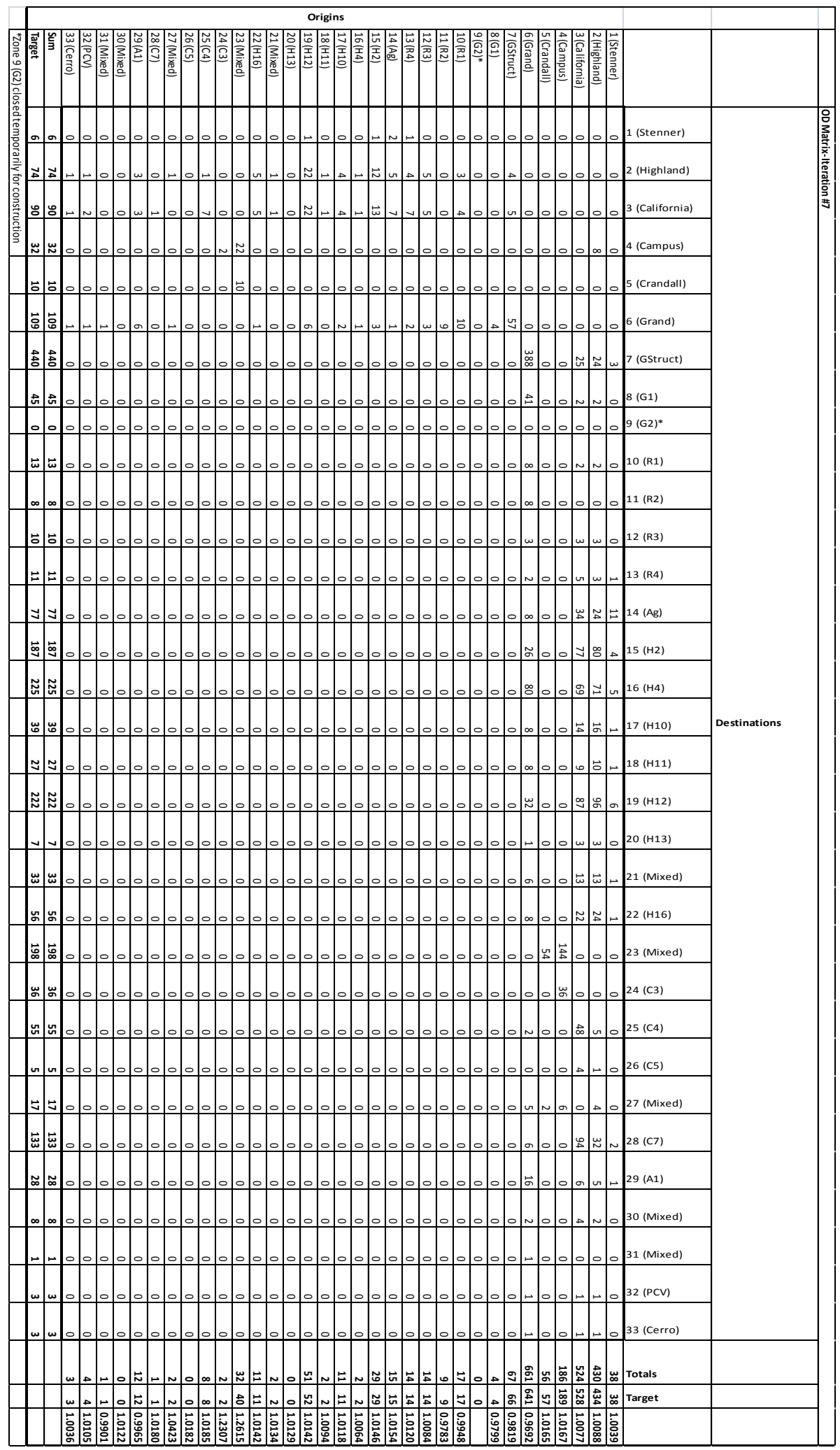




\subsection{Application of Dynamic Assignment: Trip Assignment}

For purposes of traffic assignment, dynamic assignment is chosen over static assignment due to its responsiveness to fluctuations in demand and changes to the network as well as the ability to accommodate a large size network like Cal Poly's. Based on stochastic distributions of driver parameters and current operating conditions in the simulation, driver-vehicle pairs make decisions on their routes almost continuously as described previously in Dynamic Assignment in VISSIM. The Origin/Destination matrix created from application of the gravity model is used as an input to VISSIM 's dynamic assignment module in the form of an .FMA text file.

\subsubsection{Defining the Abstract Model}

In order for the dynamic assignment module to function properly, an abstract model is constructed from the previously created nodes and parking lots (see Nodes \& Parking Lots), which were strategically placed according to the rules specified in VISSIM's v5.30 user manual. In addition to placement, it is necessary to assign each of the parking lots to their corresponding zones and properly define their types. The 12 parking lots used for each of the six entrances and exits to the Cal Poly network are classified as Zone Connectors while the remaining lots are specified as Abstract Parking Lots. Abstract Parking Lots are chosen for campus parking lots instead of Real Parking Spaces to simplify modeling efforts and because they are better suited for modeling the human understanding of route choice. Therefore, the model does not capture the traffic within parking lot aisles nor the choice of particular parking spaces within parking lots.

\subsubsection{Additional Parking Lot Parameters}

There are several other parameters that must be specified for each parking lot: capacities, attraction factors, and relative flows. These parameters are especially important for the cases where a zone is comprised of multiple parking lots.

The capacity of a parking lot is defined as the number of vehicles the parking lot can support at any given time. Capacities are only defined for abstract parking lots. For zone connectors, capacities are not specified and can be determined in simulation by the maximum flow rate of vehicles across all lanes of the parking lot. Table 5.18 below shows the capacities for all parking lots on campus. There is a discrepancy of 20 parking spaces in this figure compared to Table 5.4 which has the correct totals for simulation. This 
discrepancy is due to the addition of 10 parking spaces at the swine unit (Zone 21) and the omission of 30 parking spaces along Polyview Dr (Zone 27) due to current construction.

Attraction is measure of how likely vehicles are to utilize a certain parking lot. Similar to attraction for zones, attraction for parking lots is determined based on factors such as quantity and availability of parking, use types, proximity to campus buildings and any out-of-pocket costs (parking fees) incurred. Attraction factors are considered in VISSIM's Logit Model for parking lot selection (see Parking Lot Choice Parameters) and are only defined for entrance parking lots.

For Cal Poly's network, a heuristic approach is used to determine attraction factors for parking lots in zones containing multiple parking lots. Highly attractive lots are given an attraction value of " 5 " while lessattractive lots are given attraction values less than 5 . These values are calibrated to obtain suitable probabilities based on the Logit function for parking lot selection. Attraction is not significant in cases where a zone has only one parking lot, as all vehicles attracted to that zone are automatically attracted to the parking lot associated with it. Attraction factors can be applied to both zone connectors and abstract parking lots, although they are only needed in this model for abstract parking lots internal to the campus. The attraction factors for Cal Poly's model are shown below in Table 5.19. 
Table 5.18: Listing of Parking Lots \& Capacities for the Cal Poly Network

\begin{tabular}{|c|c|c|c|c|}
\hline Cal Poly Parking Lots & & & & \\
\hline Lot Description & Zone \# & Capacity & \# Entrances & \# Exits \\
\hline G-5 (Grand Ave Structure) Lower Levels & 7 & 711 & 1 & 1 \\
\hline G-5 (Grand Ave Structure) Upper Level & 7 & 200 & 1 & 1 \\
\hline G1 & 8 & 504 & 2 & 1 \\
\hline G2* & 9 & 109 & 2 & 2 \\
\hline R1 (Bottom Level) & 10 & 25 & 1 & 1 \\
\hline R1 (Middle Level) & 10 & 290 & 4 & 4 \\
\hline R1 (Top Levels) & 10 & 523 & 3 & 3 \\
\hline R2 & 11 & 837 & 1 & 1 \\
\hline R3 & 12 & 932 & 1 & 1 \\
\hline R4-Upper Levels & 13 & 762 & 1 & 1 \\
\hline R4-Bottom Level & 13 & 200 & 1 & 1 \\
\hline H1 Crops & 14 & 30 & 1 & 1 \\
\hline H1 Main & 14 & 336 & 2 & 2 \\
\hline Crops & 14 & 38 & 1 & 1 \\
\hline Dairy & 14 & 90 & 1 & 1 \\
\hline Poultry & 14 & 24 & 1 & 1 \\
\hline $\mathrm{H} 2$ - Engineering IV South & 15 & 137 & 1 & 1 \\
\hline H2-Engineering IV North & 15 & 84 & 1 & 1 \\
\hline H2-Highland \& University & 15 & 81 & 1 & 1 \\
\hline $\mathrm{H} 2$ - Highland Dr & 15 & 38 & 1 & 1 \\
\hline H4-BRAE & 16 & 60 & 2 & 2 \\
\hline H4 Main & 16 & 194 & 1 & 1 \\
\hline H4-Village Dr* & 16 & 8 & 1 & 1 \\
\hline H4-Triangle* & 16 & 143 & 2 & 2 \\
\hline $\mathrm{H} 10$ & 17 & 58 & 1 & 1 \\
\hline $\mathrm{H} 11$ & 18 & 28 & 1 & 2 \\
\hline $\mathrm{H} 12$ & 19 & 436 & 6 & 6 \\
\hline $\mathrm{H} 13$ & 20 & 43 & 1 & 1 \\
\hline H14-Lower & 21 & 234 & 4 & 4 \\
\hline H14-Upper & 21 & 75 & 3 & 3 \\
\hline H14-Lower Equine & 21 & 28 & 1 & 1 \\
\hline H14-Upper Equine & 21 & 28 & 1 & 1 \\
\hline H15-Sports Complex & 21 & 47 & 1 & 1 \\
\hline H14-Lower Horticulture & 21 & 10 & 1 & 1 \\
\hline H14-Upper Horticulture & 21 & 14 & 1 & 1 \\
\hline H14-Swine & 21 & 10 & 1 & 1 \\
\hline H14-Arboretum & 21 & 4 & 1 & 1 \\
\hline $\mathrm{H} 16$ & 22 & 565 & 2 & 2 \\
\hline C2 Main & 23 & 110 & 1 & 1 \\
\hline C2-Cuesta Ave & 23 & 41 & 1 & 1 \\
\hline C2-Childrens Center Main & 23 & 21 & 2 & 2 \\
\hline C2-Childrens Center Side & 23 & 9 & 1 & 1 \\
\hline C2-Health Center & 23 & 14 & 1 & 1 \\
\hline College Ave & 23 & 76 & 1 & 1 \\
\hline $\mathrm{C3}$ & 24 & 50 & 1 & 1 \\
\hline C4-California Blvd East & 25 & 61 & 1 & 1 \\
\hline C4-California Blvd West & 25 & 26 & 1 & 1 \\
\hline $\mathrm{C5}$ & 26 & 15 & 1 & 1 \\
\hline C6-Campus Dining & 27 & 21 & 1 & 1 \\
\hline Power & 27 & 2 & 1 & 1 \\
\hline Cohan Center* & 27 & 17 & 1 & 1 \\
\hline $\mathrm{C7}$ & 28 & 150 & 1 & 1 \\
\hline A1 & 29 & 66 & 1 & 1 \\
\hline Dexter Rd & 30 & 4 & 1 & 1 \\
\hline Cal Poly Foundation & 30 & 14 & 1 & 1 \\
\hline Engineering 13 & 30 & 3 & 1 & 1 \\
\hline Grand Ave & 31 & 9 & 1 & 1 \\
\hline Mountain Lane & 31 & 10 & 1 & 1 \\
\hline Poly Canyon Village-Canyon Circle/Village Dr & 32 & 31 & 1 & 1 \\
\hline Poly Canyon Village-Vista Caballo West* & 32 & 20 & 1 & 1 \\
\hline Poly Canyon Village-Vista Caballo-East* & 32 & 11 & 1 & 1 \\
\hline Lower Cerro Vista & 33 & 25 & 1 & 1 \\
\hline \multirow[t]{2}{*}{ Upper Cerro Vista } & 33 & 30 & 1 & 1 \\
\hline & Sum & 8772 & & \\
\hline
\end{tabular}

${ }^{*} \mathrm{H} 4$ lots are grouped together in simulation for simplification

*Polyview Dr excluded from model due to construction

*G2 lot is temporarily closed due to construction 
Table 5.19: Attraction Factors for Parking Lots in the Cal Poly Network

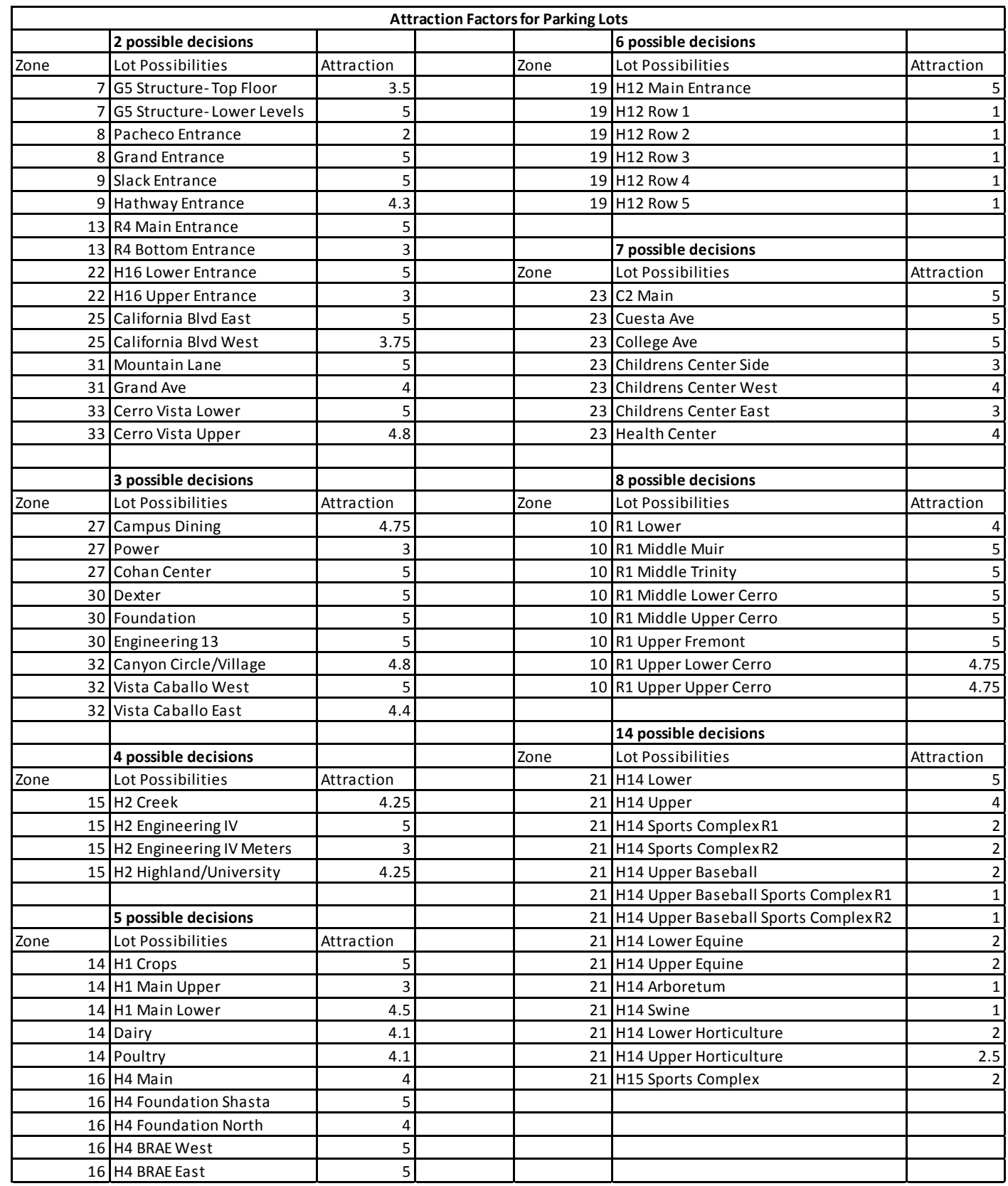

Relative flows are essentially the equivalent to attraction factors for exit parking lots. VISSIM defines the

relative flow of a parking lot as the percentage of the zone's demand that uses a certain exit parking lot to

leave the zone. Relative flows are defined only for exiting lots in zones with multiple parking lots to

distribute the flow of outbound traffic. Relative flows are not significant in cases where a zone has only

one parking lot associated with it and are assigned a default value of "1". Relative flows are also assigned

a default value of " 0 " for entrance lots, indicating the need to use an attraction factor. Relative flows can 
be applied to both zone connectors and abstract parking lots. Unlike attraction factors, relative flows do not factor in to any Logit function.

For Cal Poly's network, a heuristic approach is used to determine relative flows for parking lots based on the relative capacities of parking lots.

\subsubsection{Route Choice Parameters}

As mentioned in Cost \& Route Choice Models, VISSIM uses a variation of the Logit model for cost and route choice decisions. This model requires the input of cost coefficients for travel time (seconds), distance (feet), and link cost (\$). A model is required for each vehicle type category.

For the Cal Poly network, it is necessary to input cost coefficients for models for each of the nine vehicle types. It is assumed that the route choice parameters do not vary significantly between the vehicle classes seen on campus, so all nine models are assigned the same cost coefficients.

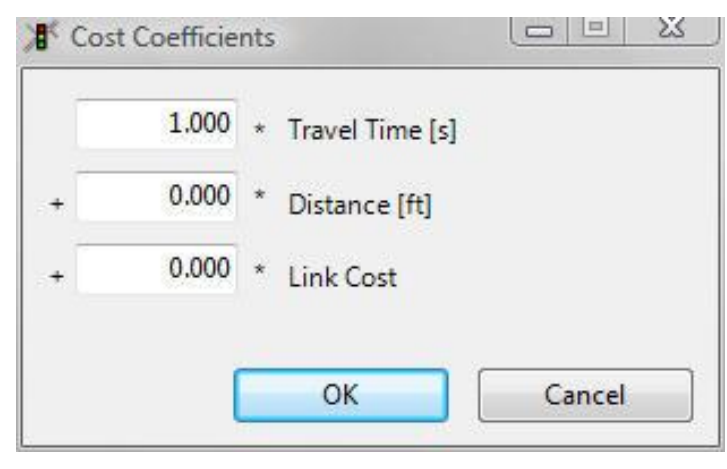

Figure 5.11: Cost Coefficents for Route Choice Model for All Vehicle Types

As seen in the Figure 5.11, a coefficient of " 1 " is assigned to travel time. This is because travel time seems to be the most important parameter to Cal Poly motorists traveling to work or school. Distance is not factored in because the Cal Poly network contains little choice in terms of paths between origins and destinations; therefore there are few distances to compare. Link cost is not factored into the model since there are no tolls or fees associated with any campus links.

\subsubsection{Parking Lot Selection Parameters}

As mentioned in Parking Lot Selection, VISSIM uses a variation of the Logit model for parking lot selection to distribute traffic between parking lots, especially in zones with multiple parking lots. This model requires the input of coefficients for cost, attraction, distance to center of zone, distance from current vehicle position, and availability of free space. A model is required for each vehicle type category. 
For the Cal Poly network, it is necessary to input coefficients for models for each of the nine vehicle types. It is assumed that the parking lot choice parameters do not vary significantly between the vehicle classes seen on campus, so all nine models are assigned the same cost coefficients.

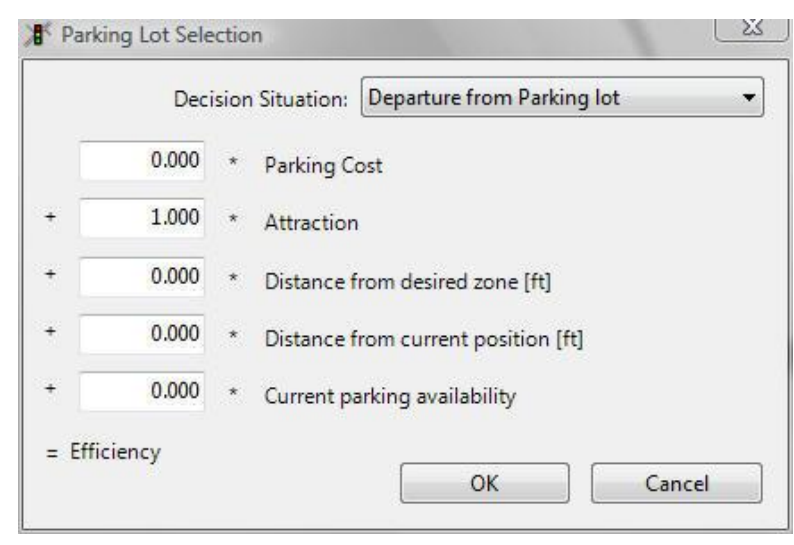

\section{Figure 5.12: Coefficients for Parking Lot Selection for All Vehicle Types}

As seen in Figure 5.12, a cost efficient of "1" is assigned to attraction. All parameters are deemed important to Cal Poly's network, but for simplification purposes and ease of calculations, it seemed easier to lump all of them into one attraction factor. The attraction factors assigned to each parking lot (see Additional Parking Lot Parameters) are tabulated with a Logit Model in Excel to compute utilities and probabilities for each parking lot. These calculations are verified for accuracy by placing data collection points at the entrances to several parking lots. The attraction factors are calibrated until the probabilities matched firsthand knowledge of vehicles distributed to each parking lot. The spreadsheet calculation of parking lots utilities and probabilities can be found in $\underline{\text { Appendix G. }}$. 


\subsection{Defining Simulation Run Parameters}

After the definition and creation of the road network, vehicle types, and travel demand, the simulation model is able to be run. The simulation parameters for the Cal Poly network are shown below in Figure 5.13 .

Traffic is defined to flow on the right-side of the road. The simulation will begin at 7:15AM and last until 8:30AM, a duration of 4500 seconds. As mentioned previously, vehicle demand is generated between 7:30AM and 8:30AM during the peak hour. The period between 7:15AM and 7:30AM is used to situate transit vehicles in the network according to their devised schedules. A simulation resolution of " 2 " was assumed for simulation resolution, which is used for smoothness in animation. A random seed of " 42 ' was chosen at random for the baseline model to initiate the calculation of parameters stochastic in nature. This seed is varied later for statistical purposes in estimating variability. The simulation speed indicates the speed at which the simulation runs. For quick computation, this speed shown is to the maximum speed possible based on the ability to process with two processing cores. The simulation speed was varied for purposes of watching the animation at speeds more representative of real-time operations.

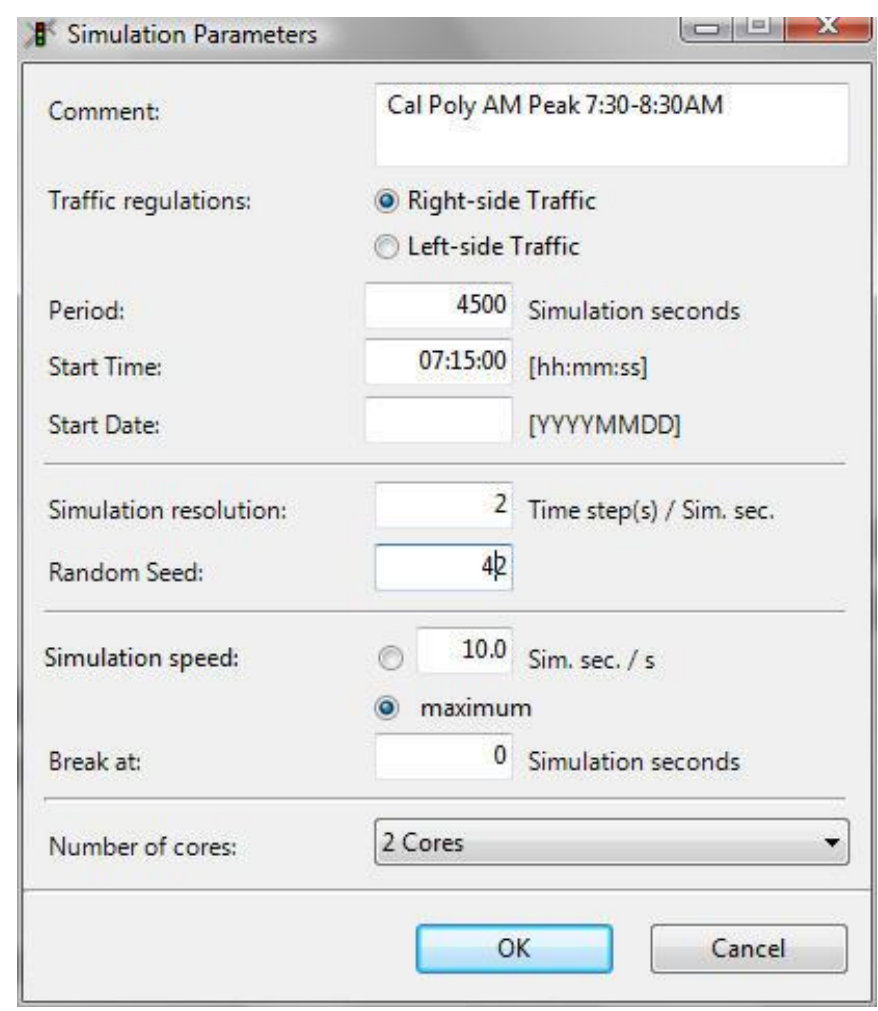

Figure 5.13: Simulation Run Parameters for the Cal Poly Network 


\subsection{Verification}

As mentioned in Verification as part of the System Overview, verification is the process of determining whether the transportation simulation model is built correctly for its intended purpose. For the Cal Poly network, verification is used to determine if the model is built correctly to portray realistic traffic conditions during a peak hour, to quantify emissions generated, and to perform sensitivity analysis on how these emissions change with changes in different parameters. Verification is done in two phases: as the model was being built and after the model is built.

As the model was being built, verification was done continuously using software functionality to trace and debug incorrect behavior. Common errors witnessed during construction included the following:

- Improper placement of stop signs and speed decisions

- Improper generation of abstract network due to incorrect node or parking lot settings

- Improper input parameters

- Use of obsolete cost or route choice files

These errors were corrected by trial and error testing and discussions with software and transportation professionals.

After the model is built, verification is done by inspecting network components for accuracy and observing behavior shown with VISSIM's state-of-the-art animation. This is done for traffic signals, stop signs, road geometry, parking lot geometry, and operating speeds. The proper placement of stop sign components is a good example of verification techniques used. Using a different view perspective, the placement of stop signs is verified to ensure stop signs were placed on links and not on connectors within an intersection. In watching the animation, behavior is verified by ensuring vehicles stop where they need to stop, stop as long as they need to, and proceed according to the correct right-of-way rules. In addition to checking network components, a double check is done to ensure all intersection configurations matched sketches obtained from field study. 


\subsection{Calibration/Validation}

\subsubsection{Calibration Parameters}

As mentioned in Calibration \& Validation in the System Overview, calibration is the process by which the demand components of a microscopic simulation model are refined and adjusted to match conditions observed in the field. The Cal Poly model is calibrated by refining and adjusting turning movement counts based on field data collected at key intersections from the interior of campus. The key intersections of Highland \& University, North Perimeter \& Village Dr, Grand \& Deer, and Grand \& Pacheco are chosen for key intersections for calibration since they represent areas of campus where many paths converge and

diverge. The field data for these intersections was collected on average weekdays during November 2010 during the AM Peak Hour and can be reviewed in Appendix I.

A total of ten random seeds are selected at random to capture the overall variability of simulation parameters. After each simulation run based on one of these random seeds, turning movements at the four key intersections are collected from the simulation for analysis. The number of random seeds is limited to ten random seeds due to the lengthy cycle times required to run each of the simulations, aggregate, filter, and summarize turning movement data, and make changes to the model for future iterations.

\subsubsection{GEH Statistics}

Once the turning movements are collected for all intersections and all ten runs of an iteration, the average volumes are computed. In order to define a reasonable amount of accuracy, GEH statistics are used for comparing average turning movement volumes to the data collected from field studies. GEH statistics are commonly used in transportation analysis and simulation to compare two sets of traffic volumes. They are computed from an empirical formula whose mathematical form is similar to that of a Chi-squared test as seen below in Figure 5.14 .

$$
\begin{aligned}
& \text { GEH }=\sqrt{\frac{2(M-C)^{2}}{M+C}} \text { where } \\
& \mathrm{M}=\text { hourly traffic volume from simulation model and } \\
& \mathrm{C}=\text { hourly traffic volume observed in real-world }
\end{aligned}
$$

Figure 5.14: Formula for Calculation of GEH Statistics to Compare Average Volumes 
This formula does not follow a linear form due to the large variation in traffic volumes and therefore avoids several pitfalls associated with using simple percentages to compare volumes. Although not a true statistical test, GEH statistics have been proven useful in field practice (Wikipedia 2010).

\subsubsection{Validation \& Changes Made in Calibration}

For calibration of Cal Poly's model, a reasonable accuracy is assumed to be achieved when GEH statistics for all 30 turning movements are less than five. These statistics are satisfied after five successful iterations of changes as shown by the summary below in Table 5.20. Approximately four iteration cycles were completed which did not yield improvements in GEH statistics and are omitted in this report.

Table 5.20: Summary of GEH Statistics for Calibration of the Cal Poly Model

\begin{tabular}{|c|c|c|c|c|c|c|c|c|}
\hline \multicolumn{9}{|c|}{ Summary of GEH Statistics } \\
\hline & Movement & VISSIM Notation & $\begin{array}{l}\text { GEH Statistic- } \\
\text { Initial }\end{array}$ & $\begin{array}{l}\text { GEH Statistic- } \\
\text { Iteration \#1 } \\
\end{array}$ & $\begin{array}{l}\text { GEH Statistic- } \\
\text { Iteration \#2 } \\
\end{array}$ & $\begin{array}{l}\text { GEH Statistic- } \\
\text { Iteration \#3 } \\
\end{array}$ & \begin{tabular}{|l|} 
GEH Statistic- \\
Iteration \#4 \\
\end{tabular} & $\begin{array}{l}\text { GEH Statistic } \\
\text { Iteration \#5 } \\
\end{array}$ \\
\hline \multirow{12}{*}{ 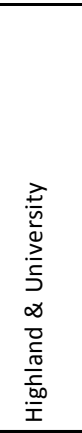 } & EbL & W-N & 3.48 & 3.21 & 1.12 & 1.16 & 1.23 & 0.99 \\
\hline & EbT & W-E & 8.66 & 8.76 & 2.96 & 3.23 & 2.01 & 2.37 \\
\hline & EbR & W-S & 6.74 & 6.72 & 0.16 & 0.42 & 0.74 & 0.48 \\
\hline & WbR & E-N & \#DIV/0! & \#DIV/0! & \#DIV/0! & \#DIV/0! & \#DIV/0! & \#DIV/0! \\
\hline & WbT & E-W & 7.78 & 1.51 & 1.50 & 1.33 & 0.95 & 0.95 \\
\hline & WbL & E-S & 0.17 & 0.70 & 0.75 & 0.47 & 0.04 & 0.04 \\
\hline & $\mathrm{NbL}$ & s-W & 0.37 & 0.09 & 0.27 & 0.46 & 0.01 & 0.17 \\
\hline & $\mathrm{NbT}$ & S-N & 0.60 & 0.56 & 0.56 & 0.60 & 0.05 & 0.65 \\
\hline & $\mathrm{NbR}$ & S-E & 0.42 & 0.96 & 0.94 & 2.17 & 2.63 & 2.61 \\
\hline & $\mathrm{SbL}$ & $\mathrm{N}-\mathrm{E}$ & 1.41 & 1.21 & 1.41 & 1.41 & 1.41 & 1.41 \\
\hline & $\mathrm{SbT}$ & $\mathrm{N}-\mathrm{S}$ & 1.10 & 1.00 & 1.00 & 1.00 & 1.26 & 1.26 \\
\hline & SbR & $\mathrm{N}-\mathrm{W}$ & 3.55 & 3.26 & 3.58 & 3.58 & 3.49 & 3.49 \\
\hline \multirow{6}{*}{ 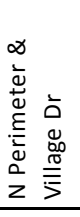 } & WbT & SE-W & 0.73 & 4.69 & 4.63 & 5.64 & 5.26 & 4.94 \\
\hline & WbR & SE-NE & 8.35 & 8.05 & 8.16 & 6.10 & 3.91 & 3.49 \\
\hline & EbT & W-SE & 3.20 & 3.10 & 1.29 & 3.53 & 2.88 & 3.03 \\
\hline & EbL & W-NE & 0.85 & 0.29 & 3.21 & 3.00 & 1.29 & 2.39 \\
\hline & $\mathrm{SbR}$ & NE-W & 1.09 & 0.91 & 0.91 & 0.73 & 0.91 & 1.06 \\
\hline & $\mathrm{SbL}$ & NE-SE & 1.47 & 2.09 & 4.99 & 3.59 & 0.10 & 0.14 \\
\hline \multirow{6}{*}{ 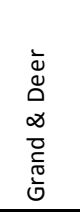 } & $\mathrm{NbT}$ & SE-NW & 3.95 & 0.43 & 0.41 & 1.99 & 2.13 & 2.10 \\
\hline & $\mathrm{NbR}$ & SE-NE & 8.17 & 0.39 & 0.50 & 2.11 & 2.51 & 2.47 \\
\hline & SbT & NW-SE & 2.77 & 4.66 & 4.33 & 5.85 & 3.49 & 3.54 \\
\hline & $\mathrm{SbL}$ & NW-NE & 2.45 & 2.45 & 2.45 & 2.45 & 2.45 & 2.45 \\
\hline & WbR & NE-NW & 2.00 & 1.23 & 1.23 & 1.01 & 2.00 & 2.00 \\
\hline & $\mathrm{WbL}$ & NE-SE & 0.74 & 2.96 & 1.18 & 4.12 & 1.41 & 1.45 \\
\hline \multirow{8}{*}{ 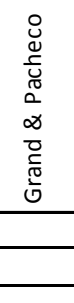 } & $\mathrm{NbL}$ & SE-SW & 0.64 & 0.64 & 0.62 & 0.64 & 0.70 & 0.69 \\
\hline & SbR & NW-SW & 0.37 & 0.65 & 0.14 & 0.47 & 0.37 & 0.33 \\
\hline & EbL & SW-NW & 2.61 & 2.12 & 2.02 & 2.09 & 0.88 & 0.88 \\
\hline & EbR & SW-SE & 4.50 & 4.30 & 4.24 & 4.20 & 0.81 & 0.91 \\
\hline & $\mathrm{NbT}$ & SE-NW & 0.07 & 0.11 & 0.13 & 2.92 & 2.96 & 2.90 \\
\hline & SbT & NW-SE & 3.71 & 4.92 & 5.18 & 5.03 & 4.21 & 4.20 \\
\hline & & & & & & & & \\
\hline & & & & \multicolumn{3}{|c|}{ GEH Statistic is greater than 5} & & \\
\hline & & & & & & & & \\
\hline
\end{tabular}

The red highlights in Table 5.20 indicate turning movements and iterations where GEH statistics exceeded the acceptable value of five. Different iterations are only classified as successful when the number of GEH 
statistics greater than five has decreased. The statistics for each simulation run and random seed are provided for all iterations in Appendix J.

In order to generate additional iterations, heuristic approaches are used to strategically change volumes in the Origin/Destination matrix which targets the reduction of GEH statistics for certain turning movements. A summary of the overall changes made from all iterations is available below in Table 5.21. 
Table 5.21: Summary of Changes Made During Calibration of the Cal Poly Model

\begin{tabular}{|c|c|c|c|}
\hline \multicolumn{4}{|c|}{ Summary of Changes } \\
\hline & & Volume & Volume \\
\hline From Zone & To Zone & Pre-Calibration & Post-Calibration \\
\hline 1 (Stenner) & $15(\mathrm{H} 2)$ & 4 & 2 \\
\hline 1 (Stenner) & $16(\mathrm{H} 4)$ & 5 & 1 \\
\hline 2 (Highland) & 12 (R3) & 3 & 4 \\
\hline 2 (Highland) & $13(\mathrm{R} 4)$ & 3 & 5 \\
\hline 2 (Highland) & $15(\mathrm{H} 2)$ & 80 & 51 \\
\hline 2 (Highland) & $16(\mathrm{H} 4)$ & 71 & 43 \\
\hline 2 (Highland) & $17(\mathrm{H} 10)$ & 16 & 9 \\
\hline 2 (Highland) & $18(\mathrm{H} 11)$ & 10 & 6 \\
\hline 2 (Highland) & $19(\mathrm{H} 12)$ & 96 & 146 \\
\hline 2 (Highland) & 21 (Mixed) & 13 & 20 \\
\hline 2 (Highland) & $22(\mathrm{H} 16)$ & 24 & 36 \\
\hline 2 (Highland) & 32 (Cerro) & 1 & 2 \\
\hline 3 (California) & 12 (R3) & 3 & 5 \\
\hline 3 (California) & 13 (R4) & 5 & 7 \\
\hline 3 (California) & $15(\mathrm{H} 2)$ & 77 & 49 \\
\hline 3 (California) & $16(\mathrm{H} 4)$ & 69 & 41 \\
\hline 3 (California) & $17(\mathrm{H} 10)$ & 14 & 8 \\
\hline 3 (California) & $18(\mathrm{H} 11)$ & 9 & 5 \\
\hline 3 (California) & $19(\mathrm{H} 12)$ & 87 & 131 \\
\hline 3 (California) & 21 (Mixed) & 13 & 19 \\
\hline 3 (California) & $22(\mathrm{H} 16)$ & 22 & 33 \\
\hline 3 (California) & 32 (Cerro) & 1 & 2 \\
\hline 6 (Grand) & 10 (R1) & 8 & 10 \\
\hline 6 (Grand) & 12 (R3) & 3 & 5 \\
\hline 6 (Grand) & 13 (R4) & 2 & 4 \\
\hline 6 (Grand) & $15(\mathrm{H} 2)$ & 26 & 20 \\
\hline 6 (Grand) & $16(\mathrm{H} 4)$ & 80 & 131 \\
\hline 6 (Grand) & $17(\mathrm{H} 10)$ & 8 & 5 \\
\hline 6 (Grand) & $18(\mathrm{H} 11)$ & 8 & 5 \\
\hline 6 (Grand) & 21 (Mixed) & 6 & 7 \\
\hline 6 (Grand) & 32 (Cerro) & 1 & 2 \\
\hline 6 (Grand) & 33 (PCV) & 1 & 2 \\
\hline 7 (GStruct) & 2 (Highland) & 4 & 7 \\
\hline 7 (GStruct) & 3 (California) & 5 & 8 \\
\hline 7 (GStruct) & 6 (Grand) & 57 & 30 \\
\hline 12 (R3) & 2 (Highland) & 5 & 1 \\
\hline 12 (R3) & 3 (California) & 5 & 1 \\
\hline 13 (R4) & 2 (Highland) & 4 & 1 \\
\hline 13 (R4) & 3 (California) & 7 & 2 \\
\hline $19(\mathrm{H} 12)$ & 2 (Highland) & 22 & 6 \\
\hline $19(\mathrm{H} 12)$ & 3 (California) & 22 & 7 \\
\hline $22(\mathrm{H} 16)$ & 2 (Highland) & 5 & 2 \\
\hline $22(\mathrm{H} 16)$ & 3 (California) & 5 & 2 \\
\hline 27 (Mixed) & 2 (Highland) & 0 & 1 \\
\hline 27 (Mixed) & 4 (Campus) & 1 & 0 \\
\hline 27 (Mixed) & 5 (Crandall) & 1 & 0 \\
\hline 27 (Mixed) & 6 (Grand) & 0 & 1 \\
\hline 32 (Cerro) & 3 (California) & 2 & 1 \\
\hline
\end{tabular}




\subsection{Emissions Modeling}

Because of its ability to quantify emissions for different vehicle operating states on a second-by-second time scale, UC Riverside's CMEM v3.01 (see Emissions Modeling in System Overview) is chosen for modeling emissions based on simulation outputs from VISSIM. CMEM also makes for easier processing as data can be parsed from simulation output to suitable text input without the use of extensive programming. More specifically, the command line version of CMEM for light duty vehicles is used for Cal Poly's network.

\subsubsection{CMEM LDV CLI Overview}

This version of CMEM is outlined in Figure 5.15 below. The version runs in batch mode based off a command line interface in Microsoft DOS.

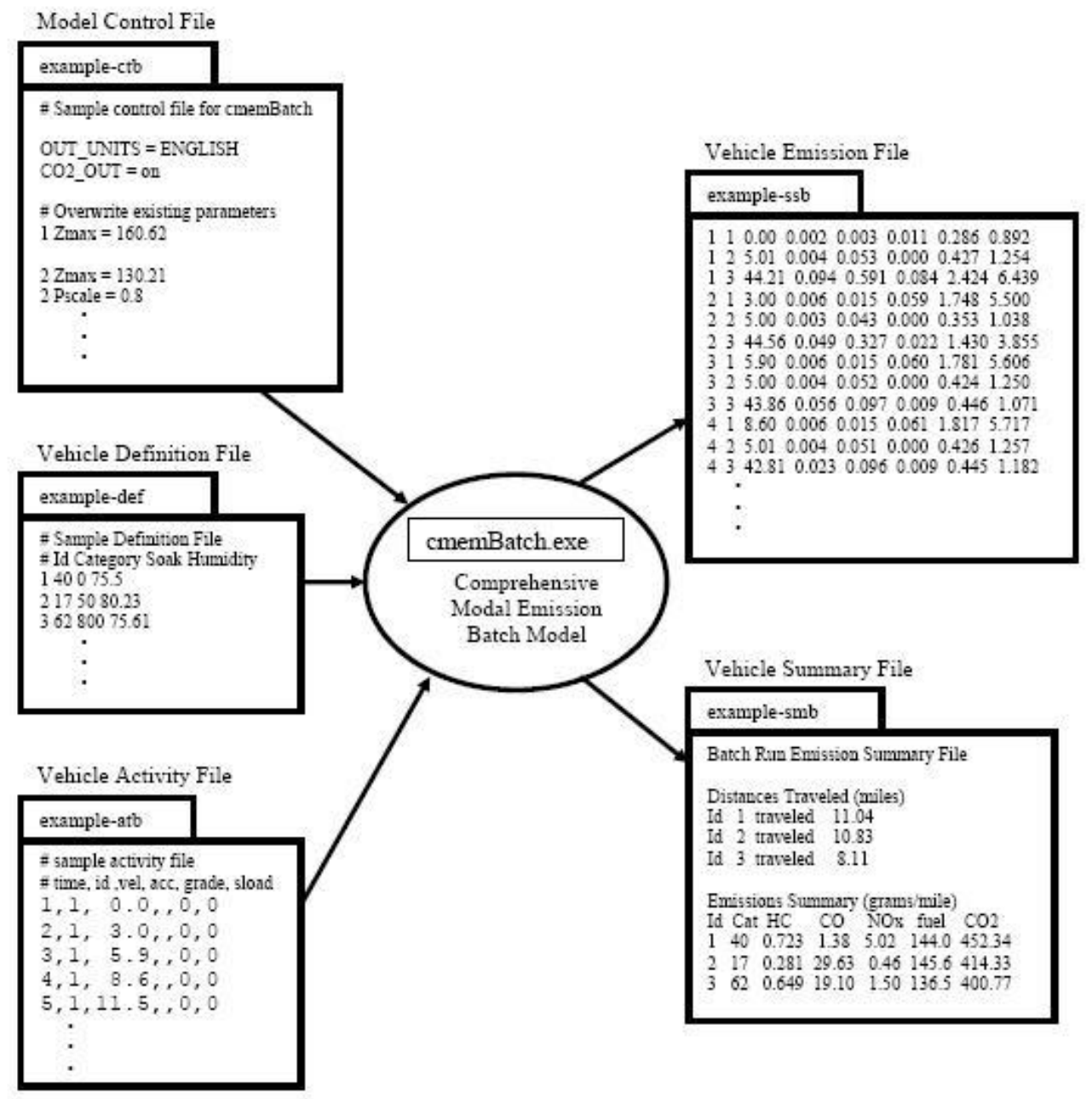

Figure 5.15: Outline of the Selected Version of the Comprehensive Modal Emissions Model Used for Modeling Emissions During Cal Poly's AM Peak Hour (Scora 2006) 
As seen in the figure, an executable file takes the inputs of three text files (Model Control File, Vehicle Definition File and Vehicle Activity file) to generate two output text files (Vehicle Emission File and Vehicle Summary File). An additional output text file, the Model Run file (not shown), contains a summary of all settings and parameters used. The Model Control input file is used for inputting run settings such as units of measure, which emissions to output, and any newly created or modified vehicle categories or parameters. The Vehicle Definition file contains a listing of all vehicles used in the model as well as their corresponding CMEM vehicle category, soak time, and humidity levels. The Vehicle Activity file contains second-by-second data on vehicle activities as obtained from simulation. These activities include current speed, acceleration, grade, and secondary loads (e.g. A/C) present. The Vehicle Emission file contains second-by-second emissions data in a time \& vehicle ordered format. The Vehicle Summary file contains a summary of miles traveled per vehicle and emissions generated per mile.

\subsubsection{Vehicle Category Mapping}

In order to create a valid Vehicle Definition input file, it is necessary to adopt CMEM vehicle categories. Table 5.22 below shows the vehicle categories used in the current version of CMEM.

Adopting CMEM categories is accomplished by mapping the vehicle types used in VISSIM to suitable matches in CMEM. A heuristic approach is used for the mapping process according to the following steps:

1. Determine which CMEM vehicle categories match specific VISSIM vehicle types

2. For each VISSIM vehicle type, determine the splits (percentage) of vehicles likely to belong to each CMEM vehicle category

3. Based on simulation output, create a unique list of all vehicles from the current simulation run

4. Apply the splits of vehicles for each VISSIM category to determine which CMEM vehicle category each vehicle in the unique list is assigned to

5. Apply these assignments to the Vehicle Definition input file 
Table 5.22: Vehicle Categories in CMEM v3.01

\begin{tabular}{|c|c|c|c|c|}
\hline \multicolumn{5}{|c|}{ Vehicle Categories in CMEM v3.01 } \\
\hline & Category\# & Vehicle Type & Title & Description \\
\hline \multirow{12}{*}{ 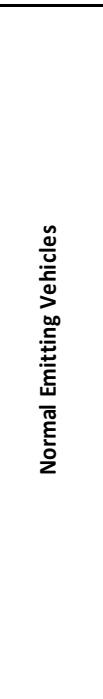 } & 1 & Cars/Trucks & No Catalyst & All cars/trucks made between 1972-1974, <8500 GVW \\
\hline & 2 & Cars/Trucks & 2-way Catalyst & All cars/trucks made between 1975-1979, <8500 GVW \\
\hline & 3 & Cars & 3-way Catalyst, Carbureted & $\begin{array}{l}\text { Some cars made between 1981-1990; decreasing gradually over } \\
\text { the years }\end{array}$ \\
\hline & 4 & Cars & $\begin{array}{l}\text { 3-way Catalyst, FI, high miles, low } \\
\text { power/weight }\end{array}$ & power/weight $<0.039 \mathrm{hp} / \mathrm{lb},>50 \mathrm{k}$ miles, $1981-1993$ model years \\
\hline & 5 & Cars & $\begin{array}{l}\text { 3-way Catalyst, Fl, high miles, high } \\
\text { power/weight }\end{array}$ & power/weight $>0.039 \mathrm{hp} / \mathrm{lb},>50 \mathrm{k}$ miles, $1981-1993$ model years \\
\hline & 6 & Cars & $\begin{array}{l}\text { 3-way Catalyst, FI, low miles, low } \\
\text { power/weight }\end{array}$ & power/weight $<0.039 \mathrm{hp} / \mathrm{lb},<50 \mathrm{k}$ miles, $1981-1993$ model years \\
\hline & 7 & Cars & $\begin{array}{l}\text { 3-way Catalyst, FI, low miles, high } \\
\text { power/weight }\end{array}$ & power/weight $>0.039 \mathrm{hp} / \mathrm{lb},<50 \mathrm{k}$ miles, $1981-1993$ model years \\
\hline & 8 & Cars/Trucks & Tier 1, high miles, low power/weight & $\begin{array}{l}\text { 1994-present model years; trucks less than } 3750 \mathrm{GVW},>50 \mathrm{k} \\
\text { miles, power/weight }<0.042 \mathrm{hp} / \mathrm{lb}\end{array}$ \\
\hline & 9 & Cars/Trucks & Tier 1, high miles, high power/weight & $\begin{array}{l}\text { 1994-present model years; trucks less than } 3750 \mathrm{GVW},>50 \mathrm{k} \\
\text { miles, power/weight }>0.042 \mathrm{hp} / \mathrm{lb}\end{array}$ \\
\hline & 10 & Cars/Trucks & Tier 1, low miles, low power/weight & $\begin{array}{l}\text { 1994-present model years; trucks less than } 3750 \mathrm{GVW},<50 \mathrm{k} \\
\text { miles, power/weight }<0.042 \mathrm{hp} / \mathrm{lb}\end{array}$ \\
\hline & 11 & Cars/Trucks & Tier 1, low miles, high power/weight & $\begin{array}{l}\text { 1994-present model years; trucks less than } 3750 \mathrm{GVW},<50 \mathrm{k} \\
\text { miles, power/weight }>0.042 \mathrm{hp} / \mathrm{lb}\end{array}$ \\
\hline & 24 & Cars/Trucks & Tier 1 , super high mileage & $\begin{array}{l}\text { 1994-present model years; }>100 k \text { miles regardless of weight or } \\
\text { power/weight ratio }\end{array}$ \\
\hline \multirow{2}{*}{ 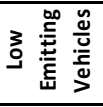 } & 26 & Cars & Ultra Low Emission Vehicles & Per Certification \\
\hline & 27 & Cars & Super Ultra Low Emission Vehicles & Per Certification \\
\hline \multirow{9}{*}{ 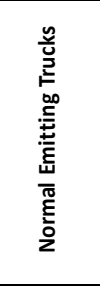 } & 12 & Trucks & Pre 1979 & \\
\hline & 13 & Trucks & $1979-1983$ & $<8500$ GVW \\
\hline & 14 & Trucks & $1984-1987$ & $<8500$ GVW \\
\hline & 15 & Trucks & 1988-1993 & $<3750$ LVW \\
\hline & 16 & Trucks & 1988-1993 & $>3750$ LVW \\
\hline & 17 & Trucks & Tier 1 Truck, LDT $2 / 3$ & 3750-5750 LVW or Alt LVW \\
\hline & 18 & Trucks & Tier 1 Truck, LDT 4 & 6001-8500 GVW, >5750 Alt LVW \\
\hline & 25 & Trucks & Truck, Gasoline Powered, $>8500$ GVW & \\
\hline & 40 & Trucks & Truck, Diesel Powered, >8500 GVW & \\
\hline \multirow{5}{*}{ 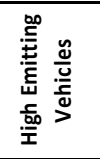 } & 19 & Cars/Trucks & Runs lean & \\
\hline & 20 & Cars/Trucks & Runs rich & \\
\hline & 21 & Cars/Trucks & Misfire & \\
\hline & 22 & Cars/Trucks & Bad catalyst & \\
\hline & 23 & Cars/Trucks & Runs very rich & \\
\hline
\end{tabular}

Steps $1 \& 2$ are summarized below in Table 5.23 and Table 5.24. Table 5.23 shows the matching vehicle

categories and splits while Table 5.24 shows the balance of vehicles fitting each VISSIM and CMEM

category. Steps 3-4 are computed in Excel for each simulation run. Due to the numerous quantities of data in these files, it is not feasible to include them in this report. A sample of one of these is available in

Appendix K with the accompanying formulas used. 
Table 5.23: Vehicle Mapping Splits for Cal Poly's AM Peak Hour

\begin{tabular}{|c|c|c|c|c|c|}
\hline \multicolumn{6}{|c|}{ Vehicle Mapping Splits } \\
\hline \multirow{2}{*}{\multicolumn{2}{|c|}{$\frac{\text { VISSIM Vehicle Category 1- }}{\text { Economy/Hybrid }}$}} & \multicolumn{2}{|c|}{ VISSIM Vehicle Category 4-Full Size } & \multicolumn{2}{|c|}{ VISSIM Vehicle Category 7-Truck } \\
\hline & & CMEM Category & Split of Volume & CMEM Category & Split of Volume \\
\hline CMEM Category & Split of Volume & 4 & $2 \%$ & 8 & $4 \%$ \\
\hline 26 & $70 \%$ & 5 & $2 \%$ & 9 & $4 \%$ \\
\hline \multirow[t]{2}{*}{27} & $30 \%$ & 6 & $0.5 \%$ & 10 & $3.5 \%$ \\
\hline & & 7 & $0.5 \%$ & 11 & $3.5 \%$ \\
\hline \multicolumn{2}{|c|}{ VISSIM Vehicle Category 2-Compact } & 8 & $9 \%$ & 15 & $3 \%$ \\
\hline CMEM Category & Split of Volume & 9 & $9 \%$ & 16 & $2 \%$ \\
\hline 4 & $4 \%$ & 10 & $8.5 \%$ & 17 & $25 \%$ \\
\hline 6 & $1 \%$ & 11 & $8.5 \%$ & 18 & $4 \%$ \\
\hline 8 & $20 \%$ & 24 & $50 \%$ & 24 & $40 \%$ \\
\hline 10 & $5 \%$ & $19-23$ & $10 \% ; 2 \%$ each & 25 & $0.5 \%$ \\
\hline 24 & $35 \%$ & & & 40 & $0.5 \%$ \\
\hline 26 & $20 \%$ & \multicolumn{2}{|c|}{ VISSIM Vehicle Category 5-Small SUV } & $19-23$ & $10 \% ; 2 \%$ each \\
\hline 27 & $5 \%$ & CMEM Category & Split of Volume & & \\
\hline \multirow[t]{2}{*}{$19-23$} & $10 \% ; 2 \%$ each & 8 & $15 \%$ & \multicolumn{2}{|c|}{ VISSIM Vehicle Category 8-Sport } \\
\hline & & 10 & $15 \%$ & CMEM Category & Split of Volume \\
\hline \multicolumn{2}{|c|}{ VISSIM Vehicle Category 3-Mid Size } & 15 & $7 \%$ & 5 & $4 \%$ \\
\hline CMEM Category & Split of Volume & 16 & $3 \%$ & 7 & $1 \%$ \\
\hline 4 & $2 \%$ & 17 & $10 \%$ & 9 & $25 \%$ \\
\hline 5 & $2 \%$ & 24 & $40 \%$ & 11 & $10 \%$ \\
\hline 6 & $0.5 \%$ & $19-23$ & $10 \% ; 2 \%$ each & 24 & $50 \%$ \\
\hline 7 & $0.5 \%$ & & & $19-23$ & $10 \% ; 2 \%$ each \\
\hline 8 & $10 \%$ & \multicolumn{2}{|c|}{ VISSIM Vehicle Category 6-Large SUV } & & \\
\hline 9 & $10 \%$ & CMEM Category & Split of Volume & \multirow{2}{*}{\multicolumn{2}{|c|}{$\frac{\text { VISSIM Vehicle Category 9- }}{\text { Wagon/Crossover/Van }}$}} \\
\hline 10 & $10 \%$ & 16 & $5 \%$ & & \\
\hline 11 & $10 \%$ & 17 & $30 \%$ & CMEM Category & Split of Volume \\
\hline 24 & $45 \%$ & 18 & $5 \%$ & 4 & $8 \%$ \\
\hline \multirow[t]{5}{*}{$19-23$} & $10 \% ; 2 \%$ each & 24 & $50 \%$ & 6 & $2 \%$ \\
\hline & & $19-23$ & $10 \% ; 2 \%$ each & 8 & $20 \%$ \\
\hline & & & & 10 & $10 \%$ \\
\hline & & & & 24 & $50 \%$ \\
\hline & & & & $19-23$ & $10 \% ; 2 \%$ each \\
\hline
\end{tabular}

Table 5.24: Balance of Vehicle Type Categories in VISSIM and CMEM

\begin{tabular}{|c|c|c|c|c|c|c|c|c|c|c|c|c|c|c|c|c|c|c|c|c|c|c|c|c|c|c|c|c|c|c|c|}
\hline \multicolumn{32}{|c|}{ Balance of Categories After Vehicle Mapping } \\
\hline & & \multicolumn{28}{|c|}{ CMEM Category } & & \multirow[b]{2}{*}{$\begin{array}{l}\text { \% of } \\
\text { Total }\end{array}$} \\
\hline & & 1 & 2 & 3 & 4 & 5 & 6 & 7 & 8 & 9 & 10 & 11 & 12 & 13 & 14 & 15 & 16 & 17 & 18 & 19 & 20 & 21 & 22 & 23 & 24 & 25 & 26 & \begin{tabular}{l|l}
27 & 4 \\
\end{tabular} & & & \\
\hline \multirow{9}{*}{\begin{tabular}{|} 
VISSIM \\
Category
\end{tabular}} & 1 & 0 & 0 & 0 & 0 & 0 & 0 & 0 & 0 & 0 & 0 & 0 & 0 & 0 & 0 & 0 & 0 & 0 & 0 & 0 & 0 & 0 & 0 & 0 & 0 & 0 & \begin{tabular}{l|l}
68 & 1
\end{tabular} & \begin{tabular}{l|l}
160 \\
\end{tabular} & & 228 & $4.60 \%$ \\
\hline & 2 & 0 & 0 & 0 & 53 & 0 & 13 & 0 & 266 & 0 & 67 & 0 & 0 & 0 & 0 & 0 & 0 & 0 & 0 & 27 & 27 & 27 & 27 & 27 & 466 & $\begin{array}{ll}02 \\
02\end{array}$ & 266 & 67 & 0 & 1332 & $26.85 \%$ \\
\hline & 3 & 0 & 0 & 0 & 21 & 21 & 5 & 5 & 106 & 106 & 106 & 106 & 0 & 0 & 0 & 0 & 0 & 0 & 0 & 21 & 21 & 21 & 21 & 21 & 478 & 0 & 0 & 0 & 0 & 1063 & $21.43 \%$ \\
\hline & 4 & 0 & 0 & 0 & 3 & 3 & 1 & 1 & 14 & 14 & 14 & 14 & 0 & 0 & 0 & 0 & 0 & 0 & 0 & 3 & 3 & 3 & 3 & 3 & 69 & 0 & 0 & 0 & 0 & 145 & $2.92 \%$ \\
\hline & 5 & 0 & 0 & 0 & 0 & 0 & 0 & 0 & 112 & 0 & 112 & 7 & 0 & 0 & 0 & 52 & 22 & 75 & 0 & 15 & 15 & 15 & 15 & 15 & 298 & 0 & 0 & 0 & & 745 & $15.02 \%$ \\
\hline & 6 & 0 & 0 & 0 & 0 & 0 & 0 & 0 & 0 & 0 & 0 & 0 & 0 & 0 & 0 & 0 & 8 & 49 & 8 & 3 & 3 & 3 & 3 & 3 & 81 & 0 & 0 & 0 & 0 & 162 & \begin{tabular}{|l|}
$3.27 \%$ \\
\end{tabular} \\
\hline & 7 & 0 & 0 & 0 & 0 & 0 & 0 & 0 & 29 & 29 & 26 & 26 & 0 & 0 & 0 & 22 & 15 & 182 & 29 & 15 & 15 & 15 & 15 & 15 & 292 & 4 & 0 & 0 & 4 & 729 & $14.69 \%$ \\
\hline & 8 & 0 & 0 & 0 & 0 & 8 & 0 & 2 & 0 & 52 & 0 & 21 & 0 & 0 & 0 & 0 & 0 & 0 & 0 & 4 & 4 & 4 & 4 & 4 & 105 & 0 & 0 & 0 & 0 & 209 & $4.21 \%$ \\
\hline & 9 & 0 & 0 & 0 & 28 & 0 & 7 & 0 & 70 & 0 & 35 & 0 & 0 & 0 & 0 & 0 & 0 & 0 & 0 & 7 & 7 & 7 & 7 & 7 & 174 & 0 & 0 & 0 & 0 & 348 & 7.019 \\
\hline \multicolumn{2}{|c|}{ Total Vehicles } & 0 & 0 & 0 & 105 & 32 & 26 & 8 & 597 & 202 & 359 & 167 & & 0 & 0 & 74 & 45 & 305 & 37 & 95 & 95 & 95 & 95 & 95 & 1963 & \begin{tabular}{l|l}
4 & 3 \\
\end{tabular} & \begin{tabular}{l|l}
335 & 2 \\
\end{tabular} & 226 & 4 & & \\
\hline \multicolumn{2}{|l|}{$\%$ of Total } & $0.0 \%$ & $0.0 \% 0$ & $0.0 \% 2$ & $2.1 \%$ & $0.7 \%$ & $0.5 \%$ & $0.2 \%$ & $12.0 \%$ & $4.1 \% 7$ & $7.2 \% 3$ & $3.4 \%$ & $0.0 \% 10$ & $0.0 \% 10$ & $0.0 \% 1$ & $1.5 \% 0$ & $0.9 \% 6$ & $\begin{array}{ll}6.2 \% & 0 .\end{array}$ & $0.8 \% 1$. & $\begin{array}{l}1.9 \% \\
1 .\end{array}$ & $1.9 \% 1$ & $1.9 \% \mid 1$. & $1.9 \% 1$ & $1.9 \% / 3$ & $39.6 \% 0$ & $0.1 \% 6$. & $6.7 \%$. 4. & \begin{tabular}{l|l}
$4.6 \%$ & 0.1 \\
\end{tabular} & $.1 \%$ & & \\
\hline
\end{tabular}




\subsubsection{Generation of CMEM Results}

In order to generate proper emission data in CMEM, the following procedure (including vehicle category mapping) is used for each simulation run:

1. In VISSIM, enable evaluation by Vehicle Record. Configure the evaluation file to record data on a second-by-second basis and to include data fields for time, vehicle ID, vehicle category and category number, speed, acceleration, and gradient.

2. Run the simulation

3. Open the output file (.fzp)

4. Copy vehicle data to create a separate file for vehicle category mapping

5. In this separate file, filter data to obtain a unique list of vehicles involved in the simulation

6. Map vehicles from VISSIM categories to CMEM categories by applying the defined splits

7. Add additional columns and fill these with soak time and humidity values

8. Copy data for vehicle number, CMEM category, soak time, and humidity to a text file and save as a Vehicle Definition File

9. Eliminate the columns for vehicle category in the original output file

10. Add a column to this file and fill it with data on secondary load values

11. Sort data according to time order first, and vehicle ID order second

12. Copy data for time, vehicle ID, velocity, acceleration, gradient, and secondary load to a text file and save as a Vehicle Activity File

13. Create a separate text file and save as a Model Control File. Write to this file settings for the simulation

14. Add headers to the Vehicle Definition and Vehicle Activity files

15. Run the CMEM model in batch mode

16. Open the Vehicle Emissions Summary file (-smb)

17. Multiply miles traveled per vehicle by emissions generated per mile

18. Sum data over all vehicles to obtain emissions levels in grams per mile 


\subsubsection{Assumptions}

In using CMEM for emissions modeling, the following assumptions are made:

- Secondary load is equal to "1". Defined in CMEM as a binary, secondary loads are either applied or not applied to each vehicle. A value of " 1 " indicates secondary loads are present for the vehicle (e.g. A/C, heater) and are applied based on statistics for the vehicle type

- For mapping, vehicles are assigned a random number based on a random number generator. This random number is looked up in an array to determine a VISSIM vehicle's CMEM vehicle category based on previously defined vehicle mapping splits. It is assumed that the random number generator in Excel is truly random.

- Soak time (minutes) is randomly distributed between 0 and 1440 . Soak time describes the time since the vehicle was last used where a zero value is equivalent to a hot stabilized operation and 1440 is equivalent to a cold start.

- Humidity is assumed to be "75" for all vehicles. A value of "75" is the default value in CMEM and represents operating conditions at 75 degrees and $40 \%$ humidity. This assumption has an affect on emissions of nitrous oxides.

- Default vehicle categories and associated parameters for CMEM are used

- All gradients are set to zero. Therefore, the Cal Poly network is assumed to be flat. 


\section{Results}

\subsection{Initial Findings}

A total of ten simulations based on ten random seeds are run for Cal Poly's AM Peak Hour in both VISSIM and then CMEM. The VISSIM portion of these simulations runs off the same random seeds used in calibration and validation, but with updated volumes. The data is then parsed through Excel for input to CMEM. CMEM's outputs are then summarized and recorded. Table 6.1 shows the quantity of fuel consumed and each type pollutant type ( $\mathrm{HC}, \mathrm{CO}, \mathrm{NOx})$ emitted for each of the ten random seeds as well as the average, minimum, and maximum values.

\section{Table 6.1: Summary of Total Emissions for Cal Poly's AM Peak Hour}

\begin{tabular}{|l|r|r|r|r|}
\hline \multicolumn{5}{|c|}{ Summary of Total Emissions for Cal Poly AM Peak Hour (7:30AM-8:30AM) } \\
\hline Description & \multicolumn{1}{|l|}{ HC (g) } & \multicolumn{1}{l|}{ CO (g) } & NOx (g) & Fuel Used (g) \\
\hline Random Seed 42 & 7,899 & 99,778 & 7,818 & 459,741 \\
\hline Random Seed 13 & 7,954 & 100,134 & 8,047 & 437,277 \\
\hline Random Seed 24 & 7,755 & 95,641 & 7,709 & 419,332 \\
\hline Random Seed 500 & 7,634 & 95,978 & 7,971 & 427,265 \\
\hline Random Seed 6 & 7,808 & 95,724 & 7,942 & 426,537 \\
\hline Random Seed 2 & 7,839 & 96,511 & 7,852 & 436,597 \\
\hline Random Seed 266 & 7,401 & 91,378 & 7,526 & 390,937 \\
\hline Random Seed 681 & 7,603 & 96,327 & 7,877 & 423,037 \\
\hline Random Seed 67 & 7,853 & 99,118 & 7,878 & 449,183 \\
\hline Random Seed 52 & 7,643 & 94,415 & 7,822 & 414,065 \\
\hline & & & & \\
\hline Minimum & 7,401 & 91,378 & 7,526 & 390,937 \\
\hline Average & $\mathbf{7 , 7 3 9}$ & $\mathbf{9 6 , 5 0 0}$ & $\mathbf{7 , 8 4 4}$ & $\mathbf{4 2 8 , 3 9 7}$ \\
\hline Maximum & 7,954 & 100,134 & 8,047 & 459,741 \\
\hline
\end{tabular}




\subsection{Statistics}

\subsubsection{Number of Runs}

Based on these runs, the number of runs required to determine a suitable confidence level for each performance metric is calculated using the following equation in Figure 6.1:

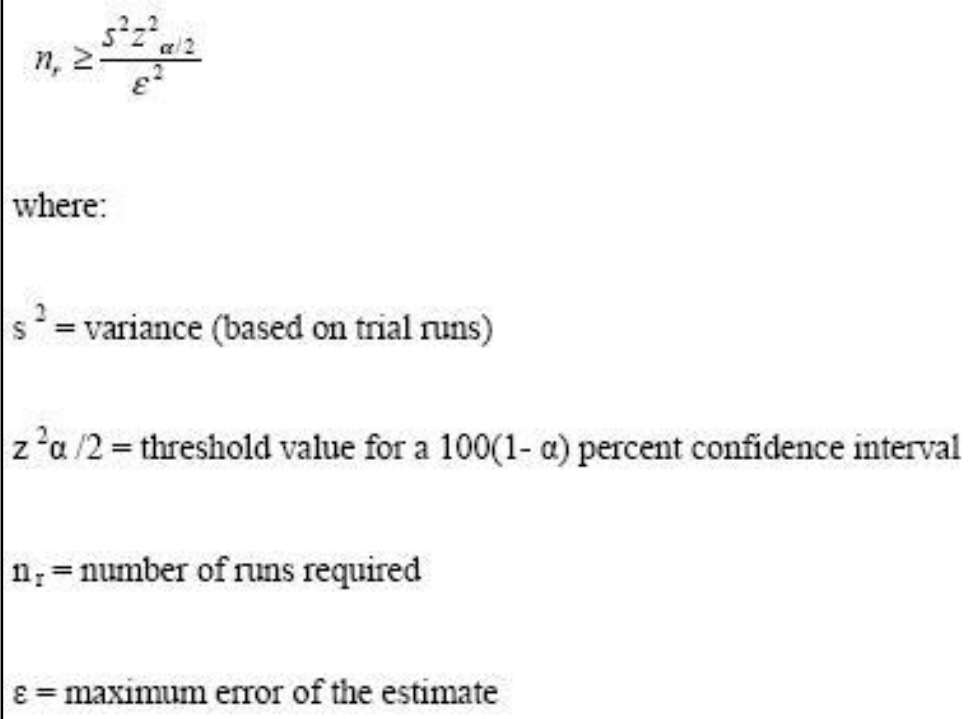

Figure 6.1: Formula for Calculating the Sufficient Number of Runs for Simulation (Harrell 2004)

This calculation is used for each performance metric. For all performance metrics, a 95\% confidence level $(\alpha / 2=0.0025, \alpha=0.05)$ is chosen which corresponds to a $z$-value of 1.96 . The maximum error of the estimate $(\varepsilon)$ is assumed to be $3 \%$ of the mean for each performance metric. The number of runs resulting from each calculation is rounded up to the nearest whole number.

As seen in Table 6.2, the minimum number of runs calculated for HC, CO, NOx, and Fuel Used are 2, 4, 2, and 9, respectively. Since all of these values are less than ten, the ten runs previously used should be sufficient to create a $95 \%$ confidence interval for each of the performance metrics. 
Table 6.2: Calculation of the Sufficient Number of Runs for Simulation by Performance Metric

\begin{tabular}{|l|r|r|r|r|}
\hline \multicolumn{5}{|c|}{ Calculating Sufficient Number of Runs } \\
\hline Emission Type & HC $(\mathrm{g})$ & CO $(\mathrm{g})$ & NOx $(\mathrm{g})$ & Fuel Used $(\mathrm{g})$ \\
\hline Average & 7,739 & 96,500 & 7,844 & 428,397 \\
\hline Standard Deviation $(\mathrm{g})$ & 167 & 2,646 & 145 & 19,105 \\
\hline Variance $\left(\mathrm{g}^{2}\right)$ & 28025 & 7003527 & 21083 & 364993436 \\
\hline $\mathrm{z}_{(\alpha / 2)}$ for $95 \%$ confidence level & 1.96 & 1.96 & 1.96 & 1.96 \\
\hline $\mathrm{z}_{(\alpha / 2)}$ for $95 \%$ confidence level & 3.8416 & 3.8416 & 3.8416 & 3.8416 \\
\hline$\varepsilon(\mathrm{g})$ & 232.16 & 2895.01 & 235.33 & 12851.91 \\
\hline Number of Runs Required $\left(\mathrm{n}_{\mathrm{r}}\right)$ & 2.00 & 3.21 & 1.46 & 8.49 \\
\hline Number of Runs Required $\left(\mathrm{n}_{\mathrm{r}}\right)$ Rounded & 2 & 4 & 2 & 9 \\
\hline
\end{tabular}

\subsubsection{T-Test of Confidence Intervals}

Given previous calculations, $95 \%$ confidence intervals are generated based off the original 10 runs. A t-test for confidence intervals is chosen because of the small sample sizes $(n=10)$ for each performance metric and because the means and standard deviations of each population are unknown. Using Minitab statistical software, the confidence intervals for each performance metric are generated as seen below in Figure 6.2.

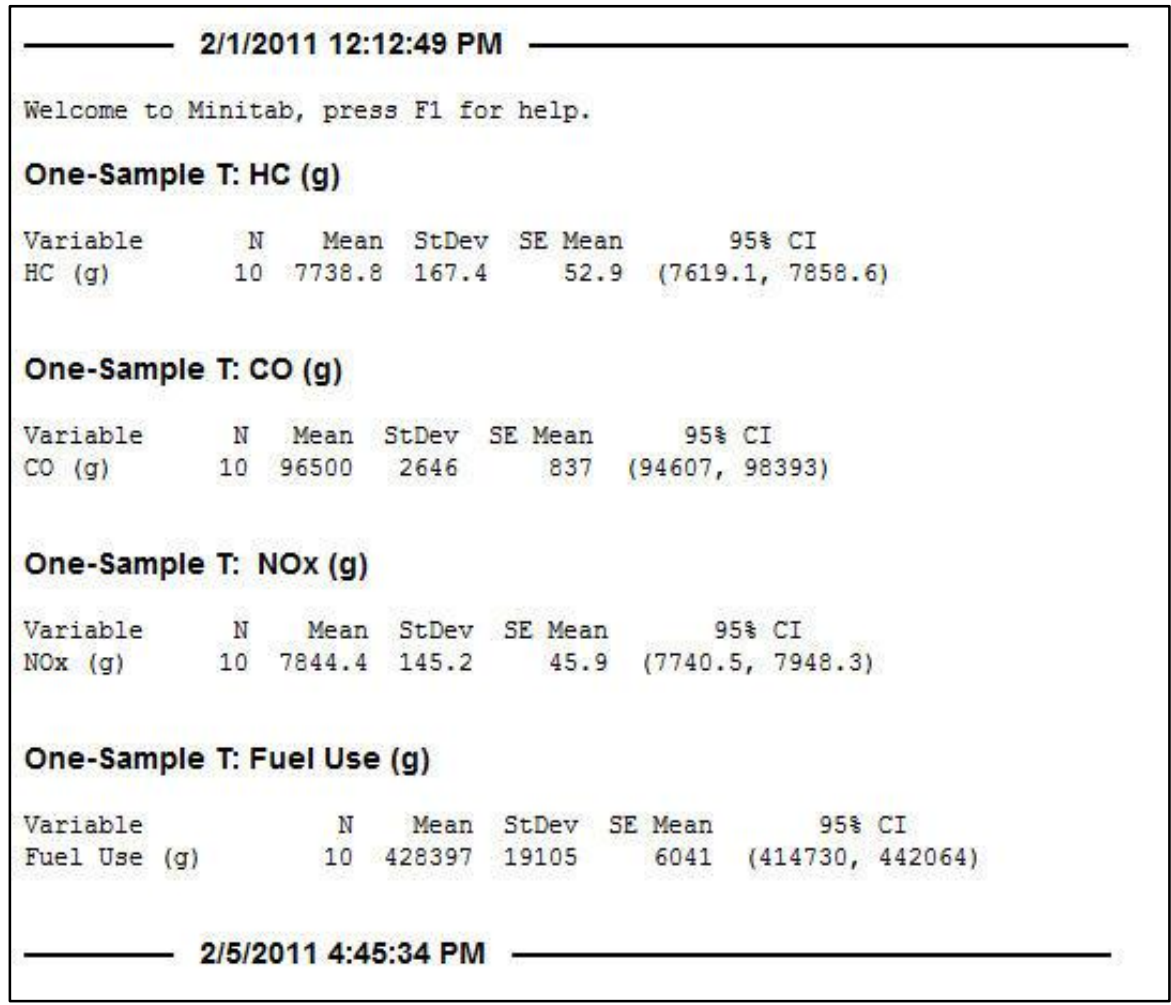

Figure 6.2: T-Test Confidence Intervals of Means for Performance Metrics 


\subsection{Analysis by Emission Type}

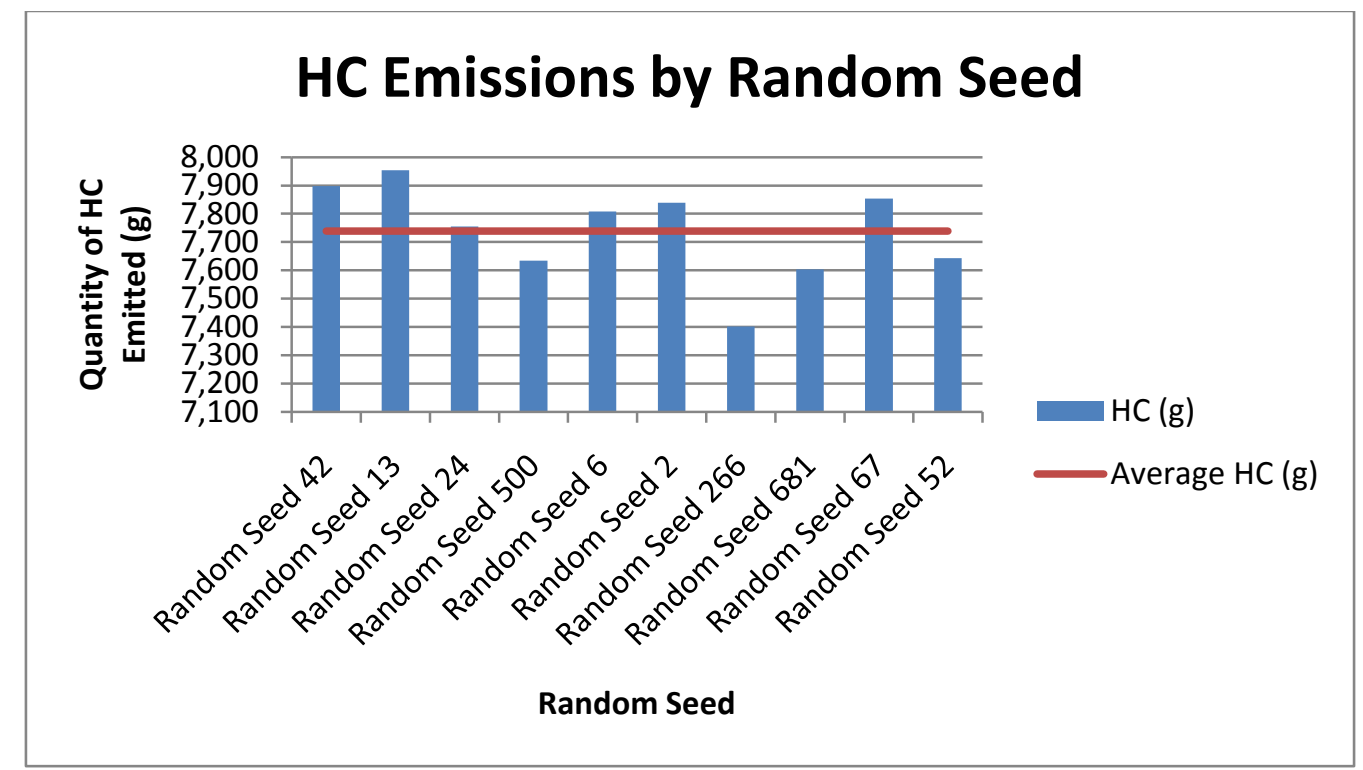

Figure 6.3: Bar Graph of HC Emissions by Random Seed

Figure 6.3 shows the $\mathrm{HC}$ emissions generated by each of the random seeds. Hydrocarbons are a type of volatile organic compound (VOC) which influences the development of ozone compounds in the lower atmosphere. Approximately 50\% of $\mathrm{HC}$ emissions nationally are sourced from motor vehicles. The quantity of hydrocarbons (HCs) emitted during an average Cal Poly AM Peak hour ranges from approximately 7,400-7,950 grams with an average of a little above 7,700 grams. Based on the t-test for confidence intervals, the true mean is $95 \%$ likely to be between 7,619-7,858 grams.

On a vehicle-trip basis, the average $\mathrm{HC}$ emissions during the AM Peak Hour equates to about 3.5 grams per vehicle-trip. Using the rule of thumb that the peak hour typically constitutes $10 \%$ of daily demand, the quantity of HCs emitted on an average weekday at Cal Poly could be about 74,000-80,000 grams. 


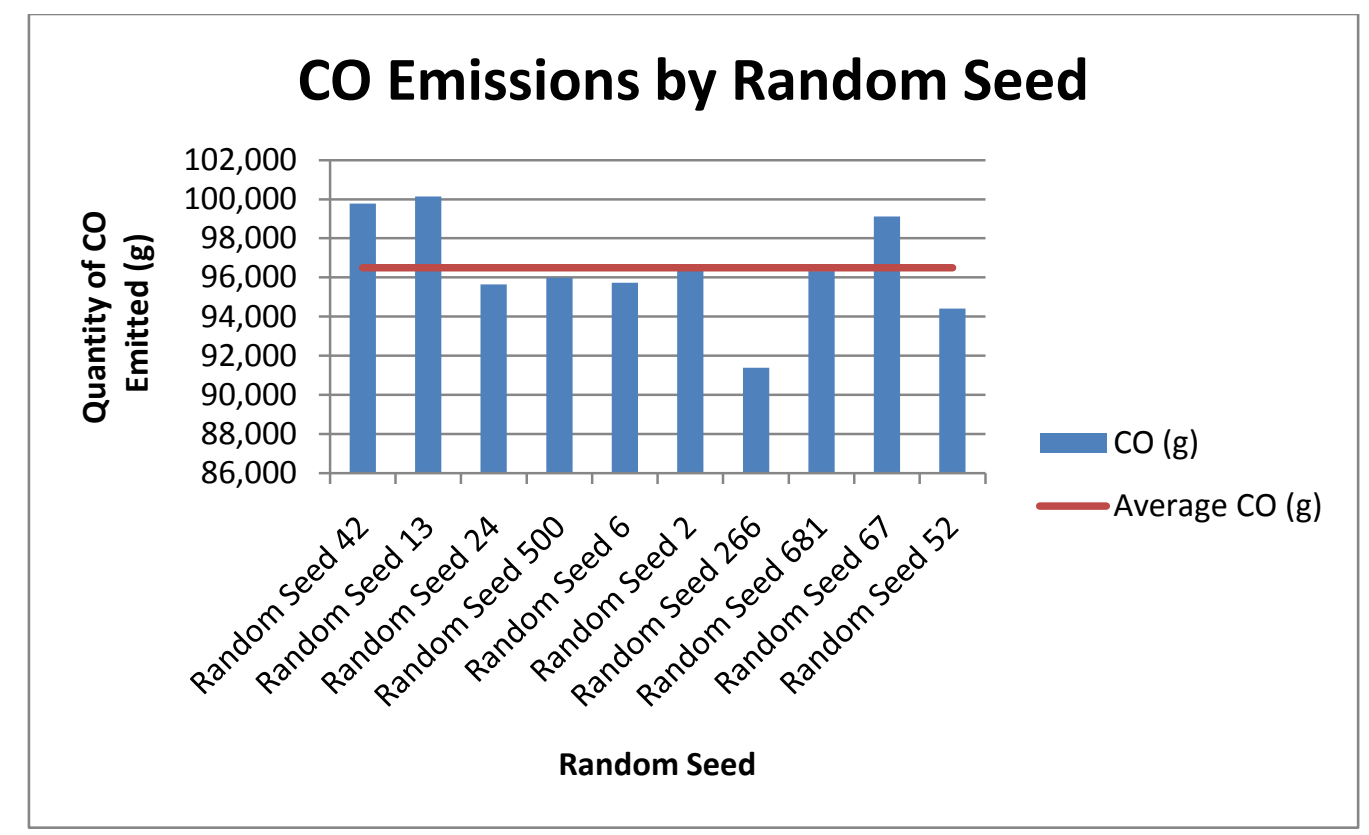

\section{Figure 6.4: Bar Graph of CO Emissions by Random Seed}

Figure 6.4 shows the $\mathrm{CO}$ emissions generated by each of the random seeds. Carbon monoxide is a criteria pollutant that immediately affects the atmosphere. Approximately $60 \%$ of $\mathrm{CO}$ emissions nationally are sourced from on-road motor vehicles. The quantity of carbon monoxide emitted during an average Cal Poly AM Peak hour ranges from approximately 91,400-100,100 grams with an average of approximately 96,500 grams. Based on the t-test for confidence intervals, the true mean is $95 \%$ likely to be between 94,607-98,393 grams.

On a vehicle-trip basis, the average $\mathrm{CO}$ emissions during the AM Peak Hour equates to about 44 grams per vehicle-trip. Using the rule of thumb that the peak hour typically constitutes $10 \%$ of daily demand, the quantity of carbon monoxide emitted on an average weekday at Cal Poly could be about 941,000-1,001,000 grams. 


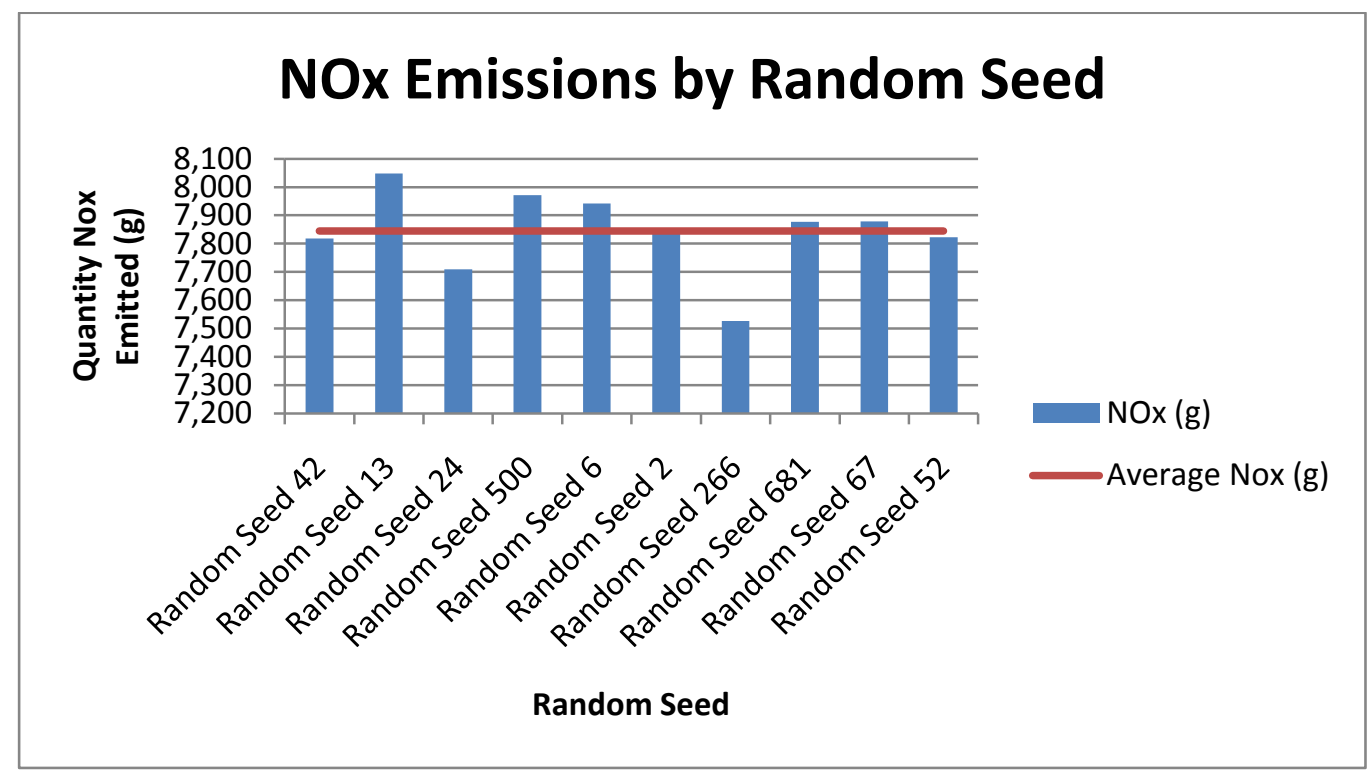

Figure 6.5: Bar Graph of $\mathrm{NO}_{\mathrm{x}}$ Emissions by Random Seed

Figure 6.5 shows the $\mathrm{NO}_{\mathrm{x}}$ (nitrogenous oxide) emissions generated by each of the random seeds. Nitrogen monoxide in particular, is a criteria pollutant that immediately affects the atmosphere. Approximately $30 \%$ of $\mathrm{NO}_{\mathrm{x}}$ emissions nationally are sourced from on-road motor vehicles. The quantity of nitrogenous oxides emitted during an average Cal Poly AM Peak hour ranges from approximately 7,550-8,050 grams with an average of approximately 7,850 grams. Based on the t-test for confidence intervals, the true mean is $95 \%$ likely to be between 7,740-7,948 grams.

On a vehicle-trip basis, the average $\mathrm{NO}_{\mathrm{x}}$ emissions during the AM Peak Hour equates to about 3.6 grams per vehicle-trip. Using the rule of thumb that the peak hour typically constitutes $10 \%$ of daily demand, the quantity of nitrogenous oxides emitted on an average weekday at Cal Poly could be about 77,400-79,480 grams. 


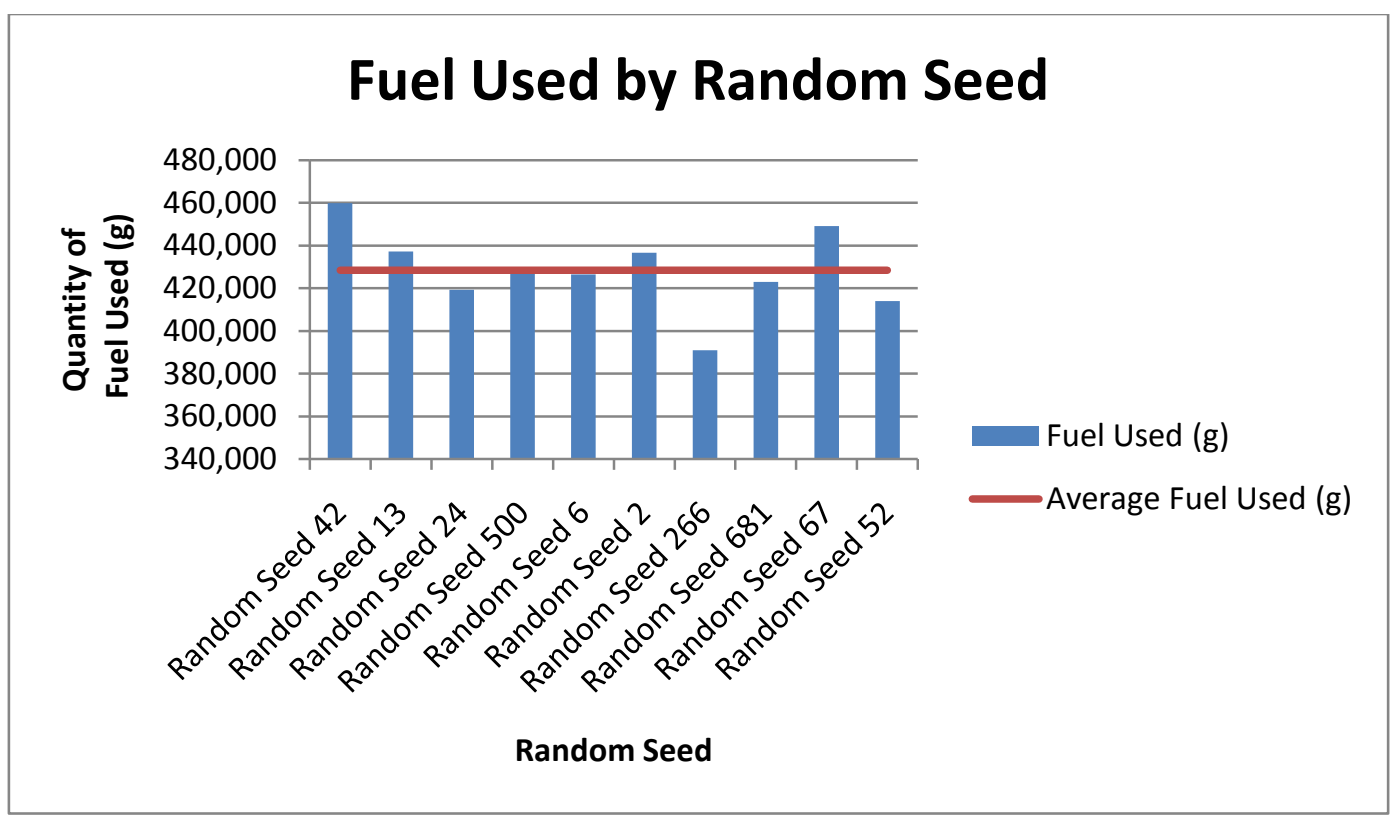

Figure 6.6: Bar Graph of Fuel Consumption by Random Seed

Figure 6.6 shows the total fuel consumption generated by each of the random seeds. The quantity of fuel consumed is an important factor in the efficiency of any internal combustion engine. Depending on the mixture of air and fuel, the internal combustion process is the key to both vehicle performance and emissions. The quantity of fuel consumed during an average Cal Poly AM Peak hour ranges from approximately $391,000-460,000$ grams with an average of approximately 428,500 grams. This equates to approximately 151 gallons consumed. Based on the t-test for confidence intervals, the true mean is $95 \%$ likely to be between 414,730-442,064 grams (146-156 gallons).

On a vehicle-trip basis, the average fuel consumption during the AM Peak Hour equates to about 197 grams per vehicle-trip. This equates to approximately 0.07 gallons per vehicle trip, assuming the density of 0.75 grams per cubic centimeter for 87 octane gasoline. Using the rule of thumb that the peak hour typically constitutes $10 \%$ of daily demand, the quantity of fuel consumed on an average weekday at Cal Poly could be about 3,910,000-4,600,000 grams (1377-1620 gallons). 


\subsection{Total Emissions \& Analysis}

Based on these simulation runs and all assumptions made, the total quantity of emissions ( $\mathrm{HCs}, \mathrm{CO}$, and $\mathrm{NO}_{\mathrm{x}}$ ) generated by transportation at Cal Poly during the AM Peak Hour is estimated to be between $106,350-116,100$ grams. Using the rule of thumb that the peak hour typically constitutes $10 \%$ of daily demand, the total quantity of emissions on an average weekday at Cal Poly could be about 1,063,500$1,161,000$ grams.

It is guessed that these totals significantly underestimate the total emissions generated by vehicles at $\mathrm{Cal}$ Poly due to the following factors:

- Not all emissions types are accounted for: This model excludes the emissions of carbon dioxide $\left(\mathrm{CO}_{2}\right)$, particulate matter (PM-5 and PM-10), sulfur oxides $\left(\mathrm{SO}_{\mathrm{x}}\right)$, and ammonia $\left(\mathrm{NH}_{4}\right)$. Although their role is not as significant as that of the types of emissions modeled, they still influence total emissions.

- Traffic during the AM Peak Hour is largely uni-directional: The AM Peak Hour is largely composed of inbound trips to Cal Poly, unlike other peak hours during the midday or evening where trips are more bi-directional. The amount of time vehicles spend in the network can increase with greater spatial density of traffic (bi-directional). Also, dwell times for stopcontrolled intersections can increase with increased multi-directional traffic due to the increased likelihood of conflicting movements.

- The impact of pedestrian traffic is largely underestimated: The impact of pedestrians crossing main campus thoroughfares is a significant impedance factor to vehicle traffic, especially when class meetings begin and end. A greater impedance increases idle times of vehicles which generate additional emissions

- In many cases, the California Blvd entrance to Cal Poly is congested to the point that not all vehicles in demand are able to enter the network: This phenomenon is commonly seen with vehicle traffic backing up to Foothill Blvd and Hathway Ave. Since vehicles enter the network at the entrance to campus, the off-campus effects of traffic and emissions are not captured.

- The slight slope of campus roads is not captured in the model. The existence of gradients on links can further increase emissions as they require vehicles to exert additional power. 


\section{Sensitivity Analysis}

Sensitivity analysis is a systematic study of how the findings of a model change with variation of key input parameters. Sensitivity analysis is important because it helps determine the dynamics of a model and relative importance of key input parameters to each other. For the simulations used to model Cal Poly's AM Peak hour, sensitivity analysis is conducted for changes in demand and changes in the share of "green" vehicles being operated.

These analyses are performed using one random seed (Random Seed \#42) which generates approximately the same driver-behavior parameters in each simulation run. The key inputs of demand and share of "green" vehicles being operated change in each scenario run, but the methodology and calculations particular to random seed \#42 remain unchanged. One random seed is chosen to establish a common basis for comparison as well as minimize the lengthy cycle time required to process multiple seeds for each scenario. 


\subsection{Demand Sensitivity}

In almost any market or economy, supply and demand are critical in accessing the value of products and services. The value of transportation, in particular, is accessed by the demand for trips and the means (roads) by which these trips can be made. Since supply is typically more fixed and difficult to change, changes in demand are very important to transportation economics and are chosen for sensitivity analysis. Furthermore, changes in demand can capture the influence many factors may have on the system.

The sensitivity of demand on vehicle emissions and fuel consumption is examined in several scenarios for Cal Poly's AM Peak Hour. A 0\% change in demand is used as a baseline case where approximately 2174 vehicle-trips are made. This corresponds to the data generated previously for random seed 42 . From there, demand is both increased and decreased by $10 \%, 20 \%$ and 50\%. Comparisons are stated as percent changes relative to the baseline because relative changes are easier to comprehend than absolute changes. The changes in each scenario are done independent of each other. Table 7.1 below shows a summary of all demand sensitivity scenarios

Table 7.1: Summary of Demand Sensitivity for Cal Poly's AM Peak Hour

\begin{tabular}{|r|r|r|r|r|}
\hline & \multicolumn{4}{|c|}{ Demand Sensitivity } \\
$\begin{array}{r}\text { \% Change in } \\
\text { Demand }\end{array}$ & $\begin{array}{l}\text { Change in HC } \\
\text { Emissions }\end{array}$ & $\begin{array}{l}\text { Change in NOx } \\
\text { Emissions }\end{array}$ & $\begin{array}{l}\text { \% Change in CO } \\
\text { Emissions }\end{array}$ & $\begin{array}{l}\text { \% Change in Fuel } \\
\text { Consumption }\end{array}$ \\
\hline$-50 \%$ & $-51.64 \%$ & $-49.57 \%$ & $-50.80 \%$ & $-56.18 \%$ \\
\hline$-20 \%$ & $-18.73 \%$ & $-16.22 \%$ & $-18.99 \%$ & $-26.66 \%$ \\
\hline$-10 \%$ & $-6.57 \%$ & $-10.22 \%$ & $-7.85 \%$ & $-15.61 \%$ \\
\hline $0 \%$ & $0.00 \%$ & $0.00 \%$ & $0.00 \%$ & $0.00 \%$ \\
\hline $10 \%$ & $5.32 \%$ & $2.99 \%$ & $1.99 \%$ & $4.04 \%$ \\
\hline $20 \%$ & $12.06 \%$ & $7.16 \%$ & $7.21 \%$ & $7.89 \%$ \\
\hline $50 \%$ & $30.20 \%$ & $27.05 \%$ & $29.68 \%$ & $77.97 \%$ \\
\hline
\end{tabular}




\subsubsection{Scenario 1: Increase Demand 10\%}

In the first scenario, Cal Poly's AM Peak Hour demand is increased by approximately $10 \%$ to 2360 vehicle-trips. This increase in demand causes an approximate 2-5\% increase in vehicle emissions and a $4 \%$ increase in fuel consumption.

\subsubsection{Scenario 2: Decrease Demand 10\%}

In the second scenario, Cal Poly's AM Peak Hour demand is decreased by approximately $10 \%$ to 1953 vehicle-trips. This decrease in demand causes an approximate 6-11\% decrease in vehicle emissions and $15 \%$ decrease in fuel consumption.

\subsubsection{Scenario 3: Increase Demand 20\%}

In the third scenario, Cal Poly's AM Peak Hour demand is increased by approximately $20 \%$ to 2607 vehicle-trips. This increase in demand causes an approximate 7-12\% increase in vehicle emissions and an $8 \%$ increase in fuel consumption.

\subsubsection{Scenario 4: Decrease Demand 20\%}

In the fourth scenario, Cal Poly's AM Peak Hour demand is decreased by approximately $20 \%$ to 1747 vehicle-trips. This decrease in demand causes an approximate 16-19\% decrease in vehicle emissions and $27 \%$ decrease in fuel consumption.

\subsubsection{Scenario 5: Increase Demand 50\%}

In the fifth scenario, Cal Poly's AM Peak Hour demand is increased by approximately 50\% to 3261 vehicle-trips. This increase in demand causes an approximate 27-30\% increase in vehicle emissions and a $78 \%$ increase in fuel consumption.

\subsubsection{Scenario 6: Decrease Demand 50\%}

In the sixth scenario, Cal Poly's AM Peak Hour demand is decreased by approximately $50 \%$ to 1087 vehicle-trips. This decrease in demand causes an approximate $49-52 \%$ decrease in vehicle emissions and $56 \%$ decrease in fuel consumption. 


\subsubsection{Overall Analysis}

The sensitivity plot in Figure 7.1 shows all six scenarios for demand sensitivity.

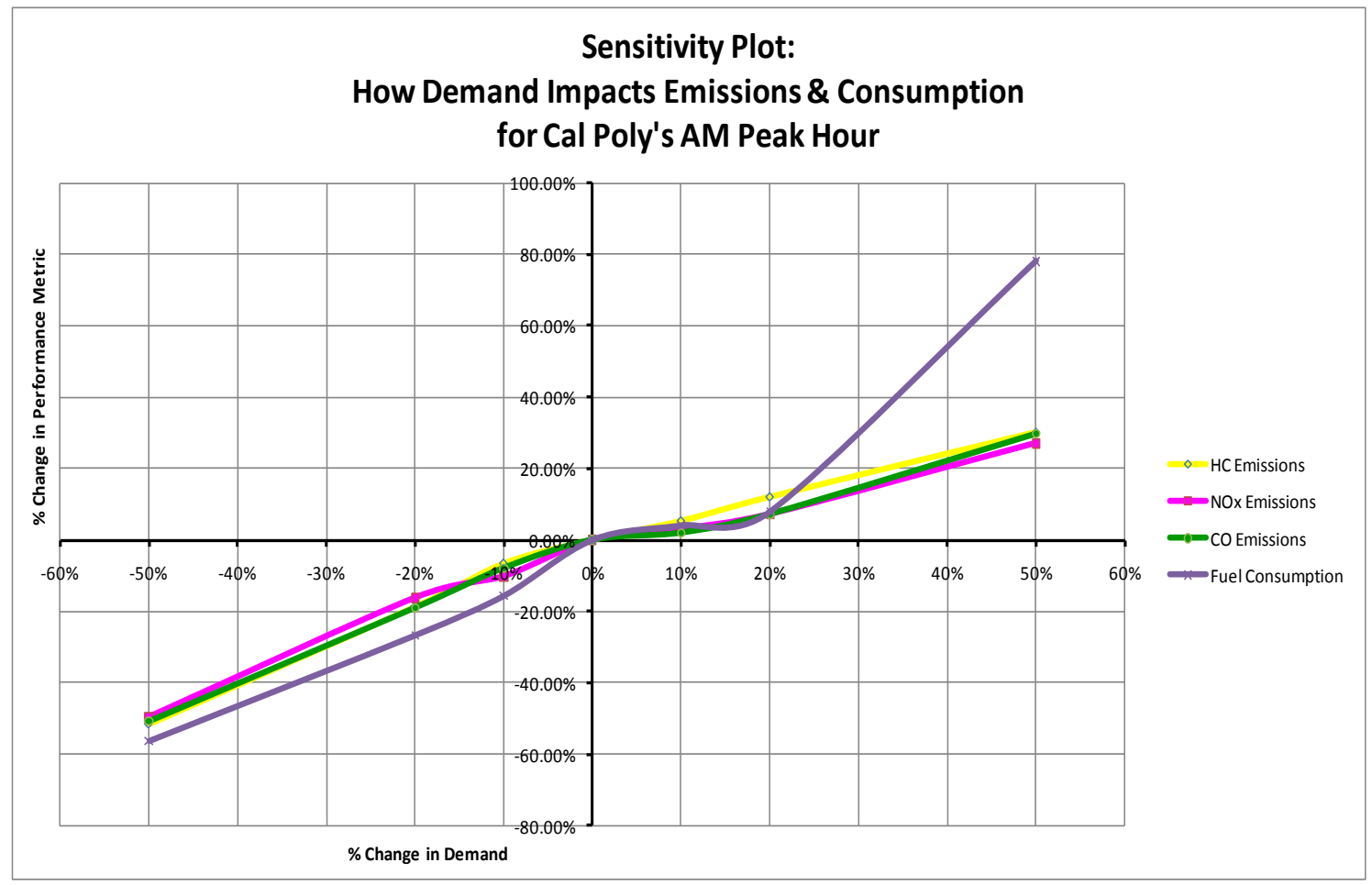

Figure 7.1: Sensitivity Plot showing how Demand Impacts Emissions and Consumption for Cal Poly's AM Peak Hour

Based on this plot the following conclusions are made:

- Emissions and fuel consumption increase with increases in demand; decrease with decreases in demand

- Fuel consumption seems to be more responsive to changes in demand than vehicle emissions

- Vehicle emissions of each type seem to change similarly due to demand

- Decreases in demand seem to decrease emissions more dynamically than increases in demand seem to increase emissions. This is evidenced by steeper slopes for lines on the left-side of the graph and flatter slopes for lines on the right-side of the graph. This is not as apparent in the figure unless the scale is clearly accounted for.

- A decrease in demand seems to decrease fuel consumption and emissions more dynamically than an increase in vehicle demand seems to increase fuel consumption. In the case of fuel consumption, this trend seems to reverse, however, when demand is increased or decreased more 
than $35 \%$. This may be due to the fact that Cal Poly's network cannot cope with $50 \%$ demand increases without experiencing excessive congestion. This is suggested by the animation during this run and the inability of the network to converge in a timely manner. The trend may also be connected to the set of driver behavior parameters generated by random seed 42 which cannot cope with the change.

- The sharp increase in fuel consumption with an increase of demand by $50 \%$ may have been caused by errors in testing 


\subsection{Sensitivity of Share of Green Vehicles}

According to a 2008 study by J.D. Power \& Associates, the sale of hybrid and diesel vehicles in the United States is projected to increase three-fold by the year 2015. This increase could mean the current market share of hybrid vehicles would increase from $2.2 \%$ as seen in year 2007 to $7 \%$ by year 2015 (Hybridcars.com 2008). Given Cal Poly's recent push for growth in the use of hybrid vehicles, policies and special programs emphasizing the increase in the share of "green" vehicles are likely to be integral in future campus planning and decisions. Currently, approximately $4-8 \%$ of private vehicles operated by students, faculty, and staff are "green" vehicles, provided the underlying assumptions made in determining vehicle categories in VISSIM and CMEM. This is slightly higher than the national average. A three-fold increase could mean market shares of "green" vehicles of around 12-24\% for Cal Poly.

The sensitivity of the share of "green" vehicles in operation on vehicle emissions and fuel consumption is examined in several scenarios for Cal Poly's AM Peak Hour. A 0\% change in "green" vehicle share is used as a baseline case where approximately 100 vehicle-trips (4.60\%) are made by "green" vehicles. This corresponds to the data generated previously for random seed 42. From there, the share of "green" vehicles is increased by $20 \%, 50 \%, 100 \%$, and $200 \%$ to test claims suggested by the J.D. Power \& Associates study and anticipated policy at Cal Poly. When the market share of 'green" vehicles increases, the market share of all other vehicles categories decreases slightly, provided the assumption that demand is unchanged. Comparisons are stated as percent changes relative to the baseline because relative changes are easier to comprehend than absolute changes. The changes in each scenario are done independent of each other. Table 7.2 below shows a summary of all demand sensitivity scenarios.

Table 7.2: Summary of Share of "Green" Vehicles Sensitivity for Cal Poly's AM Peak Hour

\begin{tabular}{|r|r|r|r|r|}
\hline \multicolumn{5}{|c|}{ Sensitivity of Share of "Green" Vehicles } \\
\hline $\begin{array}{l}\text { \% Increase in } \\
\text { Vehicles }\end{array}$ & $\begin{array}{l}\text { \% Change in } \\
\text { HC Emissions }\end{array}$ & $\begin{array}{l}\text { \% Change in } \\
\text { NOx Emissions }\end{array}$ & $\begin{array}{l}\text { \% Change in } \\
\text { CO Emissions }\end{array}$ & $\begin{array}{l}\text { \% Change in Fuel } \\
\text { Consumption }\end{array}$ \\
\hline $0 \%$ & $0.00 \%$ & $0.00 \%$ & $0.00 \%$ & $0.00 \%$ \\
\hline $20 \%$ & $-1.97 \%$ & $2.23 \%$ & $-0.39 \%$ & $-1.94 \%$ \\
\hline $50 \%$ & $-2.44 \%$ & $1.86 \%$ & $-1.76 \%$ & $0.43 \%$ \\
\hline $100 \%$ & $-2.91 \%$ & $3.76 \%$ & $-3.62 \%$ & $0.59 \%$ \\
\hline $200 \%$ & $-4.51 \%$ & $10.59 \%$ & $-6.21 \%$ & $-2.08 \%$ \\
\hline
\end{tabular}




\subsubsection{Scenario 7: Increase Share of Green Vehicles by $20 \%$}

In the seventh scenario, the share of "green" vehicles operating during Cal Poly's AM Peak Hour is increased by approximately $20 \%$ to 120 vehicle-trips (5.53\% market share). This increase causes an approximate $0-2 \%$ decrease in $\mathrm{HC}$ and $\mathrm{CO}$ emissions, a $2 \%$ increase in $\mathrm{NO}_{\mathrm{x}}$ emissions, and a $2 \%$ decrease in fuel consumption.

\subsubsection{Scenario 8: Increase Share of Green Vehicles by $50 \%$}

In the eighth scenario, the share of "green" vehicles operating during Cal Poly's AM Peak Hour is increased by approximately $50 \%$ to 150 vehicle-trips (6.90\% market share). This increase causes an approximate 1-3\% decrease in $\mathrm{HC}$ and $\mathrm{CO}$ emissions, a $2 \%$ increase in NOx emissions, and a $0 \%$ change in fuel consumption.

\subsubsection{Scenario 9: Increase Share of Green Vehicles by $100 \%$}

In the ninth scenario, the share of "green" vehicles operating during Cal Poly's AM Peak Hour is increased by approximately $100 \%$ to 200 vehicle-trips ( $9.20 \%$ market share). This increase causes an approximate 2 4\% decrease in $\mathrm{HC}$ and $\mathrm{CO}$ emissions, a $4 \%$ increase in NOx emissions, and a $1 \%$ increase in fuel consumption.

\subsubsection{Scenario 10: Increase Share of Green Vehicles by $200 \%$}

In the tenth scenario, the share of "green" vehicles operating during Cal Poly's AM Peak Hour is increased by approximately $200 \%$ (or tripled) to 300 vehicle-trips ( $13.81 \%$ market share). This increase causes an approximate $4-7 \%$ decrease in $\mathrm{HC}$ and $\mathrm{CO}$ emissions, an $11 \%$ increase in NOx emissions, and a $2 \%$ decrease in fuel consumption. 


\subsubsection{Overall Analysis}

The sensitivity plot in Figure 7.2 shows all four scenarios for share of "green" vehicles sensitivity.

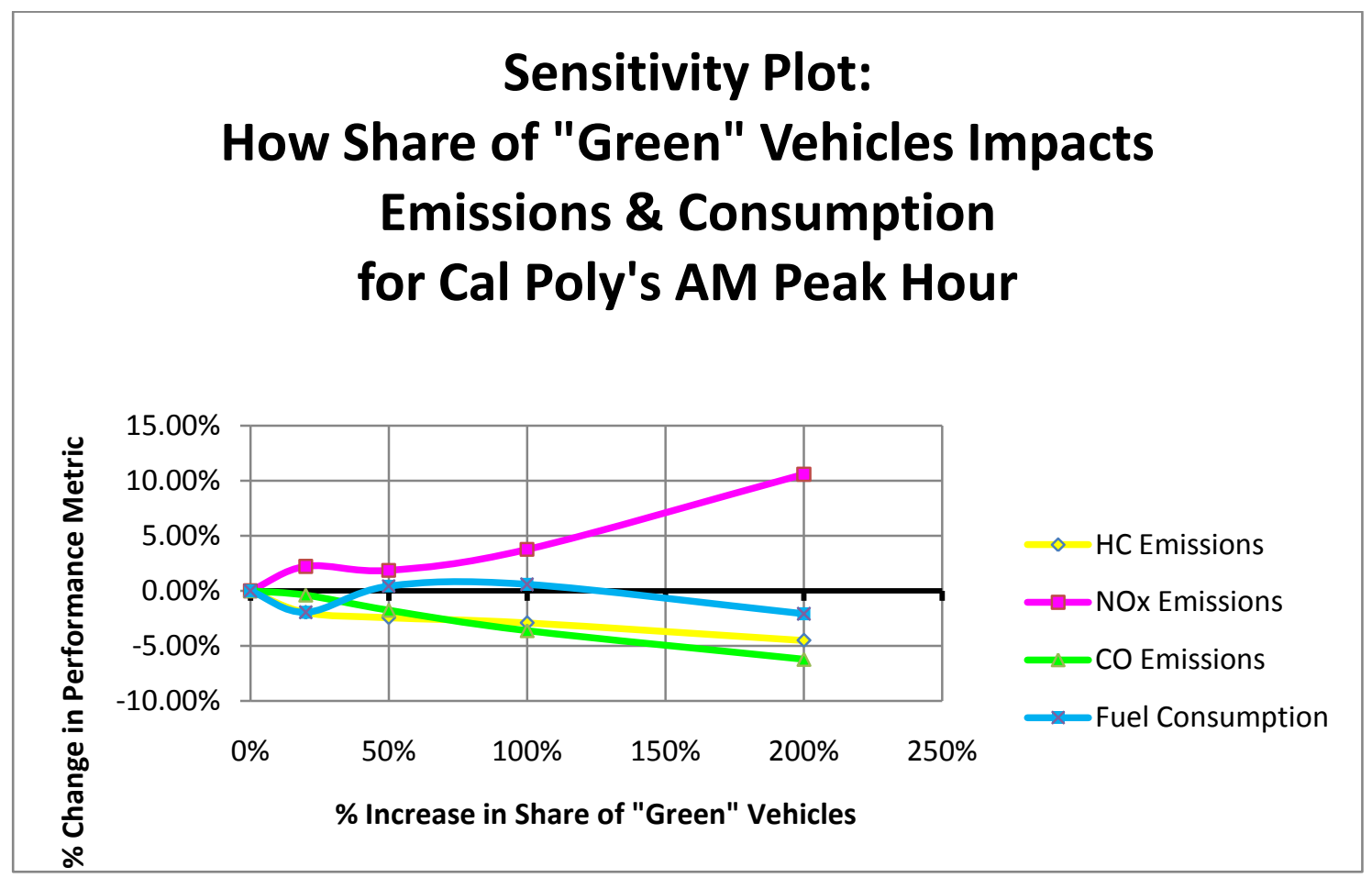

Figure 7.2: Sensitivity Plot showing how Share of "Green" Vehicles Impacts Emissions and Consumption for Cal Poly's AM Peak Hour

Based on this plot the following conclusions are made:

- Increases in the share of "green" vehicles suggests slight decreases in $\mathrm{HC}$ and $\mathrm{CO}$ emissions

- Increases in the share of "green" vehicles suggests little to no change in fuel consumption

- Increases in the share of "green" vehicles suggest slight increases in NOx emissions. This phenomenon is traced to CMEM vehicle categories. In vehicle mapping, $100 \%$ of vehicles belonging to the economy/hybrid vehicle class in VISSIM are mapped to CMEM categories 26ULEV (Ultra Low Emission Vehicle) and 27-SULEV (Super Ultra Low Emission Vehicle). An additional $25 \%$ of the compact class is also mapped to these categories. The greater majority of vehicles are in CMEM category 26- ULEV which seems to comprise about $35 \%$ of overall $\mathrm{NO}_{\mathrm{x}}$ emissions in the base scenario, provided the default settings in CMEM. When the share of "green" vehicles increases, the share of category 26 vehicles increases, resulting in increased $\mathrm{NO}_{\mathrm{x}}$ emissions. 
- Some "green" vehicles are fueled on diesel which has been known to increase $\mathrm{NO}_{\mathrm{x}}$ emissions more significantly than unleaded gasoline.

- In comparison to the previous sensitivity plot, demand seems to more dynamically influence vehicle emissions and fuel consumption than the share of "green" vehicles does. This is evidenced by steeper slopes and wider scales for the vertical axis in the demand sensitivity plot.

- If both changes in demand and the share of "green" vehicles are made simultaneously, a decrease in emissions from increasing the share of green vehicles may likely be offset by the increase in emissions associated with an increase in demand.

- The results for vehicle emissions and fuel consumption may have been influenced by errors in testing 


\section{Opportunities for Further Improvement}

There are many opportunities to expand and improve the accuracy of the model created for Cal Poly. Such opportunities include the following:

- Modeling of pedestrian crosswalks and their impact on campus circulation

- Modeling the campus with demand matrices based on smaller time intervals. The campus can experience large fluctuations in demand within a period of 10-15 minutes as commonly seen during passing periods

- Modeling of the campus during other peak periods of demand (e.g. midday, evening)

- Modeling of additional vehicle categories such as motorcycles, bicycles and campus service vehicles

- Further stratification of demand by different vehicle use types (e.g. Staff demand has its own schedule and unique set of potential parking destinations)

- Capture the emissions associated with searching for open/desired parking spaces within campus lots

- Study the impact technology can have in influence parking decisions (parking management systems)

- Implementation of improved cost and route choice parameters

- Expansion of model to include more outlying areas of San Luis Obispo including freeway interchanges

- Modeling of physical \& geometric changes stated or anticipated in Cal Poly’s Master Plan

- Increased data collection for entrances/exits to campus and parking lots

- Modeling of special policies implemented for traffic and parking for special campus events

- Implementing an updated version of VISSIM or CMEM software

- Investigating how a simulation of Cal Poly's emissions differs through use of different software or methodology

- $\quad$ Compare simulation emissions statistics with those gathered from a field test using FTP bag procedures 


\section{Conclusions}

The use of simulation has been useful in helping the Cal Poly campus recognize the collective behaviors and patterns of transportation present on campus and the implications these behaviors pose to the transportation network as a whole. A simulation model was created which mimics the real life traffic situation seen on Cal Poly's campus during the AM Peak Hour from 7:30-8:30AM. The model was created using leading software packages VISSIM and CMEM, and contains a reasonable level of accuracy for estimating the physical emissions generated by vehicles during this time period.

Based on assumptions made, the total quantity of emissions ( $\mathrm{HCs}, \mathrm{CO}$, and NOx) currently generated by transportation at Cal Poly during the AM Peak Hour is estimated to be between 106,350-116,100 grams. In particular, the average amount of $\mathrm{HC}$ emissions is estimated to be between 7619-7858 grams, the average amount of CO emissions is estimated to be between 94,607-98,393 grams, and the average amount of NOx emissions is estimated to be between 7740-7948 grams. Each of these estimates is made at a confidence level of $95 \%$. In addition, the quantity of fuel consumed during the AM Peak hour is estimated to be between 414,730-442,064 grams with $95 \%$ confidence.

In addition to the current estimates for the AM Peak Hour, scenarios were performed to see the sensitivity of emissions relative to changes in demand and the share of "green" vehicles present on campus. These scenarios found that emissions and fuel consumption increased with increased demand at a rate of about half the increase of demand. Emissions and fuel consumption had mixed results for increases in the share of "green" vehicles.

The findings of this study can serve as a basis for future decisions in campus planning such as determining parking fees, promotion of alternative forms of transportation (e.g. "green" vehicles, public transit, walking, bicycling). The study can be extended to study other applications on campus such as areas of congestion, and the impact of design and operational changes as well as the sensitivity of other key parameters. Additionally, the methods used in this study could be useful in similar environments such as business parks, corporate campuses, and downtown districts. 


\section{Works Referenced}

1. Berman, B. (2006, March 31). Emissions Standards. Retrieved from http://www.hybridcars.com/emissions-standards.html

2. Berman, B. (2008, April 08). J.D. Power Sees Three-Fold Growth for Hybrids by 2015. Retrieved from http://www.hybridcars.com/news/jd-power-forecasts-three-foldgrowth-hybrids-and-diesels.html

3. Chen, X., \& Zhan, F.B. (2006). Agent-based Modelling and Simulation of Urban Evacuation: Relative Effectiveness of Simultaneous and Staged Evacuation Strategies. Journal of the Operational Research Society, 59, 25-33.

4. Chen, X. (2008). Microsimulation of Hurricane Evacuation Strategies for Galveston Island. The Professional Geographer, 60(2), $160-173$.

5. Colvin, Kurt. "IME 420: Simulation." Cal Poly-San Luis Obispo- Department of Industrial \& Manufacturing Engineering. Bldg 14, San Luis Obispo, CA. Jan 2009. Lecture.

6. Cooper, C.D., \& Alley, F.C. (2002). Air Pollution Control: A Design Approach (3rd Edition). Long Grove, IL: Waveland Press, Inc.

7. Frey, H.C., Zhang, K., \& Rouphail, N.M. (2010). Vehicle-specific emissions modeling based upon on-road measurements. Environmental Science \& Technology, 44(9), 35943600 .

8. Fricker, J.D., \& Whitford, R.K. (2004). Fundamentals of Transportation Engineering: A Multimodal Systems Approach. Upper Saddle River, NJ: Pearson Education, Inc.

9. Harre11, C., Ghosh, B.K., \& Bowden, R.O. (2004). Simulation using ProModel. New York, NY: The McGraw-Hill Companies, Inc.

10. Hester, A.E., Fisher, D.L., \& Collura, J. (2002). Drivers'parking decisions: Advanced Parking Management Systems. Journal of Transportation Engineering, (Jan/Feb), 4957.

11. Hu-Nan, D., Lin, C., \& Zhong-Yuan, Z. (2009). Evaluation of Traffic Movement Organization Planning with Environmental Impact Consideration. Proceedings of the 2009 International Conference on Energy and Environment Technology (pp. 138$141)$. Nanjing, China: IEEE Computer Society. 10.1109/ICEET.2009.40

12. Jacobs, L., and F. Choa. "The Evolution of Greenhouse Gas Emissions Modeling." PTV America User's Group Meeting 2010 . Fehr \& Peers Transportation Consultants. Lecture Slides

13. Liu, Yan. "Sensitivity Analysis." Wright State University- Department of Biomedical, Industrial \& Human Factors Engineering. Dayton, OH. Lecture Slides

14. Mollaghasemi, M. \& Abdel-Aty, M. (2003). Thesis-Development of Emergency Response Model for Orlando National Airport. Orlando, FL

15. Multari, M. Cal Poly Administration \& Finance Division, Sustainability Advisory Committee. (2010). Sustainability for Cal Poly Facilities \& Operations: Third Biennial Progress Report $2010 \mathrm{San}$ Luis Obispo, CA: Barnett Cox \& Associates. Retrieved from http://www.afd.calpoly.edu/sustainability/docs/Metrics/2010SustainabilityReport_w eb.pdf

16. Noland, R., \& Quddus, M. (2005). Flow Improvements and Vehicle Emissions: Effects of Trip Generation and Emission Control Technology. Informally published manuscript, Center for Transport Studies- Department of Civil and Environmental Engineering, Imperial College London, London, UK, SW7 2AZ. Retrieved from http://www.scribd.com/doc/6647225/F1ow-Improvements-and-Vehicle-EmissionsEffects-of-Trip-Generation-and-Emission-Control-Technology

17. PTV Vision. VISSIM Overview. (2007). Karlsruhe, Germany: PTV AG.

18. PTV Vision. VISSIM 5.20 User Manual. (2009). Karlsruhe, Germany: PTV AG.

19. PTV Vision. VISSIM 5.30 User Manual. (2010). Karlsruhe, Germany: PTV AG.

20. Ramasamy, Shankar. (Ed.). (2002). Thesis- Development of the traffic simulation model for the UCF campus using Paramics. Orlando, FL

21. Roess, R.P., Prassas, E.S., \& McShane, W.R. (2004).Traffic Engineering (3rd edition). Upper Saddle River, NJ: Pearson Education, Inc.

22. San Luis Obispo County Air Pollution Control District. (2008). About APCD. Retrieved from http://www.slocleanair.org/who/index.php

23. Scora, G. \& Barth, M. Comprehensive Modal Emissions Model (CMEM) User Manual, Version 3.01. (June 2006). Riverside, CA: University of California Riverside Center for Environmental Research and Technology (UCR CE-CERT)

24. Author Unknown. GEH. (2010). Wikipedia. Retrieved December 29, 2011, from http://en.wikipedia.org/wiki/GEH 
25. Author Unknown. "VISSIM." 2003-2010. Online Posting to PTV America User Forum. Web. 30 Nov 2010

26. U.S. Environmental Protection Agency, Office of Air Quality Planning and Standards. (2010). Our Nation's Air: Status and Trends through 2008 (EPA-454/R-09-002). Research Triangle Park, NC: Retrieved from http://www.epa.gov/airtrends/2010/report/fullreport.pdf

27. Washington, S., Leonard, J.D.II., Roberts, C.A., Young, T., Botha, J. and Sperling, D. (1998) Forecasting vehicle modes of operations needed as input to "modal" emissions models, Int. J. of Vehicle Design, Vol. 20, Nos. 1-4 (Special Issue), pp.351-359.

28. Won, Jongsun. "PTV Vision Support Cases." June 2010-February 2011. Online Posting to PTV America Technical Support Hotline. E-mail. 4 Feb 2011.

29. Yu, L., Li, X., \& Zhuo, W. Texas Department of Transportation, Research and Technology Transfer Office. (2003). Airport Related Traffic and Mobile Emission Implications ( TX-03/4317). Houston, TX: Department of Transportation Studies Texas Southern University. Retrieved from http://transportation.tsu.edu/Reports/TxDOT_4317-1.pdf 


\section{Appendices}

\section{Appendix A: Listing of Links Forming the Network}

The following is a list of all links forming the Cal Poly network:

- Cabrillo Highway (CA-1)

- California Blvd

- Campus Way

- Canyon Circle Dr

- Casa St

- Carpenter St

- Cerro Vista Circle

- Circle Dr

- $\quad$ College Ave

- Crandall Way

- Cuesta Ave

- $\quad$ Deer Rd

- Dexter

- Entrance Way
- $\quad$ Grand Ave

- E Foothill Blvd

- Foothill Blvd

- Hathway Ave

- Highland Dr

- Kentucky St

- Klamath Rd

- Longview Ln

- Monte Vista Pl

- Mountain Ln

- Mt Bishop Rd

- Pacheco Way

- $\quad$ N Perimeter

- $\quad$ S Perimeter
- $\quad$ Pinnacles Rd

- Poly Canyon Rd

- N Poly View Dr

- S Poly View Dr

- E Safety Way

- W Safety Way

- Santa Rosa St

- $\quad$ Slack St

- Sports Complex Dr

- $\quad$ Stenner Creek Rd

- $\quad$ Truckee Rd

- University Dr

- US-101

- Via Carta 


\section{Appendix B: Listing of Speed Decisions \& Distributions}

The following is a list of the locations where speed decisions are located in the Cal Poly network. Each of these speed decisions corresponds to speed distributions based on the appropriate range of speeds the proceeding section accommodates.

- Highland Dr entrance

- Highland Dr exit

- Highland Dr inbound @ Crops Unit

- Stenner Creek Rd entrance

- Grand Ave entrance

- S Perimeter Northbound @ Grand Ave

- Deer Road inbound to residential areas

- Mountain Ln inbound to residential areas

- Klamath Rd southbound from Cerro Vista

- Cerro Vista circle entrance

- Truckee westbound from top of Cerro Vista

- Village Dr northbound just north of Truckee intersection

- $\quad$ Truckee westbound just west of Village Dr intersection

- University Dr northbound just north of N Perimeter

- University Dr southbound just south of Highland Dr

- Via Carta northbound just north of Campus Market

- Highland Dr eastbound just east of University Dr

- Highland Dr westbound after Via Carta connector

- Highland Dr westbound just west of University Dr

- Highland Dr eastbound just east of California Blvd

- Highland Dr eastbound just east of Mt Bishop Rd

- California Blvd southbound just south of Highland Dr

- Mt Bishop Rd northbound

- Mt Bishop Rd southbound

- Stenner Creek Road exit

- Sports Complex Dr

- Village Dr eastbound just east of Via Carta

- $\quad$ Pinnacles Rd westbound

- University Dr @ Kennedy Library

- $\quad$ N Perimeter between Via Carta \& University

- Via Carta southbound just south of N Perimeter

- Truckee Rd eastbound just east of E Safety Dr

- Grand Ave northbound (off-campus)

- Grand Ave southbound (off-campus)

- Klamath Rd northbound

- N Perimeter westbound just south of Village Dr

- Village Dr between N Perimeter \& Truckee

- E Safety Dr

- W Safety Dr

- Canyon Circle Dr counter-clockwise

- Canyon Circle Dr clockwise

- Vista Caballo eastbound

- Vista Caballo westbound
- Village Dr northbound within Poly Canyon Village

- Village Dr southbound within Poly Canyon Village

- Village Dr exiting Poly Canyon Village to the west

- $\quad$ Pinnacles Rd eastbound

- Via Carta southbound just south of Village Dr

- Via Carta southbound just south of Sports Complex Dr

- Via Carta northbound near lot exits

- Via Carta southbound near lot exits

- Highland Dr westbound between California Blvd and Mt Bishop Rd

- Highland Dr outbound @ Crops Unit

- S Perimeter between College Ave and Cuesta Ave

- College Ave outbound

- Campus Way eastbound

- Foothill/Crandall entrance

- Pacheco Way inbound

- Pacheco Way southbound

- College Ave begin

- Cuesta Ave @ Powerhouse

- Campus Way entrance

- California Blvd entrance

- California Blvd northbound @ C5 Parking

- California Blvd southbound @ C5 Parking

- Foothill/Crandall entrance 
The following diagrams describe the empirical speed distributions used in the Cal Poly network. Each is scaled on the $\mathrm{x}$-axis from the minimum speed to the maximum speed and on the $\mathrm{y}$-axis with proportion of vehicles.
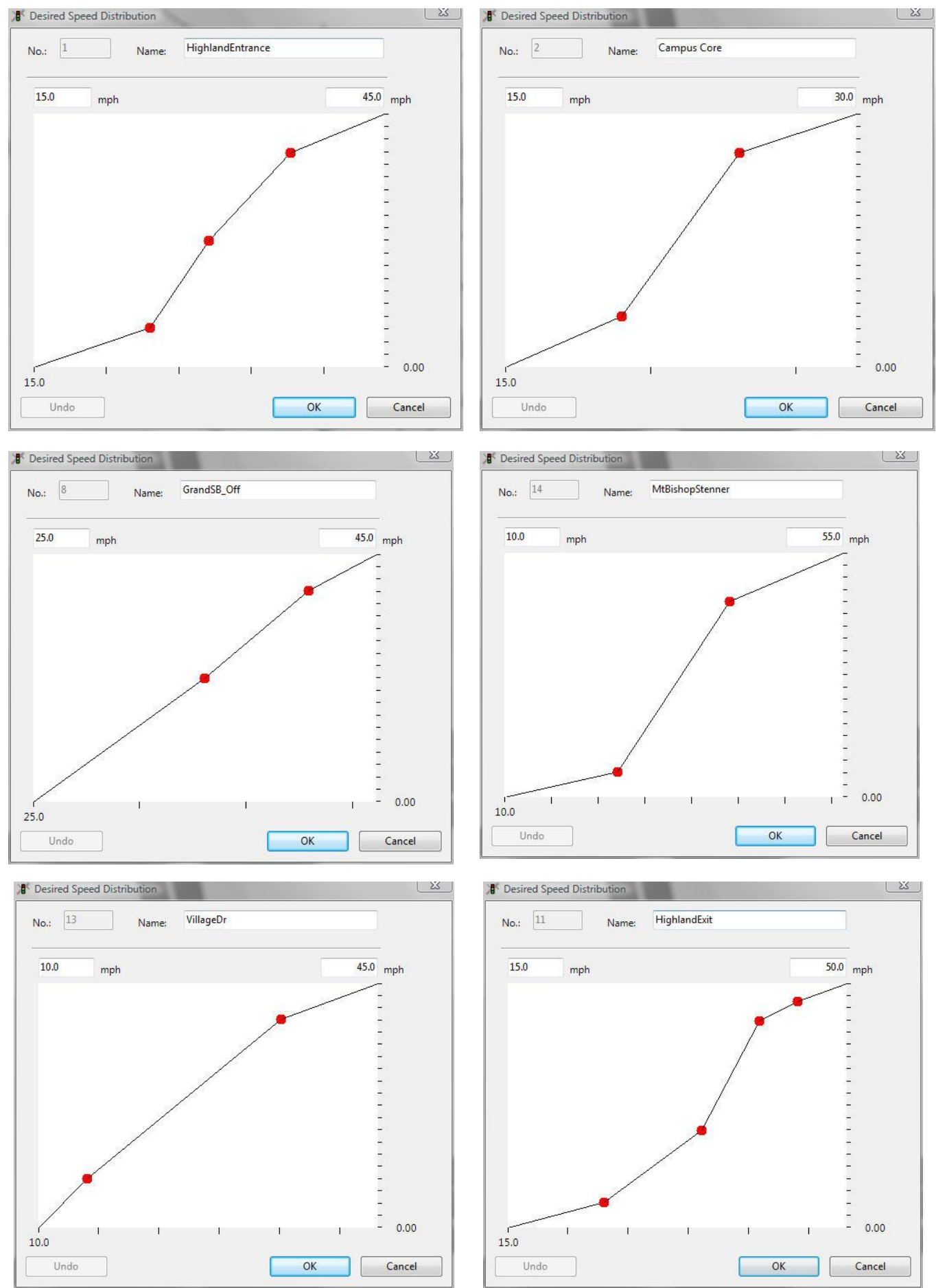

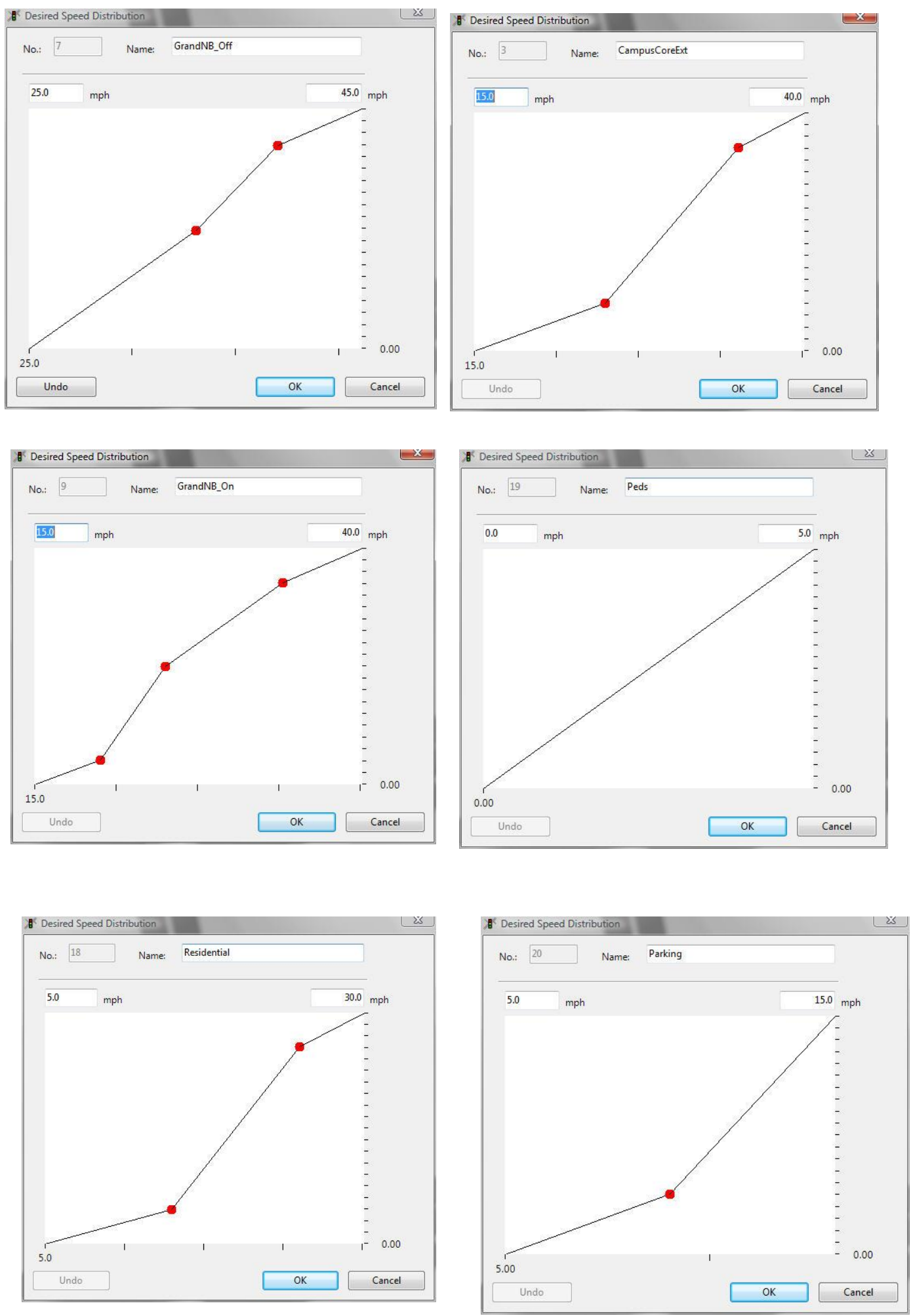


\section{Appendix C: Listing of Stop Signs}

The following is a list of stop signs used in the Cal Poly network:

\section{4-Way Stops:}

- Highland \& University

- $\quad$ N Perimeter \& University

- $\quad$ N Perimeter \& Via Carta

- $\quad$ Grand \& Slack

- $\quad$ Truckee Rd \& Village Dr (Conflict Areas used instead of Priority Rules)

- Campus Way \& \& Cuesta Ave \& C2 Children's Center Parking (Conflict Areas used instead of Priority Rules)

- $\quad$ Foothill Blvd \& California Blvd

- $\quad$ CA-1 (Cabrillo Hwy) \& Highland Dr

\section{3-Way Stops:}

- $\quad$ Deer Rd \& Klamath Rd

- $\quad$ Klamath Rd \& R1 Parking (Muir)

- $\quad$ N Perimeter \& Village Dr

- Grand Ave \& S Perimeter

- $\quad$ N Perimeter \& E Safety Way

- California Blvd \& Highland Dr

- California Blvd \& C5 Parking

- California Blvd \& Campus Way

- S Perimeter \& Cuesta Ave

- Carpenter St \& Hathway Ave

- Hathway Ave \& Kentucky St

- Hathway Ave \& Longview Ln \& G2 Parking

- $\quad$ Slack St \& Longview Ln

\section{2-Way Stops:}

- $\quad$ Klamath Rd \& Mountain Ln

- Klamath Rd \& Truckee Rd \& Cerro Vista Circle Entrance

- $\quad$ Truckee Rd \& E Safety Way

- H14 Lower Parking \& H 16 Upper Parking \& Via Carta

- H14 Baseball Parking Row 1 \& Sports Complex Dr

- H14 Baseball Parking Row 2 \& Sports Complex Dr

- $\quad$ S Perimeter @ Graphic Arts

- $\quad$ S Perimeter \& Via Carta

\section{1-Way Stops:}

- $\quad$ G2 Parking @ Slack St

- R2 Parking@ Grand Ave

- G1 Parking@Grand Ave

- Pacheco Way @ Grand Ave

- PAC Circle @ Pacheco Way

- Deer Rd @ Grand Ave

- R1 Parking (Fremont) @ Klamath Rd

- Cerro Vista Circle End @ Truckee Rd
- A1 Parking Exit (North Row) @ N Perimeter

- Tahoe Rd @ S Perimeter

- W Safety Way@ N Perimeter

- H4 BRAE Parking @ W Safety Way

- H4 Triangle Parking @ Truckee Rd

- H4 BRAE Parking @ Via Carta

- H2 Engineering @ University Dr

- H12 Parking @ Via Carta

- H16 Lower Parking @ Via Carta

- Pinnacles Rd @ Via Carta

- H12 Row 1 Parking @ Pinnacles Rd

- H12 Row 2 Parking @ Pinnacles Rd

- H12 Row 3 Parking @ Pinnacles Rd

- H12 Row 4 Parking @ Pinnacles Rd

- H12 Row 5 Parking @ Pinnacles Rd

- H14 Upper Parking @ Via Carta

- Sports Complex Dr @ Via Carta

- H15 Parking @ Sports Complex Dr

- H14 Baseball Parking @ Via Carta

- H14 Lower Equine Parking@ Via Carta

- H14 Upper Equine Parking @ Via Carta

- Village Dr @ Via Carta

- Canyon Circle Dr (North) @ Village Dr

- Canyon Circle Dr (South) @ Village Dr

- R4 Parking (West) @ Canyon Circle Dr

- R4 Parking (East) @ Canyon Circle Dr

- Vista Caballo @ Village Dr

- Vista Caballo @ Canyon Circle Dr

- R3 Parking @ Village Dr

- H2 Creek Parking @ Highland Dr

- Dexter Rd @ Entrance Way

- Entrance Way @ California Blvd

- Grand Ave Parking Kiosk

- California Blvd Parking Kiosk

- Highland Dr Parking Kiosk

- C3 Parking @ Campus Way

- S Perimeter @ College Ave

- $\quad$ C2 Children's Center @ Campus Way

- Campus Way \& Crandall Way (Health Center)

- E Foothill Blvd @ Crandall Way

- Carpenter St @ E Foothill Blvd

- Monte Vista Pl @ California Blvd

- CasaSt @ Foothill Blvd

- Mt Bishop Rd @ Highland Dr

- $\quad$ Stenner Creek Rd @ CA-1 (Cabrillo Hwy)

- Mt Bishop Rd @ Stenner Creek Rd

- Dairy Parking @ Mt Bishop Rd

- H1 Main Parking @ Mt Bishop Rd

- H1 Lower Parking @ Mt Bishop Rd

- H1 Crops Parking @ Mt Bishop Rd 


\section{Appendix D: Maps of Transit Routes in the Cal Poly Network}

The following pictures show the transit routes within the Cal Poly network as described previously.

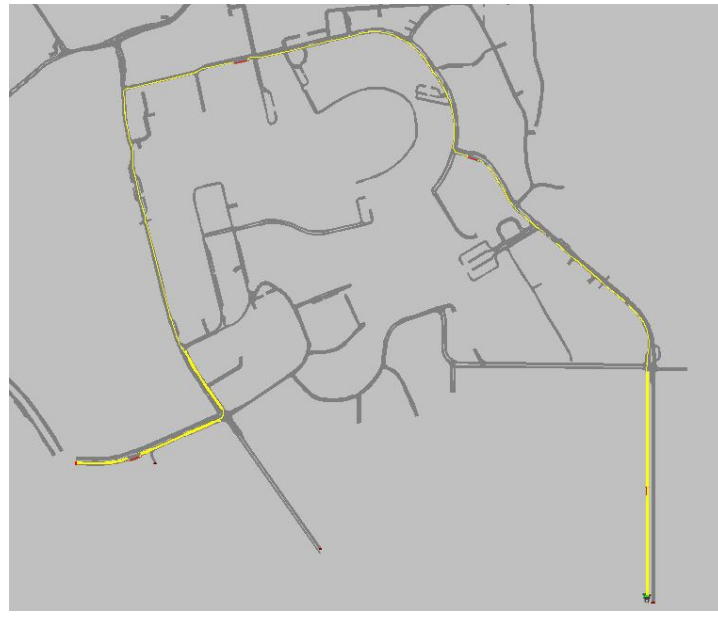

SLO Transit- Route 4

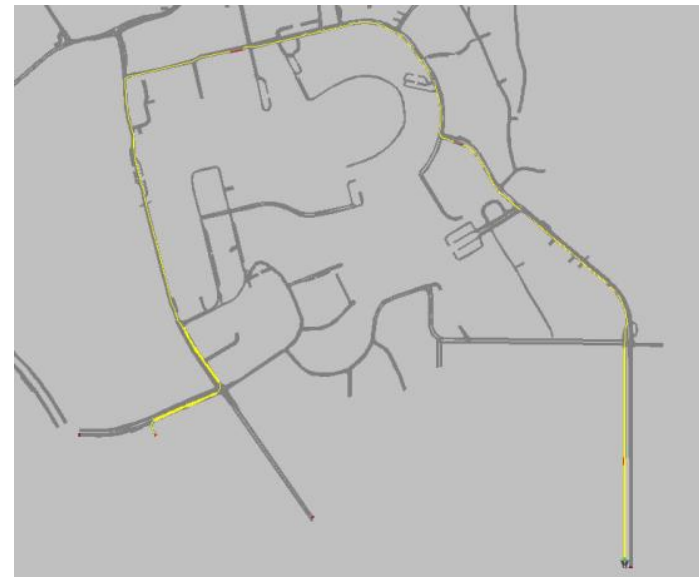

SLO-Transit- Route 6A/6B

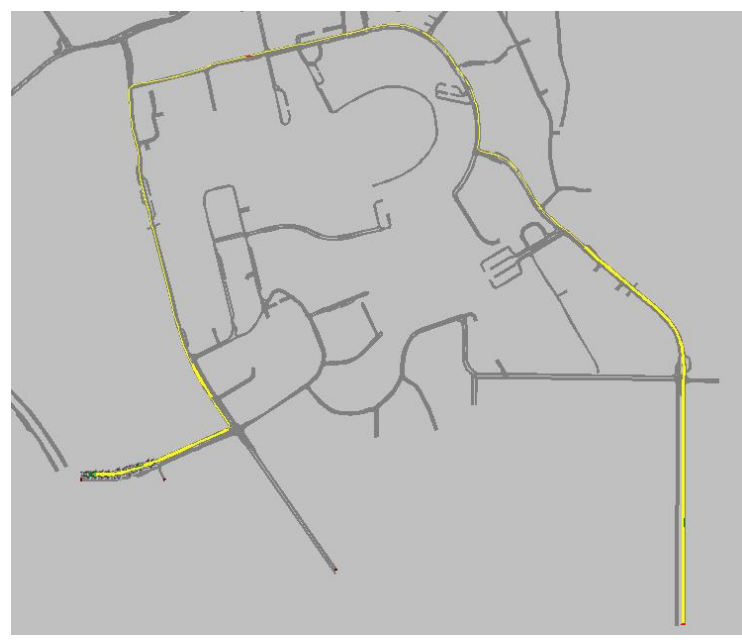

RTA- Route 9 NB

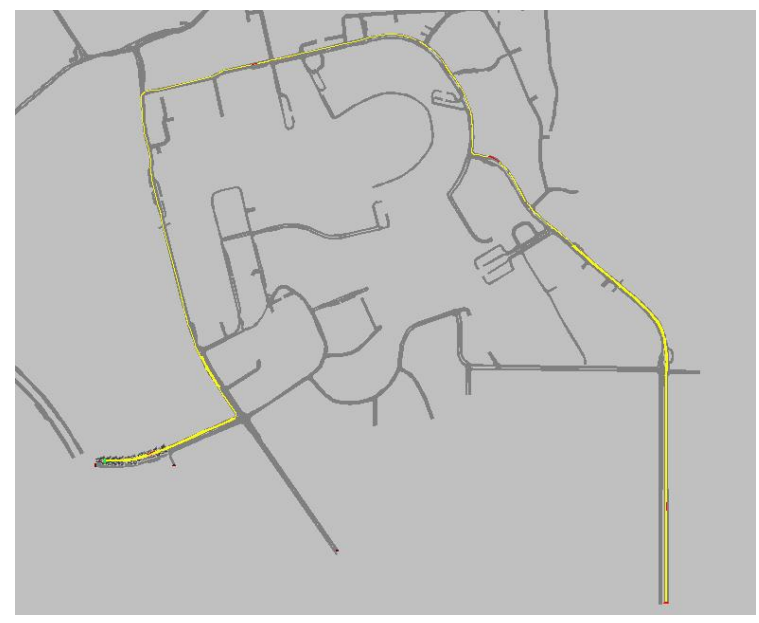

SLO-Transit Route 5

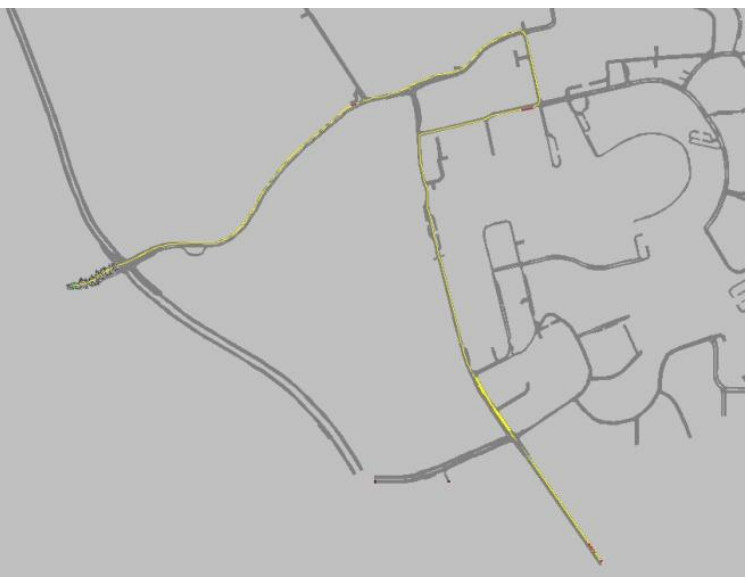

SLO-Transit Route 6B/6A

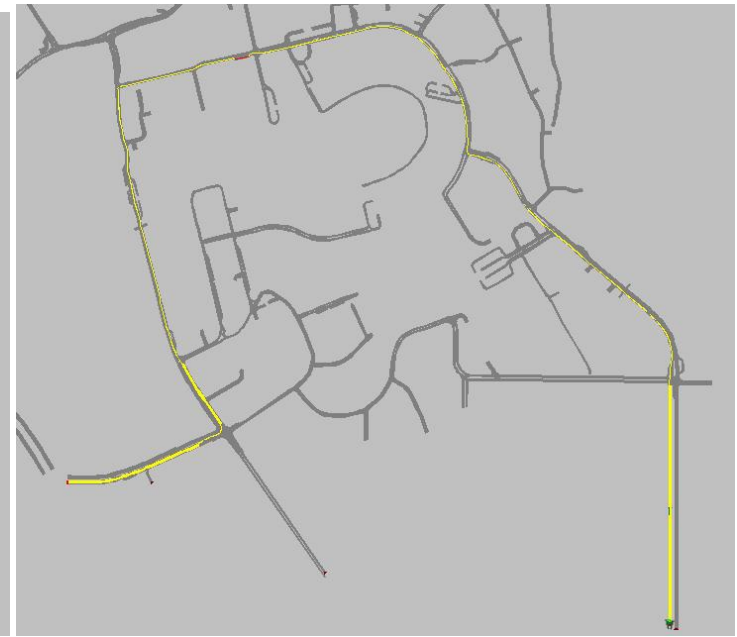

RTA- Route 10 


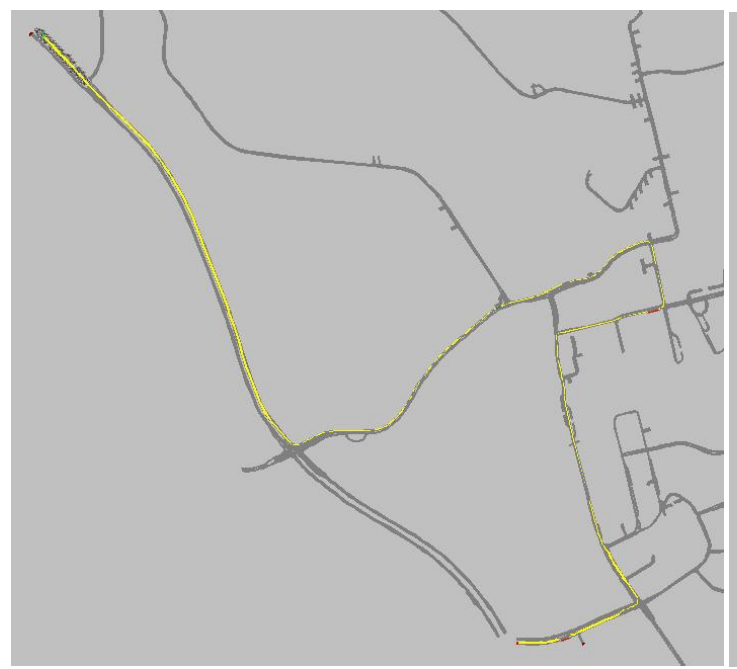

RTA- Route 12 NB

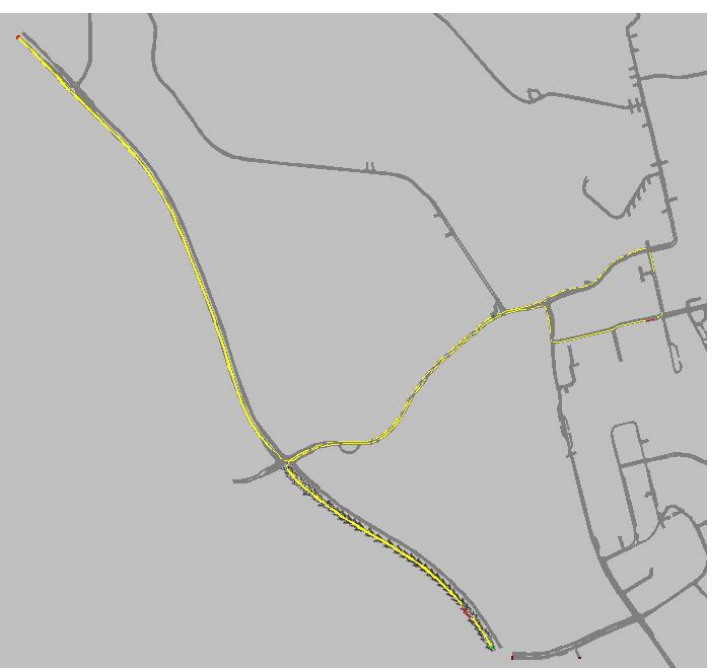

RTA- Route12 SB 


\section{Appendix E: Data Collection Summaries}

The table below summarizes inbound and outbound volumes collected at the Grand Avenue entrance to Cal

Poly in 15-minute increments. The accompanying graph shows these volumes with respect to time of day.

\begin{tabular}{|c|c|c|c|c|c|c|c|c|}
\hline \multicolumn{9}{|c|}{$\begin{array}{l}\text { Intersection: Grand/Slack } \\
\text { Observer: S. Kilbert } \\
\text { Dates (Day of Week): 10/05/10 (Tuesday), 10/12/10 (Tuesday), 10/19/10 (Tuesday) } \\
\text { Spans of about } 5 \text { hours were studied on each of these days and assembled to create the "average day" shown below }\end{array}$} \\
\hline Begin Time & End Time & Inbound & Outbound & $\%$ Inbound & $\%$ Outbound & $\begin{array}{l}\begin{array}{l}\text { Flow } \\
\text { Rate IB } \\
\text { (veh/hr) }\end{array} \\
\end{array}$ & $\begin{array}{l}\text { Flow Rate } \\
\text { OB (veh/hr) }\end{array}$ & $\begin{array}{l}\text { Flow } \\
\text { Rate } \\
\text { Overall } \\
\text { (veh/hr) }\end{array}$ \\
\hline 7:30 AM & 7:45 AM & 184 & 33 & $84.79 \%$ & $15.21 \%$ & 736 & 132 & 604 \\
\hline 7:40 AM & 8:00 AM & 258 & 31 & $89.27 \%$ & $10.73 \%$ & 1032 & 124 & 908 \\
\hline 8:00 AM & $8: 15$ AM & 122 & 28 & $81.33 \%$ & $18.67 \%$ & 488 & 112 & 376 \\
\hline 8:15 AM & 8:30 AM & 77 & 17 & $81.91 \%$ & $18.09 \%$ & 308 & 68 & 240 \\
\hline 8:30 AM & 8:45 AM & 116 & 27 & $81.12 \%$ & $18.88 \%$ & 464 & 108 & 356 \\
\hline 8:45 AM & 9:00 AM & 235 & 29 & $89.02 \%$ & $10.98 \%$ & 940 & 116 & 824 \\
\hline 9:00 AM & 9:15 AM & 106 & 65 & $61.99 \%$ & $38.01 \%$ & 424 & 260 & 164 \\
\hline 9:15 AM & 9:30 AM & 83 & 28 & $74.77 \%$ & $25.23 \%$ & 332 & 112 & 220 \\
\hline 9:30 AM & 9:45 AM & 84 & 60 & $58.33 \%$ & $41.67 \%$ & 336 & 240 & 96 \\
\hline 9:45 AM & 10:00 AM & 102 & 50 & $67.11 \%$ & $32.89 \%$ & 408 & 200 & 208 \\
\hline 10:00 AM & $10: 15$ AM & 47 & 57 & $45.19 \%$ & $54.81 \%$ & 188 & 228 & -40 \\
\hline 10:15 AM & 10:30 AM & 69 & 50 & $57.98 \%$ & $42.02 \%$ & 276 & 200 & 76 \\
\hline $10: 30 \mathrm{AM}$ & 10:45 AM & 68 & 41 & $62.39 \%$ & $37.61 \%$ & 272 & 164 & 108 \\
\hline $10: 45 \mathrm{AM}$ & 11:00 AM & 74 & 56 & $56.92 \%$ & $43.08 \%$ & 296 & 224 & 72 \\
\hline 11:00 AM & 11:15 AM & 64 & 100 & $39.02 \%$ & $60.98 \%$ & 256 & 400 & -144 \\
\hline $11: 15 \mathrm{AM}$ & $11: 30 \mathrm{AM}$ & 49 & 36 & $57.65 \%$ & $42.35 \%$ & 196 & 144 & 52 \\
\hline 11:30 AM & $11: 45 \mathrm{AM}$ & 124 & 65 & $65.61 \%$ & $34.39 \%$ & 496 & 260 & 236 \\
\hline $11: 45 \mathrm{AM}$ & 12:00 PM & 183 & 79 & $69.85 \%$ & $30.15 \%$ & 732 & 316 & 416 \\
\hline 12:00 PM & 12:15 PM & 87 & 107 & $44.85 \%$ & $55.15 \%$ & 348 & 428 & -80 \\
\hline 12:15 PM & 12:30 PM & 54 & 72 & $42.86 \%$ & $57.14 \%$ & 216 & 288 & -72 \\
\hline 12:30 PM & $12: 45 \mathrm{PM}$ & 54 & 76 & $41.54 \%$ & $58.46 \%$ & 216 & 304 & -88 \\
\hline 12:45 PM & 1:00 PM & 99 & 39 & $71.74 \%$ & $28.26 \%$ & 396 & 156 & 240 \\
\hline 1:00 PM & 1:15 PM & 79 & 110 & $41.80 \%$ & $58.20 \%$ & 316 & 440 & -124 \\
\hline 1:15 PM & 1:30 PM & 91 & 69 & $56.88 \%$ & $43.13 \%$ & 364 & 276 & 88 \\
\hline 1:30 PM & 1:45 PM & 76 & 88 & $46.34 \%$ & $53.66 \%$ & 304 & 352 & -48 \\
\hline $1: 45 \mathrm{PM}$ & 2:00 PM & 97 & 92 & $51.32 \%$ & $48.68 \%$ & 388 & 368 & 20 \\
\hline 2:00 PM & 2:15 PM & 69 & 122 & $36.13 \%$ & $63.87 \%$ & 276 & 488 & -212 \\
\hline $2: 15 \mathrm{PM}$ & 2:30 PM & 60 & 115 & $34.29 \%$ & $65.71 \%$ & 240 & 460 & -220 \\
\hline $2: 30 \mathrm{PM}$ & $2: 45 \mathrm{PM}$ & 73 & 88 & $45.34 \%$ & $54.66 \%$ & 292 & 352 & -60 \\
\hline $2: 45 \mathrm{PM}$ & 3:00 PM & 93 & 90 & $50.82 \%$ & $49.18 \%$ & 372 & 360 & 12 \\
\hline 3:00 PM & $3: 15 \mathrm{PM}$ & 52 & 150 & $25.74 \%$ & $74.26 \%$ & 208 & 600 & -392 \\
\hline 3:15 PM & 3:30 PM & 42 & 105 & $28.57 \%$ & $71.43 \%$ & 168 & 420 & -252 \\
\hline 3:30 PM & 3:45 PM & 82 & 90 & $47.67 \%$ & $52.33 \%$ & 328 & 360 & -32 \\
\hline 3:45 PM & 4:00 PM & 100 & 101 & $49.75 \%$ & $50.25 \%$ & 400 & 404 & -4 \\
\hline 4:00 PM & 4:15 PM & 80 & 212 & $27.40 \%$ & $72.60 \%$ & 320 & 848 & -528 \\
\hline 4:15 PM & 4:30 PM & 69 & 183 & $27.38 \%$ & $72.62 \%$ & 276 & 732 & -456 \\
\hline 4:30 PM & 4:45 PM & 81 & 158 & $33.89 \%$ & $66.11 \%$ & 324 & 632 & -308 \\
\hline 4:45 PM & 5:00 PM & 71 & 134 & $34.63 \%$ & $65.37 \%$ & 284 & 536 & -252 \\
\hline 5:00 PM & 5:15 PM & 47 & 213 & $18.08 \%$ & $81.92 \%$ & 188 & 852 & -664 \\
\hline 5:15 PM & 5:30 PM & 41 & 135 & $23.30 \%$ & $76.70 \%$ & 164 & 540 & -376 \\
\hline 5:30 PM & 5:45 PM & 67 & 125 & $34.90 \%$ & $65.10 \%$ & 268 & 500 & -232 \\
\hline 5:45 PM & 6:00 PM & 110 & 139 & $44.18 \%$ & $55.82 \%$ & 440 & 556 & -116 \\
\hline
\end{tabular}




\begin{tabular}{|c|c|c|c|c|c|c|c|c|}
\hline 6:00 PM & 6:15 PM & 68 & 223 & $23.37 \%$ & $76.63 \%$ & 272 & 892 & -620 \\
\hline 6:15 PM & 6:30 PM & 53 & 198 & $21.12 \%$ & $78.88 \%$ & 212 & 792 & -580 \\
\hline 6:30 PM & $6: 45 \mathrm{PM}$ & 49 & 105 & $31.82 \%$ & $68.18 \%$ & 196 & 420 & -224 \\
\hline $6: 45 \mathrm{PM}$ & 7:00 PM & 80 & 91 & $46.78 \%$ & $53.22 \%$ & 320 & 364 & -44 \\
\hline 7:00 PM & 7:15 PM & 61 & 92 & $39.87 \%$ & $60.13 \%$ & 244 & 368 & -124 \\
\hline 7:15 PM & 7:30 PM & 48 & 85 & $36.09 \%$ & $63.91 \%$ & 192 & 340 & -148 \\
\hline 7:30 PM & 7:45 PM & 72 & 110 & $39.56 \%$ & $60.44 \%$ & 288 & 440 & -152 \\
\hline 7:45 PM & 8:00 PM & 92 & 135 & $40.53 \%$ & $59.47 \%$ & 368 & 540 & -172 \\
\hline 8:00 PM & $8: 15 \mathrm{PM}$ & 63 & 118 & $34.81 \%$ & $65.19 \%$ & 252 & 472 & -220 \\
\hline 8:15 PM & 8:30 PM & 58 & 97 & $37.42 \%$ & $62.58 \%$ & 232 & 388 & -156 \\
\hline 8:30 PM & $8: 45$ PM & 51 & 62 & $45.13 \%$ & $54.87 \%$ & 204 & 248 & -44 \\
\hline 8:45 PM & 9:00 PM & 38 & 48 & $44.19 \%$ & $55.81 \%$ & 152 & 192 & -40 \\
\hline \multicolumn{2}{|c|}{ Totals } & 4368 & 4996 & $46.65 \%$ & $53.35 \%$ & & & \\
\hline
\end{tabular}

\section{5-Minute Volumes for an "Average Day" Cal Poly- Grand Avenue Entrance}

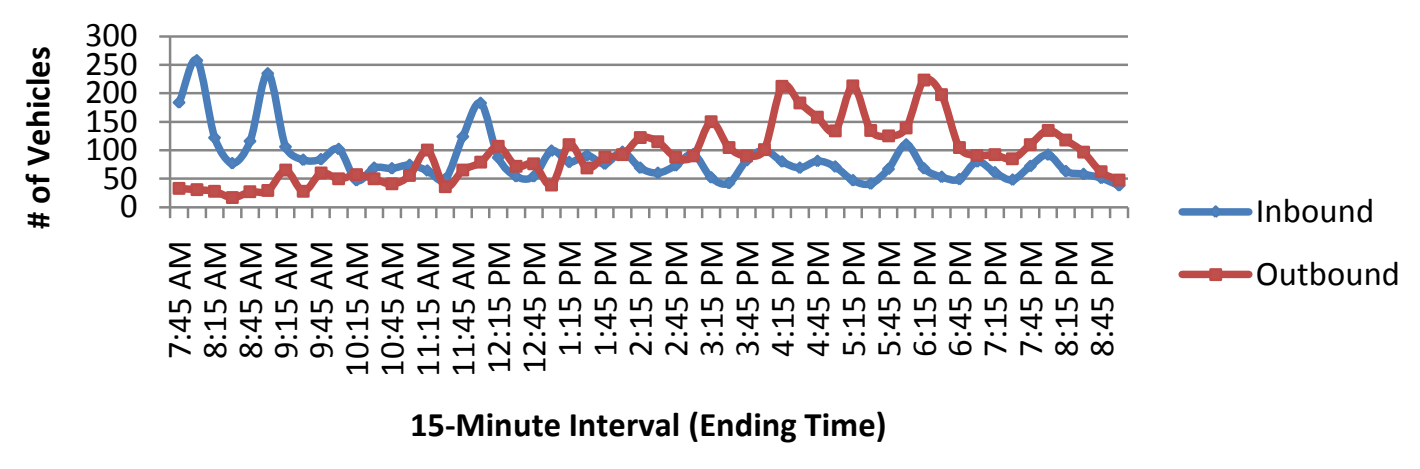

The table below shows all potential peak hours for the Grand Ave Entrance to Cal Poly. The hours highlighted are classified as peak hours according to the key at the bottom of the table. As mentioned in the report body, the AM Peak Hour between 7:30AM-8:30AM is chosen for analysis.

\begin{tabular}{|l|r|r|r|r|r|}
\hline \multicolumn{7}{|c|}{ Potential Peak Hours for Grand Avenue Entrance } \\
\hline $\begin{array}{l}\text { Hour } \\
\text { Begin }\end{array}$ & Hour End & Volume IB & Volume OB & Total Volume & Net Volume \\
\hline 7:30 AM & $8: 30 \mathrm{AM}$ & 641 & -109 & 750 & 532 \\
\hline 7:45 AM & $8: 45 \mathrm{AM}$ & 573 & -103 & 676 & 470 \\
\hline 8:00 AM & $9: 00 \mathrm{AM}$ & 550 & -101 & 651 & 449 \\
\hline 8:15 AM & $9: 15 \mathrm{AM}$ & 534 & -138 & 672 & 396 \\
\hline 8:30 AM & $9: 30 \mathrm{AM}$ & 540 & -149 & 689 & 391 \\
\hline 8:45 AM & $9: 45 \mathrm{AM}$ & 508 & -182 & 690 & 326 \\
\hline $9: 00 \mathrm{AM}$ & $10: 00 \mathrm{AM}$ & 375 & -203 & 578 & 172 \\
\hline $9: 15 \mathrm{AM}$ & $10: 15 \mathrm{AM}$ & 316 & -195 & 511 & 121 \\
\hline $9: 30 \mathrm{AM}$ & $10: 30 \mathrm{AM}$ & 302 & -217 & 519 & 85 \\
\hline $9: 45 \mathrm{AM}$ & $10: 45 \mathrm{AM}$ & 286 & -198 & 484 & 88 \\
\hline 10:00 AM & $11: 00 \mathrm{AM}$ & 258 & -204 & 462 & 54 \\
\hline 10:15 AM & $11: 15 \mathrm{AM}$ & 275 & -247 & 522 & 28 \\
\hline 10:30 AM & $11: 30 \mathrm{AM}$ & 255 & -233 & 488 & 22 \\
\hline
\end{tabular}




\begin{tabular}{|c|c|c|c|c|c|}
\hline 10:45 AM & 11:45 AM & 311 & -257 & 568 & 54 \\
\hline 11:00 AM & 12:00 PM & 420 & -280 & 700 & 140 \\
\hline $11: 15 \mathrm{AM}$ & $12: 15 \mathrm{PM}$ & 443 & -287 & 730 & 156 \\
\hline 11:30 AM & 12:30 PM & 448 & -323 & 771 & 125 \\
\hline $11: 45 \mathrm{AM}$ & 12:45 PM & 378 & -334 & 712 & 44 \\
\hline 12:00 PM & 1:00 PM & 294 & -294 & 588 & 0 \\
\hline 12:15 PM & 1:15 PM & 286 & -297 & 583 & -11 \\
\hline 12:30 PM & 1:30 PM & 323 & -294 & 617 & 29 \\
\hline 12:45 PM & 1:45 PM & 345 & -306 & 651 & 39 \\
\hline 1:00 PM & 2:00 PM & 343 & -359 & 702 & -16 \\
\hline 1:15 PM & 2:15 PM & 333 & -371 & 704 & -38 \\
\hline 1:30 PM & 2:30 PM & 302 & -417 & 719 & -115 \\
\hline 1:45 PM & 2:45 PM & 299 & -417 & 716 & -118 \\
\hline 2:00 PM & 3:00 PM & 295 & -415 & 710 & -120 \\
\hline 2:15 PM & 3:15 PM & 278 & -443 & 721 & -165 \\
\hline 2:30 PM & 3:30 PM & 260 & -433 & 693 & -173 \\
\hline 2:45 PM & 3:45 PM & 269 & -435 & 704 & -166 \\
\hline 3:00 PM & 4:00 PM & 276 & -446 & 722 & -170 \\
\hline 3:15 PM & 4:15 PM & 304 & -508 & 812 & -204 \\
\hline 3:30 PM & 4:30 PM & 331 & -586 & 917 & -255 \\
\hline 3:45 PM & 4:45 PM & 330 & -654 & 984 & -324 \\
\hline 4:00 PM & 5:00 PM & 301 & -687 & 988 & -386 \\
\hline 4:15 PM & 5:15 PM & 268 & -688 & 956 & -420 \\
\hline 4:30 PM & 5:30 PM & 240 & -640 & 880 & -400 \\
\hline 4:45 PM & 5:45 PM & 226 & -607 & 833 & -381 \\
\hline 5:00 PM & 6:00 PM & 265 & -612 & 877 & -347 \\
\hline 5:15 PM & 6:15 PM & 286 & -622 & 908 & -336 \\
\hline 5:30 PM & 6:30 PM & 298 & -685 & 983 & -387 \\
\hline 5:45 PM & 6:45 PM & 280 & -665 & 945 & -385 \\
\hline 6:00 PM & 7:00 PM & 250 & -617 & 867 & -367 \\
\hline 6:15 PM & $7: 15 \mathrm{PM}$ & 243 & -486 & 729 & -243 \\
\hline 6:30 PM & 7:30 PM & 238 & -373 & 611 & -135 \\
\hline 6:45 PM & 7:45 PM & 261 & -378 & 639 & -117 \\
\hline 7:00 PM & 8:00 PM & 273 & -422 & 695 & -149 \\
\hline 7:15 PM & 8:15 PM & 275 & -448 & 723 & -173 \\
\hline 7:30 PM & 8:30 PM & 285 & -460 & 745 & -175 \\
\hline 7:45 PM & 8:45 PM & 264 & -412 & 676 & -148 \\
\hline \multirow[t]{4}{*}{ 8:00 PM } & 9:00 PM & 210 & -325 & 535 & -115 \\
\hline & AM Peak Hour & & & & \\
\hline & $\begin{array}{l}\text { Midday Peak } \\
\text { Hour }\end{array}$ & & & & \\
\hline & PM Peak Hour & & & & \\
\hline
\end{tabular}




\section{Appendix F: OD Matrix Setup Calculations (Partial Sample)}

The calculations below are used to form the Origin/Destination matrix used for Cal Poly's AM Peak Hour.

The notations and calculations correspond to the gravity model formula:

$\mathrm{T}_{\mathrm{ij}}=\mathrm{P}_{\mathrm{i}} *\left(\mathrm{~A}_{\mathrm{j}} \mathrm{F}_{\mathrm{ij}} \mathrm{K}_{\mathrm{ij}} / \Sigma \mathrm{A}_{\mathrm{j}} \mathrm{F}_{\mathrm{ij}} \mathrm{K}_{\mathrm{ij}}\right)$

Where;

$\mathrm{T}_{\mathrm{ij}}=$ trips produced in zone $\mathrm{i}$ and attracted to zone $\mathrm{j}$

$\mathrm{P}_{\mathrm{i}}=$ total trip production at $\mathrm{i}$

$A_{j}=$ total trip production at $j$

$\mathrm{F}_{\mathrm{ij}}=$ friction or travel time factor (calibration term) for interchange $\mathrm{ij}$

$\mathrm{K}_{\mathrm{ij}}=$ socioeconomic adjustment factor for interchange $\mathrm{ij}$

Since attractions are distributed, each table is based off one $j$ value (destination) with multiple calculations for each corresponding $i$ value (origins). Due to the large size of this table, only a sample of calculations is provided.

Distribute Attractions

\begin{tabular}{|c|c|c|c|c|c|}
\hline $\mathbf{j}=\mathbf{1}$ & PiFi1 & PiFi1/Sum(PiFi1) & $\mathrm{Aj}=1$ & Ti1 & \\
\hline $\mathrm{i}=1$ & 0.0000 & 0.0000 & 6 & 0.00 & $\mathrm{~T} 11$ \\
\hline $\mathbf{i}=\mathbf{2}$ & 0.0004 & 0.0000 & 6 & 0.00 & $\mathrm{~T} 21$ \\
\hline $\mathbf{i}=\mathbf{3}$ & 0.0005 & 0.0000 & 6 & 0.00 & $\mathrm{~T} 31$ \\
\hline $\mathrm{i}=4$ & 0.0002 & 0.0000 & 6 & 0.00 & $\mathrm{~T} 41$ \\
\hline $\mathbf{i}=5$ & 0.0001 & 0.0000 & 6 & 0.00 & $\mathrm{~T} 51$ \\
\hline$i=6$ & 0.0006 & 0.0000 & 6 & 0.00 & $\mathrm{~T} 61$ \\
\hline $\mathrm{i}=7$ & 2.4597 & 0.1456 & 6 & 0.87 & $\mathrm{~T} 71$ \\
\hline $\mathrm{i}=\mathbf{8}$ & 0.1450 & 0.0086 & 6 & 0.05 & $\mathrm{~T} 81$ \\
\hline $\mathrm{i}=9$ & 0.0000 & 0.0000 & 6 & 0.00 & $\mathrm{~T} 91$ \\
\hline $\mathrm{i}=10$ & 0.6966 & 0.0412 & 6 & 0.25 & $\mathrm{~T} 101$ \\
\hline $\mathbf{i}=\mathbf{1 1}$ & 0.3175 & 0.0188 & 6 & 0.11 & $\mathrm{~T} 111$ \\
\hline $\mathrm{i}=12$ & 0.4910 & 0.0291 & 6 & 0.17 & $\mathrm{~T} 121$ \\
\hline $\mathrm{i}=13$ & 0.5737 & 0.0340 & 6 & 0.20 & $\mathrm{~T} 131$ \\
\hline $\mathrm{i}=14$ & 3.3756 & 0.1998 & 6 & 1.20 & $\mathrm{~T} 141$ \\
\hline $\mathrm{i}=15$ & 2.2729 & 0.1346 & 6 & 0.81 & $\mathrm{~T} 151$ \\
\hline $\mathrm{i}=16$ & 0.1062 & 0.0063 & 6 & 0.04 & $\mathrm{~T} 161$ \\
\hline $\mathrm{i}=17$ & 0.6393 & 0.0378 & 6 & 0.23 & $\mathrm{~T} 171$ \\
\hline $\mathrm{i}=18$ & 0.1190 & 0.0070 & 6 & 0.04 & $\mathrm{~T} 181$ \\
\hline $\mathrm{i}=19$ & 3.2827 & 0.1943 & 6 & 1.17 & $\mathrm{~T} 191$ \\
\hline $\mathbf{i}=\mathbf{2 0}$ & 0.0191 & 0.0011 & 6 & 0.01 & T201 \\
\hline $\mathrm{i}=\mathbf{2 1}$ & 0.0984 & 0.0058 & 6 & 0.03 & $\mathrm{~T} 211$ \\
\hline $\mathrm{i}=\mathbf{2 2}$ & 0.6944 & 0.0411 & 6 & 0.25 & $\mathrm{~T} 221$ \\
\hline $\mathbf{i}=\mathbf{2 3}$ & 0.0000 & 0.0000 & 6 & 0.00 & $\mathrm{~T} 231$ \\
\hline $\mathbf{i}=\mathbf{2 4}$ & 0.0000 & 0.0000 & 6 & 0.00 & $\mathrm{~T} 241$ \\
\hline $\mathrm{i}=25$ & 0.5869 & 0.0347 & 6 & 0.21 & $\mathrm{~T} 251$ \\
\hline$i=26$ & 0.0245 & 0.0014 & 6 & 0.01 & $\mathrm{~T} 261$ \\
\hline $\mathrm{i}=27$ & 0.0000 & 0.0000 & 6 & 0.00 & $\mathrm{~T} 271$ \\
\hline
\end{tabular}




\begin{tabular}{|c|c|c|c|c|c|}
$\mathbf{i}=\mathbf{2 8}$ & 0.0763 & 0.0045 & 6 & 0.03 & $\mathrm{~T} 281$ \\
$\mathbf{i}=\mathbf{2 9}$ & 0.6033 & 0.0357 & 6 & 0.21 & $\mathrm{~T} 291$ \\
$\mathbf{i}=\mathbf{3 0}$ & 0.0229 & 0.0014 & 6 & 0.01 & $\mathrm{~T} 301$ \\
$\mathbf{i}=\mathbf{3 1}$ & 0.0410 & 0.0024 & 6 & 0.01 & $\mathrm{~T} 311$ \\
$\mathbf{i}=\mathbf{3 2}$ & 0.1403 & 0.0083 & 6 & 0.05 & $\mathrm{~T} 321$ \\
$\mathbf{i}=\mathbf{3 3}$ & 0.1036 & 0.0061 & 6 & 0.04 & $\mathrm{~T} 331$ \\
Sum & 16.8918 & 1.0000 & & 6.0000 & \\
\hline
\end{tabular}

\begin{tabular}{|c|c|c|c|c|c|}
\hline $\mathbf{j}=\mathbf{2}$ & $\mathrm{PiFi} 2$ & $\mathrm{PiFi} 2 / \mathrm{Sum}(\mathrm{PiFi} 2)$ & $\mathrm{Aj}=2$ & $\mathrm{Ti} 2$ & \\
\hline $\mathbf{i}=\mathbf{1}$ & 0.0000 & 0.0000 & 74 & 0.00 & $\mathrm{~T} 12$ \\
\hline $\mathrm{i}=2$ & 0.0004 & 0.0000 & 74 & 0.00 & $\mathrm{~T} 22$ \\
\hline $\mathbf{i}=\mathbf{3}$ & 0.0005 & 0.0000 & 74 & 0.00 & $\mathrm{~T} 32$ \\
\hline$i=4$ & 0.0002 & 0.0000 & 74 & 0.00 & $\mathrm{~T} 42$ \\
\hline $\mathbf{i}=\mathbf{5}$ & 0.0001 & 0.0000 & 74 & 0.00 & T52 \\
\hline$i=6$ & 0.0006 & 0.0000 & 74 & 0.00 & T62 \\
\hline $\mathrm{i}=7$ & 5.5773 & 0.1077 & 74 & 7.97 & $\mathrm{~T} 72$ \\
\hline $\mathrm{i}=\mathbf{8}$ & 0.3156 & 0.0061 & 74 & 0.45 & $\mathrm{~T} 82$ \\
\hline $\mathrm{i}=9$ & 0.0000 & 0.0000 & 74 & 0.00 & T92 \\
\hline $\mathbf{i}=\mathbf{1 0}$ & 1.6602 & 0.0321 & 74 & 2.37 & $\mathrm{~T} 102$ \\
\hline $\mathrm{i}=\mathbf{1 1}$ & 0.6823 & 0.0132 & 74 & 0.97 & $\mathrm{~T} 112$ \\
\hline $\mathbf{i}=12$ & 1.2401 & 0.0239 & 74 & 1.77 & $\mathrm{~T} 122$ \\
\hline $\mathrm{i}=13$ & 0.9736 & 0.0188 & 74 & 1.39 & $\mathrm{~T} 132$ \\
\hline $\mathrm{i}=14$ & 2.0275 & 0.0392 & 74 & 2.90 & T142 \\
\hline $\mathrm{i}=15$ & 11.7952 & 0.2278 & 74 & 16.86 & $\mathrm{~T} 152$ \\
\hline $\mathrm{i}=16$ & 0.3742 & 0.0072 & 74 & 0.53 & T162 \\
\hline $\mathrm{i}=17$ & 2.7500 & 0.0531 & 74 & 3.93 & $\mathrm{~T} 172$ \\
\hline $\mathrm{i}=\mathbf{1 8}$ & 0.5000 & 0.0097 & 74 & 0.71 & $\mathrm{~T} 182$ \\
\hline $\mathrm{i}=19$ & 14.7125 & 0.2841 & 74 & 21.02 & $\mathrm{~T} 192$ \\
\hline $\mathbf{i}=\mathbf{2 0}$ & 0.0496 & 0.0010 & 74 & 0.07 & $\mathrm{~T} 202$ \\
\hline $\mathrm{i}=21$ & 0.2959 & 0.0057 & 74 & 0.42 & $\mathrm{~T} 212$ \\
\hline $\mathrm{i}=\mathbf{2 2}$ & 3.1123 & 0.0601 & 74 & 4.45 & $\mathrm{~T} 222$ \\
\hline $\mathbf{i}=\mathbf{2 3}$ & 0.0000 & 0.0000 & 74 & 0.00 & $\mathrm{~T} 232$ \\
\hline $\mathbf{i}=24$ & 0.0000 & 0.0000 & 74 & 0.00 & $\mathrm{~T} 242$ \\
\hline $\mathrm{i}=25$ & 2.5826 & 0.0499 & 74 & 3.69 & $\mathrm{~T} 252$ \\
\hline$i=26$ & 0.1298 & 0.0025 & 74 & 0.19 & $\mathrm{~T} 262$ \\
\hline $\mathrm{i}=27$ & 0.2703 & 0.0052 & 74 & 0.39 & T272 \\
\hline $\mathrm{i}=28$ & 0.3718 & 0.0072 & 74 & 0.53 & $\mathrm{~T} 282$ \\
\hline $\mathrm{i}=\mathbf{2 9}$ & 1.6220 & 0.0313 & 74 & 2.32 & $\mathrm{~T} 292$ \\
\hline $\mathrm{i}=\mathbf{3 0}$ & 0.0750 & 0.0014 & 74 & 0.11 & T302 \\
\hline $\mathbf{i}=\mathbf{3 1}$ & 0.1054 & 0.0020 & 74 & 0.15 & $\mathrm{~T} 312$ \\
\hline $\mathrm{i}=32$ & 0.3156 & 0.0061 & 74 & 0.45 & T322 \\
\hline $\mathrm{i}=\mathbf{3 3}$ & 0.2421 & 0.0047 & 74 & 0.35 & $\mathrm{~T} 332$ \\
\hline Sum & 51.7829 & 1.0000 & & 74.00 & \\
\hline
\end{tabular}

\begin{tabular}{|c|c|c|c|c|c|}
\hline Same & Trend & Continues & Same & Trend & Continues \\
\hline $\mathrm{j}=33$ & PiFi33 & PiFi33/Sum(PiFi33) & $\mathrm{Aj}=33$ & Ti33 & \\
\hline $\mathbf{i}=\mathbf{1}$ & 1.3129 & 0.0067 & 3 & 0.02 & $\mathrm{~T} 133$ \\
\hline $\mathrm{i}=2$ & 35.0271 & 0.1787 & 3 & 0.54 & $\mathrm{~T} 233$ \\
\hline $\mathbf{i}=\mathbf{3}$ & 44.6187 & 0.2276 & 3 & 0.68 & T333 \\
\hline $\mathrm{i}=4$ & 0.0002 & 0.0000 & 3 & 0.00 & $\mathrm{~T} 433$ \\
\hline $\mathrm{i}=5$ & 0.0001 & 0.0000 & 3 & 0.00 & T533 \\
\hline$i=6$ & 115.0891 & 0.5870 & 3 & 1.76 & T633 \\
\hline $\mathrm{i}=7$ & 0.0001 & 0.0000 & 3 & 0.00 & T733 \\
\hline
\end{tabular}




\begin{tabular}{|c|c|c|c|c|c|}
\hline $\mathrm{i}=8$ & 0.0000 & 0.0000 & 3 & 0.00 & T833 \\
\hline $\mathrm{i}=9$ & 0.0000 & 0.0000 & 3 & 0.00 & T933 \\
\hline $\mathrm{i}=\mathbf{1 0}$ & 0.0000 & 0.0000 & 3 & 0.00 & $\mathrm{~T} 1033$ \\
\hline $\mathrm{i}=\mathbf{1 1}$ & 0.0000 & 0.0000 & 3 & 0.00 & $\mathrm{~T} 1133$ \\
\hline $\mathrm{i}=12$ & 0.0000 & 0.0000 & 3 & 0.00 & $\mathrm{~T} 1233$ \\
\hline $\mathrm{i}=13$ & 0.0000 & 0.0000 & 3 & 0.00 & $\mathrm{~T} 1333$ \\
\hline $\mathrm{i}=14$ & 0.0000 & 0.0000 & 3 & 0.00 & $\mathrm{~T} 1433$ \\
\hline $\mathrm{i}=15$ & 0.0000 & 0.0000 & 3 & 0.00 & $\mathrm{~T} 1533$ \\
\hline $\mathrm{i}=16$ & 0.0000 & 0.0000 & 3 & 0.00 & $\mathrm{~T} 1633$ \\
\hline $\mathrm{i}=\mathbf{1 7}$ & 0.0000 & 0.0000 & 3 & 0.00 & $\mathrm{~T} 1733$ \\
\hline $\mathrm{i}=\mathbf{1 8}$ & 0.0000 & 0.0000 & 3 & 0.00 & T1833 \\
\hline $\mathrm{i}=19$ & 0.0001 & 0.0000 & 3 & 0.00 & T1933 \\
\hline $\mathbf{i}=\mathbf{2 0}$ & 0.0000 & 0.0000 & 3 & 0.00 & T2033 \\
\hline $\mathrm{i}=\mathbf{2 1}$ & 0.0000 & 0.0000 & 3 & 0.00 & $\mathrm{~T} 2133$ \\
\hline $\mathrm{i}=\mathbf{2 2}$ & 0.0000 & 0.0000 & 3 & 0.00 & T2233 \\
\hline $\mathbf{i}=\mathbf{2 3}$ & 0.0000 & 0.0000 & 3 & 0.00 & $\mathrm{~T} 2333$ \\
\hline $\mathrm{i}=\mathbf{2 4}$ & 0.0000 & 0.0000 & 3 & 0.00 & $\mathrm{~T} 2433$ \\
\hline $\mathrm{i}=25$ & 0.0000 & 0.0000 & 3 & 0.00 & $\mathrm{~T} 2533$ \\
\hline$i=26$ & 0.0000 & 0.0000 & 3 & 0.00 & T2633 \\
\hline $\mathbf{i}=27$ & 0.0000 & 0.0000 & 3 & 0.00 & $\mathrm{~T} 2733$ \\
\hline $\mathrm{i}=28$ & 0.0000 & 0.0000 & 3 & 0.00 & $\mathrm{~T} 2833$ \\
\hline $\mathrm{i}=29$ & 0.0000 & 0.0000 & 3 & 0.00 & T2933 \\
\hline $\mathrm{i}=\mathbf{3 0}$ & 0.0000 & 0.0000 & 3 & 0.00 & T3033 \\
\hline $\mathbf{i}=\mathbf{3 1}$ & 0.0000 & 0.0000 & 3 & 0.00 & T3133 \\
\hline $\mathrm{i}=32$ & 0.0000 & 0.0000 & 3 & 0.00 & T3233 \\
\hline $\mathbf{i}=\mathbf{3 3}$ & 0.0000 & 0.0000 & 3 & 0.00 & T3333 \\
\hline Sum & 196.0483 & 1.0000 & & 3.0000 & \\
\hline
\end{tabular}




\section{Appendix G: Calculation of Parking Lot Utilities \& Probabilities}

The table below shows the calculation of parking lot utilities and their associated probabilities in Excel using the Logit function for parking lot selection as follows:

Probability of choosing lot $\mathrm{i}=\mathrm{e}^{\wedge}\left(\right.$ utility (i))/ $/ \sum$ from $\mathrm{i}=1$ to $\mathrm{n}$ of $\mathrm{e}^{\wedge}$ (utility(i))

Where:

Utility $(\mathrm{i})=(0 *$ Parking Cost $(\mathrm{i}))+(1 *$ Attraction $(\mathrm{i}))+(0 *$ Distance from desired zone $(\mathrm{i}))+(0 *$ Distance from current position(i)) $+(0 *$ current parking availability(i))

Calculations are shown on a possible-decision basis, that is, zones that share a common number of parking lots are grouped together. Zones with a few parking lots split their probabilities only a few ways while zones with many parking lots split their probabilities many ways.

\begin{tabular}{|c|c|c|c|c|c|}
\hline \multicolumn{6}{|c|}{ Parking Lot Utilities and Probabilities } \\
\hline \multicolumn{6}{|c|}{$\begin{array}{l}\text { Assumption: All utilities and probabilities are calculated with an attraction coefficient of "1" in the Logit equation. All other } \\
\text { coefficients are equal to "0". }\end{array}$} \\
\hline \multicolumn{6}{|c|}{ The sum of probabilities for all parking lots belonging to a particular lot is equal to $100 \%$} \\
\hline & $\underline{2 \text { possible decisions }}$ & & & \multicolumn{2}{|c|}{$\begin{array}{c}\text { Simulation Results for Verifying } \\
\text { Excel Calculations }\end{array}$} \\
\hline Zone & Lot Possibilities & Utility & Probability & Vehicle Count & $\begin{array}{l}\text { Percentage (of } \\
\text { Zone Traffic) }\end{array}$ \\
\hline 7 & G5 Structure- Top Floor & 3.5 & $18.24 \%$ & 65 & $15.44 \%$ \\
\hline 7 & G5 Structure- Lower Levels & 5 & $81.76 \%$ & 356 & $84.56 \%$ \\
\hline 8 & Pacheco Entrance & 2 & $4.74 \%$ & 3 & $6.98 \%$ \\
\hline 8 & Grand Entrance & 5 & $95.26 \%$ & 40 & $93.02 \%$ \\
\hline 9 & Slack Entrance & 5 & $66.82 \%$ & 0 & unused \\
\hline 9 & Hathway Entrance & 4.3 & $33.18 \%$ & 0 & unused \\
\hline 13 & R4 Main Entrance & 5 & $88.08 \%$ & 10 & $100.00 \%$ \\
\hline 13 & R4 Bottom Entrance & 3 & $11.92 \%$ & 0 & $0.00 \%$ \\
\hline 22 & H16 Lower Entrance & 5 & $88.08 \%$ & 39 & $81.25 \%$ \\
\hline 22 & H16 Upper Entrance & 3 & $11.92 \%$ & 9 & $18.75 \%$ \\
\hline 25 & California Blvd East & 5 & $77.73 \%$ & 40 & $76.92 \%$ \\
\hline 25 & California Blvd West & 3.75 & $22.27 \%$ & 12 & $23.08 \%$ \\
\hline 31 & Mountain Lane & 5 & $73.11 \%$ & 0 & $0.00 \%$ \\
\hline 31 & Grand Ave & 4 & $26.89 \%$ & 1 & $100.00 \%$ \\
\hline 33 & Cerro Vista Lower & 5 & $54.98 \%$ & 0 & $0.00 \%$ \\
\hline \multirow[t]{3}{*}{33} & Cerro Vista Upper & 4.8 & $45.02 \%$ & 2 & $100.00 \%$ \\
\hline & & & & & \\
\hline & $\underline{3}$ possible decisions & & & & \\
\hline Zone & Lot Possibilities & Utility & Probability & & \\
\hline 27 & Campus Dining & 4.75 & $40.69 \%$ & & \\
\hline 27 & Power & 3 & $7.07 \%$ & & \\
\hline 27 & Cohan Center & 5 & $52.24 \%$ & & \\
\hline 30 & Dexter & 5 & $33.33 \%$ & & \\
\hline 30 & Foundation & 5 & $33.33 \%$ & & \\
\hline 30 & Engineering 13 & 5 & $33.33 \%$ & & \\
\hline 32 & Canyon Circle/Village & 4.8 & $34.58 \%$ & & \\
\hline
\end{tabular}




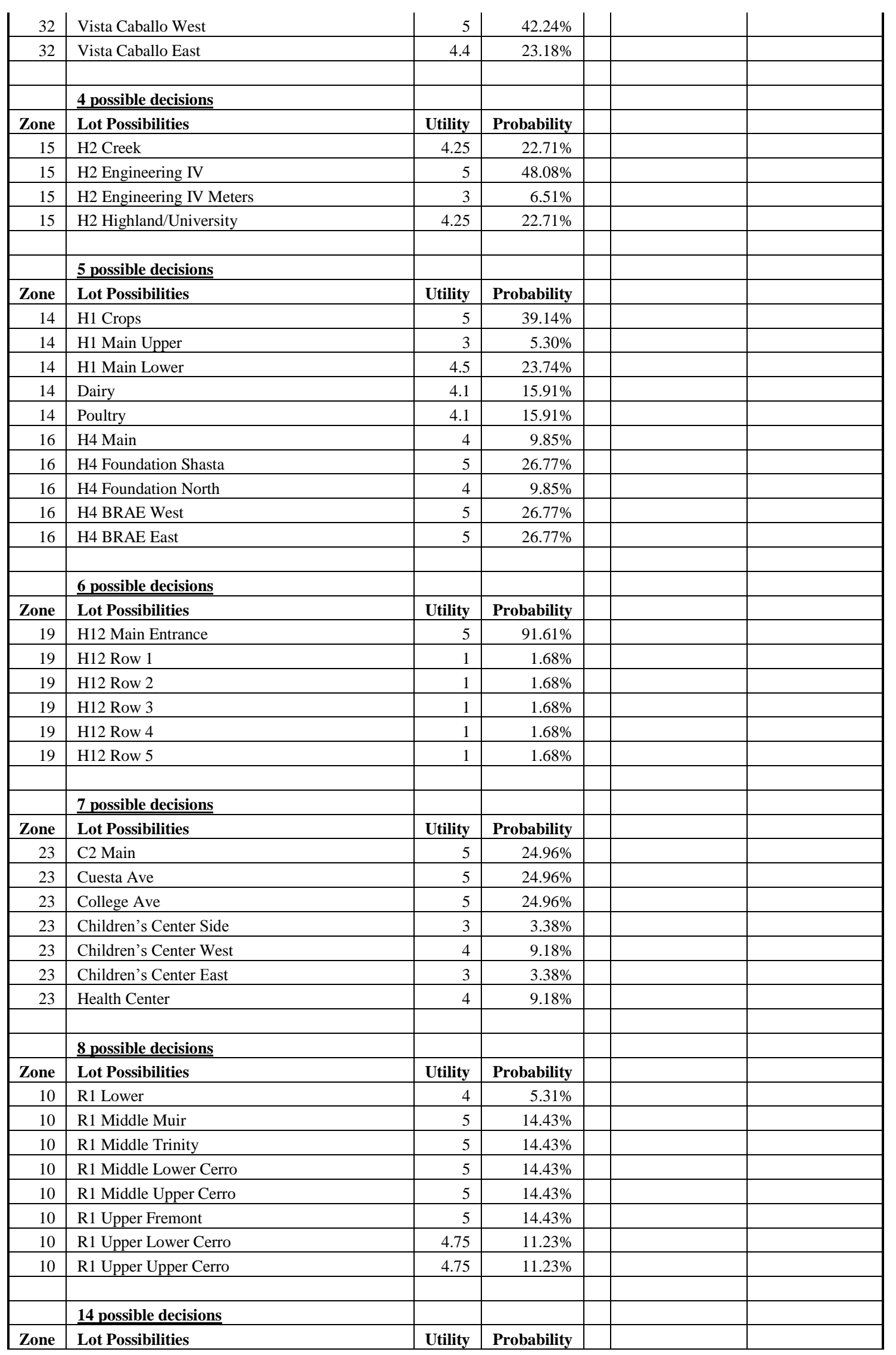




\begin{tabular}{|c|c|c|c|c|c|}
\hline 21 & H14 Lower & 5 & $53.43 \%$ & & \\
\hline 21 & H14 Upper & 4 & $19.65 \%$ & & \\
\hline 21 & H14 Sports Complex R1 & 2 & $2.66 \%$ & & \\
\hline 21 & H14 Sports Complex R2 & 2 & $2.66 \%$ & & \\
\hline 21 & H14 Upper Baseball & 2 & $2.66 \%$ & & \\
\hline 21 & H14 Upper Baseball Sports Complex R1 & 1 & $0.98 \%$ & & \\
\hline 21 & H14 Upper Baseball Sports Complex R2 & 1 & $0.98 \%$ & & \\
\hline 21 & H14 Lower Equine & 2 & $2.66 \%$ & & \\
\hline 21 & H14 Upper Equine & 2 & $2.66 \%$ & & \\
\hline 21 & H14 Arboretum & 1 & $0.98 \%$ & & \\
\hline 21 & H14 Swine & 1 & $0.98 \%$ & & \\
\hline 21 & H14 Lower Horticulture & 2 & $2.66 \%$ & & \\
\hline 21 & H14 Upper Horticulture & 2.5 & $4.39 \%$ & & \\
\hline 21 & H15 Sports Complex & 2 & $2.66 \%$ & & \\
\hline
\end{tabular}




\section{Appendix H: Intersection Configuration for Model Verification}

The following sketches are intersection configurations which are used in model development and verification.

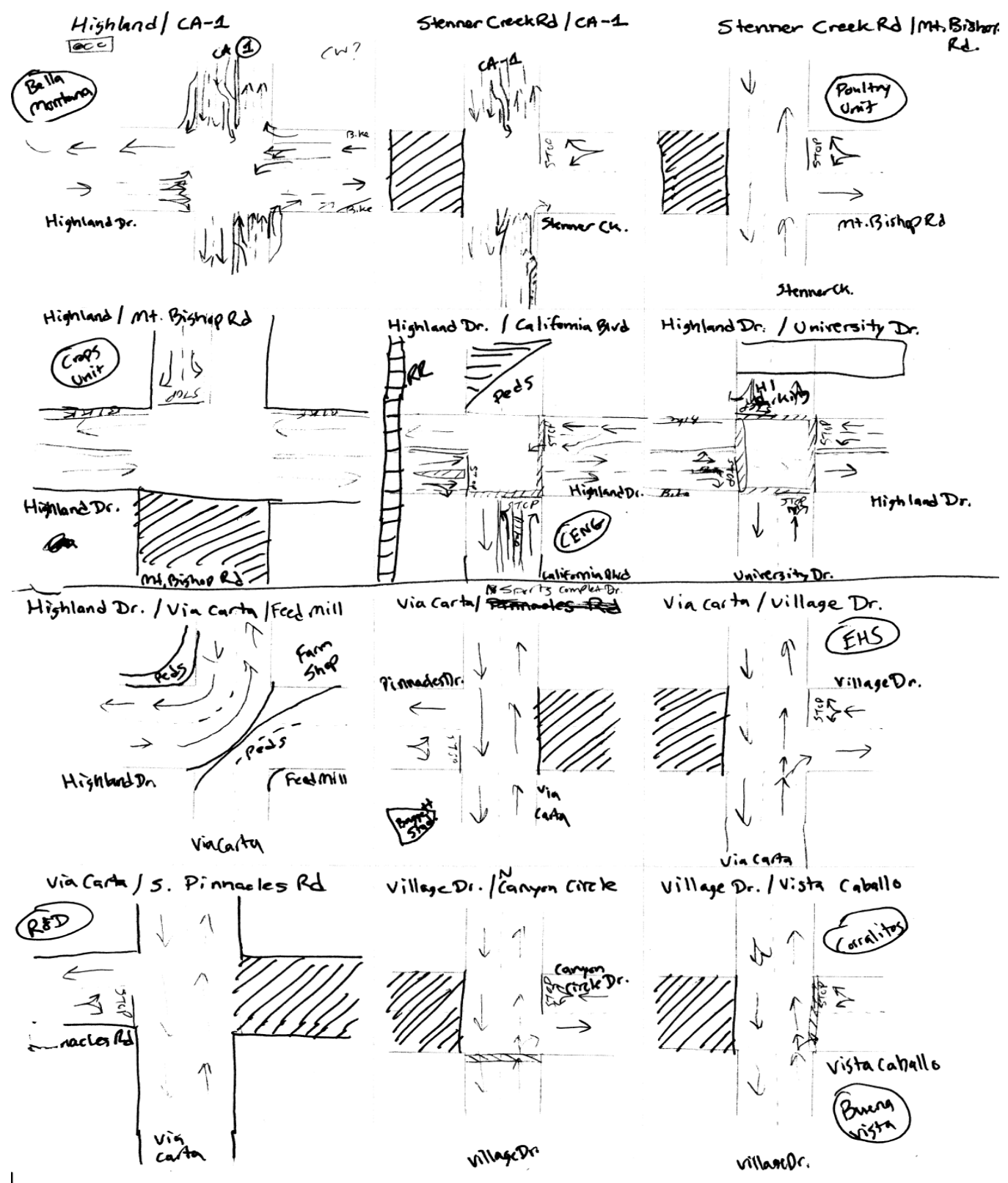


campon cirele or / v ista Caballo village Dr. 15. Campenciele / Village Dr / Truekee Rd
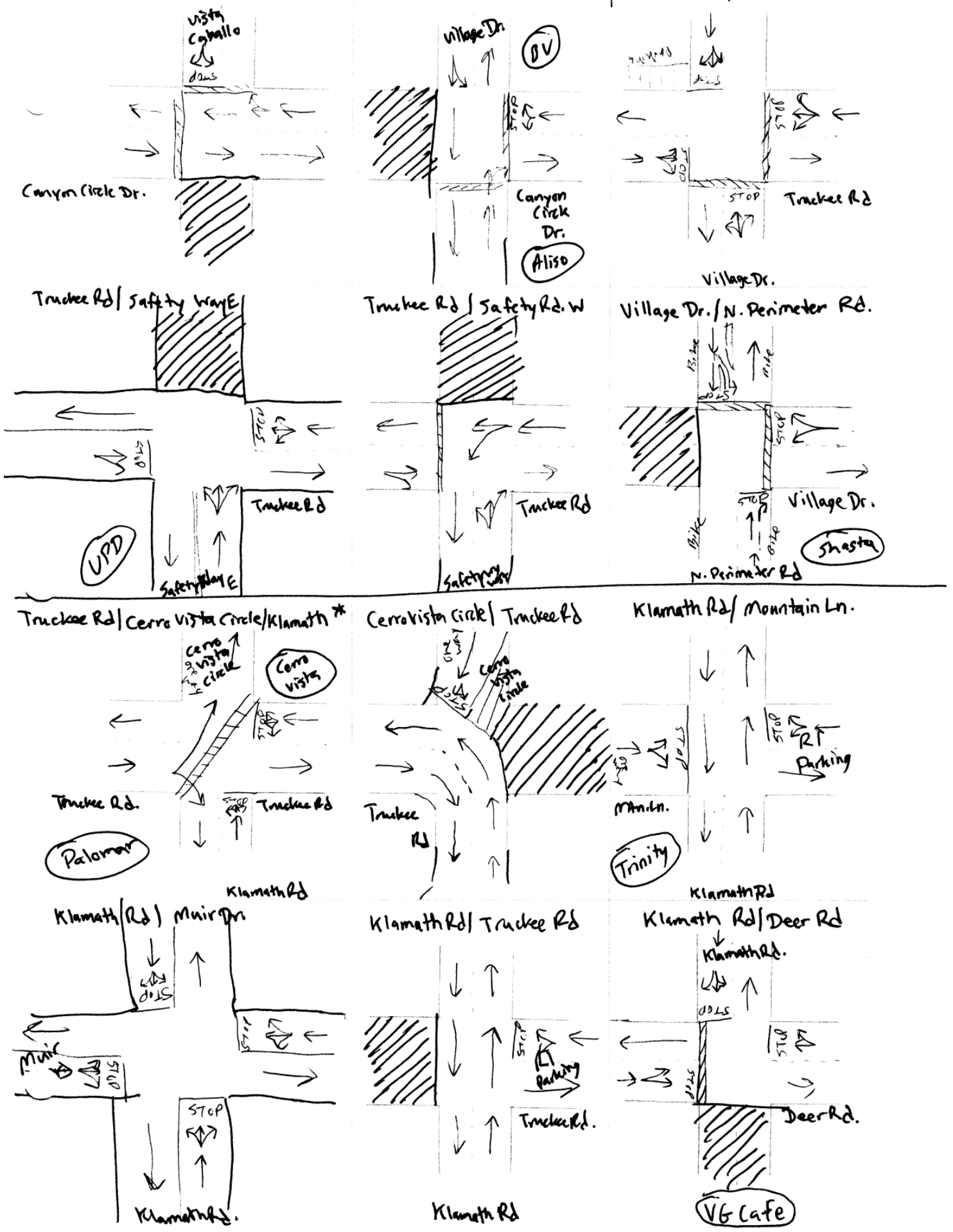

120 


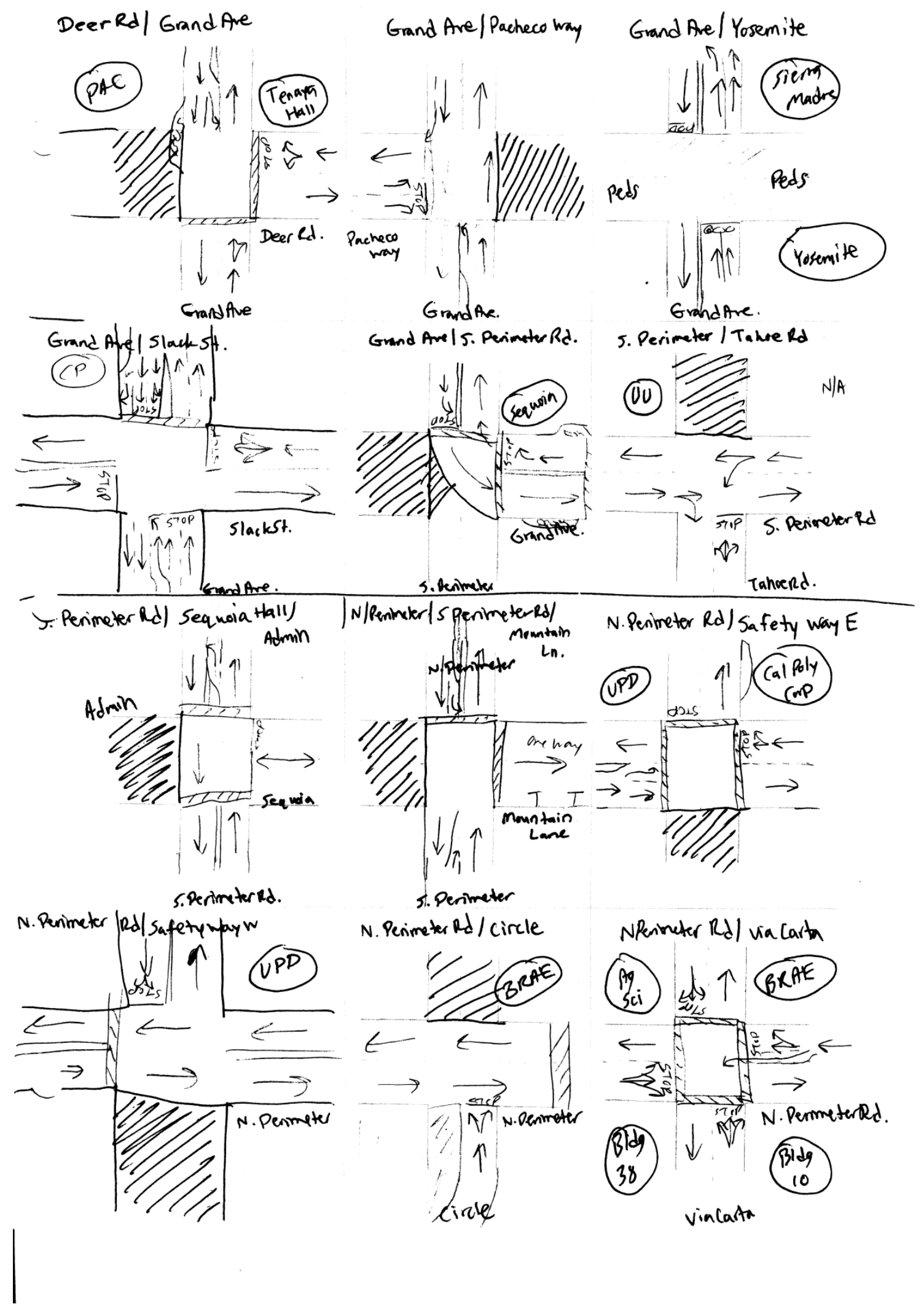


murrayst. / cas 8 \$t.

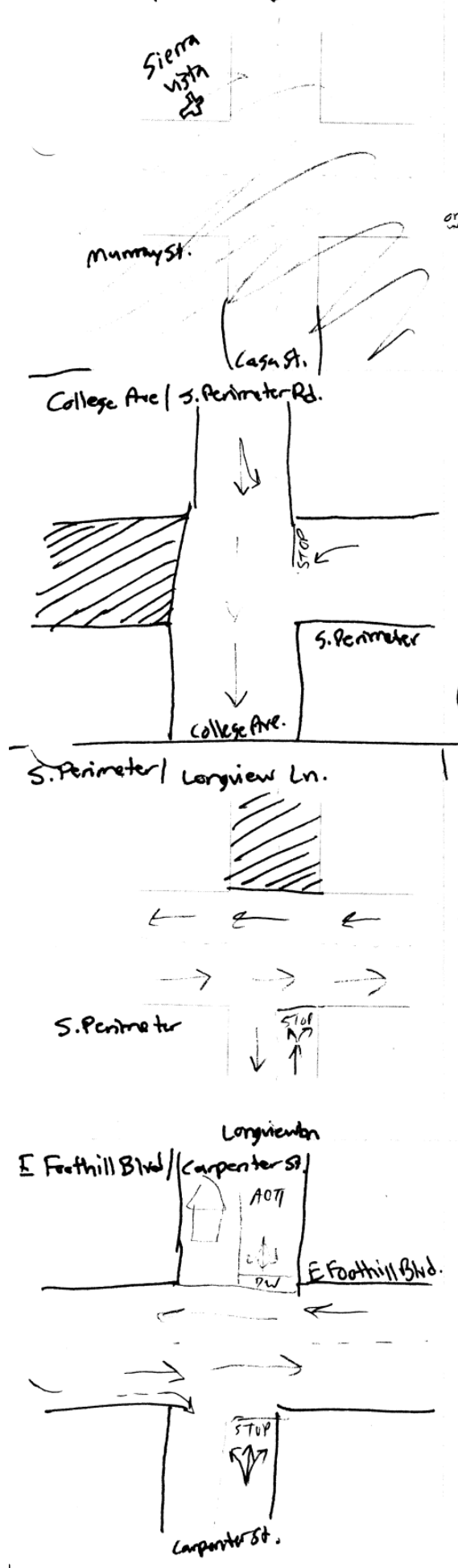

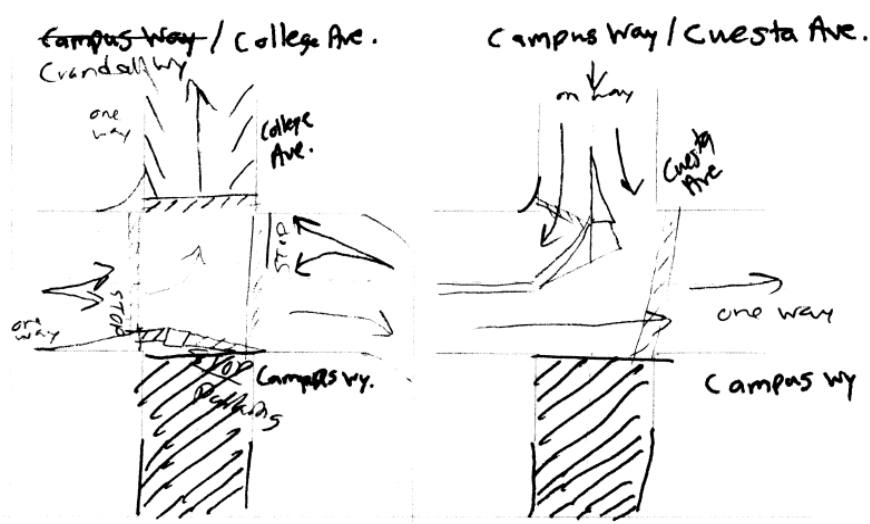

Cuesta Are. /s. Rermeter Rd.

Cuesta Are/ College Ave.

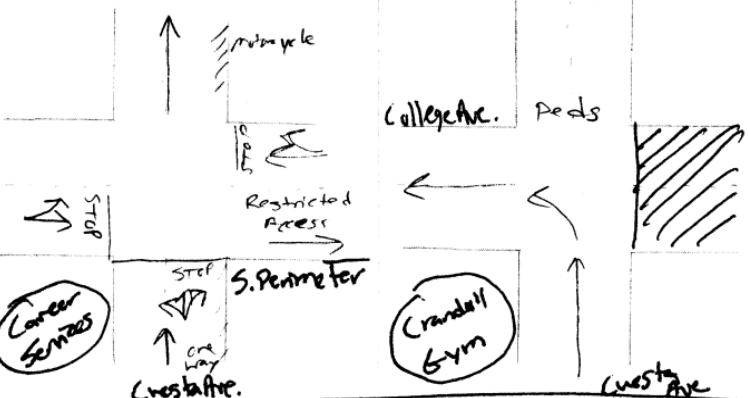

Crandall way/ campusway Crandall Woy/ E Foothill BIVd

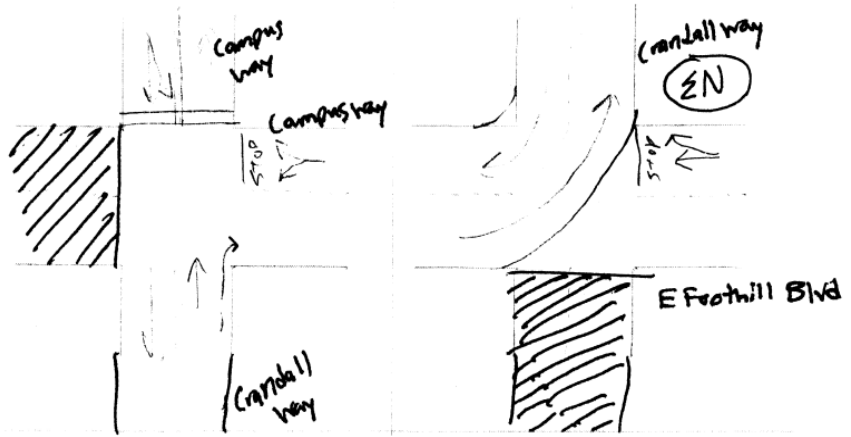
Hathway Ave/compenterst. Hathmay Are/Longview In

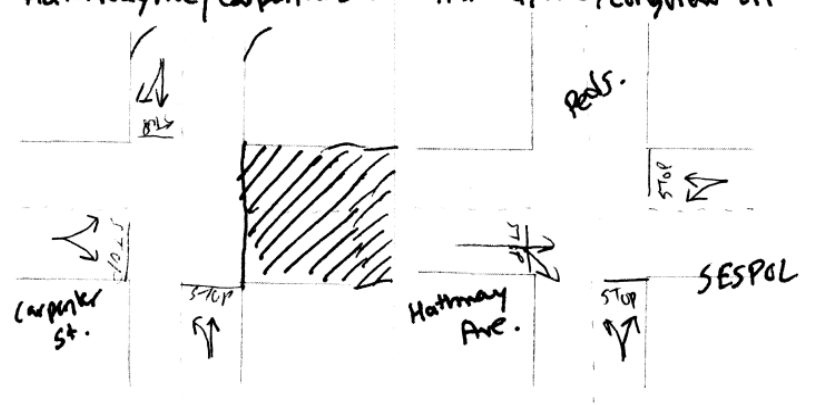
Hathrofte comprewhn. 
N. Perimeter Rd/Nowy Way/University Entanceway/Navy tray/Dexted) Califormia Blud. IEntrance way
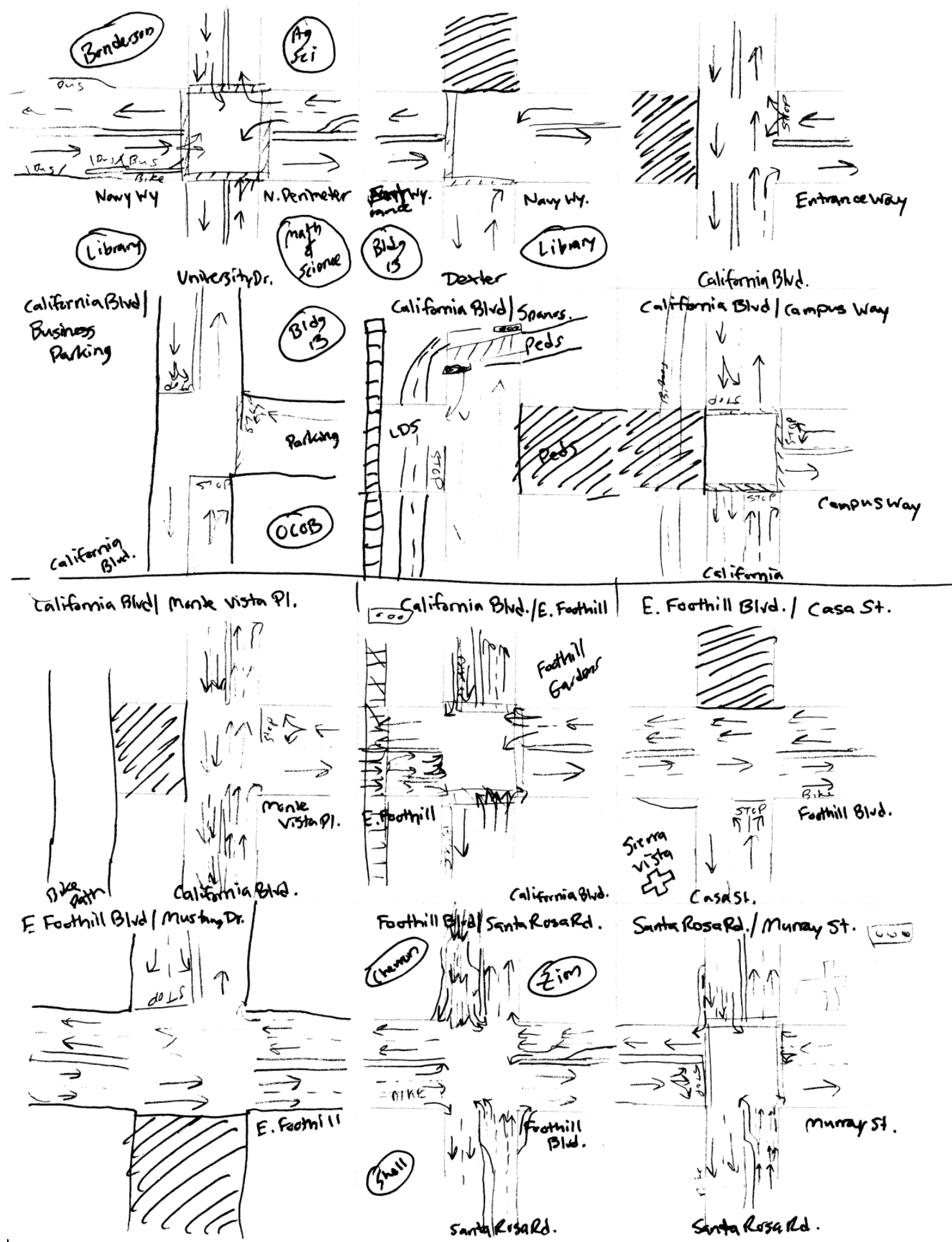
Longiowln. / Slack St.

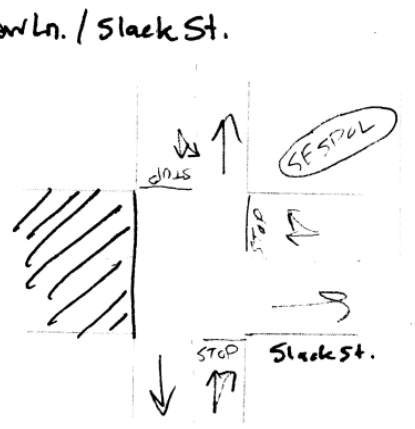

slack St. / Pacheco Way

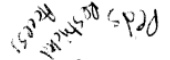
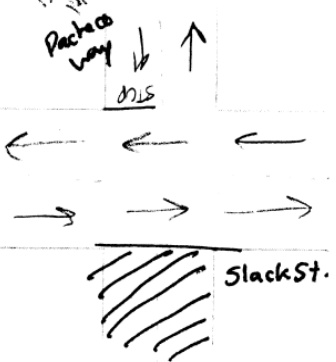

longrieuth

Grand Are / Loomis St.//101 SB Ent.
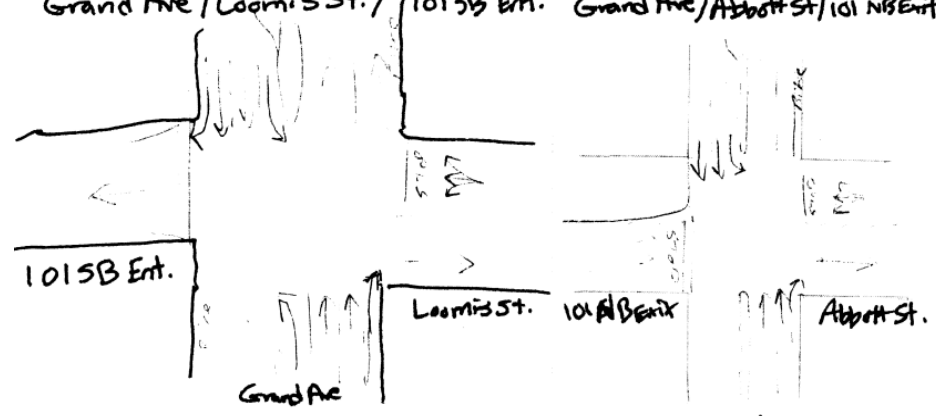

Califomia Bivd. / Taftst. 1 TaftSt. / Kentucky Are/101

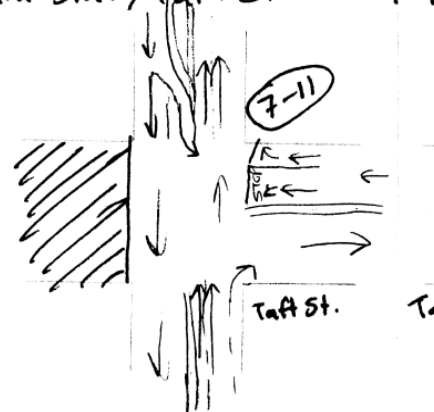

Califomia Bund.

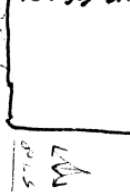

Grand Ave/Atbottst/101 NBEnit

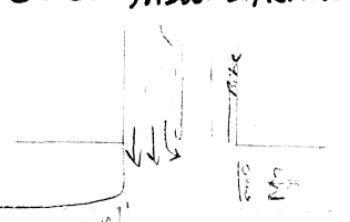

Abpottst.

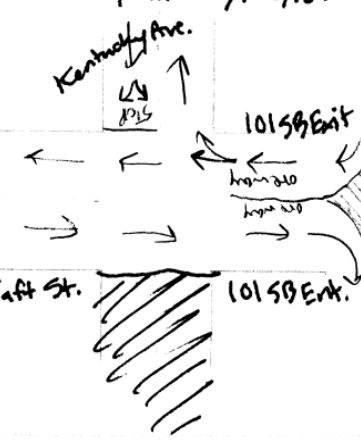

Grand Ave/ Monterey st.
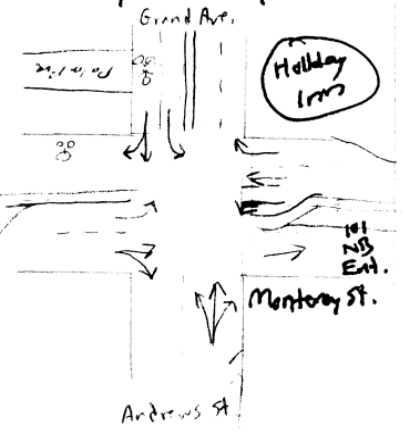

Grand Avel Slack St.

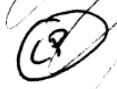

SlackSt.

Grand Ave.

Hathwry Ave/ Califormia Bud.

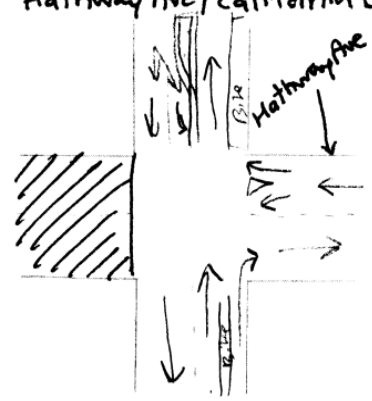

califomingute

Califormin Biod./101 NB 


\section{Appendix I: Data Collection Summaries for Key Interior Intersections}

The following tables are summaries of the traffic studies done at key intersections interior to the campus.

These studies are done at Grand/Pacheco/Deer, Highland/University and N Perimeter/Village Dr.

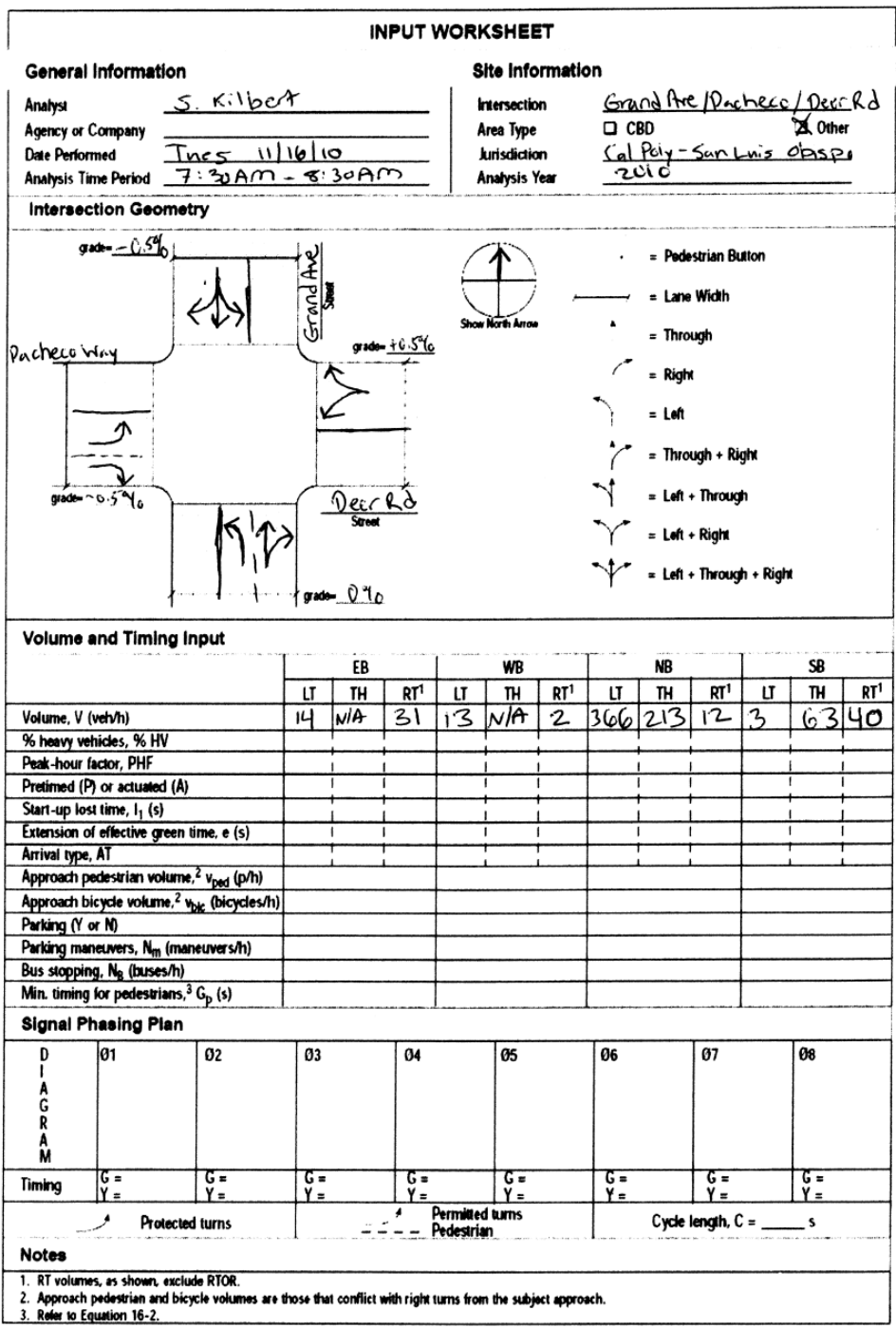

591 inberand to campus from formd

406 into 65 qange/PAC loading (366 fam 6annd, 40 from campus core)

15 into residenas vin Deer Rd ( 12 from Gamd, 3 from campus core) 6

15 out from residences vin Deer Rd $(13+2)$

107 lewing campus 


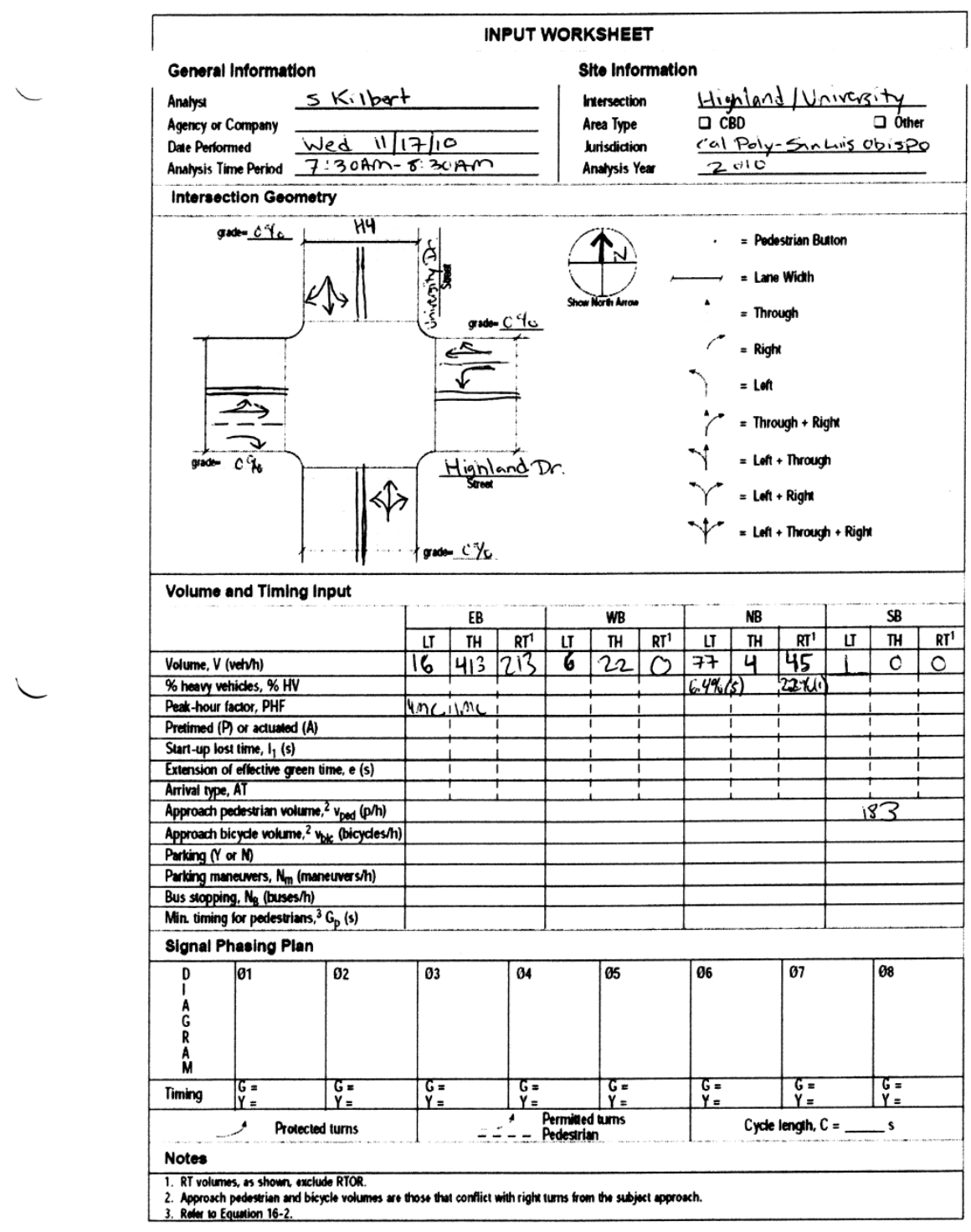

642 inbound on Highland

459 toward Via Coita parking / PCV

219 toward campus core 


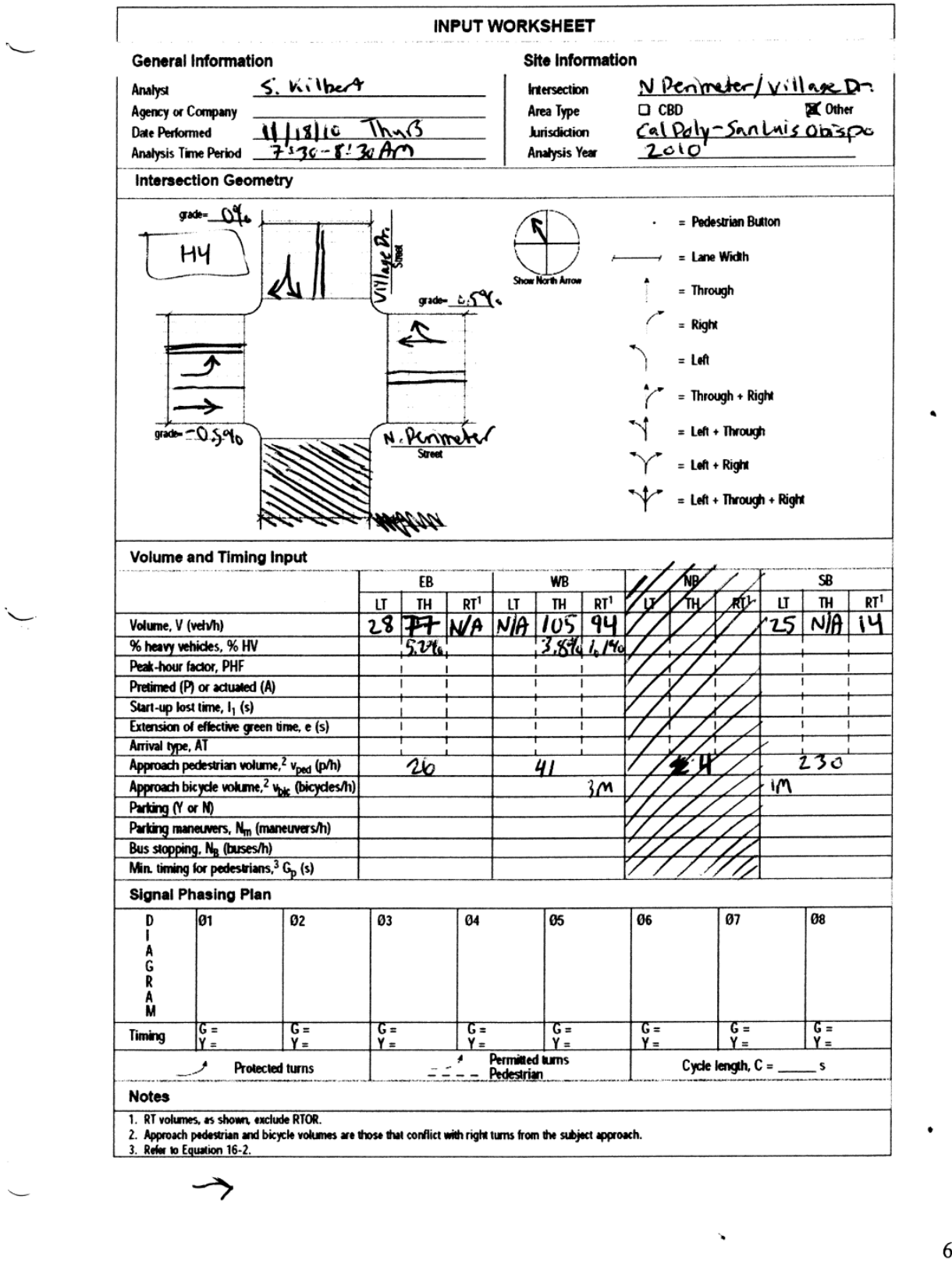




\section{Appendix J: Calibration Summaries by Iteration}

The following tables show summaries for each iteration of calibration. Ten random seeds are assumed for each of the 30 turning movements. The cells highlighted in red indicate GEH statistics in excess of the threshold of "5".

\begin{tabular}{|c|c|c|c|c|c|c|c|c|c|c|c|c|c|c|c|c|}
\hline \multicolumn{17}{|c|}{ Calibration-Initial Summary } \\
\hline & Movement & VISSIM Notation & Simulation & Actual & GEH Statistic & Seed 42 & Seed 13 & Seed 24 & Seed 500 & Seed 6 & Seed 2 & Seed 67 & Seed 681 & Seed 266 & \begin{tabular}{|l|} 
Seed 52 \\
\end{tabular} & Average \\
\hline \multirow{12}{*}{ 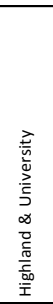 } & EbL & $\mathrm{W}-\mathrm{N}$ & 33.3 & 16 & 3.4844773 & 38 & 37 & 30 & 29 & 29 & 32 & 31 & 31 & 44 & 32 & 33.3 \\
\hline & EbT & W-E & 254.7 & 413 & 8.6637363 & 263 & 263 & 238 & 264 & 269 & 271 & 258 & 243 & 217 & 261 & 254.7 \\
\hline & $\mathrm{EbR}$ & W-S & 323.3 & 213 & 6.7357601 & 332 & 337 & 304 & 335 & 326 & 353 & 339 & 322 & 261 & 324 & 323.3 \\
\hline & WbR & E-N & 0 & 0 & \#DIV/0! & 0 & 0 & 0 & 0 & 0 & 0 & 0 & 0 & 0 & 0 & 0 \\
\hline & WbT & E-W & 76.6 & 22 & 7.7762315 & 76 & 78 & 77 & 77 & 78 & 74 & 75 & 78 & 77 & 76 & 76.6 \\
\hline & WbL & E-S & 5.6 & 6 & 0.166091 & 4 & 6 & 4 & 6 & 6 & 5 & 7 & 6 & 5 & 7 & 5.6 \\
\hline & $\mathrm{NbL}$ & s-w & 73.8 & 77 & 0.3685228 & 75 & 69 & 77 & 73 & 78 & 72 & 74 & 71 & 74 & 75 & 73.8 \\
\hline & NbT & S-N & 5.3 & 4 & 0.6028606 & 0 & 6 & 7 & 7 & 5 & 4 & 6 & 6 & 5 & 7 & 5.3 \\
\hline & $\mathrm{NbR}$ & S-E & 42.2 & 45 & 0.4240478 & 44 & 43 & 41 & 42 & 44 & 40 & 43 & 44 & 41 & 40 & 42.2 \\
\hline & $\mathrm{SbL}$ & $\mathrm{N}-\mathrm{E}$ & 0 & 1 & 1.4142136 & 0 & 0 & 0 & 0 & 0 & 0 & 0 & 0 & 0 & 0 & 0 \\
\hline & SbT & $\mathrm{N}-\mathrm{S}$ & 0.6 & 0 & 1.0954451 & 0 & 0 & 1 & 0 & 0 & 2 & 0 & 1 & 1 & 1 & 0.6 \\
\hline & $\mathrm{SbR}$ & $\mathrm{N}-\mathrm{W}$ & 6.3 & 0 & 3.5496479 & 7 & 6 & 2 & 6 & 9 & 5 & 9 & 9 & 4 & 6 & 6.3 \\
\hline \multirow{6}{*}{ 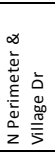 } & WbT & SE-W & 113.6 & 106 & 0.7252912 & 126 & 110 & 128 & 109 & 109 & 119 & 106 & 106 & 109 & 114 & 113.6 \\
\hline & WbR & SE-NE & 28.6 & 94 & 8.3530967 & 37 & 25 & 19 & 27 & 27 & 28 & 33 & 26 & 36 & 28 & 28.6 \\
\hline & EbT & W-SE & 51.4 & 77 & 3.1950117 & 52 & 50 & 47 & 54 & 54 & 55 & 51 & 50 & 48 & 53 & 51.4 \\
\hline & EbL & W-NE & 23.7 & 28 & 0.8457426 & 25 & 23 & 20 & 22 & 22 & 30 & 22 & 27 & 21 & 25 & 23.7 \\
\hline & SbR & NE-W & 10.2 & 14 & 1.0924232 & 13 & 10 & 8 & 11 & 11 & 12 & 8 & 11 & 6 & 12 & 10.2 \\
\hline & SbL & NE-SE & 32.9 & 25 & 1.4682595 & 35 & 37 & 31 & 32 & 32 & 34 & 37 & 33 & 27 & 31 & 32.9 \\
\hline \multirow{6}{*}{ 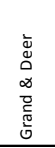 } & NbT & SE-NW & 171.2 & 227 & 3.9545636 & 190 & 161 & 176 & 168 & 179 & 169 & 168 & 164 & 177 & 160 & 171.2 \\
\hline & $\mathrm{NbR}$ & SE-NE & 61.5 & 12 & 8.1653824 & 46 & 74 & 57 & 66 & 54 & 59 & 60 & 70 & 56 & 73 & 61.5 \\
\hline & SbT & NW-SE & 76.7 & 103 & 2.7745765 & 80 & 77 & 74 & 79 & 74 & 81 & 78 & 78 & 68 & 78 & 76.7 \\
\hline & $\mathrm{SbL}$ & NW-NE & 0 & 3 & 2.4494897 & 0 & 0 & 0 & 0 & 0 & 0 & 0 & 0 & 0 & 0 & 0 \\
\hline & WbR & NE-NW & 0 & 2 & 2 & 0 & 0 & 0 & 0 & 0 & 0 & 0 & 0 & 0 & 0 & 0 \\
\hline & WbL & NE-SE & 15.8 & 13 & 0.7378648 & 17 & 19 & 19 & 17 & 15 & 14 & 14 & 12 & 17 & 14 & 15.8 \\
\hline \multirow{6}{*}{ 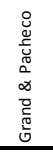 } & $\mathrm{NbL}$ & SE-SW & 378.4 & 366 & 0.6427373 & 378 & 383 & 382 & 383 & 379 & 378 & 370 & 377 & 370 & 384 & 378.4 \\
\hline & $\mathrm{SbR}$ & NW-SW & 42.4 & 40 & 0.3739062 & 46 & 44 & 44 & 47 & 40 & 45 & 42 & 40 & 33 & \begin{tabular}{l|l}
43 \\
\end{tabular} & 42.4 \\
\hline & $\mathrm{EbL}$ & SW-NW & 5.8 & 14 & 2.6061311 & 7 & 6 & 4 & 5 & 7 & 3 & 6 & 6 & 6 & 8 & 5.8 \\
\hline & $E b R$ & SW-SE & 61.6 & 31 & 4.4970833 & 60 & 61 & 62 & 62 & 60 & 65 & 62 & 62 & 61 & 61 & 61.6 \\
\hline & NbT & SE-NW & 226 & 225 & 0.0665927 & 228 & 228 & 228 & 228 & 225 & 224 & 222 & 227 & 226 & 224 & 226 \\
\hline & $\mathrm{SbT}$ & NW-SE & 50.1 & 80 & 3.707213 & 51 & 52 & 49 & 49 & 49 & 50 & 50 & 50 & 52 & 49 & 50.1 \\
\hline \multicolumn{17}{|c|}{ Calibration-Iteration \#1 Summary } \\
\hline & Movement & VISSIM Notation & Simulation & Actual & GEH Statistic & Seed 42 & Seed 13 & Seed 24 & Seed 500 & Seed 6 & Seed 2 & Seed 67 & Seed 681 & Seed 266 & \begin{tabular}{|l|l|} 
Seed 52 \\
\end{tabular} & Average \\
\hline \multirow{12}{*}{ 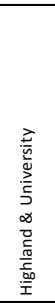 } & $\mathrm{EbL}$ & W-N & 31.7 & 16 & 3.2148111 & 32 & 35 & 41 & 22 & 27 & 33 & 37 & 24 & 41 & 25 & 31.7 \\
\hline & EbT & W-E & 253.1 & 413 & 8.7618083 & 267 & 253 & 263 & 242 & 268 & 249 & 251 & 219 & 262 & 257 & 253.1 \\
\hline & $E b R$ & W-S & 323 & 213 & 6.7193194 & 333 & 326 & 337 & 331 & 332 & 308 & 313 & 290 & 335 & 325 & 323 \\
\hline & WbR & E-N & 0 & 0 & \#DIV/0! & 0 & 0 & 0 & 0 & 0 & 0 & 0 & 0 & 0 & 0 & 0 \\
\hline & $\mathrm{WbT}$ & $E-W$ & 29.7 & 22 & 1.5144692 & 31 & 27 & 30 & 29 & 29 & 31 & 28 & 30 & 33 & 29 & 29.7 \\
\hline & WbL & E-S & 4.4 & 6 & 0.7016464 & 3 & 5 & 4 & 4 & 6 & 5 & 4 & 4 & 4 & 5 & 4.4 \\
\hline & $\mathrm{NbL}$ & s-w & 77.8 & 77 & 0.0909326 & 79 & 81 & 78 & 78 & 75 & 75 & 76 & 78 & 77 & 81 & 77.8 \\
\hline & NbT & S-N & 5.2 & 4 & 0.5595029 & 4 & 4 & 5 & 2 & 5 & 8 & 3 & 6 & 8 & 7 & 5.2 \\
\hline & $\mathrm{NbR}$ & S-E & 38.8 & 45 & 0.9578217 & 38 & 39 & 40 & 37 & 39 & 37 & 34 & 42 & 42 & 40 & 38.8 \\
\hline & $\mathrm{SbL}$ & N-E & 0.1 & 1 & 1.2135598 & 0 & 0 & 0 & 1 & 0 & 0 & 0 & 0 & 0 & 0 & 0.1 \\
\hline & $\mathrm{SbT}$ & $\mathrm{N}-\mathrm{S}$ & 0.5 & 0 & 1 & 0 & 1 & 0 & 1 & 0 & 1 & 0 & 1 & 1 & 0 & 0.5 \\
\hline & SbR & $\mathrm{N}-\mathrm{W}$ & 5.3 & 0 & 3.2557641 & 4 & 7 & 6 & 0 & 8 & 7 & 7 & 7 & 5 & 2 & 5.3 \\
\hline \multirow{6}{*}{ 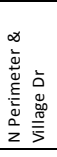 } & WbT & SE-W & 160.1 & 106 & 4.6901834 & 160 & 165 & 168 & 155 & 160 & 158 & 153 & 156 & 164 & 162 & 160.1 \\
\hline & WbR & SE-NE & 30.5 & 94 & 8.048298 & 38 & 26 & 26 & 29 & 27 & 24 & 37 & 37 & 34 & 27 & 30.5 \\
\hline & EbT & W-SE & 52.1 & 77 & 3.0992116 & 51 & 52 & 53 & 52 & 54 & 50 & 52 & 48 & 55 & 54 & 52.1 \\
\hline & EbL & W-NE & 26.5 & 28 & 0.2873479 & 28 & 28 & 29 & 31 & 28 & 20 & 26 & 23 & 25 & 27 & 26.5 \\
\hline & $\mathrm{SbR}$ & NE-W & 10.8 & 14 & 0.9087389 & 9 & 10 & 12 & 11 & 15 & 10 & 7 & 10 & 11 & 13 & 10.8 \\
\hline & $\mathrm{SbL}$ & NE-SE & 15.6 & 25 & 2.0863148 & 13 & 19 & 19 & 10 & 10 & 16 & 12 & 18 & 22 & 17 & 15.6 \\
\hline \multirow{6}{*}{ 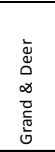 } & $\mathrm{NbT}$ & SE-NW & 220.5 & 227 & 0.4345421 & 225 & 216 & 224 & 221 & 218 & 212 & 221 & 224 & 223 & 221 & 220.5 \\
\hline & $\mathrm{NbR}$ & SE-NE & 13.4 & 12 & 0.3928495 & 13 & 20 & 11 & 11 & 15 & 17 & 10 & 11 & 8 & 18 & 13.4 \\
\hline & SbT & NW-SE & 60.8 & 103 & 4.6630546 & 56 & 64 & 61 & 57 & 57 & 58 & 68 & 60 & 62 & \begin{tabular}{l|}
65 \\
\end{tabular} & 60.8 \\
\hline & $\mathrm{SbL}$ & NW-NE & 0 & 3 & 2.4494897 & 0 & 0 & 0 & 0 & 0 & 0 & 0 & 0 & 0 & 0 & 0 \\
\hline & $\mathrm{WbR}$ & NE-NW & 0.6 & 2 & 1.2278812 & 2 & 1 & 0 & 0 & 0 & 1 & 1 & 0 & 1 & 0 & 0.6 \\
\hline & WbL & NE-SE & 26.1 & 13 & 2.9627698 & 23 & 28 & 27 & 29 & 34 & 25 & 23 & 27 & 23 & 22 & 26.1 \\
\hline & NbL & SE-SW & 378.3 & 366 & $\begin{array}{l}0.6375968 \\
\end{array}$ & 378 & 382 & 384 & 379 & 375 & 374 & 375 & 375 & 376 & 385 & 378.3 \\
\hline 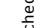 & $\mathrm{SbR}$ & NW-SW & 44.2 & 40 & 0.6473039 & 41 & 45 & 45 & 46 & 45 & 42 & 41 & 42 & 48 & \begin{tabular}{l|l|}
47 \\
\end{tabular} & 44.2 \\
\hline$\frac{u}{0}$ & EbL & SW-NW & 7.1 & 14 & 2.1243343 & 8 & 8 & 7 & 8 & 8 & 5 & 6 & 6 & 7 & 8 & 7.1 \\
\hline$\infty$ & EbR & SW-SE & 60 & 31 & 4.299246 & 59 & 60 & 59 & 60 & 60 & 61 & 61 & 60 & 62 & 58 & 60 \\
\hline ?ㄷ & \begin{tabular}{|l|}
$\mathrm{NbT}$ \\
\end{tabular} & SE-NW & 226.7 & 225 & 0.1131199 & 230 & 228 & 228 & 224 & 224 & 224 & 226 & 228 & 225 & 230 & 226.7 \\
\hline$\frac{5}{50}$ & SbT & NW-SE & 41.6 & 80 & 4.9246961 & 38 & 47 & 43 & 40 & 46 & 40 & 40 & 45 & 37 & 40 & 41.6 \\
\hline
\end{tabular}




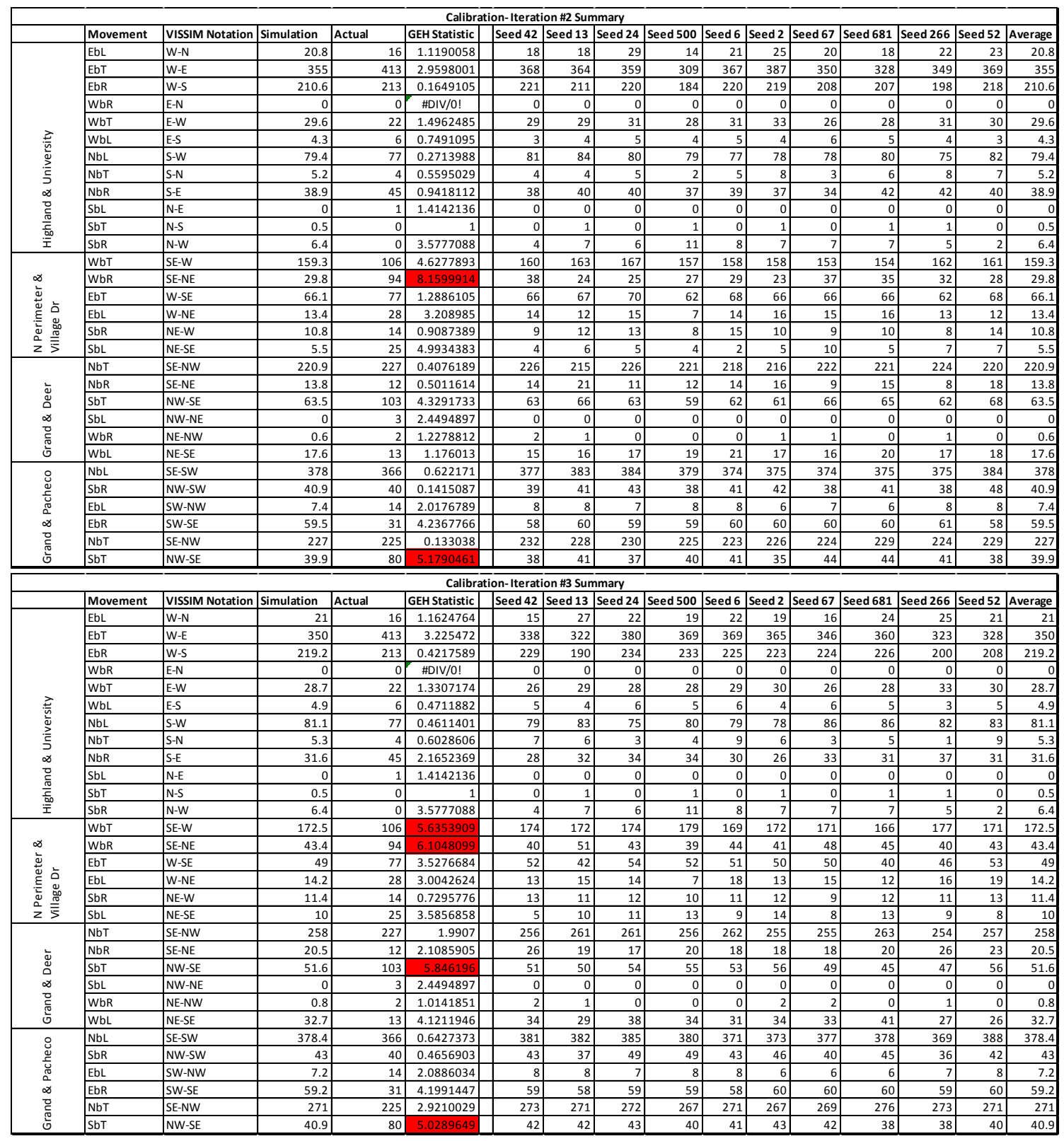




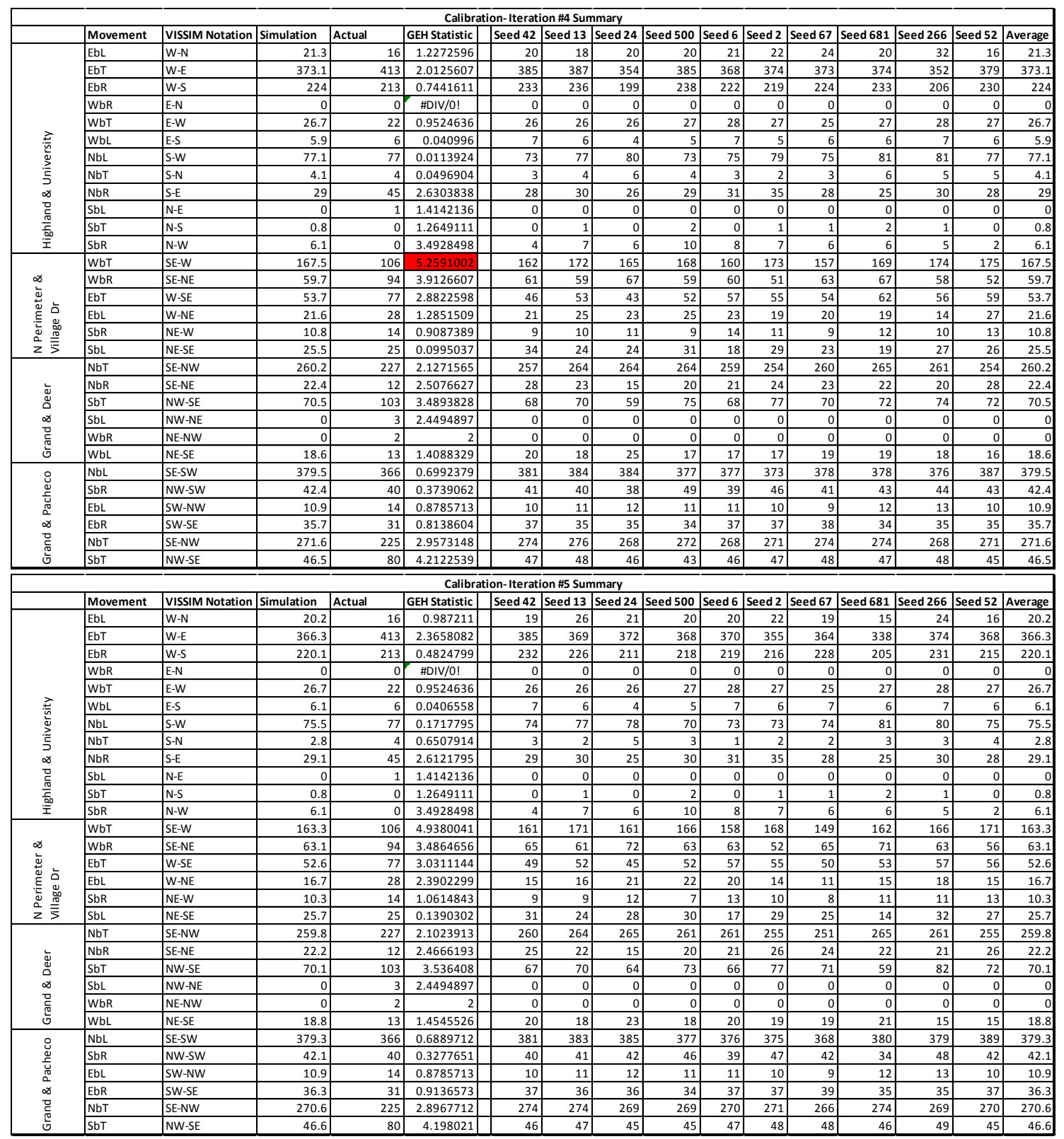




\section{Appendix K: Sample Vehicle Mapping Calculations for Emissions Modeling}

The following table shows sample calculations for taking a unique list of vehicles in the simulation and

mapping them to CMEM vehicle categories using a random number generator.

\begin{tabular}{|c|c|c|c|c|c|c|c|c|c|c|c|c|c|c|c|c|c|}
\hline \multicolumn{18}{|c|}{ Vehicle Mapping Calculations } \\
\hline \multirow[b]{2}{*}{ VehNr } & \multirow[b]{2}{*}{ Type } & \multirow[b]{2}{*}{ VehTypeName } & \multirow[b]{2}{*}{ Rand } & \multirow[b]{2}{*}{ Cat 1} & \multirow[b]{2}{*}{ Cat 2} & \multirow[b]{2}{*}{ Cat 3} & \multirow[b]{2}{*}{ Cat 4} & \multirow[b]{2}{*}{ Cat 5} & \multirow[b]{2}{*}{ Cat 6} & \multirow[b]{2}{*}{ Cat 7} & \multirow[b]{2}{*}{ Cat 8} & \multirow[b]{2}{*}{ Cat 9} & \multirow[b]{2}{*}{ Merge } & \multicolumn{4}{|c|}{ Insert Into Vehicle Definition File } \\
\hline & & & & & & & & & & & & & & Veh ID & Veh Cat & Soak & Humidity \\
\hline 1 & 3 & Mid-Size & 4 & 0 & 0 & 5 & 0 & 0 & 0 & 0 & 0 & 0 & 5 & 1 & 5 & 1014 & 75 \\
\hline 2 & 2 & Compact & 157 & 0 & 26 & 0 & 0 & 0 & 0 & 0 & 0 & 0 & 26 & 2 & 26 & 292 & 75 \\
\hline 3 & 2 & Compact & 41 & 0 & 8 & 0 & 0 & 0 & 0 & 0 & 0 & 0 & 8 & 3 & 8 & 826 & 75 \\
\hline 4 & 3 & Mid-Size & 199 & 0 & 0 & 23 & 0 & 0 & 0 & 0 & 0 & 0 & 23 & 4 & 23 & 836 & 75 \\
\hline 5 & 9 & Wagon/Crossover/Minivan/Van & 198 & 0 & 0 & 0 & 0 & 0 & 0 & 0 & 0 & 23 & 23 & 5 & 23 & 659 & 75 \\
\hline 6 & 7 & Truck & 158 & 0 & 0 & 0 & 0 & 0 & 0 & 24 & 0 & 0 & 24 & 6 & 24 & 1389 & 75 \\
\hline 7 & 2 & Compact & 43 & 0 & 8 & 0 & 0 & 0 & 0 & 0 & 0 & 0 & 8 & 7 & 8 & 1195 & 75 \\
\hline 8 & 2 & Compact & 72 & 0 & 24 & 0 & 0 & 0 & 0 & 0 & 0 & 0 & 24 & 8 & 24 & 369 & 75 \\
\hline 9 & 9 & Wagon/Crossover/Minivan/Van & 10 & 0 & 0 & 0 & 0 & 0 & 0 & 0 & 0 & 4 & 4 & 9 & 4 & 613 & 75 \\
\hline 10 & 2 & Compact & 40 & 0 & 8 & 0 & 0 & 0 & 0 & 0 & 0 & 0 & 8 & 10 & 8 & 951 & 75 \\
\hline 11 & 2 & Compact & 74 & 0 & 24 & 0 & 0 & 0 & 0 & 0 & 0 & 0 & 24 & 11 & 24 & 320 & 75 \\
\hline 12 & 2 & Compact & 184 & 0 & 20 & 0 & 0 & 0 & 0 & 0 & 0 & 0 & 20 & 12 & 20 & 1217 & 75 \\
\hline 13 & 5 & SmallsUV & 188 & 0 & 0 & 0 & 0 & 21 & 0 & 0 & 0 & 0 & 21 & 13 & 21 & 552 & 75 \\
\hline 14 & 8 & Sport & 186 & 0 & 0 & 0 & 0 & 0 & 0 & 0 & 20 & 0 & 20 & 14 & 20 & 151 & 75 \\
\hline 15 & 3 & Mid-Size & 83 & 0 & 0 & 11 & 0 & 0 & 0 & 0 & 0 & 0 & 11 & 15 & 11 & 1026 & 75 \\
\hline 16 & 2 & Compact & 31 & 0 & 8 & 0 & 0 & 0 & 0 & 0 & 0 & 0 & 8 & 16 & 8 & 1148 & 75 \\
\hline 17 & 3 & Mid-Size & 26 & 0 & 0 & 8 & 0 & 0 & 0 & 0 & 0 & 0 & 8 & 17 & 8 & 992 & 75 \\
\hline 18 & 7 & Truck & 51 & 0 & 0 & 0 & 0 & 0 & 0 & 17 & 0 & 0 & 17 & 18 & 17 & 1405 & 75 \\
\hline 19 & 5 & SmallSUV & 160 & 0 & 0 & 0 & 0 & 24 & 0 & 0 & 0 & 0 & 24 & 19 & 24 & 890 & 75 \\
\hline 20 & 2 & Compact & 168 & 0 & 26 & 0 & 0 & 0 & 0 & 0 & 0 & 0 & 26 & 20 & 26 & 1021 & 75 \\
\hline 21 & 9 & Wagon/Crossover/Minivan/Van & 21 & 0 & 0 & 0 & 0 & 0 & 0 & 0 & 0 & 8 & 8 & 21 & 8 & 1143 & 75 \\
\hline 22 & 2 & Compact & 181 & 0 & 19 & 0 & 0 & 0 & 0 & 0 & 0 & 0 & 19 & 22 & 19 & 615 & 75 \\
\hline 23 & 7 & Truck & 106 & 0 & 0 & 0 & 0 & 0 & 0 & 24 & 0 & 0 & 24 & 23 & 24 & 205 & 75 \\
\hline 24 & 5 & SmallSUV & 69 & 0 & 0 & 0 & 0 & 15 & 0 & 0 & 0 & 0 & 15 & 24 & 15 & 907 & 75 \\
\hline 25 & 2 & Compact & 134 & 0 & 26 & 0 & 0 & 0 & 0 & 0 & 0 & 0 & 26 & 25 & 26 & 998 & 75 \\
\hline 26 & 8 & Sport & 149 & 0 & 0 & 0 & 0 & 0 & 0 & 0 & 24 & 0 & 24 & 26 & 24 & 1326 & 75 \\
\hline 27 & 2 & Compact & 65 & 0 & 24 & 0 & 0 & 0 & 0 & 0 & 0 & 0 & 24 & 27 & 24 & 995 & 75 \\
\hline 28 & 5 & SmallSUV & 72 & 0 & 0 & 0 & 0 & 15 & 0 & 0 & 0 & 0 & 15 & 28 & 15 & 1394 & 75 \\
\hline 29 & 2 & Compact & 40 & 0 & 8 & 0 & 0 & 0 & 0 & 0 & 0 & 0 & 8 & 29 & 8 & 315 & 75 \\
\hline 30 & 2 & Compact & 178 & 0 & 27 & 0 & 0 & 0 & 0 & 0 & 0 & 0 & 27 & 30 & 27 & 718 & 75 \\
\hline 31 & 7 & Truck & 61 & 0 & 0 & 0 & 0 & 0 & 0 & 17 & 0 & 0 & 17 & 31 & 17 & 109 & 75 \\
\hline 32 & 2 & Compact & 108 & 0 & 24 & 0 & 0 & 0 & 0 & 0 & 0 & 0 & 24 & 32 & 24 & 787 & 75 \\
\hline 33 & 5 & SmallsUV & 46 & 0 & 0 & 0 & 0 & 10 & 0 & 0 & 0 & 0 & 10 & 33 & 10 & 1244 & 75 \\
\hline 34 & 8 & Sport & 164 & 0 & 0 & 0 & 0 & 0 & 0 & 0 & 24 & 0 & 24 & 34 & 24 & 199 & 75 \\
\hline 35 & 7 & Truck & 142 & 0 & 0 & 0 & 0 & 0 & 0 & 24 & 0 & 0 & 24 & 35 & 24 & 418 & 75 \\
\hline 36 & 3 & Mid-Size & 174 & 0 & 0 & 24 & 0 & 0 & 0 & 0 & 0 & 0 & 24 & 36 & 24 & 496 & 75 \\
\hline 37 & 2 & Compact & 65 & 0 & 24 & 0 & 0 & 0 & 0 & 0 & 0 & 0 & 24 & 37 & 24 & 823 & 75 \\
\hline 38 & 5 & SmallsUV & 109 & 0 & 0 & 0 & 0 & 24 & 0 & 0 & 0 & 0 & 24 & 38 & 24 & 1170 & 75 \\
\hline 39 & 3 & Mid-Size & 77 & 0 & 0 & 11 & 0 & 0 & 0 & 0 & 0 & 0 & 11 & 39 & 11 & 306 & 75 \\
\hline 40 & 3 & Mid-Size & 128 & 0 & 0 & 24 & 0 & 0 & 0 & 0 & 0 & 0 & 24 & 40 & 24 & 661 & 75 \\
\hline 41 & 3 & Mid-Size & 121 & 0 & 0 & 24 & 0 & 0 & 0 & 0 & 0 & 0 & 24 & 41 & 24 & 1067 & 75 \\
\hline 42 & 3 & Mid-Size & 34 & 0 & 0 & 9 & 0 & 0 & 0 & 0 & 0 & 0 & 9 & 42 & 9 & 1274 & 75 \\
\hline 43 & 4 & Full-Size & 122 & 0 & 0 & 0 & 24 & 0 & 0 & 0 & 0 & 0 & 24 & 43 & 24 & 471 & 75 \\
\hline 44 & 5 & SmallsuV & 3 & 0 & 0 & 0 & 0 & 8 & 0 & 0 & 0 & 0 & 8 & 44 & 8 & 532 & 75 \\
\hline 45 & 7 & Truck & 38 & 0 & 0 & 0 & 0 & 0 & 0 & 16 & 0 & 0 & 16 & 45 & 16 & 400 & 75 \\
\hline
\end{tabular}

...Same Idea Continues... 


\begin{tabular}{|c|c|c|c|c|c|c|c|c|c|c|c|c|c|c|c|c|c|}
\hline 2120 & 2 & Compact & 166 & 0 & 26 & 0 & 0 & 0 & 0 & 0 & 0 & 0 & 26 & 2120 & 26 & 1211 & 75 \\
\hline 2121 & 5 & SmallsuV & 63 & 0 & 0 & 0 & 0 & 15 & 0 & 0 & 0 & 0 & 15 & 2121 & 15 & 974 & 75 \\
\hline 2122 & 5 & SmallsUV & 190 & 0 & 0 & 0 & 0 & 21 & 0 & 0 & 0 & 0 & 21 & 2122 & 21 & 755 & 75 \\
\hline 2123 & 7 & Truck & 81 & 0 & 0 & 0 & 0 & 0 & 0 & 17 & 0 & 0 & 17 & 2123 & 17 & 376 & 75 \\
\hline 2124 & 2 & Compact & 136 & 0 & 26 & 0 & 0 & 0 & 0 & 0 & 0 & 0 & 26 & 2124 & 26 & 402 & 75 \\
\hline 2125 & 2 & Compact & 118 & 0 & 24 & 0 & 0 & 0 & 0 & 0 & 0 & 0 & 24 & 2125 & 24 & 113 & 75 \\
\hline 2126 & 5 & Smallsuv & 20 & 0 & 0 & 0 & 0 & 8 & 0 & 0 & 0 & 0 & 8 & 2126 & 8 & 1301 & 75 \\
\hline 2127 & 7 & Truck & 193 & 0 & 0 & 0 & 0 & 0 & 0 & 22 & 0 & 0 & 22 & 2127 & 22 & 231 & 75 \\
\hline 2128 & 7 & Truck & 24 & 0 & 0 & 0 & 0 & 0 & 0 & 11 & 0 & 0 & 11 & 2128 & 11 & 1104 & 75 \\
\hline 2129 & 3 & Mid-Size & 78 & 0 & 0 & 11 & 0 & 0 & 0 & 0 & 0 & 0 & 11 & 2129 & 11 & 1367 & 75 \\
\hline 2130 & 3 & Mid-Size & 59 & 0 & 0 & 10 & 0 & 0 & 0 & 0 & 0 & 0 & 10 & 2130 & 10 & 294 & 75 \\
\hline 2131 & 3 & Mid-Size & 152 & 0 & 0 & 24 & 0 & 0 & 0 & 0 & 0 & 0 & 24 & 2131 & 24 & 930 & 75 \\
\hline 2132 & 7 & Truck & 166 & 0 & 0 & 0 & 0 & 0 & 0 & 24 & 0 & 0 & 24 & 2132 & 24 & 926 & 75 \\
\hline 2133 & 2 & Compact & 119 & 0 & 24 & 0 & 0 & 0 & 0 & 0 & 0 & 0 & 24 & 2133 & 24 & 929 & 75 \\
\hline 2134 & 7 & Truck & 24 & 0 & 0 & 0 & 0 & 0 & 0 & 11 & 0 & 0 & 11 & 2134 & 11 & 833 & 75 \\
\hline 2135 & 6 & LargeSUV & 29 & 0 & 0 & 0 & 0 & 0 & 17 & 0 & 0 & 0 & 17 & 2135 & 17 & 1070 & 75 \\
\hline 2136 & 2 & Compact & 172 & 0 & 27 & 0 & 0 & 0 & 0 & 0 & 0 & 0 & 27 & 2136 & 27 & 1433 & 75 \\
\hline 2137 & 3 & Mid-Size & 25 & 0 & 0 & 8 & 0 & 0 & 0 & 0 & 0 & 0 & 8 & 2137 & 8 & 230 & 75 \\
\hline 2138 & 9 & Wagon/Crossover/Minivan/Van & 175 & 0 & 0 & 0 & 0 & 0 & 0 & 0 & 0 & 24 & 24 & 2138 & 24 & 507 & 75 \\
\hline 2139 & 8 & Sport & 79 & 0 & 0 & 0 & 0 & 0 & 0 & 0 & 11 & 0 & 11 & 2139 & 11 & 872 & 75 \\
\hline 2140 & 2 & Compact & 47 & 0 & 8 & 0 & 0 & 0 & 0 & 0 & 0 & 0 & 8 & 2140 & 8 & 570 & 75 \\
\hline 2141 & 3 & Mid-Size & 140 & 0 & 0 & 24 & 0 & 0 & 0 & 0 & 0 & 0 & 24 & 2141 & 24 & 177 & 75 \\
\hline 2142 & 5 & SmallSUV & 57 & 0 & 0 & 0 & 0 & 10 & 0 & 0 & 0 & 0 & 10 & 2142 & 10 & 1198 & 75 \\
\hline 2143 & 2 & Compact & 146 & 0 & 26 & 0 & 0 & 0 & 0 & 0 & 0 & 0 & 26 & 2143 & 26 & 575 & 75 \\
\hline 2144 & 2 & Compact & 41 & 0 & 8 & 0 & 0 & 0 & 0 & 0 & 0 & 0 & 8 & 2144 & 8 & 471 & 75 \\
\hline 2145 & 3 & Mid-Size & 125 & 0 & 0 & 24 & 0 & 0 & 0 & 0 & 0 & 0 & 24 & 2145 & 24 & 134 & 75 \\
\hline 2146 & 5 & SmallSUV & 138 & 0 & 0 & 0 & 0 & 24 & 0 & 0 & 0 & 0 & 24 & 2146 & 24 & 960 & 75 \\
\hline 2147 & 9 & Wagon/Crossover/Minivan/Van & 50 & 0 & 0 & 0 & 0 & 0 & 0 & 0 & 0 & 8 & 8 & 2147 & 8 & 478 & 75 \\
\hline 2148 & 9 & Wagon/Crossover/Minivan/Van & 152 & 0 & 0 & 0 & 0 & 0 & 0 & 0 & 0 & 24 & 24 & 2148 & 24 & 241 & 75 \\
\hline 2149 & 9 & Wagon/Crossover/Minivan/Van & 156 & 0 & 0 & 0 & 0 & 0 & 0 & 0 & 0 & 24 & 24 & 2149 & 24 & 383 & 75 \\
\hline 2150 & 3 & Mid-Size & 163 & 0 & 0 & 24 & 0 & 0 & 0 & 0 & 0 & 0 & 24 & 2150 & 24 & 1188 & 75 \\
\hline 2151 & 2 & Compact & 133 & 0 & 26 & 0 & 0 & 0 & 0 & 0 & 0 & 0 & 26 & 2151 & 26 & 82 & 75 \\
\hline 2152 & 2 & Compact & 66 & 0 & 24 & 0 & 0 & 0 & 0 & 0 & 0 & 0 & 24 & 2152 & 24 & 281 & 75 \\
\hline 2153 & 9 & Wagon/Crossover/Minivan/Van & 87 & 0 & 0 & 0 & 0 & 0 & 0 & 0 & 0 & 24 & 24 & 2153 & 24 & 248 & 75 \\
\hline 2154 & 4 & Full-Size & 185 & 0 & 0 & 0 & 20 & 0 & 0 & 0 & 0 & 0 & 20 & 2154 & 20 & 101 & 75 \\
\hline 2155 & 5 & SmalISUV & 121 & 0 & 0 & 0 & 0 & 24 & 0 & 0 & 0 & 0 & 24 & 2155 & 24 & 449 & 75 \\
\hline 2156 & 5 & SmallSUV & 74 & 0 & 0 & 0 & 0 & 16 & 0 & 0 & 0 & 0 & 16 & 2156 & 16 & 946 & 75 \\
\hline 2157 & 2 & Compact & 95 & 0 & 24 & 0 & 0 & 0 & 0 & 0 & 0 & 0 & 24 & 2157 & 24 & 519 & 75 \\
\hline 2158 & 2 & Compact & 107 & 0 & 24 & 0 & 0 & 0 & 0 & 0 & 0 & 0 & 24 & 2158 & 24 & 322 & 75 \\
\hline 2159 & 7 & Truck & 148 & 0 & 0 & 0 & 0 & 0 & 0 & 24 & 0 & 0 & 24 & 2159 & 24 & 850 & 75 \\
\hline 2160 & 6 & LargeSUV & 125 & 0 & 0 & 0 & 0 & 0 & 24 & 0 & 0 & 0 & 24 & 2160 & 24 & 129 & 75 \\
\hline 2161 & 7 & Truck & 181 & 0 & 0 & 0 & 0 & 0 & 0 & 19 & 0 & 0 & 19 & 2161 & 19 & 1421 & 75 \\
\hline 2162 & 7 & Truck & 89 & 0 & 0 & 0 & 0 & 0 & 0 & 17 & 0 & 0 & 17 & 2162 & 17 & 521 & 75 \\
\hline 2163 & 2 & Compact & 137 & 0 & 26 & 0 & 0 & 0 & 0 & 0 & 0 & 0 & 26 & 2163 & 26 & 1147 & 75 \\
\hline 2164 & 4 & Full-Size & 21 & 0 & 0 & 0 & 8 & 0 & 0 & 0 & 0 & 0 & 8 & 2164 & 8 & 906 & 75 \\
\hline 2165 & 7 & Truck & 163 & 0 & 0 & 0 & 0 & 0 & 0 & 24 & 0 & 0 & 24 & 2165 & 24 & 1164 & 75 \\
\hline 2166 & 3 & Mid-Size & 143 & 0 & 0 & 24 & 0 & 0 & 0 & 0 & 0 & 0 & 24 & 2166 & 24 & 1191 & 75 \\
\hline 2167 & 1 & Economy/Hybrid & 33 & 26 & 0 & 0 & 0 & 0 & 0 & 0 & 0 & 0 & 26 & 2167 & 26 & 537 & 75 \\
\hline 2168 & 9 & Wagon/Crossover/Minivan/Van & 30 & 0 & 0 & 0 & 0 & 0 & 0 & 0 & 0 & 8 & 8 & 2168 & 8 & 566 & 75 \\
\hline 2169 & 5 & SmallsuV & 193 & 0 & 0 & 0 & 0 & 22 & 0 & 0 & 0 & 0 & 22 & 2169 & 22 & 788 & 75 \\
\hline 2170 & 2 & Compact & 38 & 0 & 8 & 0 & 0 & 0 & 0 & 0 & 0 & 0 & 8 & 2170 & 8 & 946 & 75 \\
\hline 2171 & 3 & Mid-Size & 20 & 0 & 0 & 8 & 0 & 0 & 0 & 0 & 0 & 0 & 8 & 2171 & 8 & 271 & 75 \\
\hline 2172 & 1 & Economy/Hybrid & 110 & 27 & 0 & 0 & 0 & 0 & 0 & 0 & 0 & 0 & 27 & 2172 & 27 & 836 & 75 \\
\hline 2173 & 7 & Truck & 195 & 0 & 0 & 0 & 0 & 0 & 0 & 22 & 0 & 0 & 22 & 2173 & 22 & 1129 & 75 \\
\hline 2174 & 9 & Wagon/Crossover/Minivan/Van & 64 & 0 & 0 & 0 & 0 & 0 & 0 & 0 & 0 & 10 & 10 & 2174 & 10 & 1371 & 75 \\
\hline
\end{tabular}

The following formulas are used for each column of VISSIM categories 1-9 as well as the Merge column.

- $=\mathrm{IF}(\$ F 3=1, \operatorname{LOOKUP}(\$ \mathrm{I} 3,\{0,60\},\{26,27\}), 0)$

- $=\mathrm{IF}(\$ F 3=2, \operatorname{LOOKUP}(\$ 13,\{0,8,10,50,60,130,170,180,184,188,192,196\},\{4,6,8,10,24,26,27,19,20$,

$21,22,23\}), 0)$

- $=\mathrm{IF}(\$ F 3=3, \operatorname{LOOKUP}(\$ \mathrm{I} 3,\{0,4,8,9,10,30,50,70,90,180,184,188,192,196\},\{4,5,6,7,8,9,10,11,24,19$,

$20,21,22,23\}), 0)$

- $=\mathrm{IF}(\$ F 3=4, \operatorname{LOOKUP}(\$ \mathrm{I} 3,\{0,4,8,9,10,28,46,63,80,180,184,188,192,196\},\{4,5,6,7,8,9,10,11,24,19$,

$20,21,22,23\}), 0)$ 
- $=\mathrm{IF}(\$ F 3=5, \operatorname{LOOKUP}(\$ \mathrm{I} 3,\{0,30,60,74,80,100,180,184,188,192,196\},\{8,10,15,16,17,24,19,20,21,2$ $2,23\}), 0)$

- $=\mathrm{IF}(\$ \mathrm{~F} 3=6, \mathrm{LOOKUP}(\$ \mathrm{I} 3,\{0,10,70,80,180,184,188,192,196\},\{16,17,18,24,19,20,21,22,23\}), 0)$

- $=\mathrm{IF}(\$ \mathrm{~F} 3=7, \operatorname{LOOKUP}(\$ \mathrm{I} 3,\{0,8,16,23,30,36,40,90,98,178,179,180,184,188,192,196\},\{8,9,10,11,15$ $, 16,17,18,24,25,40,19,20,21,22,23\}), 0)$

- $=\mathrm{IF}(\$ \mathrm{~F} 3=8, \operatorname{LOOKUP}(\$ \mathrm{I} 3,\{0,8,10,60,80,180,184,188,192,196\},\{5,7,9,11,24,19,20,21,22,23\}), 0)$

- $=\mathrm{IF}(\$ F 3=9, \operatorname{LOOKUP}(\$ \mathrm{I} 3,\{0,16,20,60,80,180,184,188,192,196\},\{4,6,8,10,24,19,20,21,22,23\}), 0)$

- $=\mathrm{IF}(\mathrm{VALUE}(\mathrm{K} 3)<>0, \mathrm{~K} 3, \mathrm{IF}(\mathrm{VALUE}(\mathrm{L} 3)<>0, \mathrm{~L} 3, \mathrm{IF}(\mathrm{VALUE}(\mathrm{M} 3)<>0, \mathrm{M} 3, \mathrm{IF}(\mathrm{VALUE}(\mathrm{N} 3)<>0, \mathrm{~N}$ 3, IF(VALUE $(\mathrm{O} 3)<>0, \mathrm{O} 3, \mathrm{IF}(\mathrm{VALUE}(\mathrm{P} 3)<>0, \mathrm{P} 3, \mathrm{IF}(\mathrm{VALUE}(\mathrm{Q} 3)<>0, \mathrm{Q} 3, \mathrm{IF}(\mathrm{VALUE}(\mathrm{R} 3)<>0, \mathrm{R} 3$ ,IF(VALUE(S3)<>0,S3,))))))))) 


\section{Appendix L: Sample CMEM Model Control File}

The text below is a partial sample of the Vehice Definition File (-def) which is generated as an input to

CMEM. It contains a summary of vehicles and their associated categories as well as parameters (soak time and humidity) which are specific to individual vehicles.

\# Control File for VISSIM16 Batch Model v1

IN_UNITS $=$ ENGLISH

OUT UNITS $=$ ENGLISH

CO2_OUT $=$ on

\section{Appendix M: Partial Sample CMEM Vehicle Definition File}

The text below is a partial sample of the Vehicle Definition File (-def) which is generated as an input to

CMEM. It contains a summary of vehicles and their associated categories as well as parameters (soak time and humidity) which are specific to individual vehicles.

$\begin{array}{llll}\text { \# Vehicle Definition File for VISSIM16 Batch Model v1 } \\ \text { \# ID Category } & \text { Soak Humidity } & \\ 1 & 10 & 967 & 75 \\ 2 & 10 & 161 & 75 \\ 3 & 26 & 413 & 75 \\ 4 & 8 & 57 & 75 \\ 5 & 24 & 1237 & 75 \\ 6 & 17 & 466 & 75 \\ 7 & 26 & 1076 & 75 \\ 8 & 22 & 862 & 75 \\ 9 & 22 & 1340 & 75 \\ 10 & 26 & 133 & 75 \\ 11 & 10 & 895 & 75 \\ 12 & 8 & 844 & 75 \\ 13 & 24 & 875 & 75 \\ 14 & 19 & 684 & 75 \\ 15 & 11 & 73 & 75 \\ 16 & 20 & 686 & 75 \\ 17 & 10 & 1074 & 75 \\ 18 & 18 & 203 & 75 \\ 19 & 24 & 142 & 75 \\ 20 & 26 & 1115 & 75 \\ 21 & 24 & 344 & 75 \\ 22 & 24 & 678 & 75 \\ 23 & 17 & 1282 & 75 \\ 24 & 10 & 783 & 75 \\ 25 & 24 & 1106 & 75 \\ 26 & 24 & 993 & 75 \\ 27 & 24 & 1056 & 75 \\ 28 & 17 & 1148 & 75 \\ 29 & 24 & 63 & 75 \\ 30 & 8 & 558 & 75 \\ 31 & 24 & 1107 & 75 \\ 32 & 8 & 1 & 75 \\ 33 & 10 & 497 & 75 \\ 34 & 5 & 441 & 75 \\ 35 & 24 & 1368 & 75 \\ 36 & 11 & 473 & 75 \\ 37 & 24 & 954 & 75 \\ 38 & 24 & 104 & 75 \\ & & & \end{array}$




$\begin{array}{llll}39 & 24 & 257 & 75 \\ 40 & 24 & 959 & 75 \\ 41 & 10 & 284 & 75 \\ 42 & 9 & 460 & 75 \\ 43 & 24 & 173 & 75 \\ 44 & 24 & 567 & 75 \\ 45 & 8 & 1219 & 75 \\ \cdot & \cdot & \cdot & \cdot \\ \text { (Similar trend continues) } & \cdot\end{array}$

$\begin{array}{llll}\cdot & \cdot & \cdot & \cdot \\ 2150 & 21 & 1439 & 75 \\ 2151 & 24 & 985 & 75 \\ 2152 & 24 & 1292 & 75 \\ 2153 & 22 & 393 & 75 \\ 2154 & 10 & 1400 & 75 \\ 2155 & 24 & 68 & 75 \\ 2156 & 10 & 734 & 75 \\ 2157 & 23 & 88 & 75 \\ 2158 & 24 & 359 & 75 \\ 2159 & 17 & 543 & 75 \\ 2160 & 16 & 1249 & 75 \\ 2161 & 17 & 897 & 75 \\ 2162 & 24 & 8 & 75 \\ 2163 & 10 & 1301 & 75 \\ 2164 & 24 & 511 & 75 \\ 2165 & 15 & 1024 & 75 \\ 2166 & 21 & 1204 & 75 \\ 2167 & 26 & 669 & 75 \\ 2168 & 24 & 1147 & 75 \\ 2169 & 10 & 842 & 75 \\ 2170 & 4 & 1367 & 75 \\ 2171 & 24 & 1027 & 75 \\ 2172 & 26 & 339 & 75 \\ 2173 & 24 & 964 & 75 \\ 2174 & 24 & 1099 & 75\end{array}$

\section{Appendix N: Partial Sample CMEM Vehicle Activity File}

The text below is a partial sample of the Vehicle Activity File (-atb) which is generated as an input to

CMEM. It contains a summary of second-by-second vehicle activity which is ordered by time and then vehicle ID.

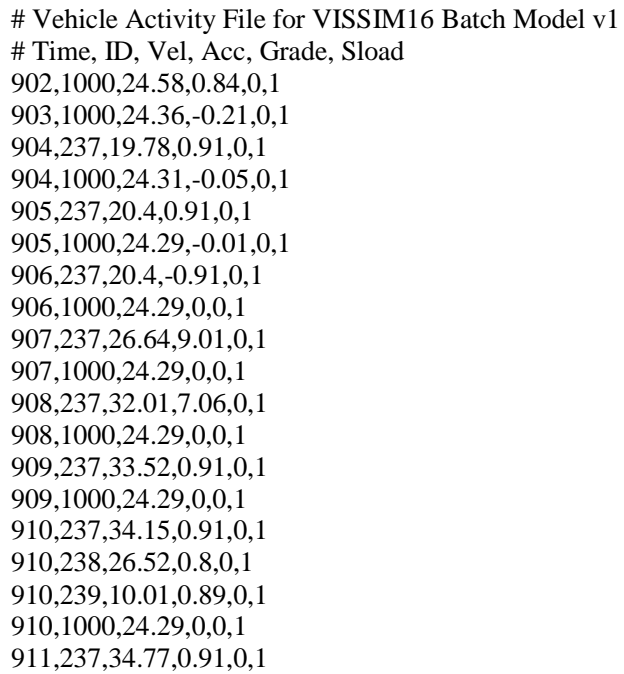


$911,238,27.06,0.8,0,1$ $911,239,10.61,0.89,0,1$ $911,1000,24.29,0,0,1$ $912,237,35.39,0.91,0,1$ $912,238,32.31,7.53,0,1$ $912,239,11.22,0.89,0,1$ $912,240,19.96,0.61,0,1$ $912,1000,24.29,0,0,1$ $913,237,34.77,-0.91,0,1$ $913,238,37.12,6.89,0,1$ $913,239,10.61,-0.89,0,1$ $913,240,20.37,0.61,0,1$ $913,1000,24.29,0,0,1$

$913,1186,21.81,0.76,0,1$

$913,1709,30.29,0.5,0,1$

$914,237,34.15,-0.91,0,1$

$914,238,39.37,0.8,0,1$

$914,239,13.81,10.26,0,1$

$914,240,23.15,7.53,0,1$

$914,241,15.82,0.41,0,1$

$914,1000,23.75,-1.59,0,1$

$914,1186,22.32,0.76,0,1$

$914,1709,30.64,0.5,0,1$

$915,237,33.52,-0.91,0,1$

$915,238,39.91,0.8,0,1$

$915,239,20.38,9.45,0,1$

$915,240,27.93,6.86,0,1$

$915,241,16.1,0.41,0,1$

$915,1000,18.96,-8.85,0,1$

$915,1186,22.83,0.76,0,1$

$915,1187,20.8,-0.07,0,1$

$915,1709,30.98,0.5,0,1$

$915,1710,33.48,-0.27,0,1$

$916,237,33.52,0.91,0,1$

$916,238,40.46,0.8,0,1$

$916,239,24.89,4.42,0,1$

$916,240,32.32,6.31,0,1$

$916,241,16.38,0.41,0,1$

$916,1000,12.93,-8.85,0,1$

$916,1186,22.32,-0.76,0,1$

$916,1187,20.51,-0.84,0,1$

$916,1709,31.32,0.5,0,1$

$916,1710,33.33,-0.21,0,1$

$917,237,34.15,0.91,0,1$

$917,238,41,0.8,0,1$

$917,239,25.5,0.89,0,1$

$917,240,32.74,0.61,0,1$

$917,241,18.81,6.74,0,1$

$917,1000,6.9,-8.85,0,1$

$917,1186,21.81,-0.76,0,1$

$917,1187,19.94,-0.84,0,1$

$917,1709,31.66,0.5,0,1$

$917,1710,33.22,-0.15,0,1$

$918,237,34.77,0.91,0,1$

$918,238,41.54,0.8,0,1$

$918,239,26.1,0.89,0,1$

$918,240,33.16,0.61,0,1$

$918,241,23.11,6.19,0,1$

$918,242,23.6,0.85,0,1$

$918,1000,2.2,-4.94,0,1$

$918,1186,21.61,-0.19,0,1$

$918,1187,19.37,-0.84,0,1$

$918,1709,31.32,-0.5,0,1$

$918,1710,33.13,-0.15,0,1$

$919,171,3.91,11.48,0,1$

$919,237,35.39,0.91,0,1$

$919,238,42.09,0.8,0,1$

$919,239,26.71,0.89,0,1$

$919,240,33.57,0.61,0,1$

$919,241,27.07,5.66,0,1$ 
$919,242,24.18,0.85,0,1$ $919,243,15.94,0.6,0,1$ $919,1000,0.95,-2.02,0,1$ $919,1186,23.97,7.02,0,1$ $919,1187,19.94,0.84,0,1$ $919,1709,30.98,-0.5,0,1$ $919,1710,33,-0.21,0,1$ $920,171,10.09,8.77,0,1$ $920,237,34.77,-0.91,0,1$ $920,238,42.09,-0.8,0,1$ $920,239,27.31,0.89,0,1$ $920,240,33.99,0.61,0,1$ $920,241,27.35,0.41,0,1$ $920,242,29.88,8.18,0,1$ $920,243,16.35,0.6,0,1$ $920,1000,0,-1.28,0,1$

$920,1186,28.45,6.43,0,1$ $920,1187,20.51,0.84,0,1$

$920,1709,30.64,-0.5,0,1$ $920,1710,32.81,-0.3,0,1$

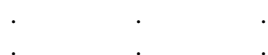

(Similar Trend Continues) $4498,6,14.8,0,0,1$ $4498,18,21.17,0,0,1$ $4498,19,3.09,9.07,0,1$ $4498,69,23.58,0,0,1$ $4498,103,28.38,6.15,0,1$ $4498,132,0,0,0,1$

$4498,134,0,0,0,1$ $4498,135,1.59,-1.69,0,1$

$4498,161,0,0,0,1$

$4498,187,26.8,0,0,1$

$4498,230,0,0,0,1$

$4498,231,0,0,0,1$

$4498,234,18.45,-8.16,0,1$

$4498,236,18.77,2.68,0,1$

$4498,255,0,0,0,1$

$4498,260,0,0,0,1$

$4498,381,0,0,0,1$

$4498,784,0,0,0,1$

$4498,848,0,0,0,1$

$4498,911,30.62,-2.34,0,1$

$4498,912,14.09,-7.59,0,1$

$4498,915,5.37,0,0,1$

$4498,917,24.29,0,0,1$

$4498,918,20.74,0,0,1$

$4498,919,2.21,-8.01,0,1$

$4498,920,5.46,-0.07,0,1$

$4498,921,12.86,8.52,0,1$

$4498,923,18.75,0,0,1$

$4498,924,6.03,-0.02,0,1$

$4498,925,4.57,11.42,0,1$

$4498,926,11.52,0,0,1$

$4498,927,11.04,-11.32,0,1$

$4498,928,24.92,0.01,0,1$

$4498,929,20.4,-0.8,0,1$

$4498,930,20.17,-0.45,0,1$

$4498,931,26.8,-2.38,0,1$

$4498,932,30.76,0,0,1$

$4498,933,29.44,-0.47,0,1$

$4498,934,0,-0.37,0,1$

$4498,935,36.17,-2.36,0,1$

$4498,936,23.84,6.11,0,1$

$4498,937,0.8,-2.19,0,1$

$4498,938,35.67,0.49,0,1$

$4498,939,31.51,0,0,1$

$4498,940,28.78,-0.48,0,1$ 


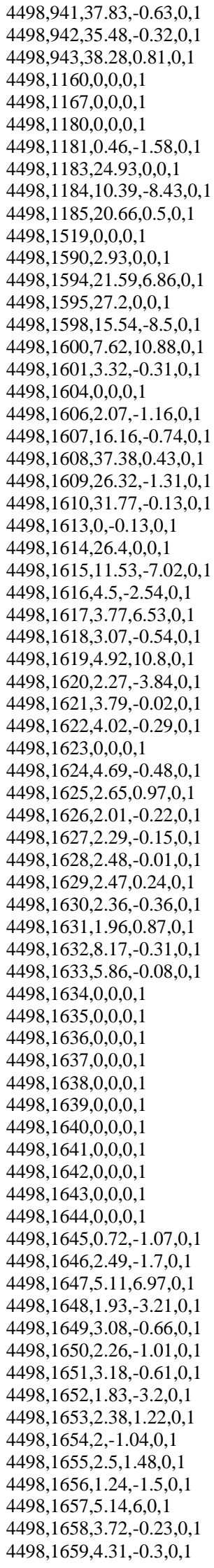




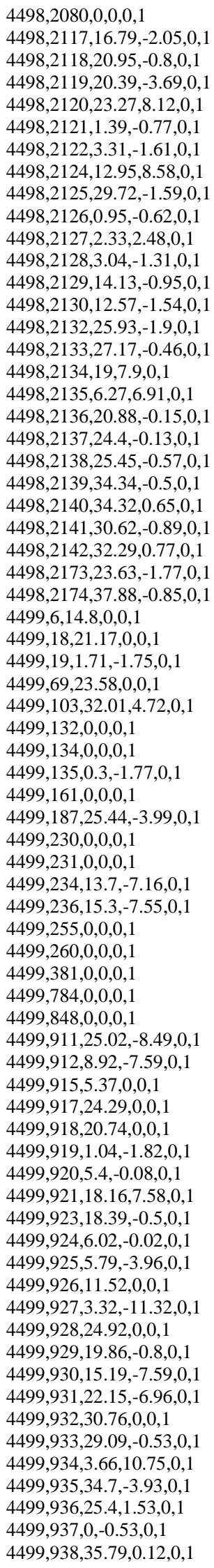


$4499,939,31.51,0,0,1$

$4499,940,28.45,-0.48,0,1$

$4499,941,37.4,-0.63,0,1$

$4499,942,35.25,-0.36,0,1$

$4499,943,37.73,-0.81,0,1$

$4499,1160,0,0,0,1$

$4499,1167,0,0,0,1$

$4499,1180,0,0,0,1$

$4499,1181,0,-0.09,0,1$

$4499,1183,24.93,0,0,1$

$4499,1184,4.64,-8.43,0,1$

$4499,1185,21,0.5,0,1$

$4499,1519,0,0,0,1$

$4499,1590,2.91,-0.03,0,1$

$4499,1594,22.35,-4.34,0,1$

$4499,1595,27.2,0,0,1$

$4499,1598,9.75,-8.5,0,1$

$4499,1600,14.34,9.49,0,1$

$4499,1601,2.22,-1.36,0,1$

$4499,1604,0,0,0,1$

$4499,1606,1.48,-0.54,0,1$

$4499,1607,15.62,-0.8,0,1$

$4499,1608,37.67,0.43,0,1$

$4499,1609,25.63,-1.28,0,1$

$4499,1610,31.66,-0.17,0,1$

$4499,1614,24.96,-4.23,0,1$

$4499,1615,6.75,-7.02,0,1$

$4499,1616,2.76,-2.54,0,1$

$4499,1617,3.2,1.05,0,1$

$4499,1618,1.79,-3.22,0,1$

$4499,1619,4.18,-1.13,0,1$

$4499,1620,1.78,-1.13,0,1$

$4499,1621,5.24,6.78,0,1$

$4499,1622,2.43,-2.66,0,1$

$4499,1623,0,0,0,1$

$4499,1624,3.27,-2.18,0,1$

$4499,1625,3.54,-2.01,0,1$

$4499,1626,3.27,2.13,0,1$

$4499,1627,2.14,-0.14,0,1$

$4499,1628,2.36,-0.34,0,1$

$4499,1629,2.46,-0.01,0,1$

$4499,1630,2.13,-0.31,0,1$

$4499,1631,2.16,0.02,0,1$

$4499,1632,7.84,-0.46,0,1$

$4499,1633,5.77,-0.12,0,1$

$4499,1634,1.86,5.44,0,1$

$4499,1635,0,0,0,1$

$4499,1636,0,0,0,1$

$4499,1637,0,0,0,1$

$4499,1638,0,0,0,1$

$4499,1639,0,0,0,1$

$4499,1640,0,0,0,1$

$4499,1641,0,0,0,1$

$4499,1642,0,0,0,1$

$4499,1643,0,0,0,1$

$4499,1644,0,0,0,1$

$4499,1645,0,-1,0,1$

$4499,1646,1.14,-1.91,0,1$

$4499,1647,3.62,-2.14,0,1$

$4499,1648,3.27,-2.44,0,1$

$4499,1649,1.57,-0.44,0,1$

$4499,1650,4.81,5.82,0,1$

$4499,1651,2.39,-0.61,0,1$

$4499,1652,4.51,-0.28,0,1$

$4499,1653,3.99,-0.36,0,1$

$4499,1654,1.65,-0.44,0,1$

$4499,1655,4.33,-1.42,0,1$

$4499,1656,2.81,4.71,0,1$

$4499,1657,2.88,-1.64,0,1$

$4499,1658,1.97,-5.01,0,1$ 


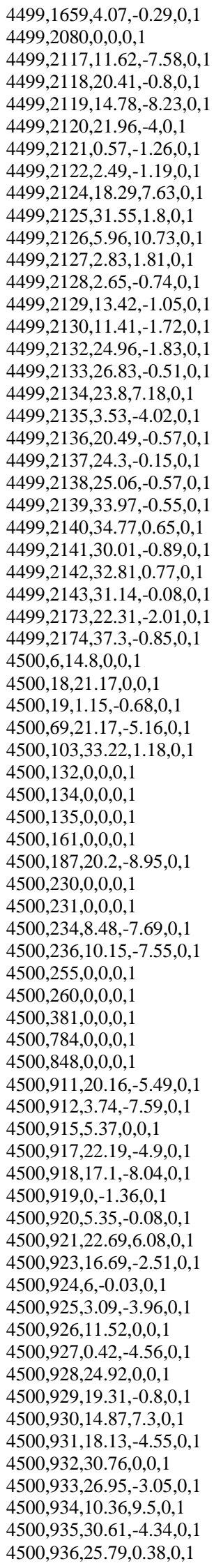


$4500,937,2.79,8.19,0,1$

$4500,938,31.79,-5.26,0,1$

$4500,939,30.49,-1.31,0,1$

$4500,940,28.13,-0.48,0,1$

$4500,941,36.97,-0.63,0,1$

$4500,942,34.98,-0.39,0,1$

$4500,943,37.18,-0.81,0,1$

$4500,1160,0,0,0,1$

$4500,1167,0,0,0,1$

$4500,1180,0,0,0,1$

$4500,1181,0,0,0,1$

$4500,1183,24.93,0,0,1$

$4500,1184,1.68,-1.64,0,1$

$4500,1185,21.26,0.25,0,1$

$4500,1519,0,0,0,1$

$4500,1590,4.43,4.55,0,1$

$4500,1594,19.23,-4.66,0,1$

$4500,1595,25.04,-4.9,0,1$

$4500,1598,3.95,-8.5,0,1$

$4500,1600,20.24,8.4,0,1$

$4500,1601,3.64,4.1,0,1$

$4500,1604,0,0,0,1$

$4500,1606,4.67,9.36,0,1$

$4500,1607,15.05,-0.85,0,1$

$4500,1608,37.97,0.43,0,1$

$4500,1609,24.97,-1.01,0,1$

$4500,1610,31.52,-0.22,0,1$

$4500,1614,19.48,-9.38,0,1$

$4500,1615,2.24,-6.21,0,1$

$4500,1616,1.5,-1.2,0,1$

$4500,1617,5.26,6.11,0,1$

$4500,1618,1.67,-0.12,0,1$

$4500,1619,2.5,-0.74,0,1$

$4500,1620,2.76,-4.39,0,1$

$4500,1621,3.17,-2.13,0,1$

$4500,1622,1.86,-3.95,0,1$

$4500,1623,0,0,0,1$

$4500,1624,3.12,-0.18,0,1$

$4500,1625,3.52,-0.04,0,1$

$4500,1626,3.81,-0.03,0,1$

$4500,1627,3.07,2.78,0,1$

$4500,1628,2.27,-0.09,0,1$

$4500,1629,2.46,-0.01,0,1$

$4500,1630,1.98,-0.17,0,1$

$4500,1631,2.16,0,0,1$

$4500,1632,7.6,-0.23,0,1$

$4500,1633,5.71,-0.07,0,1$

$4500,1634,4.32,5.85,0,1$

$4500,1635,1.23,3.6,0,1$

$4500,1636,0,0,0,1$

$4500,1637,0,0,0,1$

$4500,1638,0,0,0,1$

$4500,1639,0,0,0,1$

$4500,1640,0,0,0,1$

$4500,1641,0,0,0,1$

$4500,1642,0,0,0,1$

$4500,1643,0,0,0,1$

$4500,1644,0,0,0,1$

$4500,1645,0,0,0,1$

$4500,1646,0.31,-0.65,0,1$

$4500,1647,2.87,-6.46,0,1$

$4500,1648,5.31,8.14,0,1$

$4500,1649,4.54,11.33,0,1$

$4500,1650,2.66,-2.88,0,1$

$4500,1651,0.97,-3.71,0,1$

$4500,1652,3.78,-1.73,0,1$

$4500,1653,3.57,-0.65,0,1$

$4500,1654,2.16,2.07,0,1$

$4500,1655,3.27,-1.69,0,1$

$4500,1656,3.66,4.04,0,1$ 
$4500,1657,2.07,-1.93,0,1$

$4500,1658,4.59,-2.29,0,1$

$4500,1659,11,9.83,0,1$

$4500,2080,0,0,0,1$

$4500,2117,6.45,-7.58,0,1$

$4500,2118,19.86,-0.8,0,1$

$4500,2119,9.17,-8.23,0,1$

$4500,2120,16.96,-8.46,0,1$

$4500,2121,0,-0.51,0,1$

$4500,2122,1.67,-1.19,0,1$

$4500,2124,14.96,-4.99,0,1$

$4500,2125,32.01,0.45,0,1$

$4500,2126,4.1,-2.73,0,1$

$4500,2127,2.79,-0.12,0,1$

$4500,2128,2.36,-0.42,0,1$

$4500,2129,12.66,-1.13,0,1$

$4500,2130,10.17,-1.86,0,1$

$4500,2132,24.02,-1.44,0,1$

$4500,2133,26.42,-0.64,0,1$

$4500,2134,28.38,6.57,0,1$

$4500,2135,1.64,-1.53,0,1$

$4500,2136,20.1,-0.57,0,1$

$4500,2137,24.18,-0.19,0,1$

$4500,2138,24.67,-0.57,0,1$

$4500,2139,33.58,-0.6,0,1$

$4500,2140,34.32,-0.65,0,1$

$4500,2141,28.53,-3.46,0,1$

$4500,2142,33.34,0.77,0,1$

$4500,2143,30.52,-0.92,0,1$

$4500,2173,20.77,-2.34,0,1$

$4500,2174,36.71,-0.85,0,1$

\section{Appendix O: Partial Sample CMEM Vehicle Model Run File}

The text below is a partial sample of the Vehicle Model Run File (-rnb) which is generated by CMEM. It contains a summary of the input and output files, vehicle IDs and settings, and category parameters.

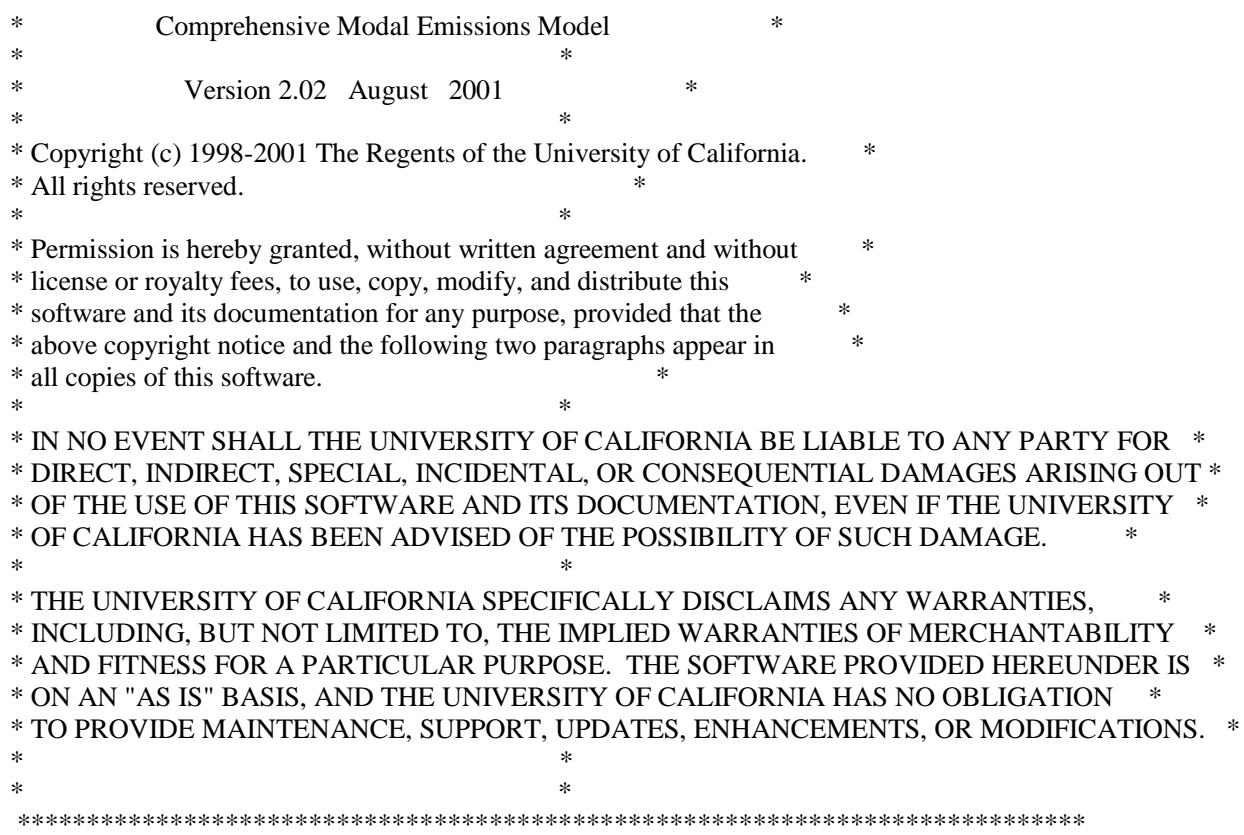


Input Files

Control File: test2-ctb

Activity File: test2-atb

Definition File: test2-def

Output Files

Model Run File: test2-rnb

Summary File: test2-smb

Sec-by-Sec File: test2-ssb

Id 1: Using given acceleration

Id 2: Using given acceleration

Id 3: Using given acceleration

Id 4: Using given acceleration

Id 5: Using given acceleration

Id 6: Using given acceleration

Id 7: Using given acceleration

Id 8: Using given acceleration

Id 9: Using given acceleration

Id 10: Using given acceleration

.....(Same trend continues)....

Id 2164: Using given acceleration

Id 2165: Using given acceleration

Id 2166: Using given acceleration

Id 2167: Using given acceleration

Id 2168: Using given acceleration

Id 2169: Using given acceleration

Id 2170: Using given acceleration

Id 2171: Using given acceleration

Id 2172: Using given acceleration

Id 2173: Using given acceleration

Id 2174: Using given acceleration

IN_UNITS set to ENGLISH

OUT_UNITS set to ENGLISH

Overwritten Parameters by Category

Id Categories

Id 1 Category set to 10

Id 2 Category set to 10

Id 3 Category set to 26

Id 4 Category set to 8

Id 5 Category set to 24

Id 6 Category set to 17

Id 7 Category set to 26

Id 8 Category set to 22

Id 9 Category set to 22

Id 10 Category set to 26

.....(Same trend continues).....

Id Fuel Type

Id 1 Fuel Type set to gasoline

Id 2 Fuel Type set to gasoline

Id 3 Fuel Type set to gasoline

Id 4 Fuel Type set to gasoline

Id 5 Fuel Type set to gasoline

Id 6 Fuel Type set to gasoline

Id 7 Fuel Type set to gasoline

Id 8 Fuel Type set to gasoline

Id 9 Fuel Type set to gasoline

Id 10 Fuel Type set to gasoline

.....(Same Trend Continues).....

Id 1

Condition Parameters

Tsoak = 967 


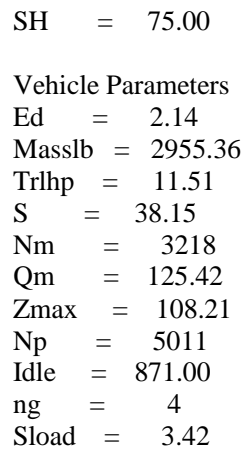

Calibrated Parameters

$\mathrm{K} \_0=0.2364$

Edt3 $=0.1000$

$\mathrm{C} 0=3.6929$

$\mathrm{aCO}=0.0908$

$\mathrm{aHC}=0.0095$

$\mathrm{rHC}=0.0028$

$\mathrm{aNO} 1=0.0363$

$\mathrm{aNO} 2=0.0325$

FRNO1 $=-0.3061$

FRNO2 $=0.1849$

MAXCO $=99.9749$

MAXHC $=99.8272$

$\mathrm{MAXNO}=99.8460$

$\mathrm{bCO}=0.0958$

$\mathrm{cCO}=0.9564$

$\mathrm{bHC}=0.0213$

$\mathrm{cHC}=0.3568$

$\mathrm{bNO}=0.8650$

$\mathrm{cNO}=1.4750$

Lamb_0 $=1.2348$

lam_m $=0.1228$

Pscale $=1.3120$

$\operatorname{maxhc}=0.0631$

hc_jk $=4.8037$

r_R $=0.3006$

spd_th $=106.3888$

$\mathrm{rO} 2=50.4484$

$\mathrm{COB} 1=9.3302$

$\mathrm{HCB} 1=10.4121$

NOB1 $=6.2056$

lam_cold $=1.1454$

$\mathrm{csHC}=4.5515$

$\mathrm{csNO}=4.8408$

Tlamb $=50.2254$

id $=0.0716$

Csoak_co $=280.6832$

Csoak_hc $=15.1177$

Csoak_no $=399.9964$

Bcat_co $=224.8712$

Bcat_hc $=239.9966$

Bcat_no $=0.2637$

Edt1 $=0.9178$

NH3_b $=100.0000$

$\mathrm{NH} 3 \_\mathrm{s} 1=2.0000$

NH3_s2 $=3.4000$

$\mathrm{NH} 3 \_\mathrm{i}=0.0450$

Id 2

Condition Parameters

Tsoak = 161

$\mathrm{SH}=75.00$

Vehicle Parameters 


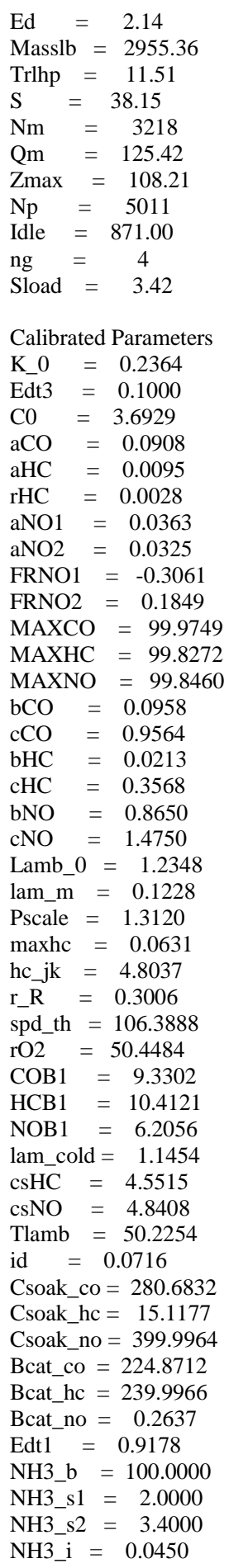

Calibrated Parameters

$\mathrm{K} \_0=0.2364$

Edt3 $=0.1000$

$\mathrm{C} 0=3.6929$

$\mathrm{aCO}=0.0908$

$\mathrm{aHC}=0.0095$

$\mathrm{rHC}=0.0028$

$\mathrm{aNO} 1=0.0363$

$\mathrm{aNO} 2=0.0325$

FRNO1 $=-0.3061$

FRNO2 $=0.1849$

MAXCO $=99.9749$

MAXHC $=99.8272$

MAXNO $=99.8460$

$\mathrm{bCO}=0.0958$

$\mathrm{cCO}=0.9564$

$\mathrm{bHC}=0.0213$

$\mathrm{cHC}=0.3568$

$\mathrm{bNO}=0.8650$

$\mathrm{cNO}=1.4750$

Lamb 0 $=1.2348$

lam_m $=0.1228$

Pscale $=1.3120$

$\operatorname{maxhc}=0.0631$

$\mathrm{hc} \_\mathrm{jk}=4.8037$

$r_{-} \mathrm{R}=0.3006$

spd_th $=106.3888$

$\mathrm{rO} 2=50.4484$

$\mathrm{COB} 1=9.3302$

$\mathrm{HCB} 1=10.4121$

NOB1 $=6.2056$

lam_cold $=1.1454$

$\mathrm{csHC}=4.5515$

$\mathrm{csNO}=4.8408$

Tlamb $=50.2254$

id $=0.0716$

Csoak_co $=280.6832$

Csoak_hc $=15.1177$

Csoak_no $=399.9964$

Bcat_co $=224.8712$

Bcat_hc $=239.9966$

Bcat_no $=0.2637$

Edt1 $=0.9178$

$\mathrm{NH} 3 \_\mathrm{b}=100.0000$

$\mathrm{NH} 3 \_\mathrm{s} 1=2.0000$

$\mathrm{NH} 3$ _s2 $=3.4000$

$\mathrm{NH} 3 \_\mathrm{i}=0.0450$

Id 3

Condition Parameters

Tsoak = 413

$\mathrm{SH}=75.00$

Vehicle Parameters

$\mathrm{Ed}=2.50$

Masslb $=3118.00$

Trlhp $=12.14$ 


$$
\begin{aligned}
& \mathrm{S}=25.39 \\
& \mathrm{Nm}=3300 \\
& \mathrm{Qm}=142.00 \\
& \mathrm{Zmax}=153.50 \\
& \mathrm{~Np}=5250 \\
& \mathrm{Idle}=967.00 \\
& \text { ng }=4 \\
& \text { Sload }=0.00
\end{aligned}
$$

Calibrated Parameters

$\mathrm{K} \_0=0.1628$

Edt3 $=0.0998$

$\mathrm{C} 0=3.4397$

$\mathrm{aCO}=0.0439$

$\mathrm{aHC}=0.0001$

$\mathrm{rHC}=0.0121$

$\mathrm{aNO} 1=0.0259$

$\mathrm{aNO} 2=0.0210$

FRNO1 $=-0.4770$

FRNO2 $=0.4501$

MAXCO $=99.9000$

MAXHC $=99.9000$

MAXNO $=99.9000$

$\mathrm{bCO}=0.0558$

$\mathrm{cCO}=0.0702$

$\mathrm{bHC}=0.0114$

$\mathrm{cHC}=0.5523$

$\mathrm{bNO}=3.5263$

$\mathrm{cNO}=1.8926$

Lamb_0 $=1.2640$

lam $\_\mathrm{m}=0.9000$

Pscale $=1.7869$

$\operatorname{maxhc}=0.0000$

$\mathrm{hc} \_\mathrm{jk}=0.5000$

$\mathrm{r} \_\mathrm{R}=0.1090$

spd_th $=2.4502$

$\mathrm{rO} 2=1.0000$

$\mathrm{COB} 1=1.2778$

$\mathrm{HCB} 1=257.3869$

NOB1 $=255.7078$

lam_cold $=1.2500$

$\mathrm{csHC}=12.3901$

$\mathrm{csNO}=72.8559$

Tlamb $=37.6651$

id $=0.1155$

Csoak_co $=253.0160$

Csoak_hc $=200.0023$

Csoak_no $=20.1941$

Bcat_co $=133.0843$

Bcat_hc $=239.9024$

Bcat_no $=132.0022$

Edt1 $=0.8265$

NH3_b $=100.0000$

$\mathrm{NH} 3 \_\mathrm{s} 1=2.0000$

$\mathrm{NH} 3 \_s 2=3.4000$

$\mathrm{NH} 3 \_\mathrm{i}=0.0450$

...(Same Trend Continues)... 


\section{Appendix P: Partial Sample CMEM Vehicle Summary File}

The chart below is a partial sample of the Emissions Summary file (-smb) which is generated by CMEM.

The first half contains a summary of miles traveled per vehicle and the second half contains a summary of emissions per vehicle in grams per mile.

Batch Run Emission Summary File

Distances Traveled (miles)

Id 1 traveled 1.24

Id 2 traveled 1.38

Id 3 traveled 1.39

Id 4 traveled 1.64

Id 5 traveled 1.79

Id 6 traveled 0.28

Id 7 traveled 0.88

Id 8 traveled 0.86

Id 9 traveled 1.09

Id 10 traveled 2.78

(Same trend continues)

Id 2164 traveled 1.59

Id 2165 traveled 1.19

Id 2166 traveled 1.67

Id 2167 traveled 0.21

Id 2168 traveled 1.59

Id 2169 traveled 2.11

Id 2170 traveled 0.21

Id 2171 traveled 1.49

Id 2172 traveled 1.47

Id 2173 traveled 1.39

Id 2174 traveled 0.19

Emissions Summary (grams/mile)

Id Cat $\mathrm{HC}$ CO NOx fuel

$\begin{array}{llllll}1 & 10 & 1.433 & 55.39 & 3.13 & 260.4\end{array}$

$\begin{array}{llllll}2 & 10 & 0.405 & 6.86 & 1.16 & 222.2\end{array}$

$\begin{array}{llllll}3 & 26 & 0.762 & 2.32 & 20.04 & 174.3\end{array}$

$\begin{array}{llllll}4 & 8 & 0.850 & 74.49 & 1.97 & 230.3\end{array}$

$\begin{array}{llllll}5 & 24 & 1.371 & 23.16 & 2.06 & 232.5\end{array}$

$\begin{array}{llllll}6 & 17 & 9.735 & 81.00 & 9.39 & 342.6\end{array}$

$\begin{array}{llllll}7 & 26 & 0.870 & 11.40 & 39.79 & 214.5\end{array}$

$\begin{array}{llllll}8 & 22 & 9.796 & 119.78 & 8.17 & 246.3\end{array}$

$\begin{array}{llllll}9 & 22 & 18.227 & 179.88 & 11.16 & 410.5\end{array}$

$\begin{array}{llllll}10 & 26 & 0.150 & 0.92 & 7.85 & 138.9\end{array}$

(Same trend continues)

$\begin{array}{llrrrr}\cdot & & & \cdot & \cdot & \\ 2164 & 24 & 1.912 & 19.15 & 1.24 & 196.6 \\ 2165 & 15 & 4.450 & 31.61 & 1.88 & 149.2 \\ 2166 & 21 & 3.890 & 40.36 & 2.17 & 188.5 \\ 2167 & 26 & 10.416 & 9.39 & 2.52 & 54.8 \\ 2168 & 24 & 2.239 & 46.34 & 2.11 & 210.8 \\ 2169 & 10 & 1.287 & 34.42 & 1.12 & 188.2 \\ 2170 & 4 & 15.266 & 52.60 & 3.24 & 101.6 \\ 2171 & 24 & 2.144 & 19.87 & 1.73 & 174.8 \\ 2172 & 26 & 1.162 & 7.15 & 18.17 & 155.9 \\ 2173 & 24 & 1.463 & 41.39 & 2.17 & 168.4 \\ 2174 & 24 & 8.762 & 58.19 & 7.22 & 122.5\end{array}$




\section{Appendix Q: Partial Sample Emissions Summary Output}

When the product of miles traveled and emissions per mile is taken, the result is the total emission per

vehicle. These emissions are summed to obtain total emissions for a simulation run or scenario. The table below shows a partial summary of total emissions per vehicle as well as the summation of all rows.

\begin{tabular}{|c|c|c|c|c|c|}
\hline Emissions & Summary & & & & \\
\hline Id & Cat & $\mathrm{HC}$ & $\mathrm{CO}$ & NOx & fuel \\
\hline 1 & 10 & 1.77692 & 68.6836 & 3.8812 & 322.896 \\
\hline 2 & 10 & 0.5589 & 9.4668 & 1.6008 & 306.636 \\
\hline 3 & 26 & 1.05918 & 3.2248 & 27.8556 & 242.277 \\
\hline 4 & 8 & 1.394 & 122.1636 & 3.2308 & 377.692 \\
\hline 5 & 24 & 2.45409 & 41.4564 & 3.6874 & 416.175 \\
\hline 6 & 17 & 2.7258 & 22.68 & 2.6292 & 95.928 \\
\hline 7 & 26 & 0.7656 & 10.032 & 35.0152 & 188.76 \\
\hline 8 & 22 & 8.42456 & 103.0108 & 7.0262 & 211.818 \\
\hline 9 & 22 & 19.86743 & 196.0692 & 12.1644 & 447.445 \\
\hline 10 & 26 & 0.417 & 2.5576 & 21.823 & 386.142 \\
\hline $\begin{array}{r}\text { Similar } \\
\text { Trend }\end{array}$ & & & & & \\
\hline Continues & ..... & ... & $\cdots \cdots$ & $\ldots \ldots$ & $\ldots \ldots$ \\
\hline 2164 & 24 & 3.04008 & 30.4485 & 1.9716 & 312.594 \\
\hline 2165 & 15 & 5.2955 & 37.6159 & 2.2372 & 177.548 \\
\hline 2166 & 21 & 6.4963 & 67.4012 & 3.6239 & 314.795 \\
\hline 2167 & 26 & 2.18736 & 1.9719 & 0.5292 & 11.508 \\
\hline 2168 & 24 & 3.56001 & 73.6806 & 3.3549 & 335.172 \\
\hline 2169 & 10 & 2.71557 & 72.6262 & 2.3632 & 397.102 \\
\hline 2170 & 4 & 3.20586 & 11.046 & 0.6804 & 21.336 \\
\hline 2171 & 24 & 3.19456 & 29.6063 & 2.5777 & 260.452 \\
\hline 2172 & 26 & 1.70814 & 10.5105 & 26.7099 & 229.173 \\
\hline 2173 & 24 & 2.03357 & 57.5321 & 3.0163 & 234.076 \\
\hline 2174 & 24 & 1.66478 & 11.0561 & 1.3718 & 23.275 \\
\hline $\mathbf{T}$ & & 7975.08 & 99435.92 & 7629.258 & 436854.3 \\
\hline
\end{tabular}




\section{Appendix R: Additional Background Information}

The following studies relate to measuring emissions and parking decisions.

\section{Emissions Modeling}

In 2009, a team of researchers from North Carolina State University studied vehicle-specific emissions based on field measurements of hot-stabilized tailpipe measurements using portable emissions measurement system (PEMS) devices. This research was done to create knowledge for more effective airquality management and to improve emissions estimates at the microscale level.

More specifically, the researchers focused on evaluating alternative microscale models based on externally observable variables (EOVs) versus internally observable variables (IOVs) as well as vehicle-specific models versus fleet average models. They compared the data in these microscale models to data collected in the field from PEMS devices which captured emissions levels of nitrogen monoxide (NO), hydrocarbons (HC), carbon monoxide $(\mathrm{CO})$ and carbon dioxide $\left(\mathrm{CO}_{2}\right)$. In modeling IOVs, the researchers used engine speed and manifold absolute pressure (MAP) data to calculate emissions because they are significant factors in fuel injection control and are strongly influenced by vehicle dynamics (Frey, Zhang, \& Rouphail 2010). A vehicle specific power (VSP) modal approach was used to model EOVs because of the strong positive relationship of vehicle emissions to fuel use. The VSP approach uses speed, acceleration, and road grade as EOVs, from which emissions were calculated.

By using parity plots to compare predicted versus actual emissions levels, it was found that the IOV models were fairly accurate in predicting emissions levels but ineffective at being precise and capturing variability among different vehicles. On the other hand, the EOV models were found to be less accurate and less precise at predicting emissions levels than the IOV models. The researchers also concluded that EOV models may be more practical in simulation, since IOVs are not usually available for use in simulation models. The efficiency of each vehicle's catalytic converter is a lurking variable that influences tailpipe emissions and the IOV and EOV models, but it was unexplored because it was difficult to quantify with the resources at hand. In comparing vehicle specific models and fleet average models to validated emissions, the researchers found little difference in which model was used. The fleet average models seemed to capture most variability. 


\section{Parking Decisions}

In 2002, researchers from the University of Massachusetts at Amherst, Virginia Tech, and 3M collaborated to study behavior rules that determine drivers' choices of parking lots. In particular, they designed a simulated driving environment where test subjects made decisions on where to park as they passed a variable message sign. This sign displayed counts of vacancies for several nearby lots downstream. Previous studies had indicated that drivers made parking decisions based off the expected utility of parking in the current lot and the next available lot. If the driver determined the current lot was full, they would have to make a decision to visit the next available lot and compute another expected utility. One of three main objectives made up a driver's expected utility: 1)minimize expected travel time (METT), 2) minimize walking distance (MWD), 3) maximize parking availability (MPA). Depending on which objective a driver favored, their expected utility function led to different outcomes. The researchers tested multiple versions of the expected utility theory and found that the objective to minimize expected travel time (METT) was most prominent. They found weakness in their tests in that participants may choose different combinations of objectives from one scenario to the next (some data sets indicated a key objective was to minimize walking distance).

To test a hypothesis that drivers make parking decisions based on a partially-computed probability in conjunction with the cognitive load of the driving task, the researchers proposed a lexicographic decision rule. This rule stated that a driver would first consider their destination lot or lot closest to their destination. If the indicated number of open spaces in the destination lot was at or above some criterion, $\mathrm{x}_{\mathrm{d}}$, then they would park in that lot. Otherwise they would park elsewhere and the process would repeat itself with each additional lot until they driver chose a lot. The criterion, $\mathrm{x}_{\mathrm{d}}$, varied inversely with the distance to the next available lot downstream;--the further away the next open lot, the smaller the criterion (Hester, Fischer, \& Collura, 2002). In testing this hypothesis the researchers found the lexicographic strategy was more accurate in determining drivers' parking decisions because it employed both multiple objectives (METT and MWD are accounted for in a driver's initial lot choice before interacting with the sign). The researchers also acknowledged several other variables of potential influence: driver familiarity, cognitive load, driver age, weather, and driver disabilities. 